\title{
Wechselwirkungen von Proteinen mit den zytoplasmatischen Domänen der Mannose-6-Phosphat- Rezeptoren
}

\author{
Dissertation \\ zur Erlangung des Doktorgrades \\ der Mathematisch-Naturwissenschaftlichen Fakultäten \\ der Georg-August-Universität zu Göttingen
}

vorgelegt von

Stephan Storch

aus Wiesbaden

Göttingen 1999 
D7

Referent:

Prof. Dr. Kurt von Figura

Korreferent:

Prof. Dr. David G. Robinson

Tag der mündlichen Prüfung: $\quad$ 02.11.1999 
1 EINLEITUNG 1

1.1 Synthese und Transport löslicher lysosomaler Enzyme 1

1.2 Mannose-6-Phosphat-Rezeptoren 2

1.3 Signalabhängiger Transport von Mannose-6-Phosphat-Rezeptoren 6

1.4 Interaktion der Mannose-6-Phosphat-Rezeptoren mit zytosolischen und membrangebundenen Proteinen

$\begin{array}{llr}3.1 .1 & \text { Geräte } & 14\end{array}$

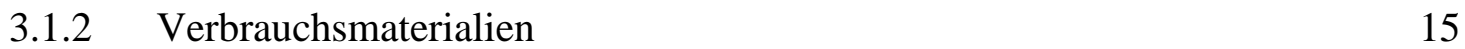

3.1.3 Enzyme und Nukleotide 16

3.1.4 Kits zur Bearbeitung von DNA, RNA und Protein 17

3.1.5 cDNA-Bibliotheken 17

3.1.6 Proteine, Proteaseinhibitoren und Proteinstandards 17

$\begin{array}{lll}3.1 .7 & \text { Detergenzien } & 17\end{array}$

$\begin{array}{lll}3.1 .8 & \text { Antikörper } & 18\end{array}$

$\begin{array}{lll}3.1 .8 .1 & \text { Primärantikörper } & 18\end{array}$

$\begin{array}{ll}\text { 3.1.8.2 Sekundärantikörper } & 18\end{array}$

$\begin{array}{ll}3.1 .9 & \text { Radioaktive Substanzen } \\ 3.18 & \end{array}$

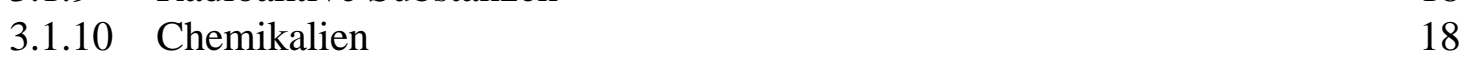

$\begin{array}{ll}3.1 .11 & \text { Vektoren, DNA-Standards } \\ 3.1 .12 & 20\end{array}$

$\begin{array}{ll}3.1 .12 & \text { Bakterienstämme }\end{array}$

3.1.13 Medien zur Anzucht von Bakterien 21

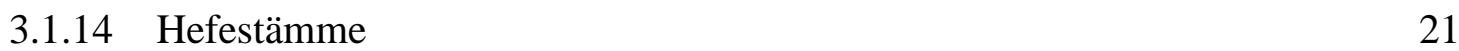

3.1.15 Medien zur Anzucht von Hefen $\quad 22$

$\begin{array}{lll}3.1 .16 & \text { Zellinien } & 23\end{array}$

3.1.17 Häufig verwendete Puffer 23

3.1.18 Standardlösungen zum molekularbiologischen Arbeiten 24

3.1.19 Zellkulturmedien und Lösungen zur Arbeit mit eukaryonten Zellen 24

3.1.20 Computer und Programme 25 
3.2.1 DNA-Präzipitation mit Ethanol

3.2.2 Extraktion von DNA mit Phenol, Phenol/Chloroform/ $\begin{array}{ll}\text { Isoamylalkohol oder Chloroform } & 26\end{array}$

$\begin{array}{lll}\text { 3.2.3 Konzentrationsbestimmung von DNA } & 26\end{array}$

3.2.4 Reinigung von DNA-Fragmenten mit QIAquick-Säulen 27

3.2.5 Spaltung von DNA mit Restriktionsendonukleasen 27

3.2.6 Transformation von E. coli mit Plasmid-DNA 28

3.2.6.1 Präparation von ,kompetenten“ E. coli-Zellen nach Hanahan 28

3.2.6.2 Transformation kompetenter Zellen 28

3.2.6.3 Präparation von elektrokompetenten Zellen 29

3.2.6.4 Transformation von kompetenten Zellen durch Elektroporation 29

$\begin{array}{ll}\text { 3.2.6.5 Anlegen einer Glyzerinkultur } & 30\end{array}$

$\begin{array}{lll}3.2 .7 & \text { Minipräparation von Plasmid-DNA } & 30\end{array}$

3.2.8 Mini-Präparation (Qiagen-Methode) 31

3.2.9 Midi-Präparation (Qiagen-Methode) 31

3.2.10 Amplifikation von cDNA-Bibliotheken 32

3.2.11 Auftrennung von DNA in Agarosegelen 33

3.2.12 Isolierung von DNA-Fragmenten aus Agarosegelen 33

3.2.13 Präparation von Vektor-DNA für die Subklonierung von
DNA-Fragmenten

3.2.14 DNA-Amplifikation über Polymerase-Ketten-Reaktion (PCR) 34

3.2.15 Gezielte Mutagenese nach der Quik ${ }^{\circledR}$-Change-Methode 35

3.2.16 Klonierung der verschiedenen Konstrukte 36

3.2.16.1 PCR-Mutagenese des MPR300-CT 36

$\begin{array}{lll}\text { 3.2.16.2 PCR-Mutagenese des MPR46-CT } & 37\end{array}$

3.2.16.3 PCR-Mutagenese von Periplakin 38

3.2.16.4 Klonierung der $\mu 2$ - und $\mu 3 \mathrm{~A}-$ Untereinheiten in den AD-Vektor

3.2.16.5 Klonierung der Periplakin-cDNA in den eukaryontischen Expressionsvektor pcDNA 3.1(+) $\quad 39$

$\begin{array}{ll}\text { 3.2.17 Sequenzierung von Plasmid-DNA } & 40\end{array}$

3.2.18 Isolierung von Gesamt-RNA $\quad 42$

3.2.19 Auftrennung von RNA in Agarose-Formaldehydgelen 42

3.2.20 Radioaktive Markierung von DNA 43

3.2.21 Hybridisierung der Hybond-N-Filter mit radioaktiv markierten
DNA-Fragmenten

$\begin{array}{ll}\text { 3.3 Zellbiologische Methoden } & 45\end{array}$

3.3.1 Kultivierung von Zellen $\quad 45$

3.3.2 Trypsinieren von Zellen $\quad 45$

3.3.3 Gefrierkonservierung und Revitalisierung von Zellen 45

3.3.4 Transfektion von Zellinien 46

3.3.5 Radioaktive Markierung von Proteinen mit Jodogen 47

3.3.6 Bestimmung der Endozytoserate durch Aufnahme von [ $\left.{ }^{125} \mathrm{~J}\right]-\mathrm{PMP}-\mathrm{BSA} \quad 48$ 
3.4.1 Herstellung und Transformation von kompetenten Hefezellen 49

$\begin{array}{ll}\text { 3.4.1.1 Anlegen einer Glyzerinkultur } & 50\end{array}$

$\begin{array}{lll}\text { 3.4.2 Isolierung von Plasmid-DNA aus Hefezellen } & 50\end{array}$

3.4.3 Bestimmung von B-Galaktosidase im Filter-Test 51

3.4.4 Bestimmung von ß-Galaktosidase im Flüssigkeits-Test 51

3.4.5 Isolierung von Proteinen aus Hefezellen 52

$\begin{array}{ll}\text { 3.5 Biochemische Methoden } & 53\end{array}$

3.5.1 Bestimmung der ß-Hexosaminidase-Aktivität 53

3.5.2 Proteinbestimmung nach Lowry 53

$\begin{array}{ll}\text { 3.5.3 Expression und Affinitätsreinigung von } & \\ \text { Glutathion-S-Transferase-Fusionsproteinen } & 54\end{array}$

3.5.4 Thrombinspaltung von Glutathion-S-Transferase-

3.5.5 Gewinnung von Antikörpern $\quad 55$

3.5.5.1 Immunisierung von Kaninchen $\quad 56$

3.5.5.2 Affinitätsreinigung von Antikörpern 56

3.5.6 Subzelluläre Fraktionierung durch

Percoll $^{\circledR}$-Dichtegradientenzentrifugation $\quad 57$

3.5.7 Subzelluläre Fraktionierung durch 58

3.5.8 Metabolische Markierung mit $\left[{ }^{35} \mathrm{~S}\right]-$ Methionin $\quad 59$

3.5.9 Immmunpräzipitation von Cathepsin D 59

3.5.10 Diskontinuierliche SDS-Polyacrylamid-Gelelektrophorese (SDS-PAGE) 61

3.5.11 Anfärbung von Polyacrylamidgelen mit Coomassie-Blue 62

3.5.12 Western-Blot-Analyse $\quad 62$

$\begin{array}{ll}\text { 3.5.13 In vitro-Translation } & 64\end{array}$

3.5.14 In vitro-Bindungsassay $\quad 64$

4 ERGEBNISSE

4.1 Das Hefe-Two-Hybrid-System 66

4.1.1 Screenen einer HeLa-cDNA-Bibliothek 67

4.1.2 Darstellung der mutanten zytoplasmatischen Domänen des MPR300 71

4.1.3 Two-Hybrid-Analyse der mutanten zytoplasmatischen

Domänen des MPR300 mit Periplakin 71

4.1.4 Quantitative Bestimmung der Protein-Protein-Interaktion

4.1.5 Two-Hybrid-Analyse der Interaktion zwischen dem MPR300-CT mit mutanten C-terminalen Periplakindomänen 74

4.1.6 Protein-Protein-Interaktion zwischen dem MPR300-CT
und Periplakin in vitro

4.1.6.1 Expression der C-terminalen Periplakindomäne und

Gewinnung von Antikörpern $\quad 76$ 
4.1.6.2 Subzelluläre Lokalisation von Periplakin 77

$\begin{array}{lll}\text { 4.1.6.3 Kopräzipitationsanalysen } & 78\end{array}$

4.1.6.4 Kompetitionsstudien zur Bindung zwischen GST-Periplakin und dem MPR300-CT durch Periplakin $\quad 81$

4.1.7 Transfektion von BHK-Zellen mit der C-terminalen Periplakindomäne 82

4.1.8. Wirkung der Überexpression der C-terminalen Periplakindomäne auf die Endozytose eines Mannose-6-Phosphat-haltigen Liganden

\subsection{Interaktion des MPR300-CT mit p93}

4.2.1 Two-Hybrid-Analyse der Wechselwirkung zwischen $\begin{array}{ll}\text { dem MPR300-CT und p93 } & 84\end{array}$

4.2.2 Northern-Blot-Analyse und cDNA-Bibliothek-Screen 85

4.2.3 Charakterisierung des ST249-Produktes 86

4.2.4 Subzelluläre Lokalisation von p93 89

4.2.5 Subzelluläre Fraktionierung nach Behandlung von HeLa-Zellen

4.3 Interaktion zwischen der zytoplasmatischen Domäne des MPR300/MPR46 und den $\mu 2$-und $\mu 3$ A-Untereinheiten der Adaptorkomplexe AP-2 und AP-3

4.3.1 Two-Hybrid-Analyse der Interaktion zwischen Wildtyp und mutanten zytoplasmatischen Domänen des MPR300/MPR46 und der $\mu 2$-Untereinheit des AP-2-Komplexes

4.3.2 Quantitative Bestimmung der Wechselwirkung zwischen dem MPR300-/MPR46-CT und $\mu 2$

4.3.3 Two-Hybrid-Analyse der Interaktion zwischen Wildtyp und mutanten zytoplasmatischen Domänen des MPR300/MPR46 und der $\mu 3$ A-Untereinheit des AP-3-Komplexes

4.3.4 Quantitative Bestimmung der Wechselwirkung zwischen dem MPR300-/MPR46-CT und $\mu 3 \mathrm{~A}$

4.3.5 Kopräzipitationsanalysen

4.3.5.1 Darstellung der GST-Fusionsproteine der zytoplasmatischen Domäne des MPR46

4.3.5.2 In vitro-Bindung zwischen Wildtyp- und mutanten MPR46-CTDomänen und der $\mu 2$-Untereinheit des AP-2-Komplexes

4.3.5.3 In vitro-Bindung zwischen Wildtyp- und mutanten MPR46-CTDomänen und der $\mu 3 \mathrm{~A}-U n t e r e i n h e i t$ des AP-3-Komplexes

5.1 Wechselwirkung des MPR300-CT mit der C-terminalen Domäne von Periplakin

5.2 Interaktion der zytoplasmatischen Domäne des MPR300/MPR46 mit den $\mu 2$ - und $\mu 3$ A-Untereinheiten der AP-2- und AP-3-Komplexe 
6 ZUSAMMENFASSUNG

125

7 LITERATURVERZEICHNIS

8 ANHANG 140

$\begin{array}{ll}\text { 8.1 Oligonukleotidsequenzen } & 140\end{array}$

8.2 Oligonukleotidsequenz des cDNA-Klons ST249 und abgeleitete Aminosäuresequenz 


\section{ABKÜRZUNGSVERZEICHNIS}

aa

Abb.

A. bidest.

$\mathrm{AD}$

AP

APS

ARF 1

AT

BHK

BLAST

bp

BPAG 1

BSA

CD

cDNA

CK2

CT

DBD

dFKS

DMSO

DNA

DTT

E. coli

EDTA

ER

et al.

FKS

G 418

GB

GDP

GST
Aminosäuren

Abbildung

doppelt destilliertes Waser

Aktivierungsdomäne

Adaptorkomplex

Ammoniumperoxodisulfat

ADP-Ribosylierungsfaktor 1

Aminotriazol

Baby-Hamster-Niere

Basic Local Alignment Search Tool

Basenpaare

bullöses Pemphigoid Antigen

Rinder-Serumalbumin (Bovine Serum Albumine)

kationenabhängig

zur mRNA komplementäre DNA

Kasein-Kinase 2

zytoplasmatische Domäne

DNA-Bindungsdomäne

dialysiertes fötales Kälberserum

Dimethylsulfoxid

Desoxyribonukleinsäure

Dithiothreitol

Escherichia coli

Ethylendiamintetraacetat

Endoplasmatisches Reticulum

et alii (und andere)

fötales Kälberserum

Neomycin-Analogon

Gen-Bank

Guanosindiphosphat

Glutathion-S-Transferase 


\section{GTP}

-HLT

IGF

$\mathrm{kb}$

$\mathrm{kDa}$

LAMP I

LAP

LIMP II

M6P

MEM

MHC II

MPR

MPR300-CT

NCBI

OD

PAGE

PBS

PCR

PNS

RNA

RT

SD-Medium

SDS

SNARE

Tab.

Taq

TGF- $\beta$

TGN

WT

$\mathrm{x} g$
Guanosintriphosphat

-Histidin/-Leucin/-Tryptophan

Insulin-ähnlicher Faktor

kilo Basen

kilo Dalton

Lysosomen-assoziiertes Membranprotein 1

Lysosomale saure Phosphatase

Lysosomales integrales Membranprotein 2

Mannose-6-Phosphat

minimal essential medium

Major Histocompatibility Complex II

Mannose-6-Phosphat-Rezeptor

Zytoplasmatische Domäne des MPR300

National Center for Biotechnology Information

optische Dichte

Polyacrylamid-Gelelektrophorese

Phosphat-gepufferte Salzlösung

Polymerase-Ketten-Reaktion

Post-Nukleärer Überstand

Ribonukleinsäure

Raumtemperatur

Synthetic Dropout-Medium

Natriumdodecylsulfat

Soluble NSF-Attachment Receptor

Tabelle

Thermophilus aquaticus

Transformierender Wachstumsfaktor $B$

trans-Golgi-Netzwerk

Wildtyp

-fache Erdbeschleunigung

Bei einigen Begriffen, wie z. B. Blot, wurden die englischen Fachtermini verwendet, da auch in der deutschsprachigen Literatur eine Übersetzung unüblich ist. 


\section{Einleitung}

\subsection{Synthese und Transport löslicher lysosomaler Enzyme}

Für den Abbau von Makromolekülen, wie Proteinen, Kohlenhydraten, Nukleinsäuren und Lipiden sind in eukaryonten Zellen Lysosomen die wichtigsten intrazellulären Organellen. Die abzubauenden Substanzen gelangen entweder über Endozytose aus dem Extrazellulärraum, über den Biosyntheseweg oder durch Verschmelzung vom Autophagosom zum Lysosom.

Lysosomen sind mit einer Vielzahl von verschiedenen sauren Hydrolasen angereichert, die durch eine lysosomale Membran vom Zytosol abgetrennt sind. Die Funktion der lysosomalen Membran besteht in der Aufrechterhaltung eines intralysosomalen sauren Milieus durch ATP-getriebene Protonenpumpen, dem selektiven Transport von Abbauprodukten ins Zytosol durch Transportproteine und dem Schutz zytoplasmatischer Strukturen vor hydrolytischem Abbau. Die Biogenese neuer Lysosomen während der Zellteilung und der konstitutive Abbau lysosomaler Bestandteile erfordern eine kontinuierliche Substitution lysosomaler Enzyme und Membranproteine zur Aufrechterhaltung der Integrität der Lysosomen (Kornfeld \& Mellman, 1989; Braulke, 1996).

Die Transportwege und Sortierungsmechanismen von neusynthetisierten, löslichen lysosomalen Enzymen sind im Vergleich mit jenen von lysosomalen Membranproteinen besser charakterisiert.

Lösliche lysosomale Enzyme werden am endoplasmatischen Reticulum (ER) mit einer N-terminalen Signalsequenz synthetisiert, die zur Steuerung der Translokation durch die ER-Membran erforderlich ist. Die Signalsequenz wird durch eine Signalpeptidase abgespalten, und Dolichol-aktivierte Oligosaccharide werden kotranslational auf spezifische Asparaginreste der Sequenz Asn-X-Thr/Ser übertragen. Nach Prozessierung der Oligosaccharidketten durch Abspaltung von drei Glukoseresten und einem Mannoserest werden die lysosomalen Enzyme in Transportvesikel abgeschnürt, die mit dem cisKompartiment des Golgi-Apparates verschmelzen. In den Golgi-Kompartimenten erfolgt eine Prozessierung der Oligosaccharidketten vom mannosereichen zum komplexen Typ, die im trans-Golgi und trans-Golgi-Netzwerk (TGN) durch Addition von Galaktose- und 
Sialinsäure-Resten komplettiert wird (von Figura \& Hasilik, 1986; Kornfeld \& Mellman, 1989).

Ein entscheidender Schritt bei der Prozessierung der Zuckerketten löslicher lysosomaler Enzyme ist die Bildung von Phosphomannosylresten an Oligosaccharidketten vom mannosereichen Typ. Dabei erfolgt im cis-Golgi-Kompartiment eine Übertragung von Phosphoryl-N-Acetylglucosamin durch die UDP-N-Acetylglucosamin-1-Phosphotransferase auf die Hydroxylgruppe an C6 eines Mannoserestes. Anschließend hydrolysiert eine Phosphodiesterase diese Bindung und erzeugt einen Mannose-6-Phosphat-Rest.

Die Phosphomannosylreste ermöglichen die Seggregation der neusynthetisierten lysosomalen Enzyme von der sekretorischen Route im TGN durch Bindung an Mannose-6Phosphat-Rezeptoren (MPR). Die Ligand-Rezeptorkomplexe werden in Clathrinbeschichtete Vesikel verpackt, die nach Verlust der Clathrinhülle mit einem prälysosomalen/endosomalen Kompartiment fusionieren, wo es aufgrund des sauren $\mathrm{pH}$ zur Dissoziation der Ligand-Rezeptorkomplexe kommt. Während die lysosomalen Enzyme auf noch ungeklärte Art und Weise ins Lysosom gelangen, rezirkulieren die Mannose-6Phosphat-Rezeptoren zum TGN und stehen für neue Transportrunden zur Verfügung (Ludwig et al., 1995).

In einigen Zelltypen und Geweben existiert ein Mannose-6-Phosphat-unabhängiger Transportweg zum Lysosom (Glickman \& Kornfeld, 1993), was durch Untersuchungen an MPR-defizienten Mäusen bestätigt wurde, in denen der Gehalt an lysosomalen Enzymen in manchen Organen normal oder gar erhöht war (Dittmer et al., 1999).

\subsection{Mannose-6-Phosphat-Rezeptoren}

In eukaryonten Zellen erfolgt die Sortierung von lysosomalen Enzymen durch zwei Mannose-6-Phosphat-Rezeptoren, die wegen ihres scheinbaren Molekulargewichts von 46 $\mathrm{kDa}$ und $300 \mathrm{kDa}$ als MPR46 und MPR300 bezeichnet werden. Da sich die Bindungsaffinität des MPR46 zu seinen Liganden im Gegensatz zum MPR300 durch Zusatz von divalenten Kationen steigern läßt (Tong \& Kornfeld, 1989), werden die Rezeptoren auch als kationen-abhängiger bzw. kationen-unabhängiger Mannose-6Phosphat-Rezeptor bezeichnet. Der MPR300 einiger Spezies bindet an der Plasmamembran mit hoher Affinität den nicht-glykosylierten Insulin-ähnlichen- 
Wachstumsfaktor II (IGF II) und wird daher als Mannose-6-Phosphat/IGF II-Rezeptor bezeichnet (Hille-Rehfeld, 1995; Le Borgne \& Hoflack, 1998).

Beide MPR zirkulieren konstitutiv sowohl zwischen dem TGN und den Endosomen als auch zwischen endosomalen Membranen und der Plasmamembran. Während der MPR300 exogene, Mannose-6-Phosphat-haltige Vorstufen lysosomaler Enzyme und IGF II an der Plasmamembran bindet und nach Rezeptor-vermittelter Endozytose zu den Lysosomen dirigiert, bindet und internalisiert der MPR46 keine Liganden an der Plasmamembran (Stein et al., 1987).

Das Optimum der Ligandenbindung liegt in vitro beim MPR300 zwischen pH 6,0-7,4 (Tong et al., 1989) und beim MPR46 zwischen $\mathrm{pH}$ 6,0-6,3 (Tong \& Kornfeld), was Befunde unterstützt, wonach beide Rezeptoren Liganden am TGN, aber nur der MPR300 Liganden an der Plasmamembran binden kann (Hoflack et al., 1987).

Die subzelluläre Verteilung der beiden Mannose-6-Phosphat-Rezeptoren ist vergleichbar und korrespondiert mit den Transportwegen lysosomaler Enzyme (Bleekemolen et al., 1988). Die Gesamtmenge an Mannose-6-Phosphat-Rezeptoren verteilt sich zelltypspezifisch auf Plasmamembran (3-20\%), endosomale Membranen (40-60\%) und das trans-Golgi-Netzwerk (20-40\%) (Griffiths et al., 1990; Klumpermann et al., 1993; Breuer et. al., 1997). Während der MPR300 vorwiegend in vesikulären endosomalen Strukturen lokalisiert ist, befindet sich der MPR46 bevorzugt in sogenannten assoziierten, tubulären Endosomenstrukturen (ATV) (Klumpermann et al., 1993). In den Lysosomen konnten keine Mannose-6-Phosphat-Rezeptoren nachgewiesen werden.

Untersuchungen an Rezeptor-defizienten Mausfibroblasten zeigen, daß beide Rezeptoren verschiedene Subpopulationen lysosomaler Hydrolasen mit unterschiedlicher Effizienz sortieren (Köster et al., 1993; Kasper et al., 1996), was wahrscheinlich auf unterschiedliche Bindungsaffinitäten für diphosphorylierte Oligosaccharide verschiedener lysosomaler Enzyme zurückzuführen ist. Der MPR300 bindet diphosphorylierte Oligosaccharidketten effektiver als der MPR46 (Tong \& Kornfeld, 1989). 


\section{MPR300}

Der MPR300 ist ein integrales Membranglykoprotein vom Typ I und besteht aus vier strukturellen Domänen von ähnlicher, Spezies-abhängiger Länge: einer N-terminalen Signalsequenz von 40-44 Aminosäuren, einer extrazytoplasmatischen Domäne von 2264-2269 Aminosäuren, einer 23 Aminosäuren umfassenden Transmembrandomäne und einer C-terminalen zytoplasmatischen Domäne von 164 Aminosäuren. Die extrazytoplasmatische Domäne ist aus 15 Wiederholungseinheiten von jeweils etwa 147 Aminosäuren aufgebaut, die untereinander eine Homologie von 16-38 \% besitzen. Von den 19 potenziellen N-Glykosylierungsstellen in der luminalen Domäne werden mindestens 2 genutzt und tragen ca. 20-30 kDa zum Molekulargewicht bei (Braulke, 1996).

Der Rezeptor besitzt zwei Mannose-6-Phosphat-Bindungsstellen in den Wiederholungseinheiten 1-3 und 7-9 der luminalen Domäne (Westlund et al., 1991), wobei die Argininreste 435 und 1334 essentiell für die Bindung sind (Dahms et al, 1993). Der MPR300 bindet als Rezeptormonomer 2 Mol eines monophosphorylierten oder 1 Mol eines diphosphorylierten Liganden (Tong et al., 1989). Neben Mannose-6-Phosphathaltigen lysosomalen Enzymen bindet auch die inaktive Vorstufe des transformierenden Wachstumsfaktors $\beta 1$ (TGF- $ß 1$ ) über Mannose-6-Phosphat-Reste an den MPR300, was als Vorrausetzung für dessen Aktivierung angesehen wird (Dennis \& Rifkin, 1991). Die Bindungsstelle für IGF II umfaßt beim bovinen und humanen MPR300 die N-terminalen Aminosäurereste 1508-1566 der Wiederholungseinheit 11 (Schmidt et al., 1995), während bei einigen Spezies wie etwa Huhn und Frosch diese Bindungsstelle fehlt (Canfield \& Kornfeld, 1989; Clairmont \& Czech, 1989). Gen Targeting Experimente zeigten, daß der MPR300 als Scavenger Rezeptor während der Embryonalentwicklung funktioniert, der die zirkulierenden IGF II-Spiegel durch Internalisierung und Abbau des extrazellulären IGF II reguliert (Lau et al., 1994).

Kürzlich sind zwei neue Typen von MPR300-Liganden beschrieben worden, deren Bindungsstellen sich von den bekannten Mannose-6-Phosphat/IGF II-Bindungsstellen unterscheiden (Kang et al., 1998 a, Nykjaer et al., 1998). Einer dieser Liganden, der Urokinasetyp-Plasminogen-Aktivator Rezeptor (uPAR), ist ein Glykosylphosphatidylinositol-verankertes Zelloberflächen-Adhäsionsprotein, das an der extrazellulären proteolytischen Aktivierung von Plasminogen und latentem TGFß-1 beteiligt ist. Es wird angenommen, daß die uPa-unabhängige Bindung an den MPR300 die subzelluläre Verteilung von uPAR ändert und es zum Lysosom dirigiert. Bei dem zweiten Liganden 
handelt es sich um Retinsäure, die das Zellwachstum während der Embryo- und Onkogenese beeinflußt, und nach Bindung an den MPR300 eine Umverteilung der Rezeptoren sowie der lysosomalen Protease Cathepsin B aus perinukleären in endosomale Strukturen induziert (Kang et al., 1998 a; 1998 b).

\section{MPR 46}

Beim MPR46 handelt es sich ebenfalls um ein integrales Membranglykoprotein vom Typ I, das aus vier strukturellen Domänen von Spezies-abhängiger, variabler Länge besteht: einer N-terminalen Signalsequenz von 21-28 Aminosäuren, einer extrazytoplasmatischen Domäne von 159 Aminosäuren, einer 25 Aminosäuren umfassenden Transmembrandomäne und einer C-terminalen zytoplasmatischen Domäne von 67 Aminosäuren. Die extrazytoplasmatische Domäne des MPR46 besitzt Sequenzhomologien von 14-28 \% zu den einzelnen Wiederholungseinheiten des MPR300. Vier der fünf potenziellen Glykosylierungsstellen der luminalen Domäne werden genutzt, und diese Oligosaccharidketten machen etwa 40\% des Molekulargewichts aus (Wendland et al., 1991). Der Rezeptor existiert in Membranen hauptsächlich als Homodimer, wobei zwei Monophosphomannosyl-Reste pro Homodimer gebunden werden können. Kürzlich wurde die 3 D-Struktur der extrazellulären Domäne des bovinen MPR46 veröffentlicht (Roberts et al., 1998). Die Bildung der Mannose-6-Phosphat-Bindungsstelle erfolgt durch Disulfidbrückenbildung zwischen den Cys106- und Cys141-Resten, wobei zwei Proteinschleifen miteinander verbunden werden. Der His105-Rest bindet die negativ geladene Phosphat-Gruppe des Liganden, und der Arg111-Rest ist durch Wasserstoffbrücken mit dem C2-gebundenen Sauerstoffatom des Mannoserings und dem Sauerstoffatom des Phosphatrestes verbunden. 


\subsection{Signalabhängiger Transport von Mannose-6-Phosphat-Rezeptoren}

Für den gerichteten, intrazellulären Transport der Mannose-6-Phosphat-Rezeptoren entlang des Biosynthese- und Endozytoseweges sind Signalstrukturen verantwortlich, die hauptsächlich in den zytoplasmatischen Domänen der Rezeptoren lokalisiert sind. Die verschiedenen Signalstrukturen in den zytoplasmatischen Domänen können mit zytosolischen und mit Proteinen der Vesikelmembranen in Wechselwirkung treten, die die Konzentrierung der MPR in bestimmten Membranbereichen, die Anlagerung von Hüllproteinen, Abschnürung, Transport und Fusion mit den Zielmembranen begünstigen. Eine ständig steigende Zahl von Proteinen ist identifiziert worden, die für einzelne Teilabschnitte des vesikulären Transportes essentiell sind. Dazu gehören verschiedene Mitglieder der kleinen GTPasen aus der Rab- und ARF-Familie, das N-Ethylmaleinimidsensitive Fusionsprotein (NSF), das "Soluble NSF-Attachment-Protein" (SNAP) und die SNAP-Rezeptoren (t-SNAREs; v-SNAREs) (Riederer et al., 1994; Itin et al., 1997; Press et al., 1998; Valdez et al., 1999). Für keines dieser Proteine ist aber bisher eine direkte Interaktion mit den zytoplasmatischen Domänen der MPRs beschrieben worden.

\section{Internalisierung an der Plasmamembran}

An der Plasmamembran erfolgt die Abschnürung in Clathrin-umhüllte, MPR-haltige Vesikel unter Beteiligung des Adaptorkomplexes AP-2, der aus je einem großen $\alpha$ - und $\beta 2-(100 \mathrm{kDa})$ Adaptin, einer mittleren $\mu 2-(50 \mathrm{kDa})$ und einer kleinen $\delta 2-(17 \mathrm{kDa})$ Untereinheit zusammengesetzt ist (Hirst \& Robinson, 1998). Die Funktion der Adaptoren wird in der Rekrutierung und Bindung des zytosolischen Hüllproteins Clathrin und der Erkennung von spezifischen Signalstrukturen in den zytoplasmatischen Domänen der MPR und anderer Membranrezeptoren gesehen (Kirchhausen et al., 1997). Dabei soll AP-2 aus dem Zytosol durch Wechselwirkung mit einem postulierten Membrankomplex an die Plasmamembran angelagert werden. Die Bindung von Clathrin an die B2-Untereinheit bewirkt eine Konformationsänderung von AP-2, die wiederum eine Affinitätsänderung der $\mu 2$-Untereinheit für die Wechselwirkung mit den zytoplasmatischen Domänen von zirkulierenden Membranrezeptoren induziert (Rapoport et al., 1997).

Für die Endozytose des MPR300 an der Plasmamembran ist ein Tyrosin-haltiges Internalisierungssignal $\left({ }^{24} \mathrm{YKYSKV}^{29}\right)$ verantwortlich, welches eine $\beta$-turn-Struktur besitzt, 
bei der die kritischen Tyrosinreste innerhalb einer Haarnadelstruktur lokalisiert sind (Lobel et al., 1989; Canfield et al.; 1991; Jadot et al., 1992). Das Tyrosin-haltige Internalisierungssignal beinhaltet eine Konsensussequenz (YXX $\varnothing$ ), die aus der Abfolge eines Tyrosinrestes (Y), zweier wenig konservierter Aminosäuren (X) und einer variablen Aminosäure $(\varnothing)$ mit hydrophober Seitenkette in Position $(Y+3)$ besteht (Sandoval \& Bakke, 1994; Marks et al., 1997). Two-Hybrid-Analysen und in vitro-Experimente zeigten, daß der Tyr-Rest und die hydrophobe Aminosäure in Position Tyr+3 kritisch für die Bindung der $\mu 2$-Untereinheit von AP-2 sind (Ohno et al., 1995).

Für die rasche und effiziente Internalisierung des MPR46 sind zwei Signalsequenzen beschrieben: ein dominantes Internalisierungssignal $\left({ }^{13} \mathbf{F P H L A F}{ }^{18}\right)$ im proximalen Bereich der zytoplasmatischen Domäne des MPR46 mit den kritischen Aminosäureresten Phe13 und Phe18 und ein schwächeres Tyrosin-haltiges Internalisierungssignal $\left({ }^{45} \mathbf{Y R G V}^{48}\right)$ (Johnson et al., 1990), welche direkt mit dem Adaptorkomplex AP-2 interagieren (Glickman et al., 1989; Sosa et al., 1993). Außerdem sollen eine zusätzliche proximale Sequenz nach der Transmembrandomäne ( $\left.{ }^{7} \mathrm{AKGMEEQF}^{13}\right)$ und eine C-terminale Sequenz $\left({ }^{47} \mathrm{G}-\mathrm{M}^{67}\right)$ mit einem essentiellen Di-Leucin-Motiv für die Internalisierung des MPR46 von Bedeutung sein (Denzer et al., 1997). Bis auf die Bedeutung des Di-Leucin-Motives konnten die erhaltenen Befunde in vitro durch Plasmon-Resonanz-Bindungsstudien zwischen AP-2 und der zytoplasmatischen Domäne des MPR46 bestätigt werden, die einen inhibierenden Einfluß der synthetischen Peptidsequenzen 2-16 und 49-67 auf die Bindung zeigen (Höning et al., 1997).

\section{Sortierung am TGN}

Am TGN erfolgt eine Verpackung der Mannose-6-Phosphat-Rezeptoren in Clathrinbeschichtete Vesikel unter Beteiligung des heterotetrameren Adaptorkomplexes AP-1, der aus je einem großen $\gamma$ - und 31 -Adaptin (100 kDa), einer mittleren $\mu 1-(50 \mathrm{kDa})$ und einer kleinen $\sigma 1-(17 \mathrm{kDa})$ Untereinheit zusammmengesetzt ist (Le Borgne \& Hoflack, 1998). Für die Bindung von Clathrin an AP-1 wird eine Beteiligung der "Gelenk"-Region der ß1-Untereinheit diskutiert (Gallusser \& Kirchhausen, 1993). Aus Hefe-Two-HybridAnalysen geht hervor, daß die $\mu 1$-Untereinheit Tyrosin-haltige Internalisierungssequenzen vom Typ $(\mathrm{YXX} \varnothing)_{3}$ bindet, die in monomerer Form in zytoplasmatischen Domänen endozytotischer Rezeptoren gefunden werden (Ohno et al., 1995). Die N-terminalen 
Aminosäurereste 1-145 von $\mu 1$ sind mit der ß1-Untereinheit assoziiert, während die C-terminalen Aminosäurereste 147-423 eine Konformation einnehmen, die eine Interaktion mit der Tyrosin-haltigen Sequenz erlaubt (Aguilar et al., 1997). In in vitro-Experimenten mit synthetischen Peptiden wurde dagegen eine Bindung von Di-Leucin-Motiven an die "trunk“-Region der B1-Untereinheit gezeigt (Rapoport et al., 1998).

Die genaue Abfolge der Schritte bei der Bindung von AP-1 an spezifische TGN-Membranabschnitte und die beteiligten Komponenten werden zur Zeit noch kontrovers diskutiert. Als erster Schritt erfolgt nach Austausch von GDP gegen GTP eine Anlagerung der kleinen, zytosolischen GTPase ARF 1 (ADP-Ribosylierungsfaktor 1) an TGN-Membranen. Das bisherige Modell ging davon aus, daß die MPRs im Komplex mit ARF-GTP und anderen bisher unbekannten Faktoren (v-SNARE's) AP-1 binden (Ludwig et al., 1995, Le Borgne \& Hoflack, 1998). Das andere Modell postuliert ein putatives membran-ständiges Bindungsprotein, das nach Aktivierung durch ARF-GTP eine hochaffine Bindungsstelle für AP-1 darstellt. Nach Bindung von AP-1 soll es zur Konzentrierung der MPR's in die entstehenden clathrinumhüllten Vertiefungen durch laterale Diffusion kommen (Zhu et al., 1999).

Für die effektive Sortierung lysosomaler Enzyme sind beim MPR300 zwei Sortierungssignale beschrieben: ein dominantes C-terminal lokalisiertes Di-Leucin-Motiv $\left({ }^{161} \mathrm{LLHV}^{164}\right)$ und eine schwächere, proximal gelegene Determinante, die mit dem Tyrosinhaltigen Internalisierungssignal $\left({ }^{24} \mathrm{YKYSKV}^{29}\right)$ überlappt (Johnson \& Kornfeld, 1992 a). In der zytoplasmatischen Domäne des bovinen MPR300 werden die Serinreste 85 und 156 beim Austritt aus dem TGN durch ein Kasein-Kinase 2 (CK2)-ähnliches Enzym phosphoryliert, das mit der $\mu 1$-Untereinheit des AP-1-Komplexes assoziiert ist (Meresse et al., 1990). Die Kasein-Kinase 2-Phosphorylierungsstelle Ser156 proximal des Di-LeucinMotives ist möglicherweise Teil des Sortierungssignals, wobei dem benachbarten Aspartatrest eine kritische Bedeutung zugesprochen wird (Chen et al., 1993; 1997).

Die zytoplasmatische Domäne des MPR46 wird am Ser56-Rest $\left({ }^{55}\right.$ ESEER $\left.^{59}\right)$ ebenfalls durch eine CK2-ähnliche Kinase phosphoryliert (Hemer et al., 1993). Dieser Sequenz wird eine kritische Rolle bei der Rekrutierung von AP-1 zugeschrieben (Mauxion et al., 1996), während das zweite Modell die AP-1-Anlagerung auch in Abwesenheit von MPRs beschreibt (Zhu et al., 1999). Diese Untersuchungen werden unterstützt durch Befunde, daß Mutationen dieses Ser56-Restes keinen Einfluß auf die Sortierung im TGN oder für die Internalisierungsrate des Rezeptors von der Plasmamembran haben (Johnson \& Kornfeld, 
1992 b). Für die vermutlich endosomale Sortierung des MPR46 in Vesikel, die zur Plasmamembran transportiert werden, ist dagegen die Phosphorylierungsstelle notwendig (Breuer et al., 1997). Das C-terminal gelegene Di-Leucin-Motiv $\left({ }^{63} \mathrm{HLLPM}^{67}\right)$ ist für die effiziente Sortierung im TGN wichtig (Johnson \& Kornfeld, 1992 b; Mauxion et al., 1996).

\section{Sortierung im Endosom}

Für den Transport der MPRs von den Endosomen zum TGN als auch von den Endosomen zur Plasmamembran müssen Signalstrukturen postuliert werden, die bisher noch wenig charakterisiert sind.

Die Transmembrandomäne und zwei nichtredundante Sequenzen in der zytoplasmatischen Domäne des MPR46 sind essentiell, um den Transport des Rezeptors ins Lysosom zu verhindern. Die beiden aromatischen Reste Phe18 und Trp19 sind Bestandteil eines endosomalen Sortierungssignals für den Rücktransport zum TGN, wobei dem Trp19-Rest eine kritische Bedeutung zugesprochen wird (Schweizer et al., 1997). Dieser Transportschritt erfolgt unter Beteiligung der GTPase Rab9 (Lombardi et al., 1993), einem 40 kDa Rab9-Effektor (Diaz et al., 1997) und weiteren zytosolischen Faktoren (NSF, $\alpha$ SNAP) in Vesikeln, die nicht mit Clathrin beschichtet sind (Draper et al., 1990; Itin et al., 1997). Durch Untersuchungen an Deletions- und Austauschmutanten wurde eine Sequenz von basischen Aminosäuren $\left({ }^{34} \mathrm{CRSKPR}^{39}\right)$ identifiziert, deren Fehlen den Transport des Rezeptors ins Lysosom bewirkt (Rohrer et al., 1995). Der Cys34-Rest und ein benachbarter Cys30-Rest werden reversibel palmitoyliert, wobei der Alaninaustausch des kritischen Cys34-Restes eine Fehlsortierung von Cathepsin D sowie eine Akkumulation der mutanten Rezeptoren im Lysosom bewirkt (Schweizer et al., 1996). Es wird diskutiert, daß durch Verankerung der Palmitatreste in die Lipiddoppelschicht eine intrazelluläre Schleife zwischen der Transmembrandomäne des MPR46 und dem Cys30-Rest gebildet wird, die als endosomales Retentionssignal fungieren soll. Die Verkürzung dieser intrazellulären Schleife um 4-5 Aminosäuren führt zu schnellem Abbau des MPR46, der nach Verlassen des Golgi-Apparates stattfindet und nur durch den Proteasomeninhibitor Lactacystin hemmbar ist (Breuer \& Braulke, 1998).

Der MPR300 ist ebenfalls palmitoyliert, jedoch sind die modifizierten Cysteinreste unbekannt (Westscott \& Rome, 1988). Ob die Palmitoylierung des MPR300 auch an der Retention in endosomalen Membranen beteiligt ist, ist unklar. 


\subsection{Interaktion der Mannose-6-Phosphat-Rezeptoren mit zytosolischen und membrangebundenen Proteinen}

Für die Mannose-6-Phosphat-Rezeptoren sind neben den bereits erwähnten Adaptorkomplexen AP-1 und AP-2 weitere Proteine beschrieben, die mit den Signalstrukturen in den zytoplasmatischen Domänen in Wechselwirkung treten.

Durch Quervernetzungsanalysen konnte die Bindung eines zytosolischen 35 kDa-Proteins (TIP35) an die durch CK2 phosphorylierten Ser82- und Ser157-Reste der zytoplasmatischen Domäne des MPR300 gezeigt werden (Rosorius et al., 1993 a). Die Interaktion mit zwei weiteren membranassoziierten $35 \mathrm{kDa}$ - und $91 \mathrm{kDa}$-Proteinen (TIP35-M; TIP91-M) war dagegen unabhängig von der Phosphorylierung des Rezeptors. Die Wechselwirkung des zytosolischen und membranassoziierten TIP35 mit dem MPR300 erfordert die Einlagerung in einen 130-150 kDa-Komplex und kann durch ATP-Hydrolyse gehemmt werden. Es wird vermutet, daß TIP35 oder eine andere Untereinheit des Komplexes ein Zink-bindendes Protein ist (Rosorius et al., 1996). Die Identität und die Bedeutung der Bindung von TIP35 für das Transportverhalten und die Sortierungsfunktion des MPR300 sind unbekannt.

Mit Hilfe des Hefe-Two-Hybrid-Systems wurde ein zytosolisches 47 kDa-Protein (TIP47) identifiziert, das die zytoplasmatischen Domänen der MPR's bindet (Diaz \& Pfeffer, 1998). TIP47 existiert im Zytosol als Homooligomer mit einem apparenten Molekulargewicht von $300 \mathrm{kDa}$. Bei Sequenzvergleichen konnten keine Homologien zu den $\mu$-Untereinheiten der bekannten Adaptorkomplexe AP-1, AP-2 und AP-3 gefunden werden. Für die Wechselwirkung von TIP47 mit dem MPR46 sind die aromatischen Reste Phe18 und Trp19 notwendig, die ein endosomales Sortierungssignal darstellen, das den Transport des Rezeptors ins Lysosom verhindert und für den Rücktransport zum TGN notwendig ist. Für die Bindung von TIP 47 an den MPR300 wird eine Beteiligung des Trp42-Restes diskutiert, da ein homologes diaromatisches Sortierungssignal in der zytoplasmatischen Domäne fehlt und Mutationen der kritischen Reste von Tyrosin- und DiLeucin-haltigen Sortierungssignalen den Rücktransport des Rezeptors nicht beeinträchtigen. 
Kürzlich wurde ein weiteres zytosolisches Protein, PACS-1 (Phosphofurin acidic cluster sorting protein-1) identifiziert, das zur Gruppe von zytosolischen "Connector"-Proteinen gehört (Wan et al., 1998). PACS-1 bindet den C-terminal lokalisierten Cluster von sauren Aminosäuren in der zytoplasmatischen Domäne des MPR300 und dirigiert die Lokalisation des Rezeptors im TGN. Dem Cluster von sauren Aminosäuren um die Phosphorylierungsstelle kommt daher nicht nur eine Bedeutung beim intrazellulären Transport des Rezeptors, sondern auch bei der AP-1-Rekrutierung zu (Mauxion et al., 1996). 


\section{Zielsetzung}

Die zytoplasmatische Domäne des MPR300 interagiert mit den $\mu 1$ - und $\mu$ 2-Untereinheiten der Adaptorkomplexe AP-1 und AP-2, dem zytosolischen TIP47-Protein sowie weiteren zytosolischen (TIP35) und membranassoziierten (TIP35-M, TIP91-M) Proteinen. Während die Bindungsstellen von $\mu 1, \mu 2$ und TIP47 in den zytoplasmatischen MPR-Domänen und ihre Bedeutung für die Transportfunktion der MPRs bekannt sind, ist die Existenz von verschiedenen anderen Proteinen zu vermuten, die für die spezifische Verpackung von MPRs in Transportvesikel aus unterschiedlichen intrazellulären Organellen, Zelltypabhängige Funktionen der MPRs sowie für MPR-spezifische Modifikationen und Konformationszustände verantwortlich oder daran beteiligt sind.

Ein Ziel dieser Arbeit war, mit Hilfe des Hefe-Two-Hybrid-Systems neue Proteine zu identifizieren, die mit der zytoplasmatischen Domäne des MPR300 interagieren. Anhand verschiedener Deletions- und Austauschmutanten der zytoplasmatischen Domäne des MPR300 sollten Signalstrukturen definiert werden, die an der Wechselwirkung mit neuen Proteinen beteiligt sind. Weiterhin sollte die Spezifität der Wechselwirkung zwischen identifizierten Proteinen und den zytoplasmatischen Domänen von MPR300 und MPR46 untersucht werden. Schließlich sollten die Protein-MPR-Wechselwirkungen in der Hefe auf Proteinebene in vitro verifiziert und ihre Bedeutung für den Transport lysosomaler Enzyme an kultivierten Zellinien untersucht werden.

Der zweite Schwerpunkt der Arbeit war auf die Identifizierung struktureller Voraussetzungen für die Wechselwirkung zwischen der $\mu 2$-Untereinheit des AP-2-Komplexes mit der gesamten zytoplasmatischen Domäne des MPR46 gerichtet. Für diese Untersuchungen war wieder die gezielte Anwendung des Two-Hybrid-Systems in der Hefe unter Verwendung der cDNAs von Wildtyp- und mutanten zytoplasmatischen Domänen des MPR46 und von $\mu 2$ vorgesehen.

Bisherige Internalisierungsstudien mit mutanten, überexprimierten MPR46 und kompetitive in vitro-Bindungsstudien mit synthetischen Peptiden belegen die Bedeutung multipler Sortierungssignale in der zytoplasmatischen Rezeptordomäne, wobei gerade die Rolle des Tyr45-haltigen Signals kontrovers diskutiert wird. 
Weiterhin sollte in diesem Schwerpunkt die Frage nach möglichen Interaktionen zwischen der $\mu 3$-Untereinheit des AP-3-Komplexes mit der zytoplasmatischen Domäne des MPR46 eingebunden werden. Der AP-3-Komplex ist am Transport von Proteinen zum Lysosom und Melanosom, einem Lysosomen-ähnlichem Organell der Melanozyten, beteiligt. Seine Bedeutung für den MPR-abhängigen Transport lysosomaler Enzyme ist weitgehend unklar. 


\section{Material und Methoden}

\subsection{Material}

\subsubsection{Geräte}

Analysenwaagen Typ 1602 MP und M5P

Autoklav Typ Tecnoclav 50

Brutschrank Typ 2771

DNA-Sequenzierer 373 A

Dounce-Homogenisator, $1 \mathrm{ml}$

Drehrad für Eppendorfgefäße

Eismaschine

Elektrophoresekammern für Agarosegele

Elektrophoresekammern für

Polyacrylamidgele

SDS-Elektrophoresesysteme

SE-600

SE-250, Mighty Small II

Elektroporator, Gene Pulser ${ }^{\circledR}$

Filmentwicklungsmaschine

Modell Gevamatic 60

Gammastrahlenzähler, 1470 Wizard ${ }^{\mathrm{T} M}$

Gefrierschrank $-80{ }^{\circ} \mathrm{C}$, Modell U 57085

Geltrockner, Modell Gel Air Dryer

Gradientenfraktionierer

Heizblock Modell Thermostat 5320

Inkubationsschüttler Modell G25

Jet-1-Automatic vacuum System; Tom

Lyophilisator

Magnetrührer Ika-Combimag Ret

Mikroskope:

Phasenkontrastmikroskop, Modell ID 03

Inverses Mikroskop, Modell IM

Mikrowellenherd

Multipette, Combitips

Naß-Blot-Systeme

Transphor Power Cid

TE 22 Mighty Small Transphor Transfer Unit

pH-Meter Knick 647

Photometer, UV 160 A

Phosphoimager, IPR 1000

Schüttelinkubator G25

Schüttelwasserbad GFL 1083

Sequenzierer ABI 373 A
Sartorius, Göttingen

Tecnorama, Zürich, Schweiz

Heraeus, Osterode

Köttermann, Häningsen

Applied Biosystem Inc., Weiterstadt

Wheaton/ USA

Eigenbau, Werkstatt des Institutes

Ziegra, Isernhagen

Eigenbau, Werkstatt des Institutes

Hoefer Scientific Instruments, USA

Hoefer Scientific Instruments, USA

Hoefer Scientific Instruments, USA

Bio Rad, München

Agfa-Gevaert, Leverkusen

Wallac, Finnland

New Brunswick, Edison

Biorad, Hercules, USA

Bender \& Hohbein

Eppendorf, Hamburg

New Brunswick Sc., Edison

Schütt, Göttingen

Bachofer, Reutlingen und Christ,

Osterode

Janke \& Kunkel, Staufen

Zeiss, Oberkochen

Zeiss, Oberkochen

Siemens, München

Netheler \& Hinz, Hamburg

Hoefer Scientific Instruments, USA

Hoefer Scientific Instruments, USA

Schütt, Göttingen

Schimadzu, Kyoto, Japan

Fuji, Tokio, Japan

New Brunswick Sc., Edison/USA

Köttermann, Häningsen

Schütt, Göttingen

Applied Biosystem, Foster City/USA 
Spannungsgeräte

Spektralphotometer Uvikon 810

Steri-Kult Inkubator, 3035/200

Sterilbank, A/B3 bzw. SG 400

Sterilfilter Minisart NML

Stickstoff-Einfriertank Biosafe Chronos

Thermocycler Gene Amp PCR 9600 bzw. 2400

Thermoprinter

Transilluminator Modell IL-400-M

UV-Handlampe (312 $\mathrm{nm}$ und $254 \mathrm{~nm}$ )

Ultraschall-Desintegrator Sonifier W-450

Vakuum Konzentrator Speed Vac SVC 100H

Video Copy Processor

Video-Drucker

Video-Kamera

Vortex-Genie

Waagen Typ 1264 MP und 1265

Wärmeschrank

Wasserbad Typ HOR 7225

Wipptisch

Profile Rocker M 1241

Zentrifugen:

Biofuge A

Biofuge Fresco

Eppendorf-Kühlzentrifuge Mikro Rapid/K

Eppendorfzentrifuge 5414 und $5415 \mathrm{C}$

Kühlzentrifuge, Modell J-21 C und J2-MC

Rotoren für die Kühlzentrifuge:

JA-10-Rotor, bis 17.680 x g

JA-20-Rotor, bis $48.300 \mathrm{x} \mathrm{g}$

Labofuge GL

Ultrazentrifuge TL-100

Rotor für TL-100

TLA-100.3, bis $430.000 \mathrm{x} \mathrm{g}$

Ultrazentrifuge L8-M

Rotor SW-40

Rotor VTI 65-1

\subsubsection{Verbrauchsmaterialien}

Einfrierkästen

Einmalkanülen

Einmalspritzen

Elektroporationsküvetten

Gewebekulturflaschen 25 und $75 \mathrm{~cm}^{2}$

Gewebekulturschalen 36 und $60 \mathrm{~mm} \varnothing$

Glaskolben $100 \mathrm{ml}, 250 \mathrm{ml}, 1000 \mathrm{ml}$
Hölzel, München

Biometra, Göttingen

Kontron, Eching

Forma Scientific, Marietta, USA

Baker Company, Inc., Stanford, USA

Sartorius AG, Göttingen

Messer Griesheim, Frankfurt

Perkin-Elmer Cetus, Norwalk, USA

Intas, Göttingen

Bachofer, Reutlingen

Bachofer, Reutlingen

Branson Ultrasonic SA,

Carouge-Geneve, USA

Savant Instruments, Farmingdale

Mitsubishi, Tokio, Japan

Intas, Göttingen

Intas, Göttingen

Bender \& Hobein AG, Zürich

Sartorius, Göttingen

Memmert, Schwabach

Köttermann, Häningsen

Eigenbau, Werkstatt des Instituts

New Brunswick Scientific, Edison

Heraeus, Osterode

Heraeus, Osterode

Hettich

Netheler \& Hinz, Hamburg

Beckman, München

Beckman, München

Heraeus, Osterode

Beckman, München

Beckman, München

Beckman, München

Beckman, München

Beckman, München

National Lab, Mölln

Neoject, Gelnhausen

Braun, Melsungen

Bio-Rad, München

Greiner, Nürtingen

Greiner, Nürtingen

Schott, Mainz 
Glasperlen $(\varnothing=425-600 \mu \mathrm{m})$

Immersionsöl $518 \mathrm{C}$

Linsenpapier MN 10 B

Nitrozellulose Blotting Membranen 0,2 $\mu \mathrm{m}$

Objektträger und Deckgläser

Parafilm $^{\circledR}$

Plastik-Petrischalen $\varnothing 92 \mathrm{~mm}$

$\varnothing 145 \mathrm{~mm}$

Polycarbonat-Zentrifugenröhrchen für

den Rotor TLA 100.3

Quick-Seal-Röhrchen für Rotor VTI 65.1

Polycarbonat-Zentrifugenröhrchen SW-40

Reaktionsgefäße: $\quad 0,2 \mathrm{ml}$

$0,5 \mathrm{ml}$

$1,5 \mathrm{ml}$ und $2,0 \mathrm{ml}$

Röntgenfilme, XAR-5

Sterile Plastikröhrchen $10 \mathrm{ml}$

Sterile Plastikröhrchen $50 \mathrm{ml}$

Sterilfilter

Whatman GB002-Papier

Whatman GB003-Papier, extra dick

Zentrifugenbecher:

JA-10 Polypropylen JA-20 Polypropylen
Sigma

Zeiss, Oberkochen

Zeiss, Oberkochen

Sartorius AG, Göttingen

Menzel Gläser

American National Can ${ }^{\mathrm{TM}}$, Neenah, USA

Sarstedt, Nümbrecht

Greiner, Nürtingen

Beckman, München

Beckman, München

Beckman, München

Perkin Elmer Cetus, Norwalk, USA

Sarstedt, Braunschweig

Greiner, Nürtingen

Kodak, Stuttgart

Greiner, Nürtingen

Sarstedt, Braunschweig

Sartorius, Göttingen

Schleicher \& Schüll, Dassel

Schleicher \& Schüll, Dassel

Nalgene, München

\subsubsection{Enzyme und Nukleotide}

DNase I

Lachsspermien-DNA

Lysoszym

Pfu-Turbo ${ }^{\text {TM-DNA-Polymerase }}$

Phosphatase, alkalische (calf intestinal), CIP

Restriktionsendonukleasen

RNase A

T4-DNA-Ligase

Taq-DNA-Polymerase

Thrombin (aus Humanplasma)

TNT $^{\circledR}$ Coupled Reticulocyte Lysate System

Ultrapure dNTP Set
Merck

Sigma

Merck

Stratagene, La Jolla, USA

Boehringer, Mannheim

New England Biolabs

Bad Schwalbach

Boehringer, Mannheim

New England Biolabs

Bad Schwalbach

Pharmacia, Freiburg

Sigma

Promega, Madison, USA

Pharmacia, Freiburg 


\subsubsection{Kits zur Bearbeitung von DNA, RNA und Protein}

ABI PRISM Dye Terminator Cycle Sequencing

Ready Reaction ( No. 402079)

QIAquick Gel Extraction

QIAquick PCR Purification

QIA-Plasmid Mini Kit

QIA-Plasmid Midi Kit

Super Signal

Rediprime DNA Labelling System
Perkin Elmer Cetus, Norwalk/ USA

Qiagen, Hilden

Qiagen, Hilden

Qiagen, Hilden

Qiagen, Hilden

Pierce

Amersham, Braunschweig

\subsection{5 cDNA-Bibliotheken}

Matchmaker ${ }^{\circledR}$ Humane HeLa S3-cDNA-Bibliothek

Matchmaker ${ }^{\circledR}$ Rattenhirn-cDNA-Bibliothek

Matchmaker ${ }^{\circledR}$ Humane Nieren-cDNA-Bibliothek
Clontech, Palo Alto, USA

Clontech, Palo Alto, USA

Clontech, Palo Alto, USA

\subsubsection{Proteine, Proteaseinhibitoren und Proteinstandards}

Glutathion, reduziert

Jodacetamid (JAA)

Leupeptin

Pansorbin-Zellen (hitzeinaktivierte

Staphylococcus aureus Zellsuspension)

Pepstatin A

Phenylmethylsulfonylfluorid (PMSF)

Rainbow $^{\mathrm{TM}}$-coloured protein MG-Standard

Rinderserumalbumin (BSA)
Sigma, Deisenhofen

Serva, Heidelberg

Biomol, Hamburg

Calbiochem, Frankfurt

Sigma, Deisenhofen

Serva, Heidelberg

Amersham, Braunschweig

Biomol, Hamburg

\subsubsection{Detergenzien}

Natriumlaurylsulfat

Nonidet P-40

Saponin

Triton X-100

Tween 20
Serva, Heidelberg

Sigma, Deisenhofen

Sigma, Deisenhofen

Sigma, Deisenhofen

Sigma, Deisenhofen 


\subsubsection{Antikörper}

\subsubsection{Primärantikörper}

\begin{tabular}{|l|l|c|l|}
\hline \multicolumn{1}{|c|}{ Antigen } & \multicolumn{1}{|c|}{$\begin{array}{c}\text { immunisierte Spezies } \\
\text { Bezeichnung }\end{array}$} & \multicolumn{1}{|c|}{ Aufbereitung } & \multicolumn{1}{|c|}{ Referenz } \\
\hline Periplakin, human & $\begin{array}{l}\text { Kaninchen, } \alpha-T A P, \\
\text { polyklonal }\end{array}$ & affinitätsgereinigt & $\begin{array}{l}\text { S. Storch, } \\
\text { unveröffentlicht }\end{array}$ \\
\hline Periplakin, human & Kaninchen, TD1, polyklonal & Serum & $\begin{array}{l}\text { Ruhrberg et al., } \\
1997\end{array}$ \\
\hline Periplakin, human & Kaninchen, CR3, polyklonal & Serum & $\begin{array}{l}\text { Ruhrberg et al., } \\
1997\end{array}$ \\
\hline MPR300, human & Ziege II-2, polyklonal & Serum & Causin et al., 1988 \\
\hline $\begin{array}{l}\text { GST, Schistosoma } \\
\text { japonicum }\end{array}$ & $\begin{array}{l}\text { Kaninchen, } \alpha-G S T, \\
\text { polyklonal }\end{array}$ & Serum & $\begin{array}{l}\text { S. Storch, } \\
\text { unveröffentlicht }\end{array}$ \\
\hline $\begin{array}{l}\text { GAL4-AD- } \\
\text { Domäne }\end{array}$ & Maus, monoklonal & $\begin{array}{l}\text { Clontech, Palo } \\
\text { Alto }\end{array}$ \\
\hline $\begin{array}{l}\text { Cathepsin D, } \\
\text { human }\end{array}$ & Ziege, polykonal & Serum & Hasilik et al., 1980 \\
\hline
\end{tabular}

\subsubsection{Sekundärantikörper}

\begin{tabular}{|l|l|}
\hline Ziege anti Kaninchen IgG, Meerettich-Peroxidase (HRP)-gekoppelt & Dianova, Hamburg \\
\hline Kaninchen anti Ziege IgG, Meerettich-Peroxidase (HRP)-gekoppelt & Dianova, Hamburg \\
\hline Esel anti Ziege IgG, Texas Rot-konjugiert & Dianova, Hamburg \\
\hline Ziege anti Kaninchen IgG, FITC-konjugiert & Dianova, Hamburg \\
\hline
\end{tabular}

\subsubsection{Radioaktive Substanzen}

$\left[{ }^{35} \mathrm{~S}\right]-$ Methionin, wäßrige Lösung $1000 \mathrm{Ci} / \mathrm{mmol}$

Amersham-Buchler, Braunschweig

$\left[{ }^{125} \mathrm{~J}\right]$-Natriumjodid, trägerfrei

in $\mathrm{NaOH}-\mathrm{Lösung} \mathrm{pH} \mathrm{7-11,100} \mathrm{mCi/ml \quad Amersham-Buchler,} \mathrm{Braunschweig}$

Desoxycytidin- $\left[\alpha_{-}{ }^{32} \mathrm{P}\right]$-triphosphat Amersham-Buchler, Braunschweig

\subsubsection{Chemikalien}

Die Chemikalien wurden, sofern nicht angegeben, von den Firmen Boehringer (Mannheim), Merck (Darmstadt), Sigma (Deisenhofen), Serva (Heidelberg) und Roth (Karlsruhe) im Reinheitsgrad pro analysi bezogen.

$30 \%$ Acrylamid/ 0,8 \% Bisacrylamid Roth L-Adenin-Hemisulfat Sigma Affigel $10 \quad$ Biorad Agar Sigma 
Agarose für DNA-Gelelektrophorese

3-Aminotriazol

Ammoniumperoxodisulfat

Ampicillin

L-Arginin-HCl

L-Aspartat-Magnesiumsalz-Hemihydrat

Bacto-Hefe-Extrakt

Bacto-Trypton

5-Bromo-4-Chloro-3-Indolyl-ß-D-Galaktopyranosid

(X-Gal)

Bromphenolblau

Calciumchlorid $\left(\mathrm{CaCl}_{2}\right)$

Chloroform

Chloro-Phenolrot-ß3-D-Galaktopyranosid (CPRG)

Coomassie, Serva Blue R

Diethylpyrocarbonat

N,N-Dimethylformamid

Dimethylsulfoxid, ultrarein (DMSO)

Dithiothreitol, ultrarein (DTT)

Ethanol

Ethidiumbromid

Ethylendiamintetraessigsäure-Dinatriumsalz

Folin-Reagenz

Formamid

Freund'sches Adjuvans, komplett und inkomplett

Glukose

Glutathion-Agarose

Glycin

Glyzerin

HEPES (N-2-Hydroxyethylpiperazin-

$\mathrm{N}^{\prime}$-2-ethansulfonsäure)

L-Histidin-Hydrochlorid-Monohydrat

$\mathrm{H}_{2} \mathrm{O}$, HPLC-Reinheitsgrad

8-Hydroxychinolin

L-Isoleucin

Isoamylalkohol

Isopropanol

Isopropyl-ß-D-thiogalaktosid

Kaliumchlorid

Kupfersulfat $\left(\mathrm{Cu}_{2} \mathrm{SO}_{4}\right)$

L-Leucin

Lithiumacetat (LiAc)

L-Lysin-HCl

Magnesiumsulfat

2-Mercaptoethanol

L-Methionin

MOPS

Natriumazetat $(\mathrm{NaAc})$

Natriumazid $\left(\mathrm{NaN}_{3}\right)$

Natriumcarbonat $\left(\mathrm{Na}_{2} \mathrm{CO}_{3}\right)$
GIBCO/BRL, Eggenstein

Sigma

Merck

Serva

Serva

Sigma

Difco

Difco

Alexis Corporation, San Diego,

USA

BioRad, München

Merck

Merck

Boehringer

Serva

Sigma

Aldrich, Steinheim

Merck

Serva

Merck

Serva

Merck

Merck

Fluka

Behring-Werke

Merck

Sigma

ICN, Ohio, USA

Merck

Serva

Sigma

Baker

Merck

Serva

Merck

Merck

Biomol, Hamburg

Merck

Merck

Serva

Sigma

Serva

Merck

Sigma

Serva

Serva

Merck

Sigma

Merck 
Natriumchlorid $(\mathrm{NaCl}) \quad$ Merck

Natriumhydroxid Merck

Paraformaldehyd Sigma

Phenol Merck

L-Phenylalanin Serva

Polyethylenglykol MW 3.500 (PEG) Sigma

Prolin Serva

Saccharose Roth

TEMED (N'N'N'N' Tetramethylethylendiamin) Sigma

Thiamin-HCl Serva

L-Threonin Serva

Tris (Tris-(hydroxymethyl)-aminomethan) Roth

L-Tyrosin Serva

L-Uracil Serva

L-Valin Serva

\subsubsection{Vektoren, DNA-Standards}

pGBT9; pAS2; pAS2-1

pGAD424; pGAD-GH; pGAD10; pACT2 Clontech, Palo Alto, USA

pLamin; pVA3; pTD1; pCL1 Clontech, Palo Alto, USA

pBluescript KS

pGEX-4T-1; pGEX-4T-2; pGEX-4T-3

Stratagene, La Jolla, USA

pcDNA 3.1. (+)

pSPUTK

pPOLY(A)luc (SP6)

$\lambda$-Hind-Standard

DNA-Ladder

Pharmacia, Freiburg invitrogen, Leek, Niederlande Stratagene, La Jolla, USA Stratagene, La Jolla, USA GIBCO/BRL, Eggenstein

GIBCO/BRL, Eggenstein

\subsubsection{Bakterienstämme}

Zur Amplifikation von DNA in Prokaryonten wurden folgende Stämme von E. coliBakterien verwendet:

DH5 $\alpha$ (Genotyp: $\mathrm{F}^{\prime} /$ end $\mathrm{A} 1$, hsd $\mathrm{R} 17\left(\mathrm{r}_{\mathrm{K}}{ }^{-}, \mathrm{mK}^{+}\right)$, supE44, thi-1, rec $\mathrm{A} 1$, gyrA, $\left(\mathrm{Na} 1^{\mathrm{r}}\right)$, relA1, D(lacZYA-argF) ${ }_{\mathrm{U} 169},(\mathrm{j} 80$ lacZDM15))

HB-101

(Genotyp: $\Delta$ (gpt-proA)62, leu $\mathrm{B} 6$, thi-1, lac $\mathrm{Y} 1, h s d S_{\mathrm{B}} 20$, rec A, rpsL20, $\left(\right.$ Str $\left.^{\mathrm{r}}\right)$, ara-14, galK2, xyl-5, mtl-1, supE44, $\left.m c r B_{\mathrm{B}}\right)$

Zur Expression von GST-Fusionsproteinen wurde der proteasedefiziente E. coli-Stamm BL-21 (Genotyp: $\mathrm{F}^{-}$, omp $\left.\mathrm{T}, h s d \mathrm{~S}_{\left(\mathrm{r}_{\mathrm{B}}^{-}\right.}, \mathrm{m}_{\mathrm{B}}{ }^{-}\right)$, gal $(38,39)$ ) verwendet. 


\subsubsection{Medien zur Anzucht von Bakterien}

\begin{tabular}{|c|c|c|}
\hline LB-Medium: & $\begin{array}{r}10 \mathrm{~g} \\
5 \mathrm{~g} \\
5 \mathrm{~g}\end{array}$ & $\begin{array}{l}\text { Bacto-Trypton } \\
\text { Bacto-Hefe Extrakt } \\
\mathrm{NaCl} \\
\text { wurden in } 800 \mathrm{ml} \text { A. dest. gelöst, auf } \mathrm{pH} 7,5 \text { eingestellt, } \\
\text { anschließend mit A. dest. auf } 1000 \mathrm{ml} \text { aufgefüllt und } \\
\text { autoklaviert. }\end{array}$ \\
\hline
\end{tabular}

LB-Ampicillin-Platten: Zur Bakterienanzucht wurde dem LB-Medium Agar in einer Agar-Endkonzentration von 1,5\% zugesetzt. Nach Autoklavieren und Abkühlen auf $50{ }^{\circ} \mathrm{C}$ wurde Ampicillin in einer Endkonzentration von $200 \mu \mathrm{g} / \mathrm{ml}$ zugefügt. Das Nährmedium wurde in Petrischalen $(\varnothing: 9 \mathrm{~cm})$ gegossen, bei Raumtemperatur abgekühlt und anschließend bei $4{ }^{\circ} \mathrm{C}$ unter Lichtauschluß gelagert.

$\begin{array}{rrl}\text { M9-Minimalmedium: } & 2,8 \mathrm{~g} & \mathrm{Na}_{2} \mathrm{HPO}_{4} \times 7 \mathrm{H}_{2} \mathrm{O} \\ 3,0 \mathrm{~g} & \mathrm{KH}_{2} \mathrm{PO}_{4} \\ 0,5 \mathrm{~g} & \mathrm{NaCl} \\ 1,0 \mathrm{~g} & \mathrm{NH}{ }_{4} \mathrm{Cl} \\ 20 \mathrm{ml} & 20 \% \text { Glukose } \\ 20 \mathrm{~g} & \text { Agar } \\ & \text { wurden in } 900 \mathrm{ml} \mathrm{A.} \mathrm{bidest.} \mathrm{gelöst} \mathrm{und} \mathrm{autoklaviert.} \\ & \text { Nach Abkühlen des Mediums auf 55 }{ }^{\circ} \mathrm{C} \text { wurden } \\ & \text { folgende sterilfiltrierte Stammlösungen hinzugefügt: } \\ & \\ 2 \mathrm{ml} & \text { Ampicillin }(25 \mathrm{mg} / \mathrm{ml}) \\ 1 \mathrm{ml} & 1 \mathrm{M} \text { Thiamin- } \mathrm{HCl} \\ 100 \mathrm{ml} & 10 \times \text { Dropout-Stammlösung (siehe 3.1.15) } \\ 4 \mathrm{ml} & \text { Prolin (10 mg/ml) }\end{array}$

Das Nährmedium wurde in Petrischalen $(\varnothing: 9 \mathrm{~cm})$ gegossen, bei Raumtemperatur abgekühlt und anschließend bei $4{ }^{\circ} \mathrm{C}$ gelagert.

\subsubsection{Hefestämme}

Saccharomyces cerevisiae

HF7c

(Genotyp: MATa, ura3-52, his 3-200, ade 2-101, lys 2-801, trp 1-901, leu 2-3, 112, can $^{\mathrm{r}}$, gal4-542, gal80-538, URA3::GAL1-lacZ)

Reportergene: lacZ, HIS3

SFY526

(Genotyp: MATa, ura3-52, his 3-200, lys 2-801, ade 2-101, trp 1-901, leu 2-3,112, gal4-542, gal80-538, LYS2::GAL1-HIS3, URA3::(GAL4 17-mere) ${ }_{3}$-CYC1-lacZ)

Reportergen: lac $Z$ 


\subsubsection{Medien zur Anzucht von Hefen}

YPD-Medium:
$20 \mathrm{~g}$
Difco-Pepton
$10 \mathrm{~g}$ Bacto-Hefe Extrakt

wurden in $950 \mathrm{ml}$ A. bidest. gelöst, auf $\mathrm{pH} 5,8$ eingestellt und autoklaviert. Anschließend wurden 50 $\mathrm{ml}$ einer $40 \%$-igen Glukosestammlösung hinzugefügt.

$10 \mathrm{x}$ Dropout-Stammlösung:

$\begin{array}{lr}\text { L-Adenin-Hemisulfat } & 200 \mathrm{mg} / \mathrm{l} \\ \text { L-Arginin-HCl } & 200 \mathrm{mg} / \mathrm{l} \\ \text { L-Isoleucin } & 300 \mathrm{mg} / \mathrm{l} \\ \text { L-Leucin } & 1.000 \mathrm{mg} / \mathrm{l} \\ \text { L-Lysin-HCl } & 300 \mathrm{mg} / 1 \\ \text { L-Methionin } & 200 \mathrm{mg} / 1 \\ \text { L-Phenylalanin } & 500 \mathrm{mg} / \mathrm{l} \\ \text { L-Threonin } & 2.000 \mathrm{mg} / 1 \\ \text { L-Tyrosin } & 300 \mathrm{mg} / 1 \\ \text { L-Uracil } & 200 \mathrm{mg} / 1 \\ \text { L-Valin } & 1.500 \mathrm{mg} / \mathrm{l}\end{array}$

wurden in $1.000 \mathrm{ml} \mathrm{A}$. bidest. gelöst, autoklaviert und bei $4{ }^{\circ} \mathrm{C}$ unter Lichtausschluß gelagert.

Synthetische Medien:

SD/-HLT-Medium: $\quad 6,7 \mathrm{~g}$ Difco Hefe-Stickstoffbase $100 \mathrm{ml} 10 \mathrm{x}$ Dropout-Stammlösung

wurden in $850 \mathrm{ml} \mathrm{A}$. bidest. gelöst, auf $\mathrm{pH} 5,8$ eingestellt und autoklaviert. Nach Abkühlen des Mediums auf $55{ }^{\circ} \mathrm{C}$ wurden $50 \mathrm{ml}$ einer sterilen $40 \%$ igen Glukosestammlösung zugefügt.

SD/-HLT + 5 mM 3-Aminotriazol: SD/-HLT-Medium wurde nach dem Autoklavieren mit $500 \mu \mathrm{l}$ einer sterilfiltrierten $1 \mathrm{M} 3$-Aminotriazollösung versetzt.

$\underline{\text { SD/-LT-Medium: }}$

SD/-HLT + 20 mg Histidin HCl-Monohydrat

SD/-L-Medium:

SD/-HLT + 20 mg Histidin HCl-Monohydrat

$+20 \mathrm{mg}$ L-Tryptophan

SD/-T-Medium:

SD/-HLT + 20 mg Histidin HCl-Monohydrat

$+100 \mathrm{mg}$ L-Leucin 
SD-Agarplatten:

$\begin{array}{rl}6,7 \mathrm{~g} & \text { Difco Hefe-Stickstoffbase } \\ 100 \mathrm{ml} & 10 \mathrm{x} \text { Dropout-Stocklösung } \\ 20 \mathrm{~g} & \text { Difco-Agar }\end{array}$

wurden in $850 \mathrm{ml} \mathrm{A}$. bidest. gelöst, die fehlenden Aminosäuren gegebenenfalls supplementiert, auf $\mathrm{pH}$ 5,8 eingestellt und autoklaviert. Nach Abkühlen auf $55^{\circ} \mathrm{C}$ und Zufügen von $50 \mathrm{ml}$ einer sterilen $40 \%$-igen Glukosestammlösung wurde das Nährmedium in Petrischalen $(\varnothing: 9 \mathrm{~cm})$ gegossen, bei RT abgekühlt und anschließend bei $4{ }^{\circ} \mathrm{C}$ gelagert.

\subsubsection{Zellinien}

Verwendete Zellinien:

\begin{tabular}{|l|l|l|}
\hline Zellinie: & \multicolumn{1}{|c|}{ Beschreibung: } & \multicolumn{1}{|c|}{ Referenz: } \\
\hline HeLa & $\begin{array}{l}\text { Epithelzellinie aus humanem Cervix- } \\
\text { Karzinom }\end{array}$ & Scherer et al., 1953 \\
\hline MCF7 & $\begin{array}{l}\text { Epithelzellinie aus humanem Mamma- } \\
\text { Adenokarzinom; ATCC-Nr. HTB 22 }\end{array}$ & J. Nat. Cancer Inst., 1973 \\
\hline BHK-21 & Baby Hamster Nierenfibroblasten & Macpherson \& Stoker, 1962 \\
\hline
\end{tabular}

\subsubsection{Häufig verwendete Puffer}

\begin{tabular}{|c|c|c|}
\hline PBS: & $\begin{array}{r}137 \mathrm{mM} \\
2,7 \mathrm{mM} \\
4,3 \mathrm{mM} \\
1,4 \mathrm{mM}\end{array}$ & $\begin{array}{l}\mathrm{NaCl} \\
\mathrm{KCl} \\
\mathrm{Na}_{2} \mathrm{HPO}_{4} \text { × } 7 \mathrm{H}_{2} \mathrm{O} \\
\mathrm{KH}_{2} \mathrm{PO}_{4}, \mathrm{pH} 7,4\end{array}$ \\
\hline PBST: & $0,05 \%$ & Triton $\mathrm{X}-100$ in PBS \\
\hline PBS-Tween: & $0,05 \%$ & Tween 20 in PBS \\
\hline TBS: & $\begin{array}{r}150 \mathrm{mM} \\
10 \mathrm{mM}\end{array}$ & $\begin{array}{l}\mathrm{NaCl} \\
\text { Tris/HCl, pH 7,4 }\end{array}$ \\
\hline Hanks: & $\begin{array}{r}8 \mathrm{~g} \\
0,4 \mathrm{~g} \\
0,06 \mathrm{~g} \\
0,06 \mathrm{~g} \\
0,35 \mathrm{~g} \\
1 \mathrm{~g}\end{array}$ & $\begin{array}{l}\mathrm{NaCl} \\
\mathrm{KCl} \\
\mathrm{Na}_{2} \mathrm{HPO}_{4} \times \mathrm{H}_{2} \mathrm{O} \\
\mathrm{KH}_{2} \mathrm{PO}_{4} \\
\mathrm{NaHCO}_{3} \\
\text { Glukose } \\
\text { wurden in } 1000 \mathrm{ml} \mathrm{A.} \mathrm{dest.} \mathrm{gelöst} \mathrm{und} \mathrm{auf} \mathrm{pH} \mathrm{7,4} \\
\text { eingestellt. }\end{array}$ \\
\hline
\end{tabular}




\subsubsection{Standardlösungen zum molekularbiologischen Arbeiten}

TE:

$$
\begin{aligned}
10 \mathrm{mM} & \text { Tris/HCl, } \mathrm{pH} 7,5 \\
1 \mathrm{mM} & \text { EDTA }
\end{aligned}
$$

TAE:

$$
\begin{aligned}
40 \mathrm{mM} & \text { Tris } \\
2 \mathrm{mM} & \text { EDTA } \\
& \text { mit Eisessig auf } \mathrm{pH} 8,0 \text { einstellen }
\end{aligned}
$$

$1 \mathrm{M}$ Tris/HCl: $\quad 121,1 \mathrm{~g}$ Tris

wurden in $800 \mathrm{ml} \mathrm{A}$. dest. gelöst, der $\mathrm{pH}-$ Wert mit konzentrierter $\mathrm{HCl}$ auf den gewünschten Wert $(7,5 ; 8,0 ; 8,5)$ eingestellt, das Volumen auf $1000 \mathrm{ml}$ aufgefüllt und autoklaviert.

20\% SDS: $\quad 20 \mathrm{~g}$ Natriumdodecylsulfat wurden in $100 \mathrm{ml} \mathrm{A}$. dest. bei $65^{\circ} \mathrm{C}$ gelöst und sterilfiltriert.

3 NaOAc: $\quad 408,1$ g Natriumacetat $x 3 \mathrm{H}_{2} \mathrm{O}$ wurden in $800 \mathrm{ml}$ dest. $\mathrm{H}_{2} \mathrm{O}$ gelöst, der pH-Wert mit Eisessig auf 5,2 eingestellt, das Volumen auf $1000 \mathrm{ml}$ aufgefüllt und autoklaviert.

0,5 M EDTA: $\quad$ 181,1 g Dinatriumethylendiamintetraessigsäure x $2 \mathrm{H}_{2} \mathrm{O}$ wurden in $800 \mathrm{ml} \mathrm{A}$. dest. gelöst, der $\mathrm{pH}-$ Wert mit etwa $20 \mathrm{~g} \mathrm{NaOH}$ Plätzchen oder konzentrierter $\mathrm{NaOH}$ auf 8,0 eingestellt, das Volumen auf $1000 \mathrm{ml}$ aufgefüllt und autoklaviert.

Phenol: $\quad 250 \mathrm{~g}$ kristallines Phenol wurde bei $60{ }^{\circ} \mathrm{C}$ im Wasserbad verflüssigt, mit $0,1 \%$ 8-Hydroxychinolin versetzt, mit $1 \mathrm{M}$ Tris, $\mathrm{pH}$ 8,0 extrahiert, anschließend mit TE gesättigt und bei $-20{ }^{\circ} \mathrm{C}$ aufbewahrt.

PCI: Phenol, Chloroform und Isoamylalkohol wurden im Verhältnis 25:24:1 gemischt.

\subsubsection{Zellkulturmedien und Lösungen zur Arbeit mit eukaryonten Zellen}

PBS (für Zellkultur):

Dulbeccos (DMEM)

Glutamax

Fötales Kälberserum (FKS)

Trypsin/EDTA-Lösung

$0,05 \%(\mathrm{w} / \mathrm{v})$ Trypsin

$0,02 \%(\mathrm{w} / \mathrm{v})$ EDTA in modifizierter

Puck' Salzlösung

$$
\begin{array}{rl}
150 \mathrm{mM} & \mathrm{NaCl} \\
120 \mathrm{mM} & \mathrm{KCl} \\
10 \mathrm{mM} & \mathrm{Na}_{2} \mathrm{HPO}_{4} / \mathrm{KH}_{2} \mathrm{PO}_{4} ; \mathrm{pH} 7,4 \\
0,002 \% & \text { Phenolrot (pH-Indikator) }
\end{array}
$$

Seromed/Biochrom, Berlin

GIBCO/BRL, Eggenstein

GIBCO/BRL, Eggenstein

GIBCO/BRL, Eggenstein 


$\begin{array}{lll}\text { Nicht essentielle Aminosäuren: } & 1,782 \mathrm{~g} & \alpha \text {-Alanin } \\ 2,642 \mathrm{~g} & \alpha \text {-Asparagin } \\ 1,502 \mathrm{~g} & \text { Glycin } \\ 2,302 \mathrm{~g} & \alpha \text {-Prolin } \\ 2,102 \mathrm{~g} & \alpha \text {-Serin in } 200 \mathrm{ml} \text { dest. } \mathrm{H}_{2} \mathrm{O} \text { lösen. }\end{array}$

Antibiotika:

Penicillin/Streptomycin (Pen/Strep)

Seromed/Biochrom, Berlin

(10 $000 \mathrm{U}$ bzw. $10000 \mu \mathrm{g} / \mathrm{ml}$ )

Geneticin $^{\circledR}$ (G418, Neomycin)

$(25 \mathrm{mg} / \mathrm{ml})$

Hygromycin B, p.A.

$(425 \mathrm{mg} / \mathrm{ml})$

GIBCO/BRL, Eggenstein

Calbiochem, Frankfurt

\subsubsection{Computer und Programme}

Hardware: $\quad$ Apple Macintosh Power PC 7.300

Apple Laser Writer 16/600 PS

PC Typ 486/586

Scan jet $4 \mathrm{c} / \mathrm{T}$

diverse

Hewlett Packard, Palo Alto, USA

Software: Windows NT, Windows 95

Microsoft

Aldus Freehand

Macromedia

Sigma Plot 2.01

Jandel Scientific

Win Cam 2.2

Raytest

Claris Works

Claris Corp.

Adobe Photoshop

Adobe Systems Inc.

Corel Draw

Corel Corp., Ottawa, Kanada 


\subsection{Molekularbiologische Methoden}

Alle folgenden Methoden und Vorschriften wurden, soweit nicht anders angegeben, dem Laborbuch „Molecular Cloning“ von Sambrook et al. (1989) entnommen.

\subsubsection{DNA-Präzipitation mit Ethanol}

Das Volumen der DNA-Lösung wurde bestimmt, die Konzentration auf 0,3 M Na-Azetat eingestellt, mit 2 Volumen Ethanol versetzt und gemischt. Die Präzipitation erfolgte 20 min bei $-70{ }^{\circ} \mathrm{C}, 10$ min auf Trockeneis oder über Nacht bei $-20{ }^{\circ} \mathrm{C}$. Die DNA wurde durch 10-minütige Zentrifugation bei $12.000 \mathrm{Upm}$ pelletiert, anschließend mit $70 \%$ Ethanol gewaschen und erneut $5 \mathrm{~min}$ zentrifugiert. Das DNA-Präzipitat wurde 3-5 min im Vakuumkonzentrator getrocknet.

\subsubsection{Extraktion von DNA mit Phenol, Phenol/Chloroform/Isoamylalkohol oder Chloroform}

Die Extraktion mit Phenol, Phenol/Chloroform/Isoamylalkohol oder Chloroform ist eine Standardmethode zur Entfernung von Proteinen aus Nukleinsäurepräparationen. Die zu extrahierende DNA-Lösung wurde mit 1 Volumen der vorgenannten Lösungen gut gemischt und 3 min zentrifugiert. Die wäßrige Phase wurde abgenommen und weiterverarbeitet.

\subsubsection{Konzentrationsbestimmung von DNA}

Photometrische Analyse:

Die photometrische Messung von DNA erfolgte bei $260 \mathrm{~nm}$ in einer Quarzküvette gegen TE bzw. A. dest. Eine $\mathrm{OD}_{260}$ von 1 entspricht einer Konzentration von $50 \mu \mathrm{g} / \mathrm{ml}$ doppelsträngiger DNA, $40 \mu \mathrm{g} / \mathrm{ml}$ RNA und $31 \mu \mathrm{g} / \mathrm{ml}$ Oligonukleotide.

\section{Ethidiumbromid-Fluoreszenzmessung im Agarosegel:}

Diese Methode empfiehlt sich zur Konzentrationsbestimmung proteinhaltiger Lösungen. In einem 1\%-igen Agarosegel (0,5 $\mu \mathrm{g}$ Ethidiumbromid pro $\mathrm{ml}$ ) wurde ein Aliquot der zu quantifizierenden DNA-Probe aufgetrennt. In einer benachbarten Spur wurden 400 ng einer 
$\lambda$-Phagen-DNA, die mit der Restriktionsendonuklease Hind III gespalten worden war, mit aufgetrennt. Die Fluoreszenzintensitäten der DNA-Probe und des Standards wurden auf einem UV-Transilluminator verglichen. Da das $\lambda$-Genom $48 \mathrm{~kb}$ groß ist, entspricht z.B. die 2,3 kb-Bande ca. 20 ng (ca. $5 \%$ des Auftrags von 400 ng).

\subsubsection{Reinigung von DNA-Fragmenten mit QIAquick-Säulen}

Die Probe wurde mit 5 Volumen Puffer PB gemischt, auf die QIAquick-Säule aufgetragen und 60 Sekunden bei 14.000 Upm zentrifugiert. Die Säule wurde einmal mit $750 \mu 1$ Puffer PE gewaschen (14.000 Upm, 30 Sekunden), einmal trockenzentrifugiert und die DNA mit $50 \mu 1$ Tris-Puffer $\mathrm{pH} 8,5$ oder A. dest. eluiert.

\subsubsection{Spaltung von DNA mit Restriktionsendonukleasen}

$\begin{array}{rrl}\text { Reaktionsansatz: } & x \mu \mathrm{g} & \text { DNA } \\ 2 \mu \mathrm{l} & \text { geeigneter } 10 \times \text { Puffer (nach Herstellerangabe) } \\ 2 \times x \mathrm{U} & \text { Restriktionsendonuklease } \\ \operatorname{ad} 20 \mu \mathrm{l} & \text { A. dest. }\end{array}$

Der Ansatz wurde eine Stunde bei $37{ }^{\circ} \mathrm{C}$ inkubiert, anschließend ein Aliquot im Agarosegel analysiert. Präparative Spaltungen wurden in größeren Volumina und mit entsprechend größerer Enzymmenge durchgeführt.

Als Reaktionspuffer wurde das New England Biolabs (NEB) Puffer-System verwendet. Diese Puffer werden vom Hersteller als 10 x Konzentrationen zusammen mit den Enzymen geliefert.

NEB 1: $\quad 50 \mathrm{mM}$ Tris/HCl $(\mathrm{pH} 7,0)+10 \mathrm{mM} \mathrm{MgCl} 2+1 \mathrm{mM}$ DTT

NEB 2: $\quad 50 \mathrm{mM}$ Tris/HCl $(\mathrm{pH} 8,0)+10 \mathrm{mM} \mathrm{MgCl}_{2}+1 \mathrm{mM} \mathrm{DTT}+50 \mathrm{mM} \mathrm{NaCl}$

NEB $3: \quad 50 \mathrm{mM}$ Tris/HCl $(\mathrm{pH} 8,0)+10 \mathrm{mM} \mathrm{MgCl}_{2}+1 \mathrm{mM} \mathrm{DTT}+100 \mathrm{mM} \mathrm{NaCl}$

NEB 4: $\quad 50 \mathrm{mM}$ Tris/HCl $(\mathrm{pH} 8,0)+10 \mathrm{mM} \mathrm{MgCl}_{2}+1 \mathrm{mM}$ DTT $+50 \mathrm{mM}$ KOAc

Alle angegebenen Konzentrationen sind Endkonzentrationen. 


\subsubsection{Transformation von E. coli mit Plasmid-DNA}

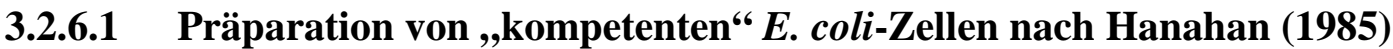

\begin{tabular}{|c|c|c|c|}
\hline Lösungen: & TfbI: & $\begin{array}{r}100 \mathrm{mM} \\
50 \mathrm{mM} \\
30 \mathrm{mM} \\
10 \mathrm{mM} \\
15 \%(\mathrm{v} / \mathrm{v}) \\
\mathrm{pH} 5,8\end{array}$ & $\begin{array}{l}\mathrm{RbCl} \\
\mathrm{MnCl}_{2} \\
\mathrm{KAc} \\
\mathrm{CaCl}_{2} \\
\mathrm{Glyzerin}_{\text {mit Essigsäure }(0,2 \mathrm{M}) \text { eingestellt }}\end{array}$ \\
\hline & TfbII: & $\begin{array}{r}10 \mathrm{mM} \\
10 \mathrm{mM} \\
75 \mathrm{mM} \\
15 \%(\mathrm{v} / \mathrm{v}) \\
\mathrm{pH} 7,0\end{array}$ & $\begin{array}{l}\text { MOPS } \\
\mathrm{RbCl} \\
\mathrm{CaCl}_{2} \\
\text { Glyzerin } \\
\text { mit } \mathrm{NaOH} \text { eingestellt }\end{array}$ \\
\hline
\end{tabular}

TfbI und TfbII wurden jeweils frisch angesetzt und sterilfiltriert. $5 \mathrm{ml}$ LB-Medium wurde mit einer Kolonie E. coli DH5 $\alpha$ von einer Stammplatte (LB-Agarplatte, ohne Ampicillin) angeimpft und auf dem Drehrad bei $37^{\circ} \mathrm{C}$ bis zu einer $\mathrm{OD}_{550}$ von 0,3 inkubiert. Mit $2 \mathrm{ml}$ dieser Vorkultur wurden $200 \mathrm{ml} \mathrm{LB}-M e d i u m$ in einem 11 Schüttelkolben mit Schikane angeimpft und 2 bis 2,5 h unter starkem Schütteln (300 Upm) auf dem Reziprokschüttler bis zu einer $\mathrm{OD}_{550}$ von 0,3 bei $37{ }^{\circ} \mathrm{C}$ inkubiert. Anschließend wurde die Kultur 10 min in Eiswasser unter Schwenken abgekühlt und in JA-10 Zentrifugenbechern 5 min bei 3.000 Upm (Beckmanzentrifuge, $4{ }^{\circ} \mathrm{C}$ ) zentrifugiert. Die Pellets wurden in $30 \mathrm{ml} \mathrm{TfbI}\left(4{ }^{\circ} \mathrm{C}\right)$ resuspendiert und erneut unter gleichen Bedingungen zentrifugiert. Anschließend wurden die Pellets in $4 \mathrm{ml}$ TfbII resuspendiert und in Aliquots von je $420 \mu \mathrm{l}$ in flüssigem Stickstoff eingefroren. Die Lagerung erfolgte bei $-80{ }^{\circ} \mathrm{C}$.

\subsubsection{Transformation kompetenter Zellen}

$200 \mu \mathrm{l}$ kompetente Zellen (E. coli DH5 $\alpha$ ) wurden auf Eis aufgetaut und mit 1 ng VektorDNA bzw. einem Ligationsansatz gemischt. Nach 20 minütiger Inkubation auf Eis erfolgte ein Hitzeschock von 2 min bei $42{ }^{\circ} \mathrm{C}$. Nach weiteren 2 min auf Eis wurden 0,8 $\mathrm{ml}$ LBMedium zugegeben und der Ansatz 60 min bei $37^{\circ} \mathrm{C}$ auf dem Drehrad inkubiert. Anschließend wurden 50 bis $150 \mu 1$ des Transformationsansatzes auf einer LB-AmpicillinAgarplatte, die $200 \mu \mathrm{g} / \mathrm{ml}$ Ampicillin enthielt, ausplattiert und über Nacht bei $37{ }^{\circ} \mathrm{C}$ inkubiert. Mit den erhaltenen Kolonien wurden $5 \mathrm{ml}$ LB-Medium mit $200 \mu \mathrm{g} / \mathrm{ml}$ 
Ampicillin angeimpft. Diese Vorkultur wurde für Plasmid-Präparationen und zum Anlegen von Glyzerinkulturen verwendet.

\subsubsection{Präparation von elektrokompetenten Zellen}

$\begin{array}{lrl}\text { Lösungen: } & 0,5 \% & \text { Hefe-Extrakt } \\ & 2 \% & \text { Tryptone } \\ & 10 \mathrm{mM} & \mathrm{NaCl} \\ & 2,5 \mathrm{mM} & \mathrm{KCl} \\ & 10 \mathrm{mM} & \mathrm{MgCl}_{2} \\ & 10 \mathrm{mM} & \mathrm{MgSO}_{4} \\ & 20 \mathrm{mM} & \text { Glukose }^{2}\end{array}$

$5 \mathrm{ml}$ LB-Medium wurden mit einer Kolonie E. coli HB-101 von einer Stammplatte (LBAgarplatte, ohne Ampicillin) angeimpft und über Nacht auf dem Reziprokschüttler bei $37^{\circ} \mathrm{C}$ inkubiert. Mit jeweils 1,25 ml dieser Vorkultur wurden 2 × $250 \mathrm{ml} \mathrm{LB}$-Medium in zwei 11 Schüttelkolben angeimpft und bei $37{ }^{\circ} \mathrm{C}$ unter starkem Schütteln bis zu einer $\mathrm{OD}_{600}$ von 0,5-0,6 inkubiert. Die Kulturen wurden für $20 \mathrm{~min}$ bei $3.000 \mathrm{Upm}$ in JA10-Zentrifugenbechern zentrifugiert, das Bakterienpellet in $500 \mathrm{ml}$ sterilem, eiskaltem A. bidest. resuspendiert und erneut unter gleichen Bedingungen zentrifugiert. Nach erneutem Waschen der Zellen wurde das Bakterienpellet in $40 \mathrm{ml}$ eiskaltem $10 \%$-igem Glyzerin vorsichtig resuspendiert und in SS 20-Röhrchen bei 3.000 Upm zentrifugiert. Das Pellet wurde in einem etwa gleichen Volumen $10 \%$-igem Glyzerin resuspendiert und in Aliquots von $200 \mu 1$ in Trockeneis eingefroren. Die Lagerung erfolgte bei $-80{ }^{\circ} \mathrm{C}$.

\subsubsection{Transformation von kompetenten Zellen durch Elektroporation}

$40 \mu \mathrm{l}$ elektrokompetente $E$. coli HB-101-Zellen wurden mit $1 \mu \mathrm{l}$ der aus Hefe isolierten Plasmid-DNA in einem 1,5 ml Reaktionsgefäß gemischt und in eisgekühlte Elektroporationsküvetten transferiert. Nach Elektroporation der Zellen $(2,5 \mathrm{kV}, 25 \mu \mathrm{F}, 400 \mathrm{Ohm})$ wurden $1 \mathrm{ml}$ SOC-Medium hinzugefügt und die Suspension mit einer sterilen Pasteurpipette in $10 \mathrm{ml}$ Sarstedt-Röhrchen pipettiert. Nach Inkubation der Ansätze für 1 Stunde bei $37{ }^{\circ} \mathrm{C}$ unter Schütteln wurden die Zellen 5 min bei 1.000 x g zentrifugiert. Nach Waschen der Zellen mit M9-Medium wurden 250-500 $\mu$ l der Transformationsansätze auf M9-Ampicillin-Minimalmedium-Agarplatten ausplattiert und anschließend für 48 Stunden bei $37^{\circ} \mathrm{C}$ inkubiert. 


\subsubsection{Anlegen einer Glyzerinkultur}

Vorkulturen mit einer $\mathrm{OD}_{260}$ von größer als 1 in LB-Medium wurden mit 0,25 Volumen $80 \%$ Glyzerin versetzt und bei $-80{ }^{\circ} \mathrm{C}$ aufbewahrt. Aus der Glyzerinkultur kann direkt eine Vorkultur angeimpft werden.

\subsubsection{Mini-Präparation von Plasmid-DNA}

Das Verfahren nach Birnboim und Doly (1979) wurde zur Isolierung kleiner DNAMengen, die zur Restriktionsanalyse und zur Sequenzierung dienten, verwendet.

\begin{tabular}{|c|c|c|}
\hline GTE: & $\begin{array}{l}50 \mathrm{mM} \\
25 \mathrm{mM} \\
10 \mathrm{mM}\end{array}$ & $\begin{array}{l}\text { Glukose } \\
\text { Tris/HCl, pH 8,0 } \\
\text { EDTA, pH 8,0 }\end{array}$ \\
\hline Lösung II: & $\begin{array}{r}0,2 \mathrm{M} \\
1 \%\end{array}$ & $\begin{array}{l}\mathrm{NaOH} \\
\mathrm{SDS}\end{array}$ \\
\hline Lösung III: & $3 \mathrm{M}$ & $\mathrm{NaOAc}, \mathrm{pH} 4,8$ \\
\hline PCI: & $25: 24: 1$ & Phenol/Chloroform/Isoamylalkohol \\
\hline TE: & $\begin{array}{r}10 \mathrm{mM} \\
1 \mathrm{mM}\end{array}$ & $\begin{array}{l}\text { Tris/HCl } \\
\text { EDTA, pH 8,0 }\end{array}$ \\
\hline
\end{tabular}

Vorkulturen von $5 \mathrm{ml}$ LB-Medium mit $200 \mu \mathrm{g} / \mathrm{ml}$ Ampicillin wurden mit einer Impföse mit Einzelkolonien angeimpft und für 6 bis 16 Stunden auf dem Drehrad bei $37{ }^{\circ} \mathrm{C}$ inkubiert. Aus $2 \mathrm{ml}$ dieser Vorkultur wurden die Bakterien in einem Eppendorfgefäß durch Zentrifugation bei 14.000 Upm für 30 Sekunden sedimentiert. Der Überstand wurde verworfen und das Pellet in $100 \mu \mathrm{l}$ GTE resuspendiert und 5 min bei RT inkubiert. Danach erfolgte durch Zugabe von $200 \mu$ l Lösung II die alkalische Lyse. Mehrmaliges Invertieren der Gefäße diente der vollständigen Durchmischung. Nach Zugabe von $150 \mu 1$ kalter Lösung III und einer Inkubation für 5 Minuten auf Eis wurde der Ansatz für 10 Minuten bei 14.000 Upm zentrifugiert. Der Überstand wurde mit einem Volumen PCI vermischt. Die organische und die wäßrige Phase wurden durch Zentrifugation für 4 min bei $14.000 \mathrm{Upm}$ getrennt und die wäßrige Phase anschließend erneut mit Chloroform extrahiert. Die DNA wurde mit 2 Volumen Ethanol aus dem wäßrigen Überstand präzipitiert. Das Pellet wurde mit $70 \%$ Ethanol gewaschen, getrocknet und in $30 \mu 1$ TE bzw. A. dest. aufgenommen. 20 $\%$ des Ansatzes wurde für eine Restriktionsanalyse verwendet. 


\subsubsection{Mini-Präparation (Qiagen-Methode)}

Plasmidpräparationen wurden nach der Vorschrift des Herstellers Qiagen und unter Verwendung der mitgelieferten Puffer durchgeführt.

$5 \mathrm{ml} \mathrm{LB}-M e d i u m$ mit $200 \mu \mathrm{g} / \mathrm{ml}$ Ampicillin wurden mit einer transformierten E. coliKolonie angeimpft und ü. N. bei $37{ }^{\circ} \mathrm{C}$ auf dem Drehrad inkubiert. 1,5 ml der Bakteriensuspension wurden $30 \mathrm{~s}$ in der Eppendorfzentrifuge bei $12.000 \mathrm{x}$ g zentrifugiert. Das Pellet wurde in $250 \mu \mathrm{l}$ eiskaltem P1-Puffer aufgenommen, mit $250 \mu \mathrm{l}$ P2-Puffer versetzt, gemischt und 5 min bei RT inkubiert. Nach der Zugabe von $350 \mu 1$ N3-Puffer erfolgte eine 10 minütige Zentrifugation bei $14.000 \mathrm{Upm}$ und $4{ }^{\circ} \mathrm{C}$. Der Überstand wurde auf eine Minisäule gegeben und diese $30 \mathrm{~s}$ bei $14.000 \mathrm{Upm}$ zentrifugiert. Nach Verwerfen des Durchflusses wurde die Säule mit $0,75 \mathrm{ml}$ PE-Puffer gewaschen. Nach erneutem Verwerfen des Durchflusses wurde die Säule erneut zentrifugiert, um Pufferreste von der Säule zu entfernen. Die Elution der gebundenen DNA erfolgte mit $100 \mu$ 1 A. bidest.. Zur Restriktionsanalyse wurden $10 \mu 1$ der DNA-Lösung benutzt.

\subsubsection{Midi-Präparation (Qiagen-Methode)}

Plasmid-Präparationen wurden nach Vorschrift des Herstellers Qiagen und unter Verwendung der mitgelieferten Puffer durchgeführt.

$\begin{array}{lrl}\text { P1: } & 50 \mathrm{~mm} & \text { Tris/HCl, pH 8,0 } \\ 10 \mathrm{mM} & \text { EDTA } \\ & 100 \mu \mathrm{g} / \mathrm{ml} & \text { RNase A } \\ & 0,2 \mathrm{M} & \mathrm{NaOH} \\ & 1 \% & \text { SDS } \\ \text { P2: } & 3 \mathrm{M} & \text { Kaliumacetat (KOAc), pH 5,5 } \\ & & \\ \text { P3: } & 750 \mathrm{mM} & \text { NaCl } \\ & 50 \mathrm{mM} & \text { MOPS, pH 7,0 } \\ \text { QBT-Puffer: } & 15 \% & \text { Ethanol } \\ & 0,15 \% & \text { Triton X-100 } \\ & 1 \mathrm{M} & \text { NaCl } \\ & & \text { MOPS, pH 7,0 } \\ & 50 \mathrm{mM} & \text { Ethanol } \\ \text { QC-Puffer: } & 15 \% & \end{array}$


QF-Puffer:

$\begin{array}{rl}1,25 \mathrm{M} & \mathrm{NaCl} \\ 50 \mathrm{mM} & \text { Tris/HCl, pH 8,5 } \\ 15 \% & \text { Ethanol }\end{array}$

$100 \mathrm{ml}$ einer Bakterienkultur mit einer $\mathrm{OD}_{600}$ von $>1$ wurden bei 6.000 Upm im JA10Zentrifugenbecher zentrifugiert. Das Bakterienpellet wurde in $4 \mathrm{ml}$ P1-Puffer resuspendiert, in JA20 Röhrchen überführt, zur Lyse mit 4 ml P2-Puffer versetzt, vorsichtig durch Invertieren gemischt und 5 min bei RT inkubiert. Durch Zugabe und sofortigem Invertieren von $4 \mathrm{ml}$ eiskaltem P3-Puffer wurde neutralisiert und anschließend $15 \mathrm{~min}$ auf Eis inkubiert. Der Ansatz wurde bei $30.000 \mathrm{x} \mathrm{g}(18.000 \mathrm{Upm})$ für $30 \mathrm{~min}$ bei $4{ }^{\circ} \mathrm{C} \mathrm{im}$ JA20-Zentrifugenbecher zentrifugiert, der Überstand auf eine mit $4 \mathrm{ml}$ QBT-Puffer äquilibrierte Qiagen-Plasmid-Prep TIP 100-Säule gegeben. Die Plasmid-DNA bindet an das Silikagel-Anionenaustauscher-Säulenmaterial. Die Säule wurde zweimal mit $10 \mathrm{ml}$ QC-Puffer gewaschen, die Plasmid-DNA anschließend mit $5 \mathrm{ml}$ QF-Puffer eluiert und in einem 15 ml-Röhrchen aufgefangen. Die DNA wurde mit 0,7 Volumen Isopropanol gefällt und bei $4{ }^{\circ} \mathrm{C}$ und $4.400 \mathrm{x}$ g für 30 Minuten zentrifugiert. Das Pellet wurde zweimal mit $70 \%$ Ethanol gewaschen, im Vakuumkonzentrator getrocknet und in einem geeignetem Volumen A. dest. aufgenommen. Die DNA-Konzentration wurde durch Messung der $\mathrm{OD}_{260}$ bestimmt.

\subsubsection{Amplifikation von cDNA-Bibliotheken}

Nach Bestimmung des Titers wurde ein Aliquot der Glyzerin-Stammlösung der cDNA-Bibliothek entnommen, das der dreifachen Anzahl der unabhängigen Klone der cDNA-Bibliothek entsprach. Die entnommene Stammlösung wurde in LB-Amp-Medium suspendiert und die Suspension in einer Dichte von ca. 20.000 Kolonien/LB-AmpAgarplatte $(\varnothing: 150 \mathrm{~mm})$ ausplattiert. Nach Inkubation der LB/Amp-Platten bei $37{ }^{\circ} \mathrm{C}$ ü. N. wurde der Bakterienrasen mit LB-Medium überschichtet, die gewachsenen Kolonien mit einem Drygalski-Spatel abgeschabt und in JA10-Zentrifugenbecher transferiert. Nach Zentrifugation der Suspension bei 6.000 Upm wurde das Bakterienpellet, wie unter 3.2.9 beschrieben, lysiert und die Plasmid-DNA nach der Qiagen-Midi-Methode isoliert. 


\subsubsection{Auftrennung von DNA in Agarosegelen}

Zur Auftrennung von DNA-Fragmenten unterschiedlicher Größe wurden Agarosegele verwendet. Abhängig von der Fragmentgröße betrug die Agarosekonzentration $1 \%$ bis $2 \%$ (w/v). Die erforderliche Agarosemenge wurde in 1 x TAE (40 mM Tris/HCl, 2 mM EDTA, $\mathrm{pH}$ 8,0) aufgekocht und nach dem Abkühlen auf etwa $55{ }^{\circ} \mathrm{C}$ mit Ethidiumbromid (Endkonzentration: 0,5 $\mu \mathrm{g} / \mathrm{ml}$ ) versetzt. Die Lösung wurde in einen Gelträger gegossen und bei RT abgekühlt. Das erstarrte Gel wurde in eine mit 1 x TAE gefüllte Elektrophoresekammer überführt, die Proben mit Ficoll-Marker (0,05 \% Bromphenolblau, 0,05\% Xylencyanol, $15 \%$ Ficoll) versetzt und aufgetragen. Die Elektrophorese wurde mit einer Spannung von 3-4 V/cm durchgeführt. Durch das in die DNA interkalierte Ethidiumbromid wurden die DNA-Fragmente unter UV-Licht als Banden sichtbar. Zur Dokumentation wurde das Agarosegel auf dem UV-Transilluminator mit einem Videosystem aufgenommen und ein Ausdruck des Bildes erstellt.

\subsubsection{Isolierung von DNA-Fragmenten aus Agarosegelen}

Es wurde der Qiaquick-Spin-Gel-Extraction Kit mit den zugehörigen Puffern der Firma Qiagen verwendet.

Die gewünschte DNA-Bande wurde unter UV-Licht (UV-Handlampe, $312 \mathrm{~nm}$ ) aus dem Agarosegel ausgeschnitten. Das Gelstück wurde gewogen, mit 3 Volumina QX1-Puffer für $1 \%$-ige bzw. 6 Volumina für $2 \%$-ige Agarosegele zur Zersetzung der Agarose versetzt und 10 min bei $50{ }^{\circ} \mathrm{C}$ unter mehrmaligem Mischen inkubiert. Nach Zugabe von 1 Volumen Isopropanol wurde das Gemisch auf eine Qiaquick-Spin-Säule gegeben und eine Minute bei 14.000 Upm zentrifugiert. Der Durchfluß wurde verworfen, $750 \mu 1$ PE-Puffer auf die Säule gegeben und eine Minute bei 14.000 Upm zentrifugiert. Der Durchfluß wurde erneut verworfen und zum Entfernen der Puffer-Reste nochmals eine Minute bei $14.000 \mathrm{Upm}$ zentrifugiert. Die DNA wurde mit $50 \mu \mathrm{l}$ A. dest. von der Säule durch 1 minütiges Zentrifugieren bei 14.000 Upm eluiert. $5 \mu 1$ der eluierten DNA wurden zur Konzentrationsbestimmung auf einem Agarosegel aufgetrennt. 


\subsubsection{Präparation von Vektor-DNA für die Subklonierung von DNA-Fragmenten}

Die Plasmid-DNA (2-5 $\mu \mathrm{g})$ wurde mit Restriktionsendonukleasen gespalten. Das Vektorfragment wurde im Agarosegel aufgetrennt und mit dem Qiaquick-Spin-GelExtraction-Kit aufgereinigt. Nach Spaltung mit nur einer Restriktionsendonuclease ist vor der Ligation mit einem Zielfragment eine Behandlung mit Phosphatase notwendig, um die Religation des Vektors zu minimieren.

Phosphatasebehandlung

Der Phosphatester der 5'-Enden wird wie folgt enzymatisch entfernt:

Reaktionsansatz:

$$
\begin{aligned}
& 48 \mu 1 \quad \text { DNA-Lösung } \\
& 1 \mu \mathrm{l} \quad \mathrm{CIP} \text { (calf intestinal phosphatase, } 25 \mathrm{U} / \mu \mathrm{l} \text { ) } \\
& 5,44 \mu \mathrm{l} \quad 10 \times \text { CIP-Puffer (0,5 M Tris/HCl, pH 9,0; } 10 \mathrm{mM} \\
& \mathrm{MgCl}_{2} ; 1 \mathrm{mM} \mathrm{ZnCl} 2 ; 10 \mathrm{mM} \text { Spermidin) }
\end{aligned}
$$

Bei 5'-überhängenden Enden wurde das Gemisch $30 \mathrm{~min}$ bei $37{ }^{\circ} \mathrm{C}$ inkubiert, bei 3'-überhängenden Enden erfolgte die Reaktion $30 \mathrm{~min}$ bei $37{ }^{\circ} \mathrm{C}$ und $30 \mathrm{~min}$ bei $56{ }^{\circ} \mathrm{C}$ nach Zugabe eines weiteren Mikroliters CIP. Zum Entfernen hitzestabiler Phosphatase und zum gleichzeitigem Umpuffern wurde der Ansatz über Qiagensäulen gereinigt.

\section{Ligation}

Ligationsmix: $\quad \mathrm{x} \mu \mathrm{l} \quad$ Vektor-DNA nach Restriktionsspaltung (10 -20 ng) y $\mu 1 \quad$ DNA-Fragment ( 3-5 molarer Überschuß)

$1 \mu \mathrm{l} \quad 10 \mathrm{x}$ T4-DNA-Ligase-Puffer Endkonzentration: $50 \mathrm{mM}$ Tris/ $\mathrm{HCl}, \mathrm{pH} 7,5 ; 10 \mathrm{mM} \mathrm{MgCl}_{2} ; 10 \mathrm{mM}$ DTT; $1 \mathrm{mM}$ ATP; $25 \mathrm{mg} / \mathrm{ml}$ BSA

$1 \mu 1 \quad$ T4-DNA-Ligase; 80 NEB-Einheiten/ $\mu 1$ ad $10 \mu \mathrm{l}$ A. dest.

Die Ligation erfolgte über Nacht bei $16{ }^{\circ} \mathrm{C}$.

\subsubsection{DNA-Amplifikation über Polymerase-Ketten-Reaktion (PCR)}

Die Polymerase-Ketten-Reaktion (PCR) ist eine Methode, um definierte DNA-Fragmente logarithmisch zu amplifizieren. Grundlage für die Automatisierung dieser Technik ist die Entdeckung und Isolierung einer thermostabilen DNA-Polymerase des thermophilen Bakteriums Thermophilus aquaticus (Taq) von Saiki et al. (1988). 
Die PCR basiert auf drei Schritten, die für jede DNA-Synthese nötig sind:

1. Denaturierung der Ausgangs-DNA (Template) in Einzelstränge

2. Annealing $=$ Bindung von Oligonukleotid-Primern an beide Einzelstränge

3. Extension $=$ Synthese der DNA, ausgehend von den gebundenen Primern .

Faktoren, die den Erfolg einer PCR beeinflussen können, sind die Auswahl und Konzentration der Oligonukleotid-Primer, Template-Qualität, Pufferbedingungen, die Zeiten und die Temperaturen der Zyklusschritte.

Als Template wurde DNA verwendet, die mit der Plasmid-Präparation nach Qiagen gewonnen wurde. Die Taq-Polymerase wurde zusammen mit dem 10 x Puffersystem und dem Ultrapure-dNTP-Set von der Firma Pharmacia bezogen. Das dNTP-Set wurde von je $100 \mathrm{mM}$ je Nukleotid auf $10 \mathrm{mM}$ verdünnt (dNTP-Mix).

$\begin{array}{lrl}\text { PCR-dNTP-Mix: } & \text { je } 10 \mathrm{mM} & \text { dATP, dCTP, dGTP, dTTP } \\ & & \\ 10 \text { x PCR-Puffer: } & 800 \mathrm{mM} & \text { Tris/HCl, pH 8,9 } \\ & 200 \mathrm{mM} & \left(\mathrm{NH}_{4}\right)_{2} \mathrm{SO}_{4} \\ & 50 \mathrm{mM} & \mathrm{MgCl}_{2}\end{array}$

Taq DNA Polymerase (2,5 U/ $\mu \mathrm{l})$

In jeder PCR wurden zwei Kontrollen mitgeführt, um die verwendeten Lösungen auf Kontaminationen zu untersuchen. Es wurde jeweils eine Probe ohne Template und eine Probe ohne Primer angesetzt. In beiden Kontrollen darf kein PCR-Fragment entstehen. Die Oligonukleotide für die PCR und für die Sequenzanalysen wurden von der Firma NAPS in Göttingen bezogen.

\subsubsection{Gezielte Mutagenese nach der Quik ${ }^{\circledR}$-Change-Methode}

Bei dieser Methode werden zwei komplementäre Oligonukleotide synthetisiert, bei denen eine Mutation von zwei Sequenzen flankiert wird. Ausgehend von den beiden Oligonukleotiden erfolgt eine Amplifikation der gesamten Template-DNA unter Verwendung von $P f u$-Polymerase, die aufgrund einer 3' $\rightarrow$ 5'-Korrekturlese-ExonukleaseAktivität eine geringere Fehlerrate bei der DNA-Synthese aufweist. 


\begin{tabular}{|c|c|c|}
\hline \multirow[t]{6}{*}{10 x Reaktionspuffer: } & $200 \mathrm{mM}$ & Tris/HCl, pH 8,8 \\
\hline & $20 \mathrm{mM}$ & $\mathrm{MgSO}_{4}$ \\
\hline & $100 \mathrm{mM}$ & $\mathrm{KCl}$ \\
\hline & $100 \mathrm{mM}$ & $\left(\mathrm{NH}_{4}\right)_{2} \mathrm{SO}_{4}$ \\
\hline & $1 \%$ & Triton $\mathrm{X}-100$ \\
\hline & $0,1 \%$ & BSA \\
\hline \multirow[t]{7}{*}{ Reaktionsansatz: } & $5 \mu 1$ & $10 \times$ Reaktionspuffer \\
\hline & $125 \mathrm{ng}$ & Primer 1 (HPLC-Grade) \\
\hline & $125 \mathrm{ng}$ & Primer 2 (HPLC-Grade) \\
\hline & $1 \mu 1$ & dNTP-Mix (2,5 mM pro dNTP) \\
\hline & $\mathrm{x} \mu \mathrm{l}$ & DNA-Template (5-50 ng) \\
\hline & ad $50 \mu 1$ & A. bidest. (HPLC-grade) \\
\hline & $1 \mu 1$ & Pfu-Turbo ${ }^{\mathrm{TM}}-\mathrm{DNA}$-Polvmerase $(2.5 \mathrm{U} / \mathrm{ul})$ \\
\hline
\end{tabular}

Ausgehend von der Länge der verwendeten Template-DNA wurden folgende Reaktionszeiten für die PCR angewendet:

Denaturierung: $\quad 95^{\circ} \mathrm{C} \quad 30$ Sekunden

16 Zyklen: $\quad$ Denaturierung: $\quad 95^{\circ} \mathrm{C} \quad 30$ Sekunden

Annealing: $\quad 45^{\circ} \mathrm{C} \quad 1$ Minute

Extension: $\quad 68^{\circ} \mathrm{C} \quad 2$ Minuten pro kb DNA-Template

Zur Spaltung der methylierten Template-DNA wurde der Ansatz mit 0,5 $\mu 1$ DpnI (20 U/ $\mu \mathrm{l})$ bei $37{ }^{\circ} \mathrm{C}$ für 2 Stunden inkubiert. $4 \mu \mathrm{l}$ des Ansatzes wurde für die Transformation von kompetenten E. coli DH 5 $\alpha$-Zellen verwendet.

\subsubsection{Klonierung der verschiedenen Konstrukte}

\subsubsection{PCR-Mutagenese des MPR300-CT}

Zur Untersuchung der Funktion des Tyrosin-haltigen Internalisierungssignals des MPR300CT für die Bindung an Periplakin wurden die Tyr26- und Val29-Reste gegen Alaninreste ausgetauscht. Ausgehend von dem Konstrukt pGBT9-MPR300-CT als Matrize wurde eine gezielte Mutagenese nach der Quik ${ }^{\circledR}$-Change-Methode mit den komplementären Oligonukleotiden ST18-F und ST18-R durchgeführt.

Durch Insertion eines Stopcodons wurde eine Deletionsmutante des MPR300-CT hergestellt, deren Sequenz beim Val29-Rest endet. Dazu wurde ein PCR-Produkt von 87 Basenpaaren mit den Oligonukleotiden ST20-F und ST21-R amplifiziert, das nach Restriktionsspaltung der durch die Oligonukleotide eingeführten EcoR I- und Xho I- 
Schnittstellen in die korrespondierenden Schnittstellen des Vektors pGBT9 subkloniert wurde.

Zur Klonierung der cDNA der zytoplasmatischen Domäne des MPR300 in den in vitroTranslationsvektor pSPUTK wurde der Vektor pAS2-300CT als DNA-Template benutzt. Die 532 bp-cDNA wurde über eine Nco I-Schnittstelle der MCS und eine Pst ISchnittstelle der 3'-nicht-kodierenden Sequenz aus dem Vektor pAS2-300CT ausgeschnitten und in die korrespondierenden Schnittstellen des Vektors pSPUTK kloniert.

\subsubsection{PCR-Mutagenese des MPR46-CT}

Für die Klonierung der mutanten zytoplasmatischen Domänen des MPR46 wurden PCRProdukte mit den in Tab. 1 angegebenen Oligonukleotid-Primern amplifiziert und die DNA-Fragmente mit der Restriktionsendonuklease BamH I gespalten. In die Oligonukleotidsequenzen wurden TGA-Stopcodons für die einzelnen Deletionsmutanten sowie BamH I-Schnittstellen im 5'-nichtkodierenden Bereich eingefügt (Anhang). Der DBDVektor pAS2 wurde ebenfalls mit BamH I gespalten, die Vektorenden mit alkalischer Phosphatase dephosphoryliert und anschließend in den Ligationsansatz mit den gespaltenen PCR-Produkten eingesetzt. Alle Konstrukte wurden anschließend mit dem OligonukleotidPrimer $D B D$ sequenziert.

Tab. 1: Oligonukleotide für die Mutagenese des MPR46-CT

\begin{tabular}{|l|c|}
\hline \multicolumn{1}{|c|}{ Konstrukt } & Oligonukleotid-Primer \\
\hline pAS2-MPR46-CT-Wildtyp & $S T 29-F, S T 26-R$ \\
\hline pAS2-MPR46-CT-Stop A 44 & $S T 29-F, S T 23-R$ \\
\hline pAS2-MPR46-CT-Stop V 48 & $S T 29-F, S T 24-R$ \\
\hline pAS2-MPR46-CT-Stop H 63 & $S T 29-F, S T 28-R$ \\
\hline pAS2-MPR46-CT- $\Delta 1-16$ & $S T 25-F, S T 26-R$ \\
\hline
\end{tabular}

Zur Herstellung der Alaninaustauschmutanten des MPR46-CT wurden die in Tab. 2 angegebenen komplementären Oligonukleotide für eine gezielte in vitro-Mutagenese nach der Quik $^{\circledR}$-Change-Methode verwendet. Der Erfolg des Alaninaustausches wurde durch Sequenzierung der Konstrukte mit dem Oligonukleotid-Primer $D B D$ überprüft. 
Tab. 2: Oligonukleotide für die Herstellung von Alanin-Austauschmutanten des MPR46-CT

\begin{tabular}{|l|c|}
\hline \multicolumn{1}{|c|}{ Konstrukt } & Oligonukleotid-Primer \\
\hline $\mathrm{pAS} 2-\mathrm{MPR} 46-\mathrm{CT}-\mathrm{F} 18, \mathrm{~W} 19 \rightarrow \mathrm{A}$ & $F 18-F, F 18-R$ \\
\hline $\mathrm{pAS} 2-\mathrm{MPR} 46-\mathrm{CT}-\mathrm{Stop} \mathrm{H} 63-\mathrm{Y} 45, \mathrm{~V} 48 \rightarrow \mathrm{A}$ & $Y 45-F, Y 45-R$ \\
\hline $\mathrm{pAS} 2-\mathrm{MPR} 46-\mathrm{CT}-\mathrm{Y} 45, \mathrm{~V} 48 \rightarrow \mathrm{A}$ & $Y 45-F, Y 45-R$ \\
\hline
\end{tabular}

Für die Klonierung der mutanten zytoplasmatischen MPR46-Domänen in die DBDVektoren pGBT9 und pAS2-1 wurden PCR-Produkte mit den Forward-Primern ST22-F (MPR-46-CT-WT; StopA44; StopV48; StopH63) bzw. ST25-F (MPR46-CT-41-16) und den in Tab. 1 angegebenen Reverse-Primern amplifiziert und die DNA-Fragmente in die EcoRI-/BamHI-Schnittstellen der Vektoren kloniert.

\subsubsection{PCR-Mutagenese von Periplakin}

Ausgehend von dem AD-Vektor pGAD-GH-97 (Klon ST4) als Matrize wurden verschiedene PCR-Produkte mit den in Tab. 3 angegebenen Oligonukleotid-Primern amplifiziert und die DNA-Fragmente mit den durch die Oligonukleotid-Primer eingefügten Schnittstellen mit den Restriktionsendonukleasen gespalten. Die gereinigten PCR-Produkte wurden anschließend über die Schnittstellen in den Vektor pGAD-GH kloniert.

Tab. 3: Oligonukleotide für die Mutagenese von Periplakin

\begin{tabular}{|c|c|}
\hline Konstrukt & Oligonukleotid-Primer \\
\hline pGAD-GH-Periplakin (aa 1646-1756) & $P P 1-F, P P 4-R$ \\
\hline pGAD-GH-Periplakin (aa 1646-1700) & $P P 1-F, P P 2-R$ \\
\hline pGAD-GH-Periplakin (aa 1701-1756) & $P P 3-F, P P 4-R$ \\
\hline
\end{tabular}

\subsubsection{Klonierung der $\mu 2$ - und $\mu 3 A$-Untereinheiten in den AD-Vektor pGAD-424 und den in vitro-Translationsvektor pSPUTK}

Zur Klonierung der Maus $\mu$ 2-cDNA (Ohno et al., 1995) des AP-2-Komplexes in den ADVektor pGAD424 wurde als DNA-Template das Plasmid pCR2.1. $\mu 2-2 *$ herangezogen, das die gesamte 1,3 kb kodierende $\mu 2$-cDNA-Sequenz enthält. Nach Amplifizierung eines 1,3 kb PCR-Produktes mit den Primern $\mu 2-F / \mu 2-R$ wurde das DNA-Fragment mit der Restriktionsendonuklease $B g l$ II gespalten. Der Vektor pGAD-424 wurde zunächst mit BamH I und anschließend mit Bgl II gespalten. Nach Dephosphorylierung der Vektorenden

\footnotetext{
* Die Konstrukte pCR2.1. 2 2-2 und pSKII- $\mu 3$ A wurden freundlicherweise von Herrn Dr. P. V. Schu (Institut für Biochemie II, Universität Göttingen) bzw. von Frau Prof. Dr. M. S. Robinson (Department of Clinical Chemistry, Cambridge) zur Verfügung gestellt.
} 
mit alkalischer Phosphatase, Reinigung des Ansatzes über Qia-Quick-Säulen wurden ca. 100 ng des gespaltenen Vektors mit ca. 500 ng des gespaltenen PCR-Produktes in den Ligationsansatz eingesetzt.

Die kodierende $\mu 3$ A-cDNA des AP-3-Komplexes der Ratte (Pevsner et al., 1994) wurde unter Verwendung des Plasmids pKSII- $\mu 3 \mathrm{~A}^{*}$ mit den Primern $\mu 3-F / \mu 3-R$ amplifiziert und nach Restriktionsspaltung in die EcoRI/BamHI-Schnittstellen des Vektors pGAD424 kloniert. Die Konstrukte wurden nach Isolierung der Plasmid-DNA aus positiven Klonen mit den Oligonukleotid-Primern $P B 6$ und $P B 7$ sequenziert.

Zur Klonierung der Maus $\mu 2$-cDNA in den Vektor pSPUTK wurde mit den Primern $\mu 2-B-F / \mu 2-R$ unter Verwendung des Plasmids pCR2.1. $\mu 2-2$ als Matrize ein 1,3 kb PCRProdukt amplifiziert und nach Restriktionsspaltung in die $B g l I I$-Schnittstelle des Vektors pSPUTK kloniert. Die Ratten $\mu 3 \mathrm{~A}-\mathrm{cDNA}$ von $1,26 \mathrm{~kb}$ wurde mit den OligonukleotidPrimern $\mu 3-B-F$ und $\mu 3-R$ amplifiziert und nach Restriktionsspaltung in die $B g l$ IISchnittstelle des Vektors pSPUTK kloniert Zur effizienten Translation wurde in den 5'Bereich der Oligonukleotide $\mu 2-B-F$ und $\mu 3-B-F$ vor das ATG-Startcodon eine KozakKonsensus-sequenz eingefügt. Die erhaltenen Konstrukte pSPUTK- $\mu 2$ und pSPUTK- $\mu 3 \mathrm{~A}$ wurden mit dem Oligonukleotid-Primer SP6 sequenziert und zur in vitro-Translation benutzt.

\subsubsection{Klonierung der Periplakin-cDNA in den eukaryontischen Expressionsvektor pcDNA 3.1(+)}

Nach Amplifikation eines 1,5 kb-PCR-Produktes mit dem Oligonukleotid-Primern PP5-F und PP6- $R$ wurde das DNA-Fragment mit der Restriktionsendonuklease BamH I gespalten und anschließend in dieselben Schnittstellen des eukaryontischen Expressionsvektors pcDNA 3.1(+) kloniert. Beide Oligonukleotid-Primer enthielten BamH I-Schnittstellen in ihren 5'-nichtkodierenden Sequenzen, und in den Primer PP5-F wurde ein ATGStartcodon mit benachbarter Kozak-Konsensus-Sequenz eingefügt. Das Konstrukt wurde mit dem Oligonukleotid-Primer $T 7$ sequenziert. 


\subsubsection{Sequenzierung von Plasmid-DNA}

Die Sequenzierung von Doppelstrang-DNA wurde mit dem DNA-Sequenzierungsgerät (Modell 373A, ABI) durchgeführt. Es wurde die Taq-Cycle-Sequencing-Methode des Herstellers Applied Biosystems angewandt, die auf der Methode nach Sanger et al. (1977) aufbaut. Statt radioaktiv-markierter werden Fluorochrom-gekoppelte Didesoxynukleotide zum Kettenabbruch eingesetzt. Dazu wurde das ABI PRISM Dye Terminator Cycle Sequencing ready reaction-Produkt der Firma Perkin-Elmer (No. 402079) verwendet, das neben dem Puffer für die Sequenzierungsreaktion und der AmpliTaq ${ }^{\circledR}$ DNA Polymerase (8 U/ $\mu 1$ ) auch den dNTP-Mix und Fluorochrom-gekoppelte Terminatoren im richtigen Verhältnis enthält. Der entscheidende Vorteil dieses Systems ist, daß aufgrund des Einsatzes von vier unterschiedlichen Fluorochromen nur eine Spur pro Probe auf dem Sequenzgel benötigt wird und daß die Auswertung computergestützt abläuft. Die Fluorochrome werden durch einen $40 \mathrm{~mW}$ Argon-Laser (488 nm und $514 \mathrm{~nm}$ ) angeregt, die Fluoreszenzsignale durch das Detektorsystem gelesen und mit den Programmen Collection und Analysis in Chromatogrammform dargestellt.

Die Sequenzierungsreaktion wurde wie folgt durchgeführt:

Premix

DNA-Template

(doppelsträngige Plasmid-DNA)

Primer

A. dest. (HPLC-grade) ad

$\begin{array}{rl}3 & \mu \mathrm{l} \\ 250-500 & \mathrm{ng} \\ & \\ 10 & \mathrm{pmol} \\ 20 & \mu \mathrm{l}\end{array}$

Zur Sequenzierung wurden folgende Oligonukleotide als Primer eingesetzt:

\begin{tabular}{|l|c|l|}
\hline Bezeichnung & (Leserichtung) & Sequenz, angegeben in Richtung: $5^{\prime} \rightarrow 3^{\prime}$ \\
\hline ST1 & $\left(5^{\prime} \rightarrow 3^{\prime}\right)$ & GGG CTG GCA AGC CAC GTT TGG TG \\
\hline PB 6 & $\left(5^{\prime} \rightarrow 3^{\prime}\right)$ & TAC CAC TAC AAT GGA TG \\
\hline PB 7 & $\left(3^{\prime} \rightarrow 5^{\prime}\right)$ & GTT GAA GTG AAC TTG CGG CG \\
\hline TB-U & $\left(5^{\prime} \rightarrow 3^{\prime}\right)$ & GGA AAC AGC TAT GAC CAT G \\
\hline TB-R & $\left(3^{\prime} \rightarrow 5^{\prime}\right)$ & GTA AAA CGA CGGCCA GT \\
\hline DBD & $\left(5^{\prime} \rightarrow 3^{\prime}\right)$ & TCA TCG GAA GAG AGT AG \\
\hline SP 6 & $\left(5^{\prime} \rightarrow 3^{\prime}\right)$ & GAT TTA GGT GAC ACT ATA \\
\hline T 7 & $\left(5^{\prime} \rightarrow 3^{\prime}\right)$ & TAA TAC GAC TCA CTA TAG G \\
\hline
\end{tabular}


Es wurden 25 Reaktionszyklen in einem Perkin Elmer Cetus Thermocycler Modell 9600 durchgeführt:

25 Zyklen:

$\begin{array}{rlr}\text { Denaturierung } & 96^{\circ} \mathrm{C} & 10 \text { Sekunden } \\ \text { Annealing } & 50{ }^{\circ} \mathrm{C} & 5 \text { Sekunden } \\ \text { Extension } & 60{ }^{\circ} \mathrm{C} & 4 \text { Minuten }\end{array}$

Nach Abschluß der Reaktion wurde die Probe auf $4{ }^{\circ} \mathrm{C}$ abgekühlt. Die DNA-Lösung wurde mit $2 \mu 13$ M Natriumacetat, $\mathrm{pH} \mathrm{5,2} \mathrm{und} 50 \mu 195 \%$ Ethanol versetzt, gemischt und bei 14.000 Upm pelletiert. Das Pellet wurde mit $250 \mu 170 \%$ Ethanol gewaschen und im Vakuumkonzentrator für 5 Minuten getrocknet. Das Pellet wurde in $4 \mu 1$ Formamid/EDTA, $\mathrm{pH}$ 8,0 (5:1) aufgenommen, 2 min bei $90{ }^{\circ} \mathrm{C}$ denaturiert, 5 min auf Eis abgekühlt und zügig auf ein $6 \%$ Polyacrylamidgel aufgetragen.

\section{Polyacrylamidgele zur DNA-Sequenzierung:}

Die zu sequenzierenden DNA-Proben wurden in Polyacrylamidgelen aufgetrennt, für die spezielle, nicht fluoreszierende Chemikalien verwendet wurden.

\begin{tabular}{|c|c|c|}
\hline 10 x TBE: & $\begin{array}{r}108 \mathrm{~g} \\
55 \mathrm{~g} \\
10 \mathrm{ml}\end{array}$ & $\begin{array}{l}\text { Tris } \\
\text { Borsäure } \\
0,5 \text { m EDTA } \\
\text { wurden in } 11 \text { A. dest. gelöst. }\end{array}$ \\
\hline
\end{tabular}

$40 \%$ Acrylamidlösung: $\quad 90 \mathrm{~g} \quad$ Acrylamid

$10 \mathrm{~g} \quad \mathrm{~N}, \mathrm{~N}$ '-Methylenbisacrylamid wurden auf $500 \mathrm{ml}$ mit A. dest. aufgefüllt und eine Stunde mit 2-4 g Ionenaustauscher (AG-501, Biorad) deionisiert, filtriert und in einer dunklen Flasche bei $4{ }^{\circ} \mathrm{C}$ gelagert.

$6 \%$ Polyacrylamidgel:

$30 \mathrm{~g} \quad$ Harnstoff

$9 \mathrm{ml} \quad 40 \%$ Acrylamidlösung wurden in $20 \mathrm{ml} \mathrm{A}$. dest. bei $37{ }^{\circ} \mathrm{C}$ gelöst, mit $1,2 \mathrm{~g}$ Ionenaustauscher versetzt und 5 min gerührt, $6 \mathrm{ml} 10 \mathrm{x}$ TBE zugegeben, entgast und auf $60 \mathrm{ml} \mathrm{A.} \mathrm{dest.} \mathrm{aufgefüllt.}$

Die Glasplatten wurden mit A. dest., Alconox und Ethanol gründlich gereinigt und an der Luft getrocknet. Die Reinheit der Platten wurde im Sequenzierungsgerät mit dem Laserstrahl überprüft. Anschließend wurden sie mit Abstandhaltern und Klammern zusammengesetzt. 
Zu 50 ml Lösung für ein $6 \%$ Polyacrylamidgel wurden $27 \mu$ TEMED und $270 \mu 110 \%$ APS pipettiert, gemischt, zügig zwischen die Glasplatten gegossen und der Kamm zur Formung der Geltaschen eingesetzt. Nach der Polymerisation (ca. 30 min) wurden die Platten von außen erneut mit A. dest., Alconox und Ethanol gründlich gereinigt und auf Gelrückstände überprüft. Anschließend wurde der Probenkamm herausgezogen, die Klammern wurden entfernt, und das Gel in die Laufkammer des Sequenzierungsautomaten eingesetzt.

Vor dem Probenauftrag wurde ein Vorlauf von mindestens 30 min durchgeführt. Die Elektrophorese fand in $1 \mathrm{x}$ TBE-Puffer bei $1300 \mathrm{~V}$ statt.

\subsubsection{Isolierung von Gesamt-RNA}

(Chirgwin et al., 1979)

$\begin{array}{lll}\text { Lösung 1: } & 4 \mathrm{mM} & \text { Guanidiumthiocyanat (GTC) } \\ 25 \mathrm{mM} & \text { NaAc, pH 6 } \\ 1 \% & \text { B-Mercaptoethanol }\end{array}$

Lösung 2: $\quad 5,7 \mathrm{M} \quad \mathrm{CsCl}$

Über Nacht in einer $10 \mathrm{~cm}$-Schale kultivierte HeLa- und BHK-Zellen wurden in $8 \mathrm{ml}$ Lösung 1 homogenisiert und $10 \mathrm{~min}$ bei $5.000 \mathrm{Upm}$ in der Labofuge zentrifugiert. Der Überstand wurde vorsichtig auf ein $3 \mathrm{ml}$ CsCl-Kissen in SW41-Zentrifugenröhrchen gegeben und ü. N. bei $32.000 \mathrm{Upm}$ und $16{ }^{\circ} \mathrm{C}$ zentrifugiert. Anschließend wurde der Überstand mit einer Pasteurpipette abgenommen. Das RNA-Pellet wurde bei RT getrocknet und in 3-5 $\mathrm{ml}$ DEPC- $\mathrm{H}_{2} \mathrm{O}$ aufgenommen.

\subsubsection{Auftrennung von RNA in Agarose-Formaldehydgelen}

$\begin{array}{lrl}10 \text { x Laufpuffer: } & 200 \mathrm{mM} & \text { MOPS } \\ & 200 \mathrm{mM} & \text { NaAc } \\ & 10 \mathrm{mM} & \begin{array}{l}\text { EDTA } \\ \text { pH 7 mit NaOH eingestellt. }\end{array} \\ & & \\ \text { Auftragspuffer: } & 4 \text { Teile } & \text { Formamid } \\ & 2 \text { Teile } & \text { Formaldehyd } \\ 4 \text { Teile } & \text { DEPC- } \mathrm{H}_{2} \mathrm{O} \\ & 2 \text { Teile } & 10 \times \text { Laufpuffer } \\ & 1 \text { Teil } & \text { Bromphenolblau (gesättigte wäßrige Lösung) }\end{array}$


RNA-Gele wurden in einer NaOH-behandelten, RNase-freien Gelkammer verwendet. $1 \%$ Agarose wurde in 1 x Laufpuffer aufgekocht, auf ca. $55^{\circ} \mathrm{C}$ abgekühlt, mit Ethidiumbromid (EK: $0,5 \mu \mathrm{g} / \mathrm{ml}$ ) und Formaldehyd (EK: 0,65 \%) versetzt und in einen RNase freien Gelträger gegossen. Die RNA-Proben $(5-10 \mu \mathrm{g})$ wurden mit Ethanol präzipitiert und das Pellet wurde in 25-30 $\mu$ l Auftragspuffer aufgenommen. Vor dem Auftragen wurden die Proben 5 min auf $65{ }^{\circ} \mathrm{C}$ erhitzt und kurz auf Eis abgekühlt. Die Elektrophorese erfolgte bei $2-3 \mathrm{~V} / \mathrm{cm}$.

\subsubsection{Radioaktive Markierung von DNA}

(nach Feinberg \& Vogelstein, 1983)

Rediprime ${ }^{\circledR}$ Labelling Kit (Lyophilisat): $\quad \begin{aligned} & \text { Klenow-DNA-Polymerase } \\ & \text { dATP, dTTP, dGTP } \\ & \text { hexamere Oligonukleotide }\end{aligned}$

$\alpha-\left[{ }^{32} \mathrm{P}\right]-\mathrm{dCTP}(50 \mu \mathrm{Ci})$

25 ng des zu markierenden DNA-Fragmentes wurden in $45 \mu \mathrm{A}$ A. bidest. gelöst, 5 min bei $95{ }^{\circ} \mathrm{C}$ erhitzt und für 2 min auf Eis gestellt. Das Lyophilisat wurde nach Zugabe der DNALösung durch Schnippen des Gefäßes gelöst. Nach Zugabe von $5 \mu 1 \alpha-\left[{ }^{32} \mathrm{P}\right]-\mathrm{dCTP}(50 \mu \mathrm{Ci})$ wurde der Ansatz für 15 min bei $37{ }^{\circ} \mathrm{C}$ inkubiert und die Reaktion durch Mischen des Ansatzes mit $150 \mu \mathrm{l}$ TE-Puffer gestoppt. Zur Entfernung von nicht-inkorporiertem $\alpha-\left[{ }^{32} \mathrm{P}\right]-\mathrm{dCTP}$ wurde der Ansatz über eine Sephadex G-50-Säule zentrifugiert. Das Volumen des Eluats wurde bestimmt und $1 \%$ des Ansatzes zur Messung der CerenkovStrahlung verwendet. 


\subsubsection{Hybridisierung der Hybond-N-Filter mit radioaktiv markierten DNA- Fragmenten}

Lachsspermien-DNA: Die Lachsspermien-DNA wurde mit einer sterilen Schere zerkleinert und in A. bidest. gelöst $(10 \mathrm{mg} / \mathrm{ml})$. Nach $10 \mathrm{~min}$ Ultraschallbehandlung wurde die Lösung in der Mikrowelle aufgekocht und nochmals ultraschallbehandelt. Die so gelöste DNA wurde aliquotiert und bei $-20{ }^{\circ} \mathrm{C}$ gelagert.

$\begin{array}{rrl}\text { Hybridisierungsmix: } & 72 \mathrm{ml} & \text { Formamid } \\ 36 \mathrm{ml} & 20 \mathrm{x} \text { SSC } \\ 1,5 \mathrm{ml} & 1 \mathrm{M} \text { Tris/HCl, pH 7,5 } \\ 1,5 \mathrm{~g} & \text { SDS } \\ 3 \mathrm{ml} & 50 \times \text { Denhardts-Lösung } \\ 15 \mathrm{~g} & \text { Dextransulfat mit A. bidest. auf } 30 \mathrm{ml} \text { auffüllen und bei } \\ & 80{ }^{\circ} \mathrm{C} \text { lösen. Anschließend die anderen aufgeführten } \\ & \text { Substanzen zusetzen und das Volumen mit A. bidest. } \\ & \text { auf } 150 \mathrm{ml} \text { auffüllen. }\end{array}$

Waschlösung I: $\quad 2 \times \quad$ SSC

$0,1 \%(\mathrm{w} / \mathrm{v}) \quad \mathrm{SDS}$ in A. bidest.

Waschlösung II: $\quad 0,2 \times \quad$ SSC

$0,1 \%(\mathrm{w} / \mathrm{v}) \quad$ SDS in A. bidest.

Zur Hybridisierung wurden die Filter mit dem Hybridisierungsmix $\left(1 \mathrm{ml} / \mathrm{cm}^{2}\right)$ in einem Plastikröhrchen vorinkubiert. Nach ca. 2 Stunden wurde die radioaktiv markierte Sonde, die vorher mit der Lachsspermien-DNA 5 min bei $95{ }^{\circ} \mathrm{C}$ denaturiert worden war, zu den Filtern in den Hybridisierungsmix pipettiert. Auf einem Drehrad wurden die Filter ü. N. mit der radioaktiven Hybridisierungslösung bei $42{ }^{\circ} \mathrm{C}$ inkubiert. Anschließend wurde die radioaktive Hybridisierungslösung abgenommen und die Filter zunächst 2 x 10 min mit Waschlösung I bei RT und dann 2 x 30 min mit Waschlösung II bei $65{ }^{\circ} \mathrm{C}$ inkubiert, bis die mit dem Handmonitor meßbare Radioaktivität auf 30-40 Zerfälle pro sec abgesunken war. Die Filter wurden feucht in Folie eingeschweißt und entweder zwischen Verstärkerfolien (Cronex Dupont) bei $-70{ }^{\circ} \mathrm{C}$ mit einem Kodak XAR-Röntgenfilm autoradiographiert oder mittels Phosphoimager analysiert. 


\subsection{Zellbiologische Methoden}

\subsubsection{Kultivierung von Zellen}

Die Zellen wurden in $5 \%$-iger $\mathrm{CO}_{2}$-Atmosphäre und $85 \%$ Luftfeuchtigkeit kultiviert. Medien und Lösungen wurden auf $37^{\circ} \mathrm{C}$ vorgewärmt, wenn nicht anders angegeben.

Die verwendeten Zellinien HeLa, MCF7, HepG2 wurden in DMEM, $10 \%$ FKS, 1x Penicillin/Streptomycin kultiviert; die Zellinie BHK wurde in DMEM, 5 \% FKS, 1x Penicillin/Streptomycin kultiviert.

\subsubsection{Trypsinieren von Zellen}

$\begin{array}{lll}\text { Trypsin-EDTA-Lösung: } & 0,05 \%(\mathrm{w} / \mathrm{v}) & \text { Trypsin } \\ & 0,02 \%(\mathrm{w} / \mathrm{v}) & \text { EDTA in modifizierter Puck`s Salzlösung }\end{array}$

Der Zellrasen wurde mit PBS gespült, um Trypsininhibitoren des FKS zu entfernen. Nach dem Absaugen des PBS wurden die Zellen ca. 5 min mit Trypsin/EDTA bei $37{ }^{\circ} \mathrm{C}$ inkubiert. Das Ablösen der Zellen wurde im inversen Mikroskop kontrolliert. Die TrypsinReaktion wurde durch Zugabe von serumhaltigem Medium gestoppt, die Zellen durch mehrfaches Aufsaugen mit der Pipette vereinzelt und gegebenenfalls die Zellzahl pro Milliliter mit der Neubauer-Zählkammer bestimmt. Die Zellen wurden in der gewünschten Dichte ausgesät.

\subsubsection{Gefrierkonservierung und Revitalisierung von Zellen}

Zur Konservierung wurden konfluent wachsende Zellen, z. B. eine $25 \mathrm{~cm}^{2}$-Flasche trypsiniert, in Medium aufgenommen und für $5 \mathrm{~min}$ bei $1.000 \mathrm{x} \mathrm{g}$ in der Labofuge sedimentiert. Nach Absaugen des Überstandes wurden die Zellen in $3 \mathrm{ml}$ Einfriermedium aufgenommen und auf drei Einfrierröhrchen verteilt. Die Zellen wurden zunächst bei $-80^{\circ} \mathrm{C}$ ü. N. eingefroren und anschließend in flüssigem Stickstoff gelagert.

Zur Revitalisierung wurde das Einfrierröhrchen aus dem Stickstofftank genommen, zunächst für ca. 1 min bei RT angewärmt und anschließend im Ethanolbad bei $37{ }^{\circ} \mathrm{C}$ aufgetaut, bis nur noch ein kleiner Eiskern zu sehen war. Die Zellsuspension wurde entnommen, in 3,5 ml kaltes Medium $\left(4^{\circ} \mathrm{C}\right.$ ) überführt und in der Labofuge 5 min bei 1.000 x g sedimentiert. Der Überstand wurde abgesaugt, das Zellpellet in $5 \mathrm{ml}$ Medium ohne 
Selektionsantibiotika resuspendiert und in eine Zellkulturflasche überführt. Am nächsten Tag wurde das Medium gewechselt, um DMSO-Reste, tote Zellen und Zelltrümmer zu entfernen sowie gegebenenfalls Selektionsantibiotika einzuführen.

\subsubsection{Transfektion von Zellinien}

Lösungen:

$\begin{array}{rrl} & 2,5 \mathrm{M} & \mathrm{CaCl}_{2} \\ \mathrm{HBS} \text { (2 fach) } & 50 \mathrm{mM} & \mathrm{HEPES}^{\mathrm{pH}} 7,13 \\ 1,5 \mathrm{mM} & \mathrm{Na}_{2} \mathrm{HPO}_{4} \\ 0,28 \mathrm{M} & \mathrm{NaCl}\end{array}$

Glyzerin-Schock: $\quad 15 \% \quad$ Glyzerin (w/v) in 1 fach HBS

Stabile Transfektionen wurden nach der Calcium-Phosphat-Methode (Chen \& Okayama, 1987) durchgeführt.

Die Zellen wurden am Vortag in einer Dichte von 2 x $10^{5}$ Zellen auf einer $60 \mathrm{~mm}$ Gewebeschale ausgesät. Vier Stunden vor Zugabe der DNA wurde das Medium gewechselt. Zur Herstellung des Präzipitats wurden $10 \mu \mathrm{g}$ des $\mathrm{zu}$ transfizierenden Plasmids (QiagenPräparation) sowie $25 \mu 12,5 \mathrm{M} \mathrm{CaCl}_{2}$ in einem Eppendorfgefäß vorgelegt, mit A. dest. auf $250 \mu \mathrm{l}$ aufgefüllt und gemischt. Diese DNA-Mischung wurde unter Lufteinstrom in $250 \mu 1$ HBS eingetropft. Das dabei entstandene Präzipitat blieb 45 min erschütterungsfrei bei RT stehen, um anschließend auf die Zellen gegeben zu werden. Nach 6 bis 16 Stunden wurde das Medium abgesaugt und die Zellen für 2 Minuten einem Glyzerin-Schock unterworfen. Das Medium wurde von den Zellen abgesaugt, und für 2,5 min wurden $3 \mathrm{ml} 15 \%$ Glyzerin in 1x HBS auf die Zellen gegeben. Anschließend wurden die Zellen $2 \mathrm{x}$ mit PBS gewaschen und mit $5 \mathrm{ml}$ Medium kultiviert.

\section{$\underline{\text { Selektion der stabil transfizierten Zellklone }}$}

BHK-Zellen:

Zwei Tage nach dem Glyzerinschock wurde dem Medium $100 \mu \mathrm{g} / \mathrm{ml}$ Hygromycin B zugesetzt. An den folgenden Tagen wurde die Hygromycin B-Konzentration um jeweils $100 \mu \mathrm{g} / \mathrm{ml}$ auf eine Endkonzentration von $500 \mu \mathrm{g} / \mathrm{ml}$ erhöht. Nach ca. 14 Tagen wurden Einzelklone auf eine 24-Napf-Gewebekulturplatte überführt. Der Expressionstest durch Western-Blot-Analyse erfolgte 3-4 Wochen nach Transfektionsbeginn. 


\subsubsection{Radioaktive Markierung von Proteinen mit Jodogen}

Lösungen:

\begin{tabular}{|c|c|c|}
\hline Jodogen: & $1 \mathrm{mM}$ & $\begin{array}{l}\text { Jodogen } \\
\left(0,8 \mathrm{mg} \text { in } 577 \mu \mathrm{l} \mathrm{CH}_{2} \mathrm{Cl}_{2} \text { lösen und } 1: 3 \text { in }\right. \\
\left.\mathrm{CH}_{2} \mathrm{Cl}_{2} \text { verdünnen }\right)\end{array}$ \\
\hline Elutionspuffer: & $\begin{array}{r}1 \mathrm{mg} / \mathrm{ml} \\
0,05 \%\end{array}$ & $\begin{array}{l}\mathrm{KJ} \\
\mathrm{BSA} \text { in } 10 \mathrm{mM} \mathrm{PBS}\end{array}$ \\
\hline Boratpuffer: & $20 \mathrm{mM}$ & Boratpuffer mit $\mathrm{NaOH}$ auf $\mathrm{pH} 8,0$ titriert \\
\hline Jodierungsansatz: & $\begin{array}{r}1 \mu \mathrm{g} \\
100 \mu \mathrm{Ci}\end{array}$ & $\begin{array}{l}\text { Pentamannose-6-Phosphat-BSA (PMP-BSA) } \\
\mathrm{Na}\left[{ }^{125} \mathrm{~J}\right] \\
\text { mit Boratpuffer ad } 60 \mu \mathrm{l}\end{array}$ \\
\hline
\end{tabular}

Iodogenbeschichtung:

Glasspitzröhrchen wurden schräg in einen Rotor eingespannt, $80 \mu \mathrm{l}$ der Jodogenverdünnung zugegeben und im Stickstoffstrom unter Rotation von Dichlormethan befreit. Beschichtete Glasspitzröhrchen sind bei $-20{ }^{\circ} \mathrm{C}$ circa 8 Wochen haltbar.

\section{Jodierung:}

Vor Jodierungsbeginn wurde eine 5 ml NAPTM_Fertigsäule mit Sephadex G-25 mit $30 \mathrm{ml}$ Elutionspuffer äquilibriert. Der Jodierungsansatz wurde 2 min auf Eis inkubiert und dann in das mit Jodogen beschichtete Röhrchen überführt. Dieses wurde 8 min auf Eis rotiert, und die Reaktion wurde durch Transfer in ein unbeschichtetes Röhrchen überführt. Das Jodogenröhrchen wurde mit $140 \mu \mathrm{l}$ Boratpuffer nachgespült und das Volumen des Ansatzes durch Zugabe von $300 \mu$ l Elutionspuffer auf $500 \mu$ l erhöht. Der Reaktionsansatz wurde auf die G25-Säule zur Entfernung des nichtumgesetzten $\left[{ }^{125} \mathrm{~J}\right]$-Na-Jodids aufgetragen und in 0,5 ml Fraktionen eluiert. Von den 10 Fraktionen wurde je $1 \mu \mathrm{l}$ im Gamma-Counter gezählt. Fraktionen, die jodiertes PMP-BSA enthielten, wurden gepoolt und bei $4{ }^{\circ} \mathrm{C}$ gelagert.

Ermittlung der spezifischen Aktivität:

Zur Bestimmung der spezifischen Aktivität wurde die cpm-Zahl der vereinigten Fraktionen berechnet und auf die Gesamtmenge des eingesetzten Proteins bei angenommener verlustfreier Wiederfindung bezogen. 


\subsubsection{Bestimmung der Endozytoserate durch Aufnahme von $\left[{ }^{125} \mathrm{~J}\right]-\mathrm{PMP}-\mathrm{BSA}$}

Bindungsmedium (BM): $\quad$ 0,1 \% BSA, 20 mM HEPES, pH 7,5 in DMEM

BM + Mannose-6-Phosphat: 6,5 mM Mannose-6-Phosphat in Bindungsmedium

Waschpuffer: $\quad 2$ mM Mannose-6-Phosphat in Hanks-Puffer

Zellen von einer konfluent bewachsenen 35 mm-Kulturschale wurden mit PBS gewaschen und anschließend für 2 Stunden in $700 \mu \mathrm{LMEM} / 0,1 \% \mathrm{BSA}$ bei $37{ }^{\circ} \mathrm{C}$ und $5 \% \mathrm{CO}_{2}$ inkubiert. Es wurden anschließend $700 \mu \mathrm{l}$ BM \pm Mannose-6-Phosphat mit $\left[{ }^{125} \mathrm{~J}\right]$-markiertem PMP-BSA ( 1 x $10^{6} \mathrm{cpm} / 35 \mathrm{~mm}$-Kulturschale) zugegeben und die Zellen für 2 Stunden bei $37^{\circ} \mathrm{C}$ inkubiert. Nach Absaugen der Überstände wurden die Zellen $5 \mathrm{x}$ mit $1 \mathrm{ml}$ Hanks-Puffer gewaschen. Anschließend erfolgte eine zweimalige Inkubation der Zellen mit je $600 \mu \mathrm{l}$ Waschpuffer für $10 \mathrm{~min}$ bei $4{ }^{\circ} \mathrm{C}$ auf einer Wippe. Die Überstände wurden vereinigt und im Gamma-Counter gemessen. Die Zellen wurden in $1 \mathrm{ml} 1 \mathrm{~N} \mathrm{NaOH}$ abgeschabt und die Endozytose durch Messung des aufgenommenem $\left[{ }^{125} \mathrm{~J}\right]$-markiertem PMP-BSA im Gamma-Counter bestimmt. Die abgeschabten Zellen wurden durch Ultraschall für $3 \times 10 \mathrm{sec}$ homogenisiert und je nach Zelltyp $20 \mathrm{bzw}$. $40 \mu \mathrm{l}$ für eine Proteinbestimmung nach Lowry (siehe 3.5.2) eingesetzt. Mit Hilfe der erhaltenen Proteinkonzentrationen konnten die Radioaktivitätsmengen auf eine absolute Proteinmenge (mg) bezogen werden. Die Bestimmung der TCA-löslichen Radioaktivität nach der angegebenen Endozytoseperiode bei verschiedenen Zelltypen zeigte keine erhöhten Werte gegenüber den zellfreien Kontrollen, so daß in weiteren Versuchen auf die Bestimmung der Abbaurate verzichtet wurde. 


\subsection{Methoden zur Arbeit mit Hefezellen}

\subsubsection{Herstellung und Transformation von kompetenten Hefezellen}

(Gietz et al., 1992)

TE/LiAc-Puffer:

$$
\begin{aligned}
100 \mathrm{mM} & \text { Lithium-Acetat } \\
10 \mathrm{mM} & \text { Tris/HCl pH 7,5 } \\
10 \mathrm{mM} & \text { EDTA }
\end{aligned}
$$

PEG/LiAc-Puffer: $\quad 40 \% \quad$ Polyethylenglycol (durchschnittliches Molekulargewicht: 3.500) in A. bidest.

$$
\begin{aligned}
100 \mathrm{mM} & \text { Lithium-Acetat } \\
10 \mathrm{mM} & \text { Tris/HCl pH 7,5 } \\
10 \mathrm{mM} & \text { EDTA }
\end{aligned}
$$

Lachsspermien-DNA: $\quad 10 \mathrm{mg} / \mathrm{ml} \quad$ Lachsspermien-DNA

$50 \mathrm{ml}$ YPD-Medium wurden mit einer Kolonie S. cerevisiae HF 7c oder SFY 526 von einer Stammplatte (YPD-Agarplatte) angeimpft und unter Schütteln $(230 \mathrm{rpm})$ bei $30{ }^{\circ} \mathrm{C}$ für 48 Stunden inkubiert. $300 \mathrm{ml}$ YPD-Medium wurden mit dieser Vorkultur auf eine $\mathrm{OD}_{600}$ von $0,2-0,3$ angeimpft und unter Schütteln bei $30{ }^{\circ} \mathrm{C}$ bis zu einer $\mathrm{OD}_{600}$ von 0,8 inkubiert. Die Kultur wurde in JA 10-Zentrifugenbechern transferiert und bei RT für 5 min bei 1.000 x g zentrifugiert. Nach Dekantieren des Überstandes wurde das Zellpellet in 50 $\mathrm{ml}$ sterilem A. bidest. resuspendiert, erneut unter gleichen Bedingungen zentrifugiert und das Pellet anschließend in 1,5 ml TE/LiAc-Puffer resuspendiert. In einem Eppendorfgefäß wurden $1 \mu \mathrm{g}$ Plasmid-DNA, $100 \mu \mathrm{g}$ Lachsspermien-DNA und $100 \mu$ l kompetente Zellen gemischt und mit $600 \mu \mathrm{l}$ PEG/LiAc-Puffer versetzt und durchmischt. Die eingesetzte Lachsspermien-DNA wurde nach dem Protokoll von Schiestl \& Gietz (1989) hergestellt, vor der Transformation für $7 \mathrm{~min}$ gekocht und anschließend auf Eis abgekühlt. Die Suspension wurde bei RT für 30 min bei $200 \mathrm{rpm}$ geschüttelt und anschließend mit $70 \mu 1$ DMSO versetzt. Nach einem Hitzeschock für 15 Minuten bei $42{ }^{\circ} \mathrm{C}$ wurden die Zellen für 2 min auf Eis inkubiert. Die Suspensionen wurden für 5 Sekundern bei $14.000 \mathrm{Upm}$ zentrifugiert und das Pellet in $500 \mu \mathrm{l}$ A. bidest. resuspendiert. Jeweils $100 \mu \mathrm{l}$ der Transformationsansätze wurden auf SD/-HLT (+ $5 \mathrm{mM} \mathrm{3-Aminotriazol)} \mathrm{und} \mathrm{SD/-LT-}$ Agarplatten ausplattiert und bei $30^{\circ} \mathrm{C}$ für 3-5 Tage inkubiert. 


\subsubsection{Anlegen einer Glyzerinkulur}

Einzelkolonien von einer Agarplatte wurden in $500 \mu 1$ YPD- oder SD-Selektions-Medium transferiert, gemischt und anschließend mit $500 \mu 150 \%$ (v/v) Glyzerin versetzt. Die Hefesuspensionen wurden bei $-70{ }^{\circ} \mathrm{C}$ gelagert. Aus der Glyzerinkultur konnten Einzelkolonien durch Ausstreichen auf YPD- oder SD-Selektionsmedium-Agarplatten gewonnen werden.

\subsubsection{Isolierung von Plasmid-DNA aus Hefezellen}

(Hoffman \& Winston, 1987)

Lysispuffer:

$\begin{array}{rl}2 \% & \text { Triton } \mathrm{X}-100 \\ 1 \% & \text { SDS } \\ 100 \mathrm{mM} & \mathrm{NaCl} \\ 10 \mathrm{mM} & \text { Tris/HCl pH } 8,0 \\ 1 \mathrm{mM} & \text { EDTA }\end{array}$

PCI: $\quad 25: 24: 1 \quad$ Phenol/Chloroform/Isoamylalkohol

Hefetransformanten wurden von SD/-HLT-Agarplatten gepickt, in $3 \mathrm{ml} \mathrm{SD/-Leu-Medium}$ resuspendiert und über Nacht unter Schütteln bei $30{ }^{\circ} \mathrm{C}$ inkubiert. 1,5 ml der Kultur wurden in ein Eppendorfgefäß überführt und für 5 Sekunden bei $14.000 \mathrm{Upm}$ zentrifugiert. Das Pellet wurde in $200 \mu \mathrm{l}$ Lysispuffer resuspendiert, mit $200 \mu \mathrm{l}$ PCI und $300 \mathrm{mg}$ Glasperlen $(\varnothing=425-600 \mu \mathrm{m})$ gemischt und für $3 \mathrm{~min}$ kräftig durchmischt. Die Hefesuspension wurde für 5 min bei $14.000 \mathrm{Upm}$ zentrifugiert, die wässrige Phase in ein neues Eppendorfgefäß transferiert und erneut mit Chloroform extrahiert. Der DNA-enthaltende Überstand wurde mit 2,5 Volumen Ethanol für 30 Minuten bei $-80{ }^{\circ} \mathrm{C}$ gefällt, zentrifugiert und das Pellet mit $70 \%$ Ethanol gewaschen und anschließend getrocknet. Die DNA wurde in $10 \mu \mathrm{l}$ A. bidest. resuspendiert.

\subsubsection{Bestimmung von B-Galaktosidase im Filter-Test}

(Breeden \& Nasmyth, 1985)

$\begin{array}{lll}60 \mathrm{mM} & \mathrm{Na}_{2} \mathrm{HPO}_{4} \times 7 \mathrm{H}_{2} \mathrm{O} \\ 40 \mathrm{mM} & \mathrm{NaH}_{2} \mathrm{PO}_{4} \times \mathrm{H}_{2} \mathrm{O} \\ 10 \mathrm{mM} & \mathrm{KCl} \\ 1 \mathrm{mM} & \mathrm{MgSO}_{4} \times 7 \mathrm{H}_{2} \mathrm{O}\end{array}$


X-Gal-Stammlösung:

Z-Puffer/ X-Gal-Stammlösung: $100 \mathrm{ml}$

$270 \mu 1$

$1,67 \mathrm{ml}$
5-Bromo-4-Chloro-Indolyl-ß-D-Galaktopyranosid in N,N-Dimethylformamid

Z-Puffer

B-Mercaptoethanol

X-Gal-Stammlösung

Nach Transformation von kompetenten S. cerevisiae HF7c-Zellen, Ausplattieren und Inkubation der SD/-HLT-(+ $5 \mathrm{mM} 3$-AT)-Agarplatten bei $30{ }^{\circ} \mathrm{C}$ für 5 Tage wurden die gewachsenen Kolonien auf einen Whatman-Filter transferiert. Die Filter wurden auf SD/HLT-(+ 5 mM 3-AT)-Agarplatten aufgelegt und für 1-2 Tage bei $30{ }^{\circ} \mathrm{C}$ inkubiert. Der Filter wurde anschließend für 10 Sekunden in flüssigen Stickstoff eingetaucht und bei RT aufgetaut. In einer Petrischale wurde ein Whatman-Filter mit 1,5 ml Z-Puffer/ X-GalStammlösung getränkt und der aufgetaute Filter mit der Kolonieseite nach oben zeigend bei $30{ }^{\circ} \mathrm{C}$ bis zu 8 Stunden inkubiert.

\subsubsection{Bestimmung von B-Galaktosidase im Flüssigkeits-Test}

Puffer 1:

$$
\begin{array}{r}
100 \mathrm{mM} \\
154 \mathrm{mM} \\
3,6 \mathrm{mM} \\
1 \%(\mathrm{w} / \mathrm{v}) \\
0,05 \%(\mathrm{v} / \mathrm{v})
\end{array}
$$

Puffer 2:

Stoppuffer:
$2,23 \mathrm{mM}$

$$
3 \mathrm{mM}
$$

HEPES

$\mathrm{NaCl}$

L-Aspartat-Kaliumsalz-Hemihydrat

BSA

Tween 20

Der $\mathrm{pH}-$ Wert des Puffers wurde auf $\mathrm{pH} 7,25$ eingestellt.

S. cerevisisae SFY526-Zellen wurden mit den $\mathrm{zu}$ untersuchenden Plasmiden kotransformiert, auf SD/-LT-Agarplatten ausplattiert und bei $30{ }^{\circ} \mathrm{C}$ für 3 Tage inkubiert. Einzelkolonien wurden in $5 \mathrm{ml}$ SD/-LT-Medium suspendiert und ü. N. im Schüttelinkubator $(230 \mathrm{rpm})$ bei $30{ }^{\circ} \mathrm{C}$ inkubiert. Mit $2 \mathrm{ml}$ der Vorkultur wurden $8 \mathrm{ml}$ YPD-Medium angeimpft und 4-6 Stunden bis zu einer $\mathrm{OD}_{600}$ von 0,8 inkubiert. 1,5 ml der Kultur wurden bei 14.000 Upm für 30 Sekunden zentrifugiert, in $1 \mathrm{ml}$ Puffer 1 resupendiert und erneut unter gleichen Bedingungen zentrifugiert. Nach Entfernen des Überstandes wurde das Zellpellet in Abhängigkeit von der Stärke der untersuchten Protein-ProteinWechselwirkung in 100-300 $\mu 1$ Puffer 1 resuspendiert und $100 \mu 1$ der Suspension in ein 
neues Eppendorfgefäß überführt. Die Zellsuspension wurde für 30-60 Sekunden in flüssigem Stickstoff eingefroren und anschließend für 60 Sekunden bei $37{ }^{\circ} \mathrm{C}$ aufgetaut. Nach zweimaliger Behandlung der Zellen unter den gleichen Bedingungen wurden $700 \mu 1$ Puffer 2 unter kräftigem Mischen hinzugefügt (Startzeit der Inkubation). Nachdem die Farbe der Suspension von gelb auf rot umgeschlagen war, wurde die Reaktion durch Zugabe von $500 \mu$ l Stoppuffer beendet. Die Proben wurden anschließend für $1 \mathrm{~min}$ bei 14.000 Upm zentrifugiert und der Überstand in neue Eppendorfgefäße überführt. Die Absorption der Proben wurde mit einem Einstrahlphotometer gegen eine Nullprobe bei 578 nm gemessen.

\subsubsection{Isolierung von Proteinen aus Hefezellen}

Lysispuffer-Stammlösung:

$\begin{aligned} 8 \mathrm{M} & \text { Harnstoff } \\ 5 \%(\mathrm{w} / \mathrm{v}) & \text { SDS } \\ 40 \mathrm{mM} & \text { Tris/HCl } \\ 0,1 \mathrm{mM} & \text { EDTA } \\ 0,4 \mathrm{mg} / \mathrm{ml} & \text { Bromphenolblau } \\ & \text { ad } 100 \mathrm{ml} \text { A.bidest. }\end{aligned}$

Proteaseinhibitoren-Stammlösung:

$$
\begin{aligned}
0,15 \mathrm{mM} & \text { Pepstatin A } \\
0,03 \mathrm{mM} & \text { Leupeptin } \\
145 \mathrm{mM} & \text { Benzamidin } \\
0,06 \mathrm{mM} & \text { Aprotinin }
\end{aligned}
$$

Lysispuffer:
$1 \mathrm{ml} \quad$ Lysispuffer-Stammlösung

$\begin{aligned} 0,9 \%(\mathrm{v} / \mathrm{v}) & \text { ß-Mercaptoethanol } \\ 70 \mu 1 & \text { Proteaseinhibitoren-Stammlösung } \\ 4,4 \mathrm{mM} & \text { PMSF }\end{aligned}$

Einzelkolonien von transformierten S. cerevisiae HF7c-Zellen und nicht-transformierte HF7c-Zellen als Negativkontrolle wurden in $5 \mathrm{ml}$ Selektionsmedium suspendiert und bei $30{ }^{\circ} \mathrm{C}$ über Nacht unter Schütteln inkubiert. $50 \mathrm{ml}$ YPD-Medium wurden mit der Vorkultur unter gleichen Bedingungen bis $\mathrm{zu}$ einer von $\mathrm{OD}_{600}$ von 0,8 inkubiert, anschließend in einen mit Eis gefüllten Zentrifugenbecher transferiert und 5 min bei $4{ }^{\circ} \mathrm{C}$ bei $1.000 \mathrm{x} \mathrm{g}$ zentrifugiert. Nach Dekantieren des Überstandes wurde das Zellpellet in $50 \mathrm{ml}$ eiskaltem A. bidest. resuspendiert und unter gleichen Bedingungen zentrifugiert. Das Zellpellet wurde in flüssigem Stickstoff eingefroren und bei $-80{ }^{\circ} \mathrm{C}$ gelagert. Zur Lyse der Zellen wurde das Pellet in $550 \mu \mathrm{l}$ vorgewärmtem Lysispuffer $\left(60{ }^{\circ} \mathrm{C}\right)$ resuspendiert, die Suspension mit $500 \mu \mathrm{l}$ Glasperlen versetzt und für $10 \mathrm{~min}$ bei $70{ }^{\circ} \mathrm{C}$ inkubiert. Nach 
kräftigem Durchmischen der Suspension für 1 min wurde die Probe bei 14.000 Upm für 5 min bei $4{ }^{\circ} \mathrm{C}$ zentrifugiert und der Überstand in ein Eppendorfgefäß überführt. Verschiedene Aliquots des Überstandes wurden mit 2 x Solubilizer im Verhältnis 1:1 versetzt, 5 min bei $95{ }^{\circ} \mathrm{C}$ erhitzt, durch SDS-PAGE aufgetrennt und die Expression der Gal4-DBD- bzw. AD-Fusionsproteine durch Western-Blot-Analyse getestet.

\subsection{Biochemische Methoden}

\subsubsection{Bestimmung der B-Hexosaminidase-Aktivität}

Substrat: $\quad 10 \mathrm{mM}$ para-Nitrophenyl-2-acetamido-2-deoxy-ß-D-glukopyranosid in

$0,1 \mathrm{M} \quad$ Na-Citrat, $\mathrm{pH} 4,6$

$0,04 \% \quad \mathrm{NaN}_{3}$

$0,2 \% \quad \mathrm{BSA}$

Ansatz: $\quad 20 \mu 1 \quad$ Homogenat

$100 \mu \mathrm{l} \quad$ Substrat

30 min im Wasserbad bei $37^{\circ} \mathrm{C}$

$500 \mu \mathrm{l} \quad$ 0,4 M Glycin/NaOH; pH 10,4

Die Messung der optischen Dichte erfolgte bei $405 \mathrm{~nm}$. Der molare Extinktionskoeffizient beträgt 18500 .

\subsubsection{Proteinbestimmung nach Lowry}

(Lowry et al., 1951)

Reagenz A:

100 Teile $\quad 3 \% \mathrm{Na}_{2} \mathrm{CO}_{3}$ in $0,1 \mathrm{~N} \mathrm{NaOH}$

1 Teil $4 \% \mathrm{Na}^{+} / \mathrm{K}^{+}$-Tartrat in A. bidest.

1 Teil $2 \% \mathrm{CuSO}_{4}$ in $\mathrm{A}$. bidest.

Reagenz B: $\quad 1$ Teil Folin Reagenz

2 Teile A. bidest.

Beide Lösungen wurden erst kurz vor Gebrauch aus den Stammlösungen angesetzt. Verschiedene Verdünnungen der zu messenden Probe in $1 \mathrm{~N} \mathrm{NaOH}$ oder in SDS-, TX100-freiem Puffer wurde mit 0,1 N NaOH auf $100 \mu$ l aufgefüllt, mit $1 \mathrm{ml}$ alkalischer Kupfersulfatlösung versetzt und für 10 Minuten bei RT inkubiert. Nach Zugabe von $100 \mu 1$ 
Folinlösung, kräftigem Mischen und weiterer 10 minütiger Inkubation, wurde die $\mathrm{OD}_{660}$ in einem Einstrahlphotometer bestimmt. Aus den Meßwerten für mitgeführte Standards (5-20 $\mu \mathrm{g}$ Rinderserumalbumin in $0,1 \mathrm{~N} \mathrm{NaOH}$ ) konnte eine Eichgerade erstellt werden, aus der sich der Proteingehalt der unbekannten Probe bestimmen ließ.

\subsubsection{Expression und Affinitätsreinigung von Glutathion-S-Transferase- Fusionsproteinen}

$\begin{array}{lrl}\text { IPTG-Stammlösung: } & 100 \mathrm{mM} & \begin{array}{l}\text { Isopropyl- } \beta-D-t h i o g a l a k t o s i d \\ \text { (sterilfiltriert) }\end{array} \\ \text { Lysispuffer: } & 10 \mathrm{mM} & \text { PBS } \\ & 1 \mathrm{mg} / \mathrm{ml} & \text { Lysoszym } \\ 25 \%(\mathrm{w} / \mathrm{v}) & \text { Saccharose } \\ 1 \% & \text { Triton X-100 } \\ 1 \mathrm{mM} & \text { EDTA } \\ 1 \mathrm{mM} & \text { PMSF }\end{array}$

Glutathion-Agarose-Matrix: $\quad 41 \mathrm{mg}$ Glutathion-Agarose wurden in $10 \mathrm{ml} 10 \mathrm{mM}$ PBS suspendiert und nach einer Quellzeit von 2 Stunden $2 \mathrm{x}$ mit $10 \mathrm{ml} 10 \mathrm{mM}$ PBS gewaschen. Nach Abziehen des Überstandes wurden $500 \mu \mathrm{l}$ PBS hinzugefügt, um $1 \mathrm{ml}$ einer $50 \%$ (v/v) Glutathion-Agarose-Matrix zu erhalten.

$\begin{array}{lrl}\text { Waschpuffer: } & 10 \mathrm{mM} & \text { PBS } \\ 1 \% & \text { Triton X-100 } \\ 1 \mathrm{mM} & \text { PMSF } \\ & & \\ \text { Elutionspuffer: } & 15 \mathrm{mM} & \text { reduziertes Glutathion } \\ & 50 \mathrm{mM} & \text { Tris/HCl pH } 8,0\end{array}$

$100 \mathrm{ml}$ LB-Medium (100 $\mu \mathrm{g} / \mathrm{ml}$ Ampicillin) wurden mit einer Einzelkolonie der transformierten E. coli BL-21-Zellen angeimpft und über Nacht auf dem Reziprokschüttler bei $37{ }^{\circ} \mathrm{C}$ inkubiert. $900 \mathrm{ml}$ LB-Medium $(100 \mu \mathrm{g} / \mathrm{ml}$ Ampicillin) wurden mit der Vorkultur angeimpft und für 60 Minuten bei $37^{\circ} \mathrm{C}$ unter Schütteln inkubiert. Nach Zugabe von 100 $\mu 1$ IPTG-Stammlösung (Endkonzentration: 0,1 mM IPTG) und Inkubation für 4 Stunden bei $37{ }^{\circ} \mathrm{C}$ wurde die Bakteriensuspension in JA 10-Zentrifugenbecher transferiert und für $10 \mathrm{~min}$ bei $5.000 \mathrm{x} \mathrm{g}$ zentrifugiert. Das Bakterienpellet wurde in $40 \mathrm{ml}$ Lysispuffer resuspendiert und für 30 min bei $4{ }^{\circ} \mathrm{C}$ auf dem Magnetrührer gerührt. Die Zellyse wurde durch eine Ultraschallbehandlung für 3 x 10 Sekunden auf Eis komplettiert. Nach Inkubation der Bakteriensuspension mit DNase I $(0,1 \mathrm{mg} / \mathrm{ml})$ für $20 \mathrm{~min}$ bei $4{ }^{\circ} \mathrm{C}$ wurde 
das Lysat bei 10.000 x g in SS 20-Röhrchen für 10 min zentrifugiert. Der lösliche Überstand wurde mit $1 \mathrm{ml} 50 \%$ (v/v) Glutathion-Agarose für $60 \mathrm{~min}$ bei $4{ }^{\circ} \mathrm{C}$ auf dem Drehrad inkubiert und für $10 \mathrm{~min}$ bei 500 x g zentrifugiert. Die GlutathionAgarosekügelchen wurden mit 3 x $20 \mathrm{ml}$ Waschpuffer gewaschen. Durch Inkubation der Agarosekügelchen mit 3 x $500 \mu$ l Elutionsspuffer wurden die GST-Fusionsproteine von der Glutathion-Agarose-Matrix entfernt. Zur Entfernung des Glutathions und zur Umpufferung wurde das Eluat bei $4{ }^{\circ} \mathrm{C}$ über Nacht gegen $50 \mathrm{mM}$ Tris/ $\mathrm{HCl}(\mathrm{pH} 7,5), 150 \mathrm{mM} \mathrm{NaCl}$, 0,1\% TX-100 dialysiert. Die isolierten und eluierten GST-Fusionsproteine wurden bei $-20^{\circ} \mathrm{C}$ gelagert.

\subsubsection{Thrombinspaltung von Glutathion-S-Transferase-Fusionsproteinen in vitro}

Waschpuffer:

$50 \mathrm{mM} \quad$ Tris/HCl pH 7,5

$150 \mathrm{mM} \quad \mathrm{NaCl}$

Thrombinspaltungpuffer:

$\begin{array}{rl}50 \mathrm{mM} & \text { Tris/HCl } \mathrm{pH} 7,5 \\ 150 \mathrm{mM} & \mathrm{NaCl} \\ 2,5 \mathrm{mM} & \mathrm{CaCl}_{2}\end{array}$

Thrombin:

aus Humanplasma

Nach Bindung von GST-Fusionsproteinen $(500 \mu \mathrm{g})$ an $1 \mathrm{ml}(50 \% \mathrm{v} / \mathrm{v})$ Glutathion-Agarose in $10 \mathrm{mM}$ PBS wurde die Matrix mit $20 \mathrm{ml}$ Waschpuffer gewaschen. Nach Zentrifugation für 30 Sekunden bei 500 x g wurde der Überstand abgenommen, die Matrix mit $20 \mathrm{ml}$ Thrombinspaltungspuffer gewaschen und in $1 \mathrm{ml}$ des gleichen Puffers resuspendiert. Nach Zugabe von $1 \%$ (w/w) Thrombin wurde der Ansatz für 1 Stunde bei $25{ }^{\circ} \mathrm{C}$ auf dem Drehrad inkubiert, mit $500 \mu \mathrm{l}$ Waschpuffer versetzt und der Überstand nach Zentrifugation abgenommen. Das gespaltene Fusionsprotein wurde anschließend 5 x mit je $500 \mu 1$ Waschpuffer von der Matrix eluiert. Zur Beurteilung der Effizienz der Spaltung wurde ein Aliquot des Ansatzes über SDS-PAGE aufgetrennt und das Polyacrylamidgel mit Coomassie-Blue angefärbt.

\subsubsection{Gewinnung von Antikörpern}

Zur Gewinnung von Antikörpern wurden affinitätsgereinigte GST-Fusionsproteine aus E. coli BL-21 als Antigene verwendet. Hierbei wurden thrombingespaltene Fusionsproteine 
(Periplakin; ST 249) sowie das gesamte GST-Fusionsprotein (GEF) für die Immunisierung eingesetzt.

\subsubsection{Immunisierung von Kaninchen}

Ca. $100 \mu \mathrm{g}$ des gespaltenen bzw. gesamten GST-Fusionsproteins wurden in $700 \mu \mathrm{PBS}$ aufgenommen und mit 0,3 ml komplettem Freund'schem Adjuvans gemischt. Die Immunisierung erfolgte durch 5 subkutane Injektionen in den Rücken von ca. 4 Monate alten New Zeeland Kaninchen. Jedem Kaninchen wurde vor der 1. Immunisierung ca. 10 ml Präimmunserum abgenommen. Nach 4 Wochen wurden die Tiere erneut mit dem gleichen Antigen in inkompletten Freund'schen Adjuvans immunisiert. 10 Tage nach der 2. Immunisierung wurde das 1. Blut entnommen (ca. $10 \mathrm{ml}$ ) und danach in Abständen von 2-3 Wochen. Das Blut wurde nach der Entnahme für 30 min bei RT und danach über Nacht bei $4{ }^{\circ} \mathrm{C}$ stehengelassen. Nach Zentrifugation für $30 \mathrm{~min}$ bei $4.000 \mathrm{Upm}$ in der Labofuge wurde das klare Serum abgenommen und in Aliquots bei $-20{ }^{\circ} \mathrm{C}$ gelagert. Die Reaktivität des Serums mit dem Antigen wurde durch Western-Blot-Analyse (siehe 3.5.12) bestimmt. Bei absinkender Reaktivität wurde das Kaninchen erneut mit dem Antigen geboostert (ca. 2 x pro Jahr).

\subsubsection{Affinitätsreinigung von Antikörpern}

Startpuffer: $\quad 10 \mathrm{mM} \quad$ Tris/HCl pH 7,4

$0,9 \% \quad \mathrm{NaCl}$

$0,02 \% \quad \mathrm{NaN}_{3}$

Puffer 1: $\quad 2 \mathrm{M} \quad \mathrm{MgCl}_{2}$ in Startpuffer

Puffer 2: $\quad 0,1 \mathrm{M} \quad$ Glycin, $\mathrm{pH} 2,65$

$1 \mathrm{~g}$ Affigel 10 wurden in einer Mobicolsäule mit $3 \mathrm{ml}$ Isopropanol und $3 \mathrm{ml} \mathrm{A}$. bidest. bei 4 ${ }^{\circ} \mathrm{C}$ gewaschen. Das gewaschene Affigel 10 wurde mit $200 \mu 10,5 \mathrm{M}$ HEPES/ pH 7,5 versetzt und mit $1 \mathrm{mg}$ des Proteins (in $1 \mathrm{ml} \mathrm{A}$. bidest.) gemischt. Nach Inkubation der Suspension bei $4{ }^{\circ} \mathrm{C}$ über Nacht wurde der Durchfluß gesammelt und die Kopplung des Proteins durch Messung der $\mathrm{OD}_{280}$ nach schrittweisem Ansäuern auf $\mathrm{pH}<2$ überprüft. Zur Blockierung von reaktiven Gruppen wurde das Gel in $1 \mathrm{ml} 0,1 \mathrm{M}$ HEPES/ pH 7,5 resuspendiert, mit $200 \mu 11 \mathrm{M}$ Ethanolamin versetzt und für 1 Stunde bei $4{ }^{\circ} \mathrm{C}$ auf dem Drehrad inkubiert. Das Gel wurde mit 10 ml 10 mM PBS und anschließend mit Startpuffer 
bis zu einer $\mathrm{OD}_{280}<0,02$ der Waschfraktionen gewaschen. Die Säule wurde mit $4 \mathrm{ml}$ Puffer 1, $5 \mathrm{ml}$ Puffer 2 und $10 \mathrm{ml}$ Startpuffer gewaschen. Anschließend wurden $1 \mathrm{ml}$ des Kaninchen-Periplakin Antiserums auf die Säule aufgetragen und bei $4{ }^{\circ} \mathrm{C}$ über Nacht auf dem Drehrad inkubiert. Nach Sammeln der Fraktion wurde die Säule mit Startpuffer bis zu einer $\mathrm{OD}_{280}$ der Fraktionen $<0,02$ gewaschen. Die unspezifisch gebundenen Antikörper wurden 4 x mit $1 \mathrm{ml}$ Puffer 1 eluiert. Nach Waschen der Säule mit $2 \mathrm{ml}$ Startpuffer erfolgte eine Elution der spezifisch gebundenen AK 5 x mit 1 ml Puffer 2. Die Fraktionen wurden sofort mit $2 \mathrm{M}$ Tris-Base neutralisiert. Die $\mathrm{OD}_{280}$ der einzelnen Fraktionen wurde gegen den Startpuffer gemessen und Fraktionen mit hoher $\mathrm{OD}_{280}$ im Western-Blot (siehe 3.5.12) analysiert.

\subsubsection{Subzelluläre Fraktionierung durch Percoll $^{\circledR}$-Dichtegradientenzentrifugation}

Puffer A:

$20 \%$ Percoll $^{\circledR}$-Lösung:
0,25 M Saccharose in $3 \mathrm{mM}$ Imidazol, $\mathrm{pH} 7,4$

$\begin{array}{rl}9,2 \mathrm{ml} & \text { Percoll }^{\circledR} \\ 10 \mathrm{ml} & 1,25 \mathrm{M} \text { Saccharose } \\ 0,5 \mathrm{ml} & 300 \mathrm{mM} \text { Imidazol, pH 7,4 } \\ \text { ad } 50 \mathrm{ml} & \text { A.dest. } \\ & \text { Mittlere Dichte : } 1,347 \mathrm{~g} / 1 \\ & \text { Kontrolle mit Refraktometer }\end{array}$

Ernten und Aufschließen der Zellen:

Zellen wurden am Vortag auf $100 \mathrm{~mm}$ Gewebekulturschalen ausgesät. Die konfluenten Schalen wurden auf Eis 5 x mit 3 ml Hanks pH 7,4 und einmal mit Puffer A gewaschen. Nach Abschaben der Zellen in $5 \mathrm{ml}$ Puffer A wurden die Zellen durch Zentrifugation (5 min, $500 \mathrm{x}$ g) pelletiert und anschließend in $1 \mathrm{ml}$ Puffer A aufgenommen und durch 30 Hübe im Dounce-Homogenisator (Wheaton, $1 \mathrm{ml}$ ) aufgeschlossen. Ein Aliquot (40 $\mu 1)$ des Homogenats wurde abgenommen, der Rest für 10 min bei 1.000 x g zentrifugiert. Der postnukleäre Überstand (PNS) wurde vorsichtig abgenommen und ein $40 \mu \mathrm{l}$ Aliquot abgeteilt. Die Kernfraktion wurde in $1 \mathrm{ml}$ Puffer A resuspendiert. Die Bestimmung der ß-Hexosaminidaseaktivität in Ausgangshomogenat, PNS und der Kernfraktion gibt Auskunft über die Effizienz des Zellaufschlusses. Nach dem hier beschriebenen Protokoll sind in Abhängigkeit vom verwendeten Zelltyp 65-70 \% der Gesamtaktivität der ß-Hexosaminidase im PNS. 


\section{Subzelluläre Fraktionierung:}

In einem Quickseal-Röhrchen wurden $11 \mathrm{ml} 20 \%$ Percoll $^{\circledR}$-Lösung vorgelegt und mit PNS überschichtet. Die Quickseal-Röhrchen wurden austariert, zugeschweißt und für 30 min bei 35.000 x g (20.000 Upm) bei $4{ }^{\circ} \mathrm{C}$ im Vertikalrotor VTi 65.1. zentrifugiert. Der Gradient wurde dann von unten in $12 \times 1 \mathrm{ml}$ Portionen fraktioniert und Aliquots $(50 \mu \mathrm{l})$ für die Bestimmung der ß-Hexosaminidaseaktivität und des Refraktionsindex abgenommen. Jeweils 3 Fraktionen wurden vereinigt (1-3 = I; 4-6 = II; 7-9 = III).

Zur Entfernung von Percoll ${ }^{\circledR}$ werden die vereinigten Fraktionen I, II und III in 3,5 ml Polycarbon-Röhrchen im Rotor TLA 100.3. in der Tisch-Ultrazentrifuge für 90 min bei 100.000 x g (45.000 Upm) und $4{ }^{\circ} \mathrm{C}$ zentrifugiert. Die Membranen, die als eine Schicht über dem Percoll ${ }^{\circledR} \mathrm{zu}$ sehen sind, wurden vorsichtig im minimalen Volumen mit einer ausgezogenen Pasteurpipette abgenommen (ca. 300-400 $\mu \mathrm{l}$ ), das Volumen durch Wiegen bestimmt und aneinander angeglichen. Die Proben wurden beschallt und für Enzymaktivitätsmessungen (ß-Hexosaminidase) und Western-Blots eingesetzt.

\subsubsection{Subzelluläre Fraktionierung durch Saccharose-Dichtegradienten- zentrifugation}

$\begin{array}{lrl}\text { Puffer C: } & 0,3 \mathrm{M} & \text { Saccharose } \\ 10 \mathrm{mM} & \text { Tris-HCl, pH 7,4 } \\ 1 \mathrm{mM} & \text { EGTA }\end{array}$

Nach Waschung der Zellen mit eiskalter Hanks-Lösung wurden die Zellen in $8 \mathrm{ml}$ Puffer C abgeschabt, 5 min durch Zentrifugation (500 x g) sedimentiert und in $1 \mathrm{ml}$ Puffer C mit 45 Stempelhüben (Stempel B; Wheaton-Dounce) homogenisiert. Die Gewinnung des PNS und die Bestimmung der Effizienz des Aufschlusses erfolgte wie unter 3.5.6. beschrieben. Der PNS wurde dann vorsichtig auf einen kontinuierlichen Saccharose-Gradienten aufgetragen, der über ein 0,6 $\mathrm{ml}$ 2,0 M Saccharosekissen mit Hilfe eines kombinierten GradientGenerators/Fraktionators (Bender-Hohbein-Gradi-Mix) errichtet wurde. Nach einer 3 stündigen Zentrifugation im SW 40 Ti-Rotor bei 35.000 Upm wurde der Gradient von oben automatisch in 15 Fraktionen zu $750 \mu$ fraktioniert. Das Zentrifugenröhrchen und eventuell pelletierte Partikel wurden mit $250 \mu 10 \mathrm{mM}$ Tris, $\mathrm{pH}$ 7,4 ausgespült und als Fraktion 16 weiter untersucht (ß-Hexosaminidaseaktivität, Refraktionsindex, WesternBlot). 


\subsubsection{Metabolische Markierung mit $\left[{ }^{35} \mathrm{~S}\right]-$ Methionin}

(Lemansky et al., 1985)

Hungermedium:

Methionin-freies MEM

Markierungsmedium:

Methionin-freies MEM

$4 \%(\mathrm{v} / \mathrm{v}) \quad$ dialysiertes FKS (hitze-inaktiviert)

30-100 $\mu \mathrm{Ci} \quad\left[{ }^{35} \mathrm{~S}\right]-$ Methionin

Chase-Medium:

$\begin{aligned} & \text { MEM } \\ 0,1 \% & \text { BSA } \\ 0,25 \mathrm{mg} / \mathrm{ml} & \text { Methionin }\end{aligned}$

Zur metabolischen Markierung wurden die Zellen typabhängig 1-3 Tage vor dem Experiment in der benötigten Dichte ausgesät. Die Zellen wurden mit 3 x 2 ml PBS gewaschen und anschließend für eine Stunde mit Hungermedium inkubiert, bevor das Medium gegen 600-1000 $\mu 1$ Markierungsmedium ausgetauscht wurde. Die Zellen wurden bei $37{ }^{\circ} \mathrm{C}$ und $5 \% \mathrm{CO}_{2}$ für 1 (Cathepsin D) oder 16 (MPR300) Stunden inkubiert. Zur Bestimmung der Sortierung und Prozessierung von Cathepsin D wurde das Markierungsmedium abgenommen, die Zellen 1 x gewaschen und nach Zugabe von 0,7 ml Chase-Medium für weitere 6-8 $\mathrm{h}$ inkubiert. Nach Markierung wurde das Medium in Reaktionsgefäße abgenommen, 5 min bei 1.000 x g zentrifugiert und der Überstand in ein neues Reaktionsgefäß überführt. Die Zellen wurden mit 3 x $2 \mathrm{ml}$ PBS gewaschen und anschließend mit $1260 \mu$ l Cathepsin D-Lysispuffer mit einem Gummispatel abgeschabt. Die Zellextrakte und Medien wurden zur Immunpräzipitation eingesetzt.

\subsubsection{Immmunpräzipitation von Cathepsin D}

\section{Lösungen:}

Cathepsin D-Lysispuffer 1,25 Teile Puffer A:

$\begin{array}{rl}50 \mathrm{mM} & \text { Tris/HCl, } \mathrm{pH} \mathrm{7,0} \\ 150 \mathrm{mM} & \mathrm{NaCl}\end{array}$

1 Teil Puffer B:

$\begin{aligned} 0,2 \% & \text { SDS } \\ 10 \% & \text { BSA in PBS }\end{aligned}$

Protease-Inhibitoren:

$\begin{array}{ll}1 \mathrm{mM} & \text { EDTA in A. dest. } \\ 1 \mathrm{mM} & \text { PMSF in DMSO } \\ 2 \mathrm{mM} & \text { JAA in A. dest. }\end{array}$


Immunomix (IMM):

$1 \%$ Triton X-100

$0,5 \%$ Na-Desoxycholat in PBS

Neufeld-Puffer:

$10 \mathrm{mM}$

Tris/HCl, $\mathrm{pH} 8,5$

$0,6 \mathrm{M}$

$\mathrm{NaCl}$

$0,1 \%$

SDS

$0,05 \%$

NP-40

IMM/ 2 M KCl:

$1 \% \quad$ Triton $\mathrm{X}-100$

$0,5 \%$

Na-Desoxycholat in PBS

$2 \mathrm{M}$

$\mathrm{KCl}$

0,1 fach PBS:

$15 \mathrm{mM}$

$\mathrm{NaCl}$

$12 \mathrm{mM}$

$\mathrm{KCl}$

$0,1 \mathrm{mM}$

$\mathrm{Na}_{2} \mathrm{HPO}_{4} / \mathrm{NaH}_{2} \mathrm{PO}_{4}, \mathrm{pH} 7,4$

Pansorbin:

Pansorbin, gewaschen:

\section{Staphylococcus aureus-Suspension}

Staphylococcus aureus-Suspension; gewaschen nach dem Protokoll von Lemansky et al. 1985.

Das Markierungs- bzw. Chasemedium $(700 \mu 1)$ wurde mit $560 \mu 1$ Puffer B vermischt. Die Zellen wurden $2 \times$ mit $2 \mathrm{ml}$ PBS gewaschen und in $1260 \mu$ l Cathepsin-D-Lysispuffer abgeschabt. Zellen und Medien wurden für $10 \mathrm{~min}$ auf Eis inkubiert und $10 \mathrm{~min}$ zentrifugiert (EZ, 14.000 Upm). $1 \mu 1$ des Zellüberstandes und $10 \mu 1$ des Medienüberstandes wurden einer TCA-Fällung unterzogen. Die Überstände wurden mit $1 \mu 1$ Präimmunserum und $40 \mu \mathrm{l}$ Pansorbin versetzt und eine Stunde auf dem Drehrad bei $4{ }^{\circ} \mathrm{C}$ inkubiert. Nach einer zweiminütigen Zentrifugation bei $14.000 \mathrm{Upm}$ in einer Eppendorfzentrifuge wurden die Überstände in ein neues Gefäß überführt und für 30 min bei 45.000 Upm im TL100.3Rotor zentrifugiert, um Reste an Pansorbin zu entfernen. Aliquots der Überstände (250 $\mu 1$; ca. $20 \%$ von Total) wurden mit $2 \mu$ l Anti-Cathepsin D-Antiserum vermischt und bei $4{ }^{\circ} \mathrm{C}$ über Nacht auf dem Drehrad inkubiert. Nach Zugabe von $40 \mu 1$ gewaschenem Pansorbin und einer weiteren Stunde Inkubation auf dem Drehrad wurden die Immunpräzipitate durch eine zweiminütige Zentrifugation mit 14.000 Upm in der Eppendorfzentrifuge von den Überständen getrennt. Jedes Pansorbin-Pellet wurde mit jeweils 0,8 ml Neufeld-Puffer, IMM, IMM/KCl und $2 \times 1 \mathrm{mM}$ PBS gewaschen, anschließend in $50 \mu \mathrm{l}$ A. dest. und $50 \mu \mathrm{l} 2$ x Solubilizer resuspendiert, $5 \mathrm{~min}$ bei $95^{\circ} \mathrm{C}$ gekocht und $2 \mathrm{~min}$ bei $14.000 \mathrm{Upm}$ in der Eppendorfzentrifuge pelletiert. Der Überstand wurde durch SDS-PAGE (10\% Acrylamid) aufgetrennt. 


\subsubsection{Diskontinuierliche SDS-Polyacrylamid-Gelelektrophorese (SDS-PAGE)}

(Laemmli, 1970)

\begin{tabular}{|c|c|c|c|}
\hline Lösungen: & Trenngelpuffer: & $\begin{array}{l}1,5 \mathrm{M} \\
0,4 \%\end{array}$ & $\begin{array}{l}\text { Tris/HCl, pH 8,8 } \\
\text { SDS (w/v) }\end{array}$ \\
\hline & Sammelgelpuffer: & $\begin{array}{l}0,5 \mathrm{M} \\
0,4 \%\end{array}$ & $\begin{array}{l}\text { Tris/HCl, pH 6,8 } \\
\text { SDS (w/v) }\end{array}$ \\
\hline & Acrylamidlösung: & $\begin{array}{r}30 \% \\
0,8 \%\end{array}$ & $\begin{array}{l}\text { Acrylamid (w/v) } \\
\text { Bisacrylamid (w/v) } \\
\text { in A. dest. }\end{array}$ \\
\hline & APS: & $10 \%$ & $\begin{array}{l}\text { Ammoniumperoxodisulfat } \\
\text { in A. dest. }(\mathrm{w} / \mathrm{v})\end{array}$ \\
\hline & Anodenpuffer: & $\begin{array}{r}50 \mathrm{mM} \\
192 \mathrm{mM}\end{array}$ & $\begin{array}{l}\text { Tris/HCl } \\
\text { Glycin } \\
\text { in A. dest., pH 6,8 }\end{array}$ \\
\hline & Kathodenpuffer: & $\begin{array}{r}1 \% \\
0,001 \%\end{array}$ & $\begin{array}{l}\text { SDS (w/v) } \\
\text { Bromphenolblau in } \\
\text { Anodenpuffer }\end{array}$ \\
\hline & $\begin{array}{l}2 \text { x Probenpuffer: } \\
\text { (nicht reduzierend) }\end{array}$ & $\begin{array}{r}250 \mathrm{mM} \\
2 \% \\
20 \%\end{array}$ & $\begin{array}{l}\text { Tris/HCl, pH 6,8 } \\
\text { SDS (w/v) } \\
\text { Glyzerin }\end{array}$ \\
\hline & $\begin{array}{l}2 \text { x Probenpuffer: } \\
\text { (reduzierend) }\end{array}$ & $\begin{array}{r}250 \mathrm{mM} \\
2 \% \\
20 \% \\
20 \mathrm{mM}\end{array}$ & $\begin{array}{l}\text { Tris/HCl, pH 6,8 } \\
\text { SDS (w/v) } \\
\text { Glyzerin } \\
\text { DTT }\end{array}$ \\
\hline
\end{tabular}

Ansatz:

\begin{tabular}{|l|c|c|}
\hline & Trenngel 5\% oder $10 \%$ & Sammelgel 4 \% \\
\hline Acrylamidlösung $(\mathrm{ml})$ & 5,25 oder 10,5 & 1,3 \\
\hline Trenngelpuffer $(\mathrm{ml})$ & 7,5 & - \\
\hline Sammelgelpuffer $(\mathrm{ml})$ & - & 2,5 \\
\hline $10 \%$ APS $(\mu \mathrm{l})$ & 250 & 100 \\
\hline TEMED $(\mu \mathrm{l})$ & 25 & 10 \\
\hline A. dest. & ad $30 \mathrm{ml}$ & $\mathrm{ad} 10 \mathrm{ml}$ \\
\hline
\end{tabular}

Die Elektrophorese wurde in einem System mit vertikal ausgezielten Platten durchgeführt (Größe der Glasplatten: 160 mm x 18 cm, $1 \mathrm{~mm}$ Spacer). Das frisch gemischte Trenngel wurde zwischen zwei Glasplatten gegossen und sofort mit wassergesättigtem Butanol überschichtet. Nach 30 min Polymerisation bei RT wurde das Butanol abgegossen, die Trenngeloberfläche mit Wasser gespült, das Sammelgel eingegossen und der Probenkamm 
eingefügt. Nach 20 min Polymerisation wurde der Probenkamm entfernt, die Probentaschen mit Wasser gespült und Gelreste aus den Taschen entfernt. Die Proben wurden 1:1 mit Probenpuffer gemischt, $5 \mathrm{~min}$ bei $95{ }^{\circ} \mathrm{C}$ denaturiert, aufgetragen und mit Kathodenpuffer überschichtet. Die Elektrophorese erfolgte mit $50 \mathrm{~mA}$ bei $4{ }^{\circ} \mathrm{C}$ für 2-3 Stunden.

\subsubsection{Anfärbung von Polyacrylamidgelen mit Coomassie Blue}

Fixierungslösung:

$\begin{array}{ll}50 \% & \text { Methanol } \\ 40 \% & \mathrm{H}_{2} \mathrm{O} \\ 10 \% & \text { Essigsäure }\end{array}$

Coomassie Blue-Färbelösung: $\quad 0,05 \% \quad$ Serva Blue R in Fixierungslösung

Nach Auftrennung der Proteine über SDS-PAGE wurde das Polyacrylamidgel für 2 Stunden bei RT in Fixierungslösung inkubiert. Es erfolgte eine 60 minütige Inkubation in der Coomassie Blue-Färbelösung, nach der das Polyacrylamidgel ü. N. in Fixierungslösung entfärbte. Anschließend wurde das Gel für 20 min gewässert und getrocknet.

\subsubsection{Western-Blot-Analyse}

Zum Nachweis der Expression des transfizierten Plasmids wurden $35 \mathrm{~mm}$ Gewebekulturschalen von konfluent gewachsenen Klonen 2 x mit $1 \mathrm{ml}$ eiskalter Hanks-Lösung gewaschen. Die Zellen wurden in $1 \mathrm{ml}$ Hanks-Puffer abgeschabt und die Zellsuspension für 5 min bei 3.000 Upm zentrifugiert. Nach Absaugen des Überstandes wurden die Zellpellets in $75 \mu \mathrm{ldd} \mathrm{H}_{2} \mathrm{O}$ aufgenommen und $3 \mathrm{x}$ für $10 \mathrm{sec}$ beschallt. Nach Zugabe von $75 \mu \mathrm{l} 2 \mathrm{x}$ Solubilizer wurden die Zellen für $5 \mathrm{~min}$ bei $95{ }^{\circ} \mathrm{C}$ erhitzt, $5 \mathrm{~min}$ zentrifugiert und der Überstand zur Elektrophorese eingesetzt.

Naßblot:

Transferpuffer:

$\begin{aligned} 25 \mathrm{mM} & \text { Tris } \\ 192 \mathrm{mM} & \text { Glycin } \\ 20 \% & \text { Methanol }\end{aligned}$

A. dest. ad $5.000 \mathrm{ml}$

Nitrozellulose (Bioblot, Costar, 0,45 $\mu \mathrm{m}$ ) und 4 Filterpapierstücke wurden entsprechend der Gelgröße zugeschnitten und zusammen mit dem Gel 15 min in Transferpuffer getränkt. Der Blot wurde dann im Pufferbad luftblasenfrei wie folgt zusammengelegt: 
Kathodenseite

$$
\begin{aligned}
& \text { durchlöcherte Plastikplatte } \\
& 1 \text { x Schaumstoff } \\
& 2 \text { x Filterpapier } \\
& \text { Gel } \\
& \text { Nitrozellulosemembran } \\
& 2 \text { x Filterpapier } \\
& 1 \text { x Schaumstoff } \\
& \text { durchlöcherte Plastikplatte }
\end{aligned}
$$

Anodenseite

Der Transfer erfolgte in Abhängigkeit vom Molekulargewicht des zu transferierenden Proteins für 1-4 Stunden bei $900 \mathrm{~mA}$.

\section{Immunodetektion von Periplakin:}

PBS-T:

$$
\begin{aligned}
10 \mathrm{mM} & \text { PBS } \\
0,1 \% & \text { Tween } 20
\end{aligned}
$$

Blotto:

$$
\text { PBS-T mit } 5 \% \text { (w/v) Milchpulver }
$$

1. Antikörper: $\quad \alpha$-Human-Periplakin aus Kaninchen (1: 1.500 in Blotto)

2. Antikörper: $\quad \alpha$-Kaninchen-IgG-Antiserum, HR-Peroxidase-gekoppelt aus Ziege (1: 5.000 in PBS-T)

Immunodetektion des MPR300:

1. Antikörper: $\quad \alpha$-hMPR300 aus Ziege $(1: 1.500$ in Blotto $)$

2. Antikörper: $\quad \alpha$-Ziege-IgG-Antiserum, HR-Peroxidase-gekoppelt aus Kaninchen $(1: 5000$ in PBS-T)

Die Nitrozellulosemembran wurde wie folgt behandelt:

Blocken: $\quad$ über Nacht bei $4{ }^{\circ} \mathrm{C}$ in Blotto auf einer Wippe

1. Antikörper: $\quad 2$ Stunden bei RT auf einer Wippe

Waschen (RT): $\quad 1 \times 10$ min PBS

$3 \times 10$ min PBS-T

$1 \times 10$ min PBS

2. Antikörper: $1: 5.000$ in PBS-T 
$\begin{array}{ll}\text { Waschen }(\mathrm{RT}): \quad & 1 \times 10 \mathrm{~min} \text { PBS } \\ & 3 \times 10 \mathrm{~min} \text { PBS-T } \\ & 1 \times 10 \mathrm{~min} \text { PBS }\end{array}$

ECL: $\quad 1 \quad \min$

Exposition: $\quad 1-15 \min$

\subsubsection{In vitro-Translation}

Zur in vitro-Translation wurde das gekoppelte $\mathrm{TNT}^{\circledR}$ Kaninchen-Retikulozyten-LysatSystem des Herstellers Promega verwendet. Es erlaubt eine effiziente Transkription und Translation in einem Ansatz. Als DNA-Template wurde eine nach der Quiagen-Midi-PräpMethode gereinigte Plasmid-DNA verwendet, welche nach der Isopropanol-Fällung erneut mit Ammoniumacetat zur Entfernung von bei der in vitro-Transkription/Translation störenden $\mathrm{Na}^{+}$-Ionen gefällt wurde.

Ansatz:

$\begin{aligned} 25 \mu \mathrm{l} & \text { TNT }^{\circledR} \text {-Kaninchen-Retikulozyten-Lysat } \\ 2 \mu \mathrm{l} & \mathrm{TNT}^{\circledR} \text {-Reaktionspuffer } \\ 1 \mu \mathrm{l} & \mathrm{TNT}^{\circledR} \text {-SP6-Polymerase } \\ 1 \mu \mathrm{l} & \left.\text { RNasin }^{\circledR} \text { (Ribonukleaseinhibitor, 40 U/ } \mu \mathrm{l}\right) \\ 1 \mu \mathrm{l} & \text { Aminosäuremix ohne Methionin }(1 \mathrm{mM}) \\ 4 \mu \mathrm{l} & \left.{ }^{35} \mathrm{~S}\right]- \text { Methionin }(10 \mu \mathrm{Ci} / \mu \mathrm{l}) \\ 1 \mu \mathrm{g} & \text { Plasmid-DNA } \\ \text { ad } 50 \mu \mathrm{l} & \text { A. bidest. }\end{aligned}$

Nach Durchmischen wurde der Ansatz für 120 min bei $30{ }^{\circ} \mathrm{C}$ inkubiert und anschließend zur Entfernung von unlöslichen Proteinen für 30 Minuten bei 100.000 x g zentrifugiert.

\subsubsection{In vitro-Bindungsassay}

Bindungspuffer:

$\begin{array}{rl}50 \mathrm{mM} & \text { HEPES, } \mathrm{pH} 7,5 \\ 150 \mathrm{mM} & \mathrm{KCl} \\ 10 \mathrm{mM} & \mathrm{MgCl}_{2} \\ 10 \%(\mathrm{v} / \mathrm{v}) & \text { Glyzerin } \\ 1 \%(\mathrm{v} / \mathrm{v}) & \text { Triton X-100 } \\ 0,1 \%(\mathrm{w} / \mathrm{v}) & \text { BSA } \\ 1 \mathrm{x} & \text { Inhibitoren-Cocktail }\end{array}$

10-50 $\mu \mathrm{g}$ des jeweiligen GST-Fusionsproteins wurden in $500 \mu$ l Bindungspuffer mit $5 \mu 1$ des $\left[{ }^{35} \mathrm{~S}\right]-$ Methionin-markierten, in vitro-translatierten Proteins gemischt und auf dem 
Drehrad bei $4{ }^{\circ} \mathrm{C}$ für 2 Stunden inkubiert. Nach Zugabe von $50 \mu \mathrm{l}$ (v/v) GlutathionAgarose in Bindungspuffer wurden die Proben erneut für 1 Stunde bei $4{ }^{\circ} \mathrm{C}$ auf dem Drehrad inkubiert. Nach Zentrifugation für $30 \mathrm{sec}$ bei $1.000 \mathrm{x}$ g wurden die Überstände abgenommen, und die Glutathion-Agarose-Kugeln 3 x mit $500 \mu$ l Bindungspuffer ohne BSA gewaschen. Nach dem letzten Waschschritt wurden Pufferreste mit einer ausgezogenen Pasteur-Pipette entfernt, die Glutathion-Agarose-Kugeln mit $120 \mu 11 \mathrm{x}$ Solubilizer versetzt und für $5 \mathrm{~min}$ bei $95{ }^{\circ} \mathrm{C}$ gekocht. Die gebundenen $\left[{ }^{35} \mathrm{~S}\right]$-Methioninmarkierten, in vitro-translatierten Proteine wurden über ein SDS-PAGE-Gel aufgetrennt und über Phosphoimaging analysiert und quantifiziert. 


\section{Ergebnisse}

\subsection{Das Hefe-Two-Hybrid-System}

Das Two-Hybrid-System ist ein genetischer Assay zur Untersuchung von Protein-ProteinInteraktionen in vivo in einem Hefesystem (Fields \& Song, 1989; Chien et al., 1991; Guarante, 1993). Das System kann zur Charakterisierung von bekannten Protein-ProteinInteraktionen und zur Identifizierung von neuen Proteinen, die mit einem Köderprotein (Bait) interagieren, angewendet werden. Der Vorteil des Systems gegenüber biochemischen Methoden zum Nachweis von Protein-Protein-Interaktionen besteht in der Empfindlichkeit der Methode und der sofortigen Verfügbarkeit der cDNA-Sequenz des interagierenden Proteins. Das Hefe-Two-Hybrid-System basiert auf der modularen Struktur des Hefe Gal4-Transkriptionsfaktors, der aus einer N-terminalen DNA-Bindungs-(DBD) und einer C-terminalen Transaktivierungsdomäne (AD) zusammengesetzt ist (Keegan et al., 1986). Hierbei bindet die DNA-Bindungsdomäne an eine „Upstream“-Aktivatorsequenz der DNA, während die Transaktivierungsdomäne die Transkription der Zielgene Gall und Gal10 aktiviert. Beide Domänen allein sind transkriptionell inaktiv, jedoch reicht die nichtkovalente Bindung der beiden isolierten Domänen aus, einen funktionsfähigen Transkriptionsfaktor zu rekonstituieren (Abb. 1).

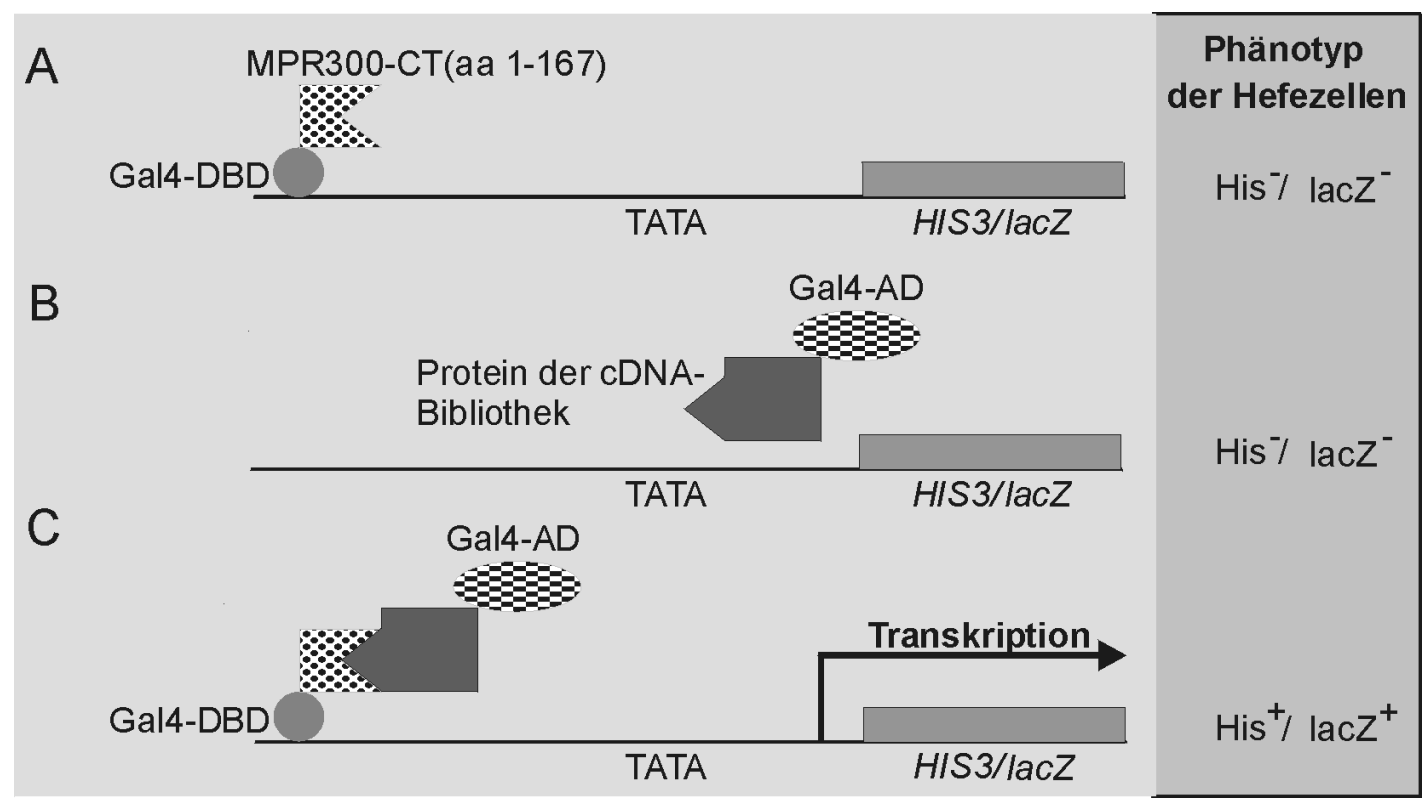

Abb. 1: Schematische Darstellung der Funktionsweise des Two-Hybrid-Systems. In einem Two-HybridScreen wird das Köderprotein, das aus der N-terminal lokalisierten Gal4-DBD und der zytoplasmatischen Domäne des MPR300 (MPR300-CT) zusammengesetzt ist, mit der Gesamtheit der exprimierten Proteine einer cDNA-Bibliothek, die an den C-Terminus der Gal4-AD-Domäne fusioniert sind, in einem Hefewirtsstamm koexprimiert. Nach Translation im Zytosol werden das Köderprotein und die 
AD-Fusionsproteine durch Kernlokalisierungssignale in den Kern der Hefezelle dirigiert. Die Reportergene HIS3 und lacZ wurden in Verbindung mit Gall-Promotoren in die chromosomale DNA des Hefestammes HF7c inseriert. Das Köderprotein allein bindet über die DBD-Domäne an den Gall-Promotor, was jedoch nicht zur Transaktivierung der Reportergene führt (A). Ebenso sind die AD-Fusionsproteine der cDNA-Bibliothek allein nicht in der Lage, die Reportergene zu aktivieren (B). In beiden Fällen wachsen die Hefezellen nicht auf Histidin-Mangelmedium (His") und zeigen keine $\beta$-Galaktosidase-Aktivität (lacZ). Wenn die zytoplasmatische Domäne des MPR300 mit einem Protein der cDNA-Bibliothek interagiert, werden die einzeln nicht-funktionellen DBD- und AD-Domänen verbunden, so daß ein funktioneller Gal4-Transkriptionsfaktor rekonstituiert wird (C). Nach Bindung des Transkriptionsfaktors an die „Upstream“-Aktivatorsequenz des Gall-Promotors werden die HIS3- und lacZ-Reportergene aktiviert, so daß ein His ${ }^{+}$- (Wachstum auf Histidin-Mangelmedium) und lac $^{+}$- (Blaufärbung mit X-Gal Substrat) Phänotyp der Hefezelle resultiert. Die Aktivierung der Reportergene ist ein Nachweis einer möglichen Protein-ProteinWechselwirkung, die jedoch durch unabhängige biochemische und zellbiologische Methoden verifiziert werden muß.

Bei dem Two-Hybrid-System werden Hefewirtsstämme verwendet, bei denen die endogenen Gal4- und Gal 80-Gene durch Deletionen inaktiviert sind. Durch Deletion der TRP1-, LEU2- und HIS3-Gene resultiert ein Trp-, Leu-, His- auxotropher Phänotyp, der durch Selektionsmarker, die sich auf den Vektoren befinden, komplementiert werden kann. Die meisten Wirtsstämme enthalten das Hefe HIS3- und das E. coli lacZ-Reportergen, deren Transkription unter der Kontrolle des Gal1-Promotors steht.

\subsubsection{Screenen einer HeLa-cDNA-Bibliothek}

Zur Identifizierung von Proteinen, die mit der zytoplasmatischen Domäne des humanen MPR300 (MPR300-CT) interagieren, wurde diese Domäne als Köderprotein für das Screenen einer HeLa-cDNA-Bibliothek im Hefe-Two-Hybrid-System benutzt. Hierzu wurde ein 510 bp cDNA-Fragment, das für die 167 Aminosäuren umfassende zytoplasmatische Domäne des MPR300 kodiert, über eine eingefügte BamHI-Schnittstelle und eine interne PstI-Schnittstelle in der 3'-nichtkodierenden Sequenz des MPR300 in den Hefe-Expressionsvektor pAS2 subkloniert. Die Transformation dieses Konstruktes in den HF7c-Hefestamm induziert unter der Kontrolle des kompletten ADH1-Promotors die Expression eines Fusionsproteins, das aus der N-terminal lokalisierten DNA-Bindungsdomäne des Hefe Gal4-Transkriptionsfaktors (Gal4-DBD; aa 1-147) und dem C-terminal lokalisierten MPR300-CT zusammengesetzt ist. Zur Analyse der Expression des Fusionsproteins im Western-Blot befindet sich zwischen der Gal4-DBD und dem MPR300-CT eine cDNA-Sequenz, die für das Hämagglutinin-Epitop kodiert. Aufgrund des Fehlens einer N-terminalen Signalsequenz erfolgt die Proteinsynthese des Fusionsproteins im Zytosol an freien Ribosomen. Durch ein internes 
Kernlokalisierungssignal der Gal4-DBD des Transkriptionsfaktors werden die Fusionsproteine nach der Translation in den Kern der Hefezelle dirigiert.

Für das Hefe-Two-Hybrid-Screening wurden der DBD-Vektor pAS2-MPR300-CT und die Gesamtheit der AD-Vektoren einer HeLa-cDNA-Bibliothek sequentiell transformiert, da die Transformationseffizienzen im Vergleich zur Kotransformation um den Faktor 10-100 höher sind (Gietz et al., 1992). Im ersten Schritt wurde der Hefewirtsstamm HF7c mit dem Konstrukt pAS2-MPR300-CT transformiert und positive Klone auf Tryptophandefizientem Agarmedium selektioniert. Der Hefewirtsstamm HF7c besitzt eine Trp- und Leu-Auxotrophie, die durch das TRP1-Gen eines DBD-Vektors bzw. das LEU2-Gen eines AD-Vektors komplementiert werden kann (Feilotter et al., 1994). Zum Ausschluß einer autonomen Aktivierung des HIS3-Reportergens des Hefewirtsstammes HF7c durch den MPR300-CT wurde ein Aliqot des Ansatzes auf Tryptophan/Histidin-defizienten Agarplatten ausplattiert und die Agarplatten für 5 Tage bei $30{ }^{\circ} \mathrm{C}$ inkubiert. Hierbei wuchsen keine His-positiven $\left(\mathrm{His}^{+}\right.$) Kolonien, so daß eine Transaktivierung des HIS3Reportergens durch den MPR300-CT ausgeschlossen werden kann.

Für das Screening wurde eine HeLa-S3-cDNA-Bibliothek der Firma Clontech verwendet, deren cDNA-Gesamtheit nach Erststrangsynthese mit XhoI-Oligo-dT-Primern, Zweitstrangsynthese, Selektion von cDNA-Sequenzen > 400 Basenpaaren und Ligation von EcoRI-Adaptoren in den AD-Vektor pGAD-GH kloniert wurde (Gubler \& Hoffman, 1983). Der AD-Vektor induziert in einem geeigneten Hefewirtsstamm die Expression eines Fusionsproteins, das aus der N-terminal lokalisierten Gal4-Transaktivierungsdomäne (GAL4-AD; aa 768-881) und den C-terminal gelegenen Proteinen der cDNA-Bibliothek zusammengesetzt ist. Ein N-terminal eingefügtes Kernlokalisierungssignal des großen T-Antigens des SV40-Virus dirigiert die Fusionsproteine in den Kern der Hefezelle.

Zur Amplifikation der HeLa-cDNA-Bibliothek wurde zuerst der Titer der HeLa-cDNABibliothek mit 6,2 x $10^{8}$ Kolonien/ml bestimmt. In zahlreichen Vorversuchen zur Transformation der HeLa-cDNA-Bibliothek wurden die höchsten Transformationsraten bei einer $\mathrm{OD}_{600}$ der Hefesuspension von 0,8 bestimmt, was einer Zellzahl von 2,4 x 10 $/ \mathrm{ml}$ entspricht.

Die Vorversuche zeigten außerdem, daß die Aufteilung in Aliquots zu je $10 \mu \mathrm{g}$ pro Ansatz bei größeren Plasmid-DNA-Mengen und eine Inkubation der transformierten Hefezellen in YPD-Medium nach dem Hitzeschock höhere Transformationsraten ergibt. Da der HIS3-Promotor im Hefewirtsstamm HF7c eine niedrige Expression der His3p-Proteins in 
Abwesenheit einer Protein-Protein-Interaktion zwischen den Fusionsproteinen induziert, wurde dem Medium der Inhibitor 3-Amino-1,2,4-triazol (3-AT) zugesetzt. Unter diesen Bedingungen ergab sich aus der Bestimmung des Mittelwertes typischerweise eine Transformationsrate von 4,8 x $10^{4}$ Transformanden/ $\mu$ g eingesetzter AD-Plasmid-DNA. Kolonien, die zwischen dem 5. und 10. Tag nach Transformation auf His/Leu/TrpMangelmedium (SD/-HLT) in Gegenwart von $5 \mathrm{mM}$ 3-AT wuchsen, wurden auf kleinere Platten überführt und Filterabdrücke der Kolonien auf ß-Galaktosidase-Aktivität im Vergleich mit einer Positivkontrolle im lacZ-Filter-Test bestimmt.

Von 9,6 x $10^{6}$ untersuchten Transformanden waren $288 \mathrm{His}^{+}$und 28 Kolonien im lacZFilter-Test positiv, was einem Prozentsatz von ca. $10 \%$ entspricht.

Nach Seggregation von multiplen Plasmiden und negativer Selektion der DBD-Plasmide, wurden die AD-Plasmide isoliert und zur Elektroporation des E. coli-Stammes HB-101 benutzt. Die isolierten Plasmid-DNAs wurden auf ihre Spezifität zur Wechselwirkung mit dem MPR300-CT sowie zum Ausschluß einer autonomen Aktivierung des HIS3Reportergens durch das AD-Plasmid analysiert. Dazu wurde der Hefewirtsstamm HF7c mit den isolierten AD-Plasmiden und folgenden DBD-Konstrukten kotransformiert (Bartel et al., 1993):

Tab. 4: Spezifität isolierter AD-Plasmide mit verschiedenen DBD-Konstrukten in HF7c:

\begin{tabular}{|c|c|c|c|c|c|}
\hline Ansatz & $\begin{array}{c}\text { DBD- } \\
\text { Konstrukt }\end{array}$ & $\begin{array}{c}\text { AD- } \\
\text { Plasmid }\end{array}$ & Selektionsmedium & Wachstum & $\boldsymbol{\beta}$-Galaktosidase \\
\hline 1 & - & + & SD/-Leu & + & - \\
\hline 2 & pAS2 & + & SD/-HLT (-His) & - & - \\
\hline 3 & pLamin C & + & SD/-HLT (-His) & - & - \\
\hline 4 & pAS2-300CT & + & SD/-HLT (-His) & + & + \\
\hline
\end{tabular}

Bei alleiniger Transformation des AD-Plasmids wird bei fehlender B-GalaktosidaseExpression der transformierten Hefezellen eine autonome Aktivierung des lacZReportergens durch das isolierte AD-Fusionsprotein ausgeschlossen (Tab. 4, Ansatz 1). Bei Kotransformation des DBD-Konstruktes pAS2 mit dem AD-Plasmid kann durch Selektion auf Histidin-freiem Nährmedium (-His) ausgeschlossen werden, daß die Wechselwirkung des AD-Fusionsproteins mit dem MPR300-CT aufgrund der Bindung an die Gal4-DBD erfolgt (Ansatz 2). Durch Kotransformation des DBD-Konstruktes Lamin C mit dem AD-Plasmid kann bei fehlendem Wachstum der Hefezellen auf (-His)-Nährmedium eine unspezifische Wechselwirkung zwischen dem MPR300-CT und dem isolierten 
AD-Fusionsprotein ausgeschlossen werden, da das Protein Lamin C der Kernlamina eine Reihe unspezifischer Wechselwirkungen mit anderen Proteinen eingeht (Ansatz 3). Die Kotransformation des DBD-Konstruktes pAS2-MPR300-CT mit dem AD-Plasmid soll die gefundene Wechselwirkung zwischen dem MPR300-CT und dem AD-Fusionsprotein verifizieren (Ansatz 4).

Nach Restriktionsspaltung positiver AD-Plasmide und PCR konnten im Agarosegel identische Klone anhand des Restriktionsfragmentmusters identifiziert werden. Zur weiteren Charakterisierung der cDNA-Sequenzen wurde jeweils ein AD-Plasmid einer identischen Gruppe sequenziert und die erhaltenen cDNA-Sequenzen mit Hilfe der NCBIBLASTN- und BLASTX-Programme auf Homologien zu bekannten cDNA-Sequenzen aus Datenbanken verglichen (Altschul et al., 1990). Nach Festlegung des durch die Gal4-DBD vorgegebenen Leserahmens wurden die abgeleiteten Aminosäuresequenzen mit dem NCBIBLASTP-Programm mit bekannten Proteinen verglichen.

In drei unabhängigen Screens der HeLa-cDNA-Bibliothek wurden eine Gruppe von identischen Klonen verschiedener cDNA-Länge identifiziert, deren Plasmide mehrfach isoliert wurden. Weiterhin wurde in einem Screen eine Gruppe von 6 identischen Klonen verschiedener cDNA-Länge gefunden.

Als Auswahlkriterien für die weitere Analyse der Klone und deren Interaktion mit dem MPR300-CT wurde der Koloniedurchmesser der His ${ }^{+}$-Kolonien sowie die Intensität und der Zeitpunkt des Auftretens der Blaufärbung im lacZ-Filter-Test herangezogen. Hierzu wurden Kolonien mit einem Durchmesser von $>2 \mathrm{~mm}$ bei Wachstum auf Histidin-freiem Medium und einer Blaufärbung der Filterabdrücke nach 30 min ausgewählt.

Durch Sequenzierung konnten 6 positive Klone mit cDNA-Längen von 1.300 bp (Klone: 111, 238, G21 und M8), 1.638 bp (Klon G4) und 2.325 bp (Klon ST4) identifiziert werden, die nach den obengenannten Auswahlkriterien eine starke Interaktion mit der zytoplasmatischen Domäne des MPR300 zeigten. Sämtliche Klone enthielten in ihren cDNA-Sequenzen einen 3'-nichttranslatierten Bereich von 830 bp Länge. Durch Vergleich der cDNA- und Aminosäuresequenzen der Klone mit bekannten Sequenzen konnte gezeigt werden, daß es sich bei dem Protein um die C-terminale Domäne von Periplakin handelt, dessen gesamte cDNA aus 6,3 kb besteht. Periplakin ist ein Mitglied der Plakin-Familie von Intermediärfilament-assoziierten Proteinen mit einer apparenten molaren Masse von 195 kDa, dem allerdings die Intermediärfilament-bindende Domäne fehlt (Ruhrberg et al., 1997). 


\subsubsection{Darstellung der mutanten zytoplasmatischen Domänen des MPR300}

Zur weiteren Charakterisierung der Wechselwirkung zwischen dem MPR300-CT und dem C-terminalen Bereich von Periplakin wurden verschiedene Konstrukte hergestellt, die Mutationen in verschiedenen bekannten Signalstrukturen enthielten (Abb. 2A).

So wurden die Tyr26- und Val29-Reste des Internalisierungssignals gegen Alanin-Reste ausgetauscht (MPR300-CT-Y26V29 $\rightarrow$ A) bzw. die zytoplasmatische Domäne bis auf die ersten 29 Aminosäuren verkürzt (MPR300-CT-StopV29), die aber noch das vollständige, funktionelle Internalisierungssignal enthalten (Canfield et al., 1991). Um die Bedeutung C-terminaler Regionen des MPR300-CT für die Bindung von Periplakin zu untersuchen, wurden auf analoge Weise Stopcodons hinter die Leu75-(MPR300-CT-StopL75) und Val86-(MPR300-CT-StopV86) Reste eingeführt. Die StopL75-Mutante enthielt zugleich keine der durch CK2 phosphorylierbaren Serinreste (Ser82; Ser157).

\subsubsection{Two-Hybrid-Analyse der mutanten zytoplasmatischen Domänen des MPR300 mit Periplakin}

Zur Analyse der Protein-Protein-Interaktion und der Spezifität der Interaktion wurden die verschiedenen cDNAs der mutanten zytoplasmatischen Domänen des MPR300 im DBD-Vektor pGBT9 bzw. verschiedener Kontrollvektoren mit der 2,3 kb PeriplakincDNA (Klon ST4) im AD-Vektor pGAD-GH in den Hefewirtsstamm HF7c kotransformiert. Die Transformationsansätze wurden auf SD/-LT(+His)- und SD/-HLT (-His)-Agarplatten ausplattiert. Zur Repression der endogenen Expression des His3p-Proteins im Hefewirtsstamm HF7c wurde den SD/-HLT-Agarplatten der Inhibitor 3-Aminotriazol in einer Endkonzentration von $5 \mathrm{mM}$ zugefügt. Das Ausplattieren der Ansätze auf SD/-LT-Selektionsmedium erfolgte zur Kontrolle der Transformation. Zur Depletion von endogenen Histidinspeichern wurden die (-His)-Agarplatten für 5 Tage bei $30{ }^{\circ} \mathrm{C}$ inkubiert und Einzelkolonien auf neue (-His)-Agarplatten ausgestrichen. Das Wachstum dieser Einzelkolonien wurde nach einer weiteren Inkubation von 5 Tagen dokumentiert. Ein Wachstum der Kolonien auf Histidin-freiem Nährmedium ist der Nachweis für eine Protein-Protein-Interaktion zwischen den Fusionsproteinen und die resultierende Aktivierung des HIS3-Reportergens. 
A

B

C

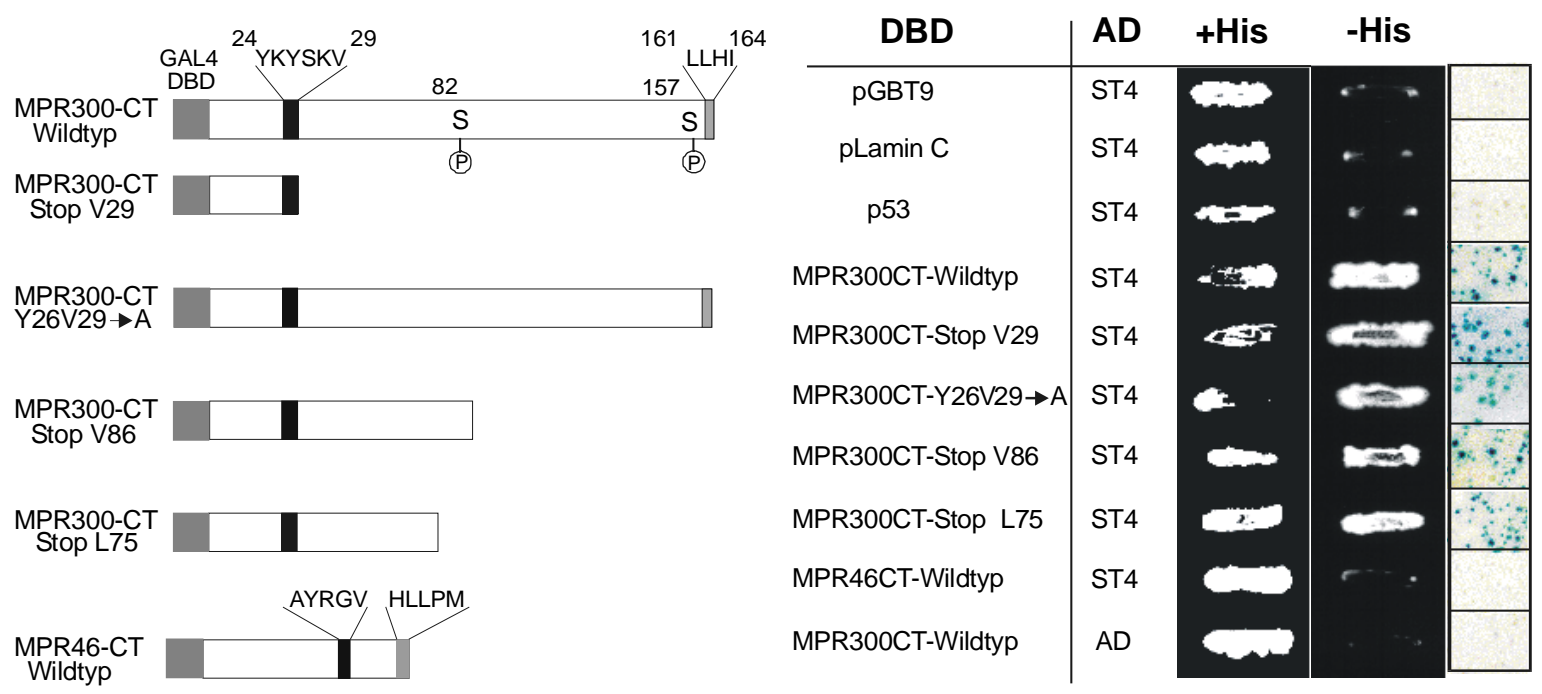

Abb. 2A: Schematische Darstellung von Wildtyp- und mutanten zytoplasmatischen Domänen des MPR300 (MPR300-CT) als Fusionsprotein mit der N-terminalen Gal4-DNA-Bindungsdomäne (Gal4-DBD). Wichtige Sortierungssignale und Phosphorylierungsstellen sind hervorgehoben. B: Kompetente HF7c-Zellen wurden mit den angegebenen DBD-Konstrukten und Klon ST4 kotransformiert, Aliquots der Ansätze auf (+His)- und (-His/5 mM 3-AT)-Selektionsmedium ausplattiert und das Wachstum der Kolonien nach 5 Tagen Inkubation bei $30{ }^{\circ} \mathrm{C}$ analysiert. C: SFY526-Zellen wurden in analoger Weise kotransformiert, auf (+His)-Medium ausplattiert und die B-Galaktosidase-Aktivität der Hefekolonien im Filter-Test bestimmt.

Hefezellen, die den Wildtyp-MPR300-CT sowie die mutierten zytoplasmatischen Domänen StopL75, StopV86 und StopV29 und Periplakin koexprimieren, wuchsen auf Histidin-freiem Medium (-His) (Abb. 2 B). Das Wachstum von Hefezellen, die die MPR300-CT-Y26,V29 $\rightarrow$ A-Mutante und Periplakin enthielten, war deutlich verzögert. Erfolgt die Kotransformation der Hefezellen mit der isolierten Gal4-DBD (pGBT9) und Periplakin oder der isolierten Gal4-AD und dem Wildtyp-MPR300-CT, war kein Wachstum auf (-His)-Medium nachweisbar. Das fehlende Wachstum der Hefezellen, die Periplakin und die Proteine Lamin C, p53 sowie die zytoplasmatische Domäne des MPR46 koexprimieren, unterstreicht die Spezifität der Interaktion des Periplakins mit dem MPR300-CT.

Sämtliche His ${ }^{+}$-Kolonien zeigten $ß$-Galaktosidase-Aktivität, die durch eine Blaufärbung im lacZ-Filter-Test nachgewiesen wurde (Abb. 2 C). Hierbei zeigten sich jedoch zwischen den einzelnen kotransformierten Hefezellen Unterschiede hinsichtlich des Zeitpunktes des Auftretens und der Intensität der Blaufärbung. Der Beginn der Blaufärbung der Filterabdrücke war bei der MPR300-Wildtypdomäne und der Deletionsmutante MPR300-CT-StopV29 30 Minuten nach Inkubationsbeginn zu beobachten, während bei den Deletionsmutanten StopV86, StopL75 und der Tyr26,Val29-Alanin-Austauschmutante die Färbung erst nach ca. 2 Stunden auftrat. 


\subsubsection{Quantitative Bestimmung der Protein-Protein-Interaktion zwischen dem MPR300-CT und Periplakin}

Um das Maß der Protein-Protein-Interaktion zu bestimmen, wurde die ß-GalaktosidaseAktivität in Zellhomogenaten kotransformierter Hefezellen analysiert. Für die Bestimmung der B-Galaktosidase-Aktivität im Flüssig-Test wurde der Hefewirtsstamm SFY526 verwendet, dessen lacZ-Reportergen-Transkription unter der Kontrolle des intakten Gal1Promotors steht. Die Expression des lacZ-Reportergens in dem Wirtstamm SFY526 ist im Vergleich zu HF7c um den Faktor 10 höher (Yeast Protocols Handbook, Clontech).

Der Hefewirtsstamm wurde mit den bezeichneten DBD-Konstrukten und Klon ST4 kotransformiert und positive Kolonien durch Wachstum auf SD/-LT-Agarplatten selektioniert. Nach einer Inkubation von drei Tagen bei $30{ }^{\circ} \mathrm{C}$ wurden Filterabdrücke der gewachsenen Kolonien gezogen und die B-Galaktosidase-Aktivität im Filter-Test bestimmt. Positive Kolonien wurden anschließend von der Agarplatte in SD/-LT-Medium transferiert und die B-Galaktosidase-Aktivität bestimmt (Abb. 3).

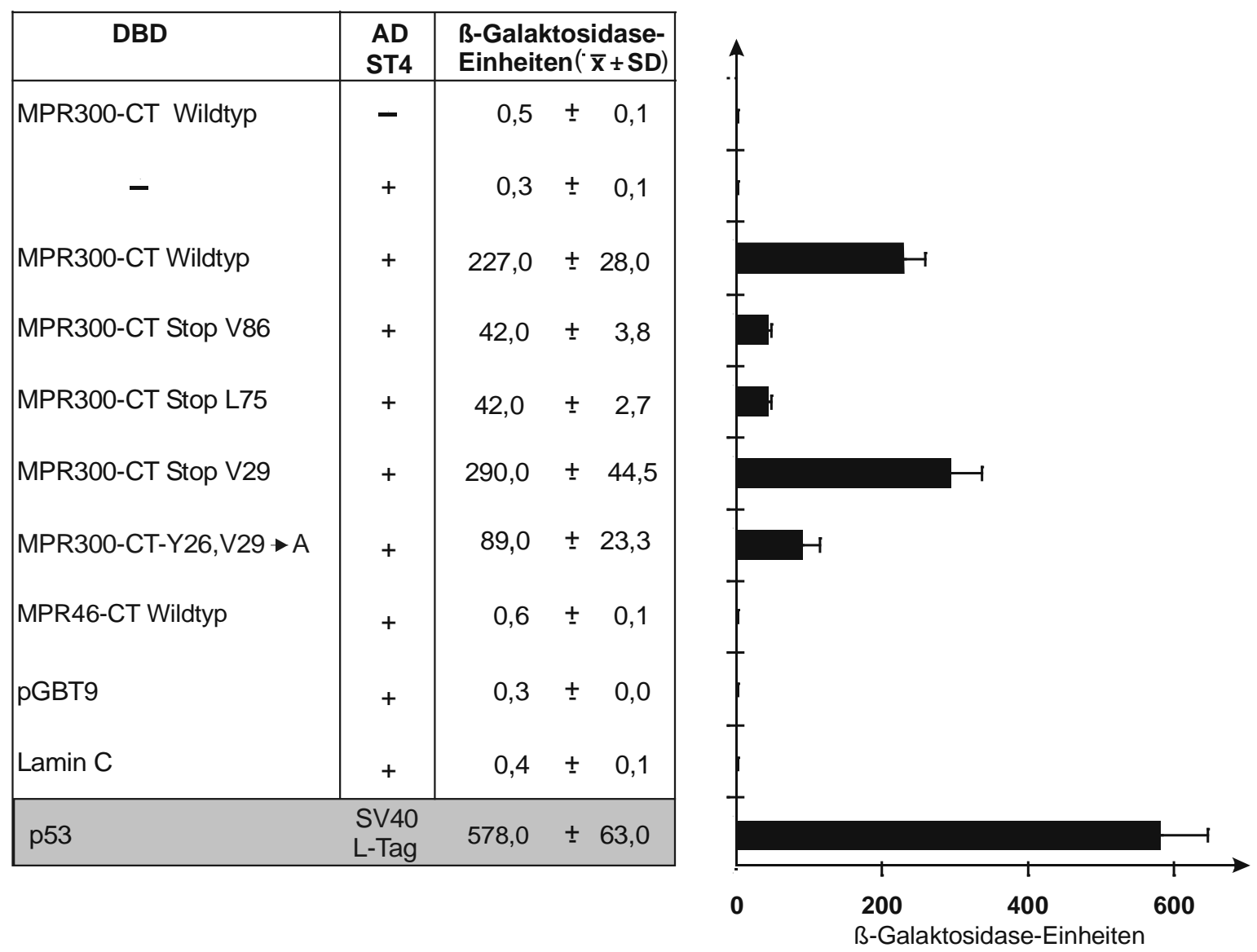

Abb. 3: Bestimmung der B-Galaktosidase-Aktivität in Hefehomogenaten. SFY526-Hefezellen wurden mit den bezeichneten DBD-Konstrukten und Klon ST4 kotransformiert, in SD/-LT-Medium bis zu einer OD 600 von 0,5-0,8 unter Schütteln kultiviert und die $\beta$-Galaktosidase-Aktivität in den Hefehomogenaten bestimmt. In dem Balkendiagramm sind die nach Miller berechneten Mittelwerte der ß-Galaktosidase-Einheiten von 5 Einzelkolonien und die errechneten Standardabweichungen dargestellt. Als Positivkontrolle (grau unterlegt) diente die Wechselwirkung zwischen p53 und dem großen T-Antigen des SV40-Virus (SV40 L-Tag). 
Bei der Kotransformation des Wildtyp-MPR300-CT und der C-terminalen Periplakindomäne (Klon ST4) war eine durchschnittliche $\beta$-Galaktosidase-Aktivität von 227 Einheiten meßbar (Abb. 3). Die C-terminale Deletion des MPR300-CT um 78 (StopV86) oder 89 Aminosäuren (StopL75) führt zu einer Reduktion der Wechselwirkung um 81\%. Der Austausch der Aminosäuren Tyr26 und Val29 zu Alanin im sonst intakten MPR300-CT reduzierte die Wechselwirkung auf 39\% der Wildtyp-Kontrolle. Dagegen war die Deletionsmutante MPR300-CT-StopV29 in stärkerem Maße zur Wechselwirkung mit Periplakin fähig als der Wildtyp. Nach Kotransformation der isolierten Gal4-DBD (pGBT9), Lamin C und der zytoplasmatischen Domäne des MPR46 (MPR46-CT) mit Periplakin sowie nach Transformation mit dem MPR300-CT bzw. Periplakin war keine ß-Galaktosidase-Aktivität meßbar, was mit dem Unvermögen zum Wachstum auf Histidinfreiem Medium übereinstimmt. Als positive Kontrolle diente die im Two-Hybrid-System verifizierte Wechselwirkung zwischen p53 und dem großen T-Antigen des SV40-DNATumorvirus (Li \& Fields, 1993).

\subsubsection{Two-Hybrid-Analyse der Interaktion des MPR300-CT mit mutanten C- terminalen Periplakindomänen}

Die 2,3 kb-cDNA-Sequenz des Klons ST4 kodiert für die 506 C-terminalen Aminosäuren von Periplakin, die aus der gesamten Linker-Domäne und Anteilen der zentralen, stabförmigen Rod-Domäne (aa 1260-1756) besteht (Abb. 4).

Um die Bindungsstellen des MPR300-CT in der C-terminalen Periplakindomäne einzugrenzen, wurden Konstrukte hergestellt, bei denen die isolierte Linker-Domäne (aa 1646-1756), die zentrale, stabförmige Domäne (aa 1260-1645) sowie die C- (aa 17011756) und N-terminalen Hälften (aa 1646-1700) der Linker-Domäne in den AD-Vektor pGAD-GH kloniert wurden.

Die in Abb. 4 bezeichneten AD-Konstrukte wurden mit dem DBD-Vektor pGBT9MPR300-CT in den Hefewirtsstamm HF7c kotransformiert und Aliquots der Transformationsansätze auf SD/-LT(+His)- und SD/-HLT(-His/5 mM 3-AT)-Agarplatten ausplattiert. Das Wachstum der Hefekolonien nach 5 Tagen Inkubation bei $30{ }^{\circ} \mathrm{C}$ ist in Abb. 4 dargestellt. 


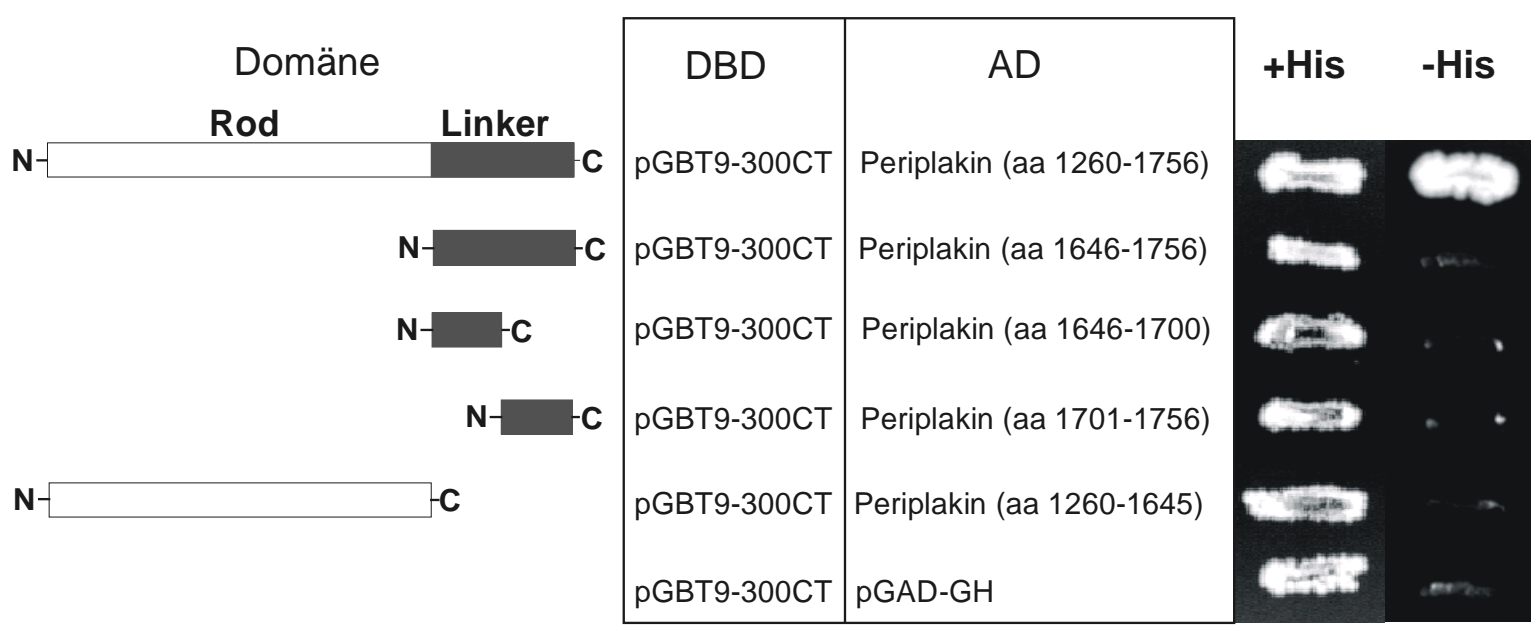

Abb. 4: Two-Hybrid-Analyse der Interaktion zwischen dem MPR300-CT und Deletionsmutanten der C-terminalen Periplakindomäne. Kompetente HF7c-Zellen wurden mit den bezeichneten DBD- und ADKonstrukten kotransformiert, Aliquots der Transformationsansätze auf (+His)- und (-His/5 mM 3-AT)Selektionsmedium ausplattiert und das Wachstum der Kolonien nach 5 Tagen dargestellt.

Weder HF7c-Zellen, die mit der cDNA der gesamten Linker-Domäne noch mit der der Cund N-terminalen Hälften der Linker-Domäne kotransformiert wurden, zeigten Wachstum auf Histidin-freiem Medium (-His). Ebenso zeigt die isolierte stabförmige RodPeriplakindomäne keine Interaktion mit dem MPR300-CT. Nur Hefezellen, die die gesamte Linker-Domäne im Zusammenhang mit Anteilen der zentralen stabförmigen Domäne in Gegenwart des MPR300-CT exprimieren, zeigen nach Ausplattieren auf Histidin-freiem Medium positive Kolonien.

Alle Hefetransformanden wurden anschließend in einem lacZ-Filter-Test auf Expression von B-Galaktosidase getestet. Gleichzeitig wurden hier noch die kürzeren PeriplakincDNA-Klone G4 (Abschnitt 2) und 111 (Abschnitt 3) untersucht.

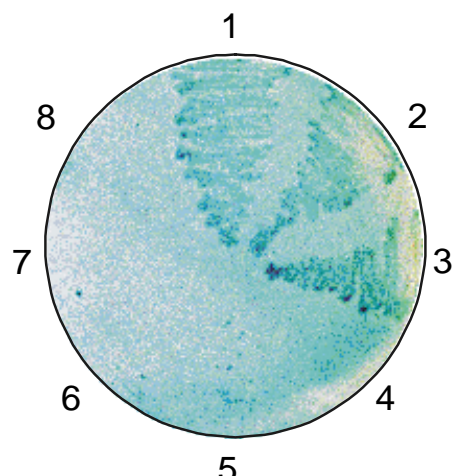

$\begin{array}{ll}1 & \text { aa } 1260-1756 \text { (Klon ST4) } \\ 2 & \text { aa } 1449-1756 \text { (Klon G4) } \\ 3 & \text { aa } 1602-1756 \text { (Klon 111) } \\ 4 & \text { aa } 1646-1756 \\ 5 & \text { aa } 1646-1700 \\ 6 & \text { aa } 1701-1756 \\ 7 & \text { aa } 1260-1645 \\ 8 & \text { Gal4-DBD }\end{array}$

Abb. 5: Analyse der BGalaktosidase-Expression im lacZ-Filter-Test.

HF7c-Hefezellen wurden nach der Transformation auf (+His)Medium ausgestrichen, die Kolonien nach dreitägiger Inkubation auf Whatman-Filter transferiert und die ß-Galaktosidase-Aktivität nach Aufschluß der Zellen bestimmt.

In Übereinstimmung mit dem Histidin-unabhängigen Wachstum war nur in Hefezellen, die Anteile der stabförmigen Rod-Domäne und der gesamten Linker-Domäne in Gegenwart des MPR300-CT exprimieren, eine Expression von B-Galaktosidase nachweisbar (Abb. 5, Abschnitt 1-3). 


\subsubsection{Protein-Protein-Interaktion zwischen dem MPR300-CT und Periplakin in vitro}

Der genetische Nachweis der Wechselwirkung zwischen der zytoplasmatischen Domäne des MPR300 mit der C-terminalen Region des Periplakins muß auf Proteinebene verifiziert werden. Dieser Nachweis ist notwendig, da die Interaktion zwischen den Fusionsproteinen aufgrund mißgefalteter Proteine oder unter Vermittlung eines Hefeproteins zustandekommen kann (Fields \& Sternglanz, 1994).

\subsubsection{Expression der C-terminalen Periplakindomäne und Gewinnung von Antikörpern}

Zur Subklonierung der Periplakin-cDNA wurde das 1,3 kb-Insert des Klons 111 aus dem Vektor pGAD-GH mit den Restriktionsendonukleasen EcoR I und Xho I ausgeschnitten und über diese Schnittstellen in den Expressionsvektor pGEX-4T-3 sukloniert. Das 1,3 kb cDNA-Fragment kodiert für die C-terminalen 155 Aminosäuren von Periplakin (aa 16021756). Nach Transformation des Konstruktes in den proteasedefizienten Wirtsstamm $E$. coli BL-21 wurde die Periplakindomäne als Fusionsprotein mit GST exprimiert und über eine Glutathion-Agarose-Matrix gereinigt. Die Ausbeuten nach der Proteinaufreinigung betrugen typischerweise $1 \mathrm{mg} / 500 \mathrm{ml}$ Kultur. Ca. $500 \mu \mathrm{g}$ des GST-Fusionsproteins wurden mit Thrombin gespalten. Das GST-Periplakin-Fusionsprotein zeigt in der SDS-PAGE nach Coomassie-Färbung eine molare Masse von $45 \mathrm{kDa}$ (Bahn 2) und nach Thrombinvermittelter Abspaltung des GST-Anteils (28 kDa, Bahn 1) eine 17 kDa-Periplakin-Bande (Abb. 6, Bahn 3).

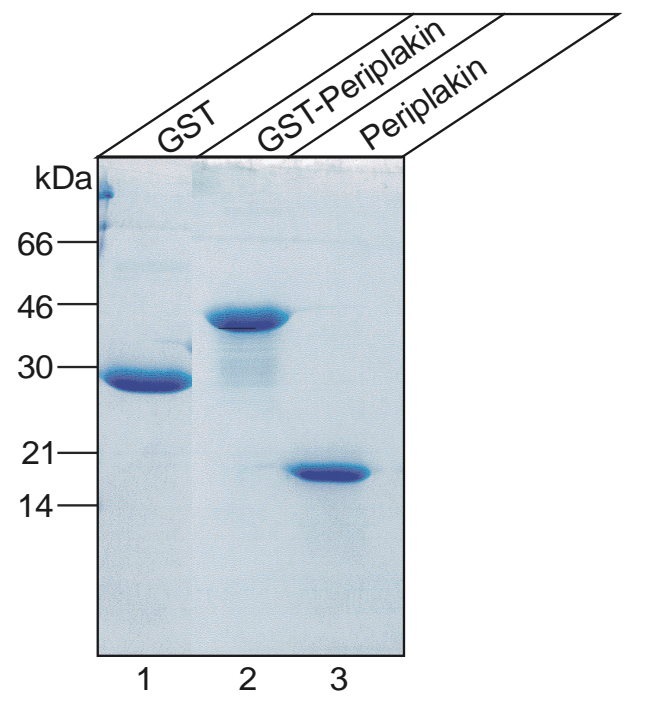

Abb. 6: Analyse der GST-Fusionsproteine nach Auftrennung durch SDS-PAGE und CoomassieFärbung. Jeweils $10 \mu \mathrm{g}$ GST (Bahn 1), GST-Periplakin (Bahn 2) und thrombingespaltenes GST-Periplakin (Bahn 3) wurden über SDS-PAGE aufgetrennt und die Proteinbanden durch Coomassie angefärbt. 
Die thrombingespaltene $17 \mathrm{kDa}$ C-terminale Periplakindomäne wurde zur Immunisierung von Kaninchen benutzt. Mit dem gewonnenen Antiserum können in Western-BlotAnalysen noch $1 \mathrm{ng}$ der C-terminalen Periplakindomäne nachgewiesen werden.

Wenn das Antiserum in Western-Blot-Analysen von HeLa-Zellhomogenaten getestet wird, wird spezifisch ein $195 \mathrm{kDa}$ Protein detektiert (Abb. 7, Bahn 1). Eine Proteinbande mit gleicher elektrophoretischer Mobilität wird nachweisbar unter Verwendung von CR3- und TD1-Antiseren, die gegen Peptide des Periplakins gemacht wurden (Ruhrberg et al., 1997) (Abb. 7, Bahn 2 bzw. 3). Diese Daten zeigen, daß das Translationsprodukt des cDNA-Klons ST4 Teil des 195 kDa Periplakinmoleküls ist.
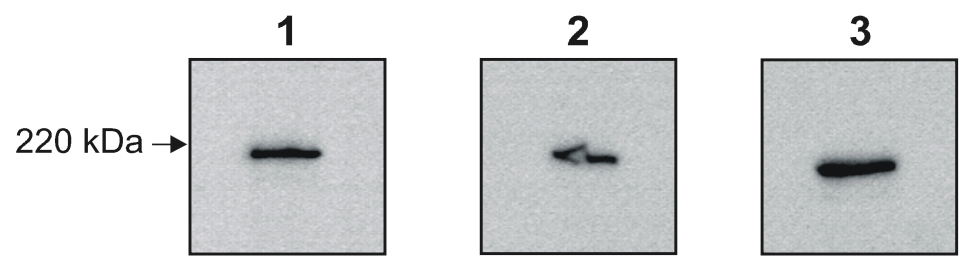

Abb. 7: Western-Blot-Analyse von HeLa-Zellhomogenaten. $30 \mu \mathrm{g}$ HeLa-Zellhomogenat wurden nach Solubilisierung über SDS-PAGE (5\% Acrylamid) aufgetrennt, auf Nitrozellulose geblottet und mit dem gewonnenen Antiserum (Bahn 1) sowie den Antikörpern CR3 (Bahn 2) und TD1 (Bahn 3) inkubiert. Der immunologische Nachweis der Proteine erfolgte über eine Chemoluminiszenzreaktion.

\subsubsection{Subzelluläre Lokalisation von Periplakin}

Um die subzelluläre Lokalisation des Periplakins mit der des MPR300 zu vergleichen, wurde der postnukleäre Überstand auf einen kontinuierlichen Saccharose-Gradienten aufgetragen und bis zum Gleichgewicht zentrifugiert. Nach Fraktionierung des Gradienten in 11 Fraktionen wurden Aliquots jeder Fraktion für die Bestimmung der Dichte, des lysosomalen Leitenzyms B-Hexosaminidase sowie für Western-Blot-Analysen von Periplakin und MPR300 analysiert. 23\% des zellulären Periplakins sind in der membranfreien, löslichen Gradientenfraktion nachweisbar (Abb. 8, Fraktion 1 und 2), während sich der Hauptteil des Periplakin (75\%) in Membranfraktionen relativ hoher Dichte (1,135- 1,2 g/ml) befindet (Abb. 8, Fraktionen 6-9). Die Verteilung des MPR300 überlappt nur teilweise mit der des Periplakins und erstreckt sich mehr auf Membranfraktionen mittlerer Dichte von 1,06-1,155 g/ml (Abb. 8, Fraktionen 3-7). 

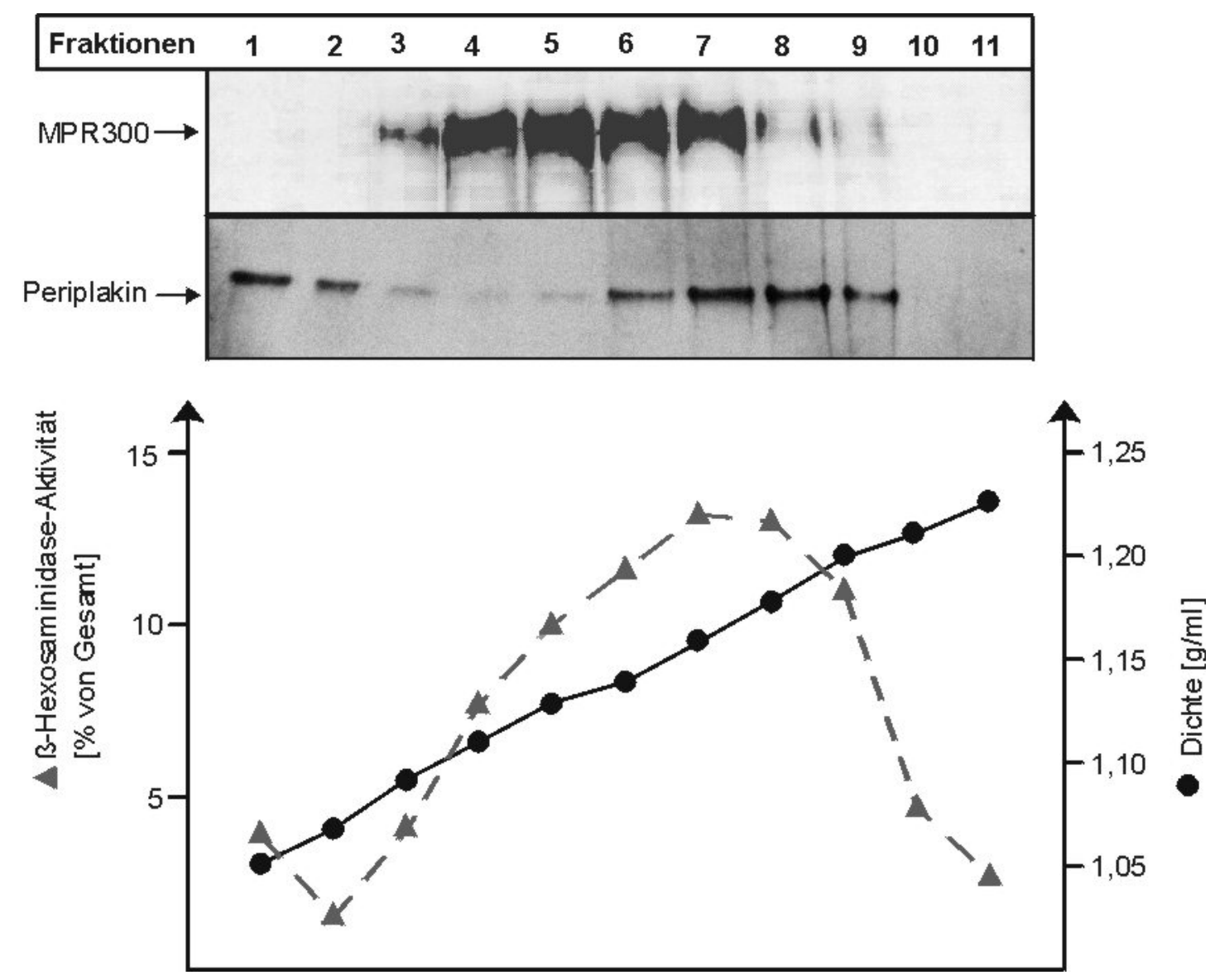

Abb. 8: Western-Blot-Analyse von MPR300 und Periplakin nach subzellulärer Fraktionierung. Der PNS aus HeLa-Zellen wurde auf einen Saccharose-Gradienten aufgetragen und bei $218.000 \times \mathrm{g}$ für $3 \mathrm{~h}$ zentrifugiert. 11 Fraktionen wurden abgenommen und die B-Hexosaminidase-Aktivität $(\boldsymbol{\Delta})$ und Dichte $(\bullet)$ bestimmt. Anschließend erfolgte die Auftrennung der Fraktionen durch SDS-PAGE, Transfer auf Nitrozellulose und Analyse durch MPR300- bzw. Periplakin-Western-Blot. Der immunologische Nachweis der Proteine erfolgte über eine Chemoluminiszenzreaktion.

\subsubsection{Kopräzipitationsanalysen}

Die cDNA der zytoplasmatischen Domäne des MPR300 wurde in den in vitro-Translationsvektor pSPUTK kloniert. Durch Subklonierung der cDNA in die NcoI-Schnittstelle des pSPUTK-Vektors entsteht ein ATG-Startcodon mit einer benachbarten Kozak-Konsensus-Sequenz, wobei die cDNA des MPR300-CT im Leserahmen des Startcodons liegt.

Mit Hilfe des TNT $^{\circledR}$ gekoppelten Retikulozyten-Lysat-Systems wurde die MPR300-CT cDNA in Gegenwart von $\left[{ }^{35} \mathrm{~S}\right]$-Methionin transkribiert und translatiert. Nach Auftrennung des Translationsproduktes über SDS-PAGE und anschließender Autoradiographie ergibt sich eine einzelne, radioaktiv markierte Bande von $25 \mathrm{kDa}$ (Abb. 9, Bahn 2). Als Negativkontrolle für die Spezifität der Protein-Protein-Wechselwirkung wurde die vollständige cDNA für Luciferase (pPOLY(A)Luciferase) wurde unter identischen 
Bedingungen translatiert. Das markierte Hauptprodukt zeigt nach SDS-PAGE und Autoradiographie eine apparente molare Masse von $61 \mathrm{kDa}$ (Abb. 9, Bahn 1).

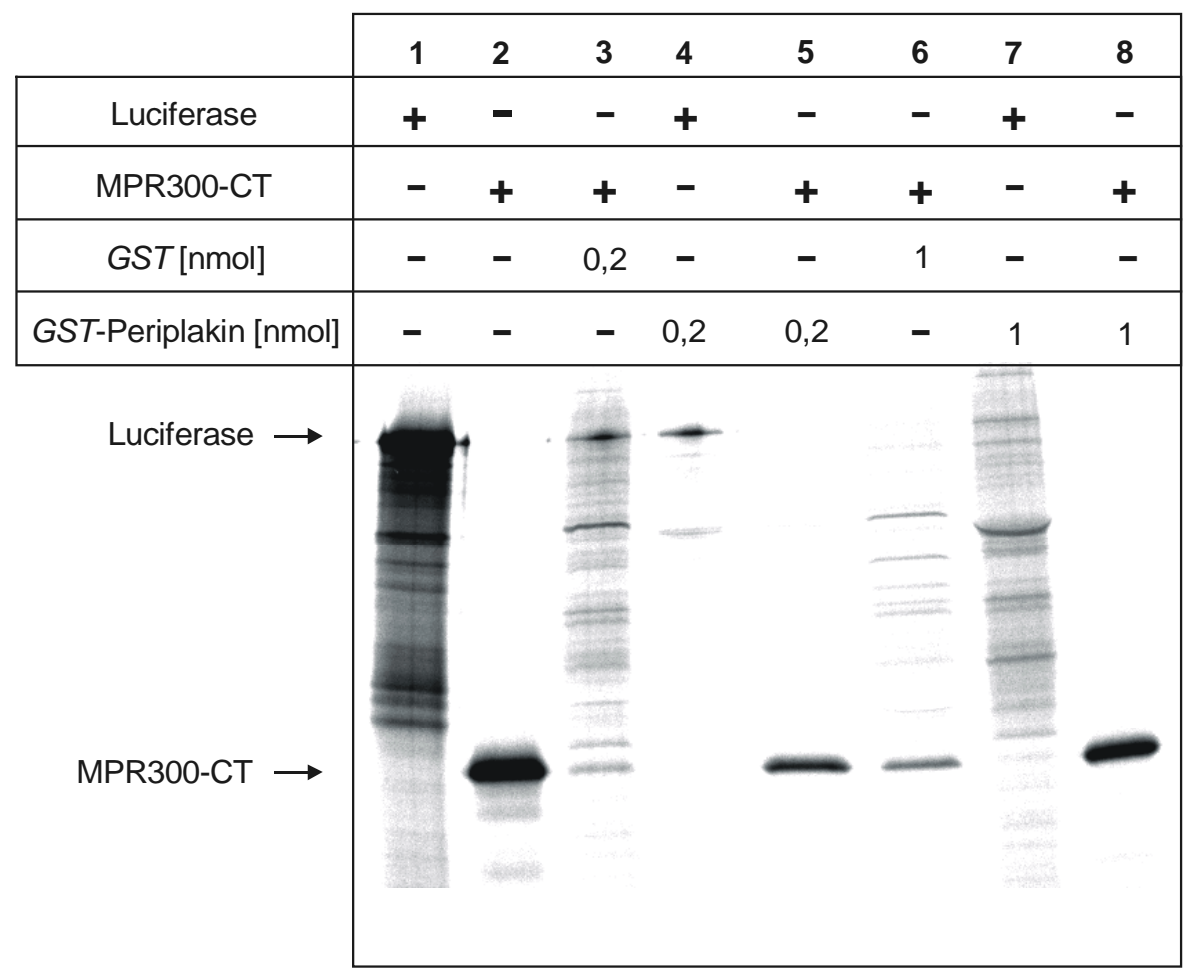

Abb. 9: In vitro-Bindung zwischen der C-terminalen Periplakindomäne und dem MPR300-CT. Verschiedene, äquimolare Mengen an GST und GST-Periplakin wurden mit $\left.{ }^{35} \mathrm{~S}\right]$-markierter, in vitrotranslatierter Luciferase (Bahn 4 und 7) bzw. MPR300-CT (Bahn 3, 5, 6 und 8) inkubiert, präzipitiert und nach SDS-PAGE durch Autoradiographie analysiert. Zur quantitativen Auswertung der Bindung wurden 20\% der eingesetzten Translationsprodukte Luciferase (Bahn 1) und MPR300-CT (Bahn 2) ebenfalls durch SDSPAGE aufgetrennt und autoradiographisch ausgewertet.

Die $\left[{ }^{35} \mathrm{~S}\right]$-markierten MPR300-CT- und Luciferase-Translationsprodukte wurden anschließend in Gegenwart von 0,2 oder 1,0 nmol des GST-Periplakin-Fusionsproteins bzw. äquimolarer Mengen an $G S T$ allein für 2 Stunden bei $4{ }^{\circ} \mathrm{C}$ inkubiert. Nach Zugabe von Glutathion-Agarose und Waschen der Komplexe wurden die gebundenen und kopräzipitierten Proteine extrahiert, durch SDS-PAGE getrennt und autoradiographisch analysiert. Zur quantitativen Auswertung der gebundenen Proteine wurden jeweils 20\% der eingesetzten Mengen an Luciferase- und MPR300-CT-Translationsprodukten aufgetragen (Abb. 9, Bahn 1 und 2). In Abhängigkeit von der eigesetzten GST-Periplakin-Menge können 3\% und 5,6\% kopräzipitiert werden (Abb. 9, Bahn 5 bzw. 8). Der Anteil des MPR300-CT, der unspezifisch an GST allein bindet, wurde subtrahiert (Abb. 9, Bahn 3 und 6). Das Kontrollprotein Luciferase bindet nicht spezifisch an Periplakin (Abb. 9, Bahn 4 und 7). 
Auf den umgekehrten Ansatz, nämlich in vitro-translatiertes, $\left[{ }^{35} \mathrm{~S}\right]$-markiertes Periplakin mit dem MPR300-CT als GST-Fusionsprotein kozupräzipitieren, wurde aus folgenden Gründen verzichtet:

Wenn die cDNA des MPR300-CT in den Vektor pGE-KT-0 kloniert und in E. coli BL-21 exprimiert wurde, zeigte das über Glutathion-Agarose gereinigte Produkt nach SDS-PAGE und Coomassie-Färbung neben der Haupt-Fusionsprotein-Bande bei $47 \mathrm{kDa}$ zahlreiche kleinere Abbau-Banden. Da diese Banden nach Thrombinbehandlung alle verschwanden und nur noch ein $28 \mathrm{kDa}-G S T$-Protein übrig blieb, sind die zahlreichen Banden auf Proteolyse im MPR300-CT Bereich zurückzuführen. Die Veränderung verschiedener Parameter bei der Expression (Inkubationstemperatur und Dauer) oder des Zellaufschlusses unter Austestung verschiedener Bakterienstämme und Einbeziehung verschiedener Proteaseinhibitoren verbesserte nicht die Stabilität des Fusionsproteins. Da die quantitative Auswertung des Bindungsassays die Integrität des GST-MPR300-CT-Fusionsproteins erfordert, wurde der obengenannte Kopräzipitationsansatz gewählt. 


\subsubsection{Kompetitionsstudien zur Bindung zwischen GST-Periplakin und dem MPR300-CT durch Periplakin}

Gleiche Mengen an GST-Periplakin (336 pmol) wurden an eine Glutathion-Agarose-Matrix gekoppelt und in Gegenwart von $5 \mu \mathrm{l}$ des in vitro-translatierten, $\left[{ }^{35} \mathrm{~S}\right]$-markierten MPR300-CT und ansteigenden Mengen des thrombingespaltenen Periplakins inkubiert. Nach Waschen der Matrix wurden die gebundenen Proteine über SDS-PAGE aufgetrennt und über Phosphoimaging analysiert und quantifiziert. Die Kompetition zwischen rekombinantem Periplakin und GST-Periplakin um den MPR300-CT gilt als Maß für die spezifische Bindung.
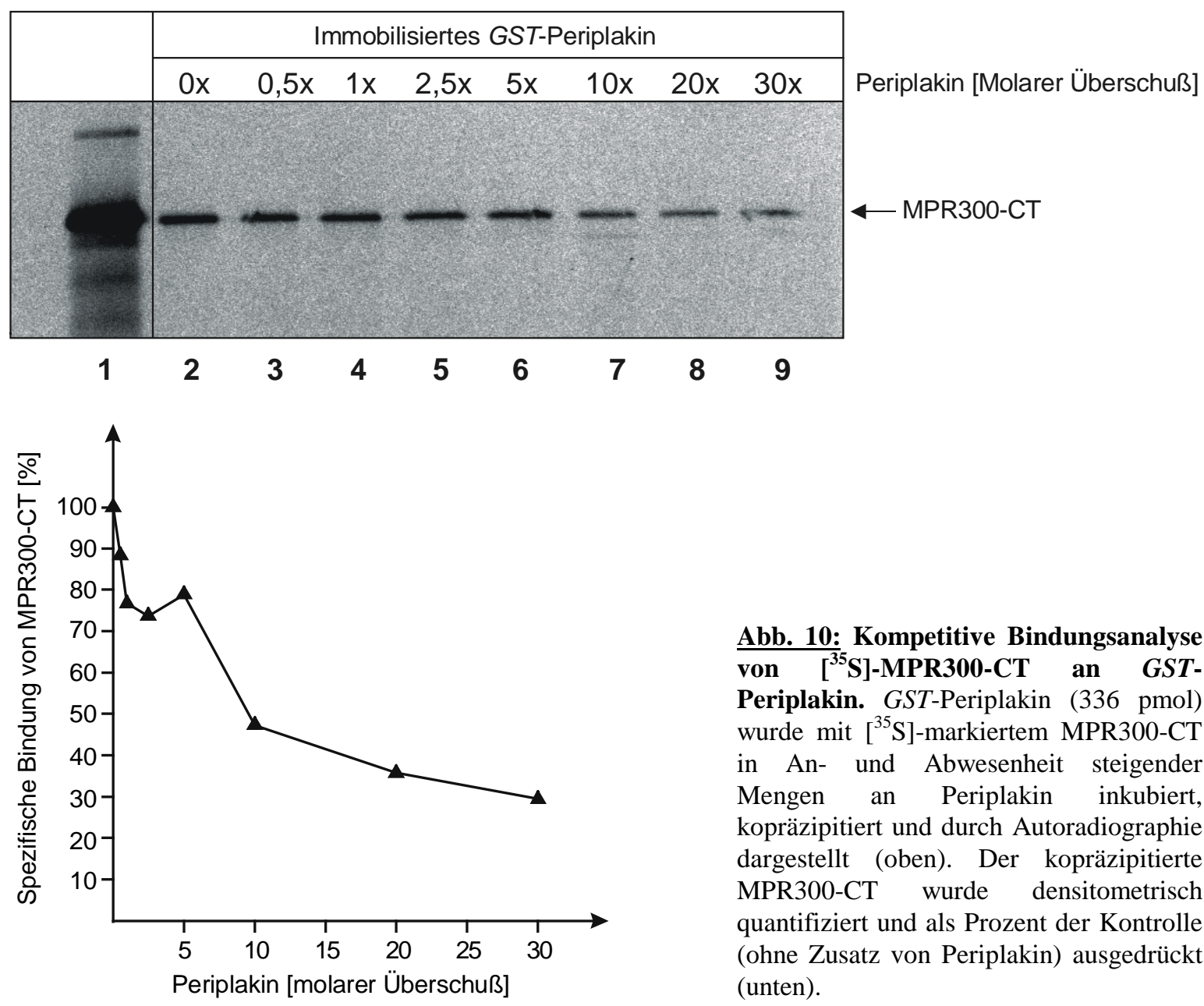

Abb. 10: Kompetitive Bindungsanalyse
von ${ }^{35}$ S]-MPR300-CT an GST-
Periplakin. GST-Periplakin (336 pmol)
wurde mit ${ }^{35}$ S]-markiertem MPR300-CT
in An- und Abwesenheit steigender
Mengen an Periplakin inkubiert,
kopräzipitiert und durch Autoradiographie
dargestellt (oben). Der kopräzipitierte
MPR300-CT wurde densitometrisch
quantifiziert und als Prozent der Kontrolle
(ohne Zusatz von Periplakin) ausgedrückt
(unten).

Mit ansteigenden Mengen von thrombingespaltenem Periplakin im Kopräzipitationsansatz vermindert sich die spezifische Bindung des MPR300-CT an das gekoppelte GST-Periplakin (Abb. 10). Die densitometrische Quantifizierung der Banden ergab, daß bei 10-fachem Überschuß an Periplakin die Bindung des MPR300-CT um 55\% gehemmt ist (Bahn 7). 


\subsubsection{Transfektion von BHK-Zellen mit der C-terminalen Periplakindomäne}

Die Interaktion des MPR300-CT mit der C-terminalen Periplakindomäne ist abhängig von der Intaktheit des Internalisierungssignals $\left({ }^{26} \mathbf{Y R G V}^{29}\right.$ ) (siehe Abb. 2 A). Um diese Wechselwirkung funktionell zu belegen, wurden BHK-Zellen, die den humanen MPR300 überexprimieren (Körner et al., 1995), mit der cDNA für die C-terminale Periplakindomäne stabil transfiziert.

Dazu wurde das Konstrukt pcDNA3.1(+)-Periplakin mit dem Vektor pGKhygro in BHK-Zellen kotransfiziert und Zellklone mit Hygromycin B selektioniert. Zum Nachweis der Expression der C-terminalen Periplakindomäne wurden die Extrakte verschiedener Klone durch Western-Blot mit einem affinitätsgereinigten Antikörper gegen die Cterminale Periplakindomäne analysiert (Abb. 11). Die Klone C1, C4 und F6, die unterschiedliche Spiegel an Periplakindomäne exprimieren, sowie der vektortransfizierte Klon A6 und die nicht-transfizierte Ausgangszellinie wurden für weitere Versuche verwendet.

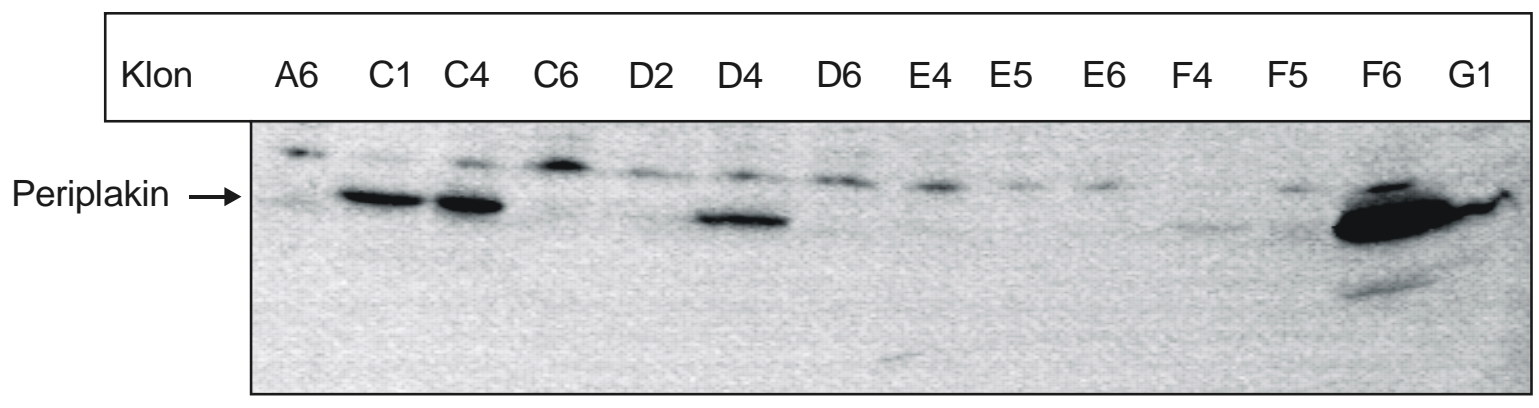

Abb. 11: Western-Blot-Analyse von Zellhomogenaten positiver Klone der stabil transfizierten BHKZellen. Konfluente, transfizierte BHK-Zellen wurden von $35 \mathrm{~mm}$-Schalen abgeschabt, zentrifugiert und die Pellets solubilisiert. Nach Auftrennung durch SDS-PAGE und Transfer auf Nitrozellulose wurde die Membran mit einem affinitätsgereinigten Antikörper gegen Periplakin inkubiert. Der immunologische Nachweis des Periplakins erfolgte über eine Chemoluminiszenzreaktion.

\subsubsection{Wirkung der Überexpression der C-terminalen Periplakindomäne auf die Endozytose eines Mannose-6-Phosphat-haltigen Liganden}

BHK-MPR300-Zellen, die immunonegativ (Klon A6) oder positiv für die überexprimierte Periplakindomäne sind (Klon C1), wurden mit dem ${ }^{125} \mathrm{~J}$-markierten Mannose-6-Phosphat (M6P)-haltigen Neoglykoprotein PMP-BSA für $2 \mathrm{~h}$ bei $37{ }^{\circ} \mathrm{C}$ in Gegenwart oder Abwesenheit von $10 \mathrm{mM}$ M6P inkubiert. Nach Entfernung des Mediums und der an Zelloberflächen-Rezeptoren gebundenen Liganden, wurde die internalisierte Radioaktivität bestimmt. Vorversuche haben ergeben, daß die Aufnahme von ${ }^{125} \mathrm{~J}-\mathrm{PMP}-\mathrm{BSA}$ bis zu $2 \mathrm{~h}$ 
linear erfolgt und daß während dieser Zeit kein Abbau des Liganden stattfindet (gemessen an TCA-präzipitierbaren PMP-BSA im Medium) stattfindet. Die Aufnahme von ${ }^{125}$ J-PMP-BSA kann durch M6P um durchschnittlich $62 \%$ gehemmt werden. Die M6P-abhängige Endozytose von ${ }^{125} \mathrm{~J}$-PMP-BSA betrug in BHK-C1-Zellen nur $72 \%$ der Aufnahme in Kontrollzellen (BHK-A6), die nur mit dem Vektor transfiziert wurden. In Zellen eines anderen BHK-Klons, C4, die die C-terminale Periplakindomäne exprimieren, erreicht die Endozytose zwischen 32 und 49\% der Kontrollen (Abb. 12). Es ist zu bemerken, daß die spezifischen Aufnahme des ${ }^{125} \mathrm{~J}$-PMP-BSA-Liganden in die BHK-Zellen nur dann gut auswertbare Daten liefert, wenn die Zellen subkonfluent (ca. 80\%) sind. Bei konfluent gewachsenen Zellen sinkt die Aufnahme sowohl in An- wie in Abwesenheit von M6P ab, und die Differenz zwischen beiden Werten verringert sich, d.h. die Bestimmung der M6P-abhängigen Endozytose ist nicht möglich.

A

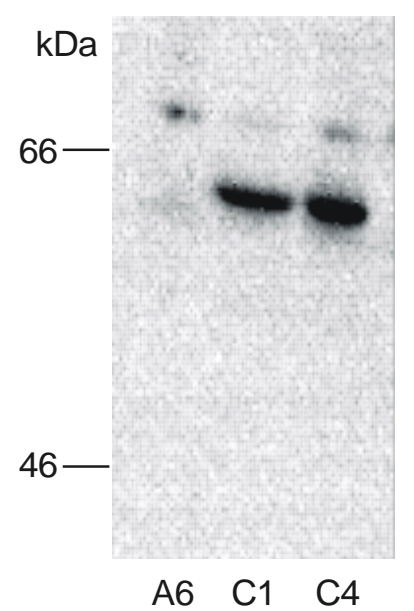

B

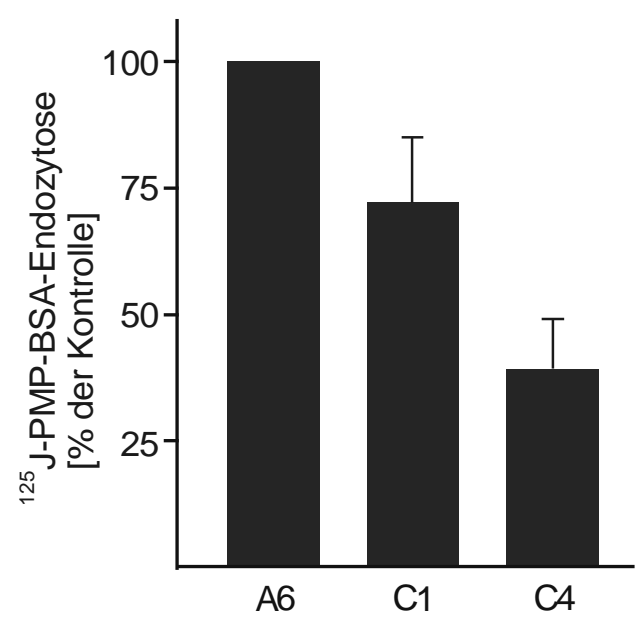

Abb. 12: Endozytose von $\left[{ }^{125} \mathrm{~J}\right]$-markiertem PMP-BSA in transfizierten BHK-Zellen. BHK-MPR300Zellen, die die C-terminale Periplakindomäne überexprimieren (Klon $\mathrm{C} 1$ und $\mathrm{C} 4$ ), und vektortransfizierte Kontrollzellen (A6) wurden mit [ $\left.{ }^{125} \mathrm{~J}\right]$-markiertem PMP-BSA in An- oder Abwesenheit von $10 \mathrm{mM}$ M6P für 2 $\mathrm{h}$ bei $37^{\circ} \mathrm{C}$ inkubiert. Nach Entfernung des Mediums und der an Zelloberflächen-Rezeptoren gebundenen Liganden wurde die internalisierte Radioaktivität bestimmt und im Vergleich zur Kontrolle dargestellt. Fehlerbalken zeigen die Standardabweichung. 


\subsection{Interaktion des MPR300-CT mit p93}

\subsubsection{Two-Hybrid-Analyse der Wechselwirkung zwischen dem MPR300-CT und p93}

In einem weiteren Two-Hybrid-Screen wurden 5 identische Klone mit cDNA-Längen von 860 bp, 833 bp und 804 bp isoliert, die eine starke Wechselwirkung mit der zytoplasmatischen Domäne des MPR300 zeigten. Die Analyse des Leserahmens und die Identifizierung der Stopcodons der cDNA-Sequenzen ergab, daß Klon ST249 eine kodierende Sequenz von 614 bp und einen 3'-nichtkodierenden Bereich von 246 bp enthielt. Klon ST42 enthielt den identischen 3'-nichtkodierenden Bereich, besaß aber einen um 27 bp verkürzten kodierenden Bereich. Die identischen Klone ST66A, ST89 und ST132 enthielten eine kodierende Sequenz von 395 bp Länge und eine 3'-nichtkodierenden Bereich von 409 bp. Da im kodierenden Sequenzbereich kein ATG-Startcodon mit benachbarter Kozak-Konsensus-Sequenz gefunden wurden, ist zu vermuten, daß es sich um unvollständige cDNA-Klone handelt.

HF7c-Zellen wurden mit den in Abbildung 13 dargestellten DBD-Konstrukten und der cDNA des Klons ST249 kotransformiert und Aliquots der Transformationsansätze auf SD/-LT-(+His)- und SD/-HLT-(-His)- Agarplatten ausplattiert. Das Wachstum der Hefezellen nach 5 Tagen Inkubation bei $30{ }^{\circ} \mathrm{C}$ ist in Abb. 13 dargestellt.

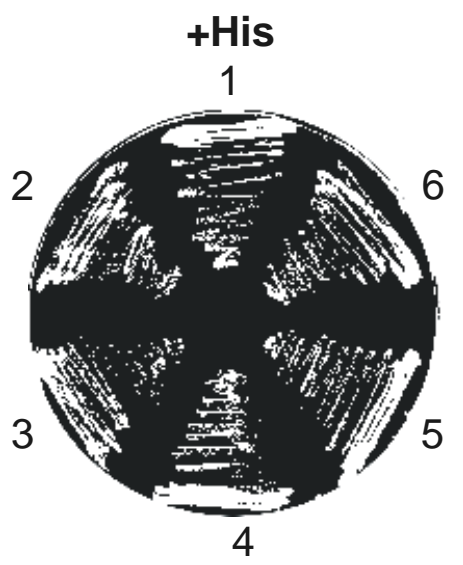

DBD

1 pAS2-MPR300CT-Wildtyp

2 pAS2-MPR300CT Stop V86

3 pAS2-MPR300CT Stop L75

4 pAS2-MPR46CT-Wildtyp

5 pAS2

6 pLamin
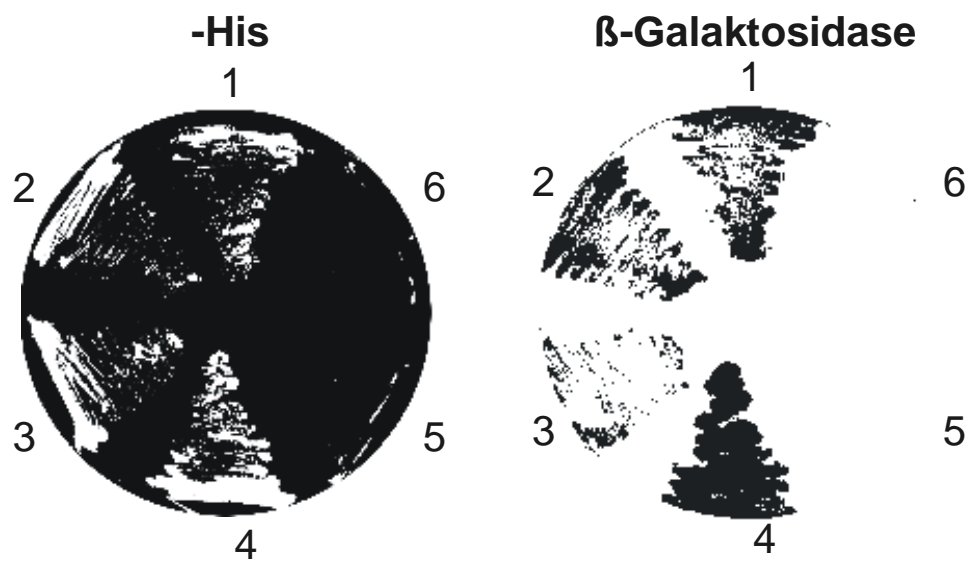

Abb. 13: Two-Hybrid-Analyse der Interaktion zwischen Wildtyp und mutanten zytoplasmatischen Domänen des MPR300/MPR46 mit Klon ST 249. HF7c-Hefezellen wurden mit den bezeichneten DBD-Konstrukten und dem cDNA-Klon pGADGH-249 kotransformiert und das Wachstum der Zellen auf (+His)und (-His/5 mM 3-AT)-Medium sowie die Expression von BGalaktosidase im Filter-Test analysiert. 
Während Hefezellen, die die zytoplasmatischen Domänen des MPR300/MPR46 bzw. die Deletionsmutanten StopV86 und StopL75 in Gegenwart der Klons ST 249 exprimieren, auf (-His)-Selektionsmedium wachsen (Abschnitt 1-4), besitzen Hefezellen, die mit der isolierten Gal4-DBD bzw. Lamin C kotransformiert wurden (Abschnitt 5 und 6), kein Histidin-unabhängiges Wachstum. Im lacZ-Filter-Test wurde bei allen His $^{+}$-Transformanden B-Galaktosidase-Aktivität nachgewiesen, während die isolierte Gal4-DBD und Lamin C das lacZ-Reportergen nicht aktivieren. Die Blaufärbung der ausgestrichenen Hefekolonien ist jedoch bei der Deletionsmutante StopL75 (Abschnitt 3) schwächer im Vergleich zum Wildtyp-MPR300CT.

\subsubsection{Northern-Blot-Analyse und cDNA-Bibliothek-Screen}

Um die vollständige Länge der mRNA des cDNA-Klons ST249 zu bestimmen, wurden zunächst Gesamt-RNA aus HeLa- und HepG2-Zellen isoliert. $20 \mu \mathrm{g}$ der Gesamt-RNA wurden unter denaturierenden Bedingungen aufgetrennt, auf Nitrozellulose geblottet und mit der 0,8 kb [ $\left.{ }^{32} \mathrm{P}\right]$-dCTP-markierten cDNA-Sonde des Klons 249 hybridisiert. Die autoradiographische Analyse ergab keine radioaktiv markierten RNA-Banden. Um eine sensitivere Methode zum Nachweis des RNA-Transkriptes anzuwenden, wurde PolyA ${ }^{+}$-RNA isoliert, $5 \mu \mathrm{g}$ unter gleichen Bedingungen aufgetrennt und nach Transfer auf Nitrozellulose mit der 0,8 kb cDNA-Sonde hybridisiert. Die autoradiographische Auswertung ergab zwei Banden von 2,8 kb und 4 kb. Der Nachweis der RNA-Transkripte bestätigt die Vermutung, daß der Klon 249 unvollständig ist.
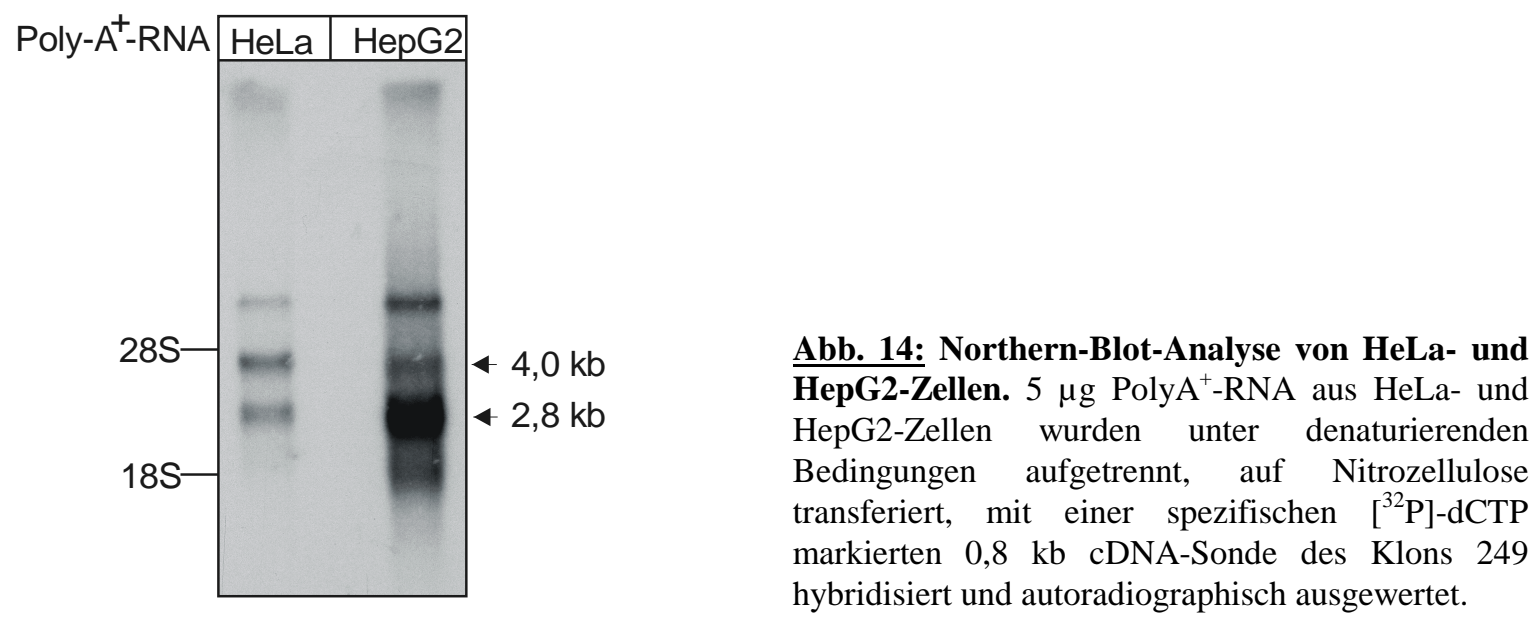

Abb. 14: Northern-Blot-Analyse von HeLa- und HepG2-Zellen. $5 \mu \mathrm{g}$ PolyA ${ }^{+}$-RNA aus HeLa- und HepG2-Zellen wurden unter denaturierenden Bedingungen aufgetrennt, auf Nitrozellulose transferiert, mit einer spezifischen $\left[{ }^{32} \mathrm{P}\right]-\mathrm{dCTP}$ hybridisiert und autoradiographisch ausgewertet. 
Zur Isolierung des gesamten cDNA-Klons wurde eine humane HeLa-cDNA-Bibliothek (Clontech) im Vektor $\lambda$-gt10 mit einer $\left[{ }^{32} \mathrm{P}\right]$-dCTP-markierten $0,8 \mathrm{~kb}$ cDNA-Sonde gescreent. Hierbei wurden zwei $\lambda$-Phagen-Klone mit cDNA-Insertlängen von $3 \mathrm{~kb}$ und 2,4 $\mathrm{kb}$ isoliert, deren cDNA-Sequenzen im 3'-nicht-translatierten Bereich identisch mit Klon 249 waren. Die 2,4 kb und $3 \mathrm{~kb}$ cDNA-Inserts wurden mit EcoRI aus dem Vektor $\lambda$-gt10 ausgeschnitten, in den Vektor pBluescript KS kloniert und sequenziert. Die Sequenzierung ergab im 5'-Bereich der cDNA-Sequenzen einen Bereich mit einem GC-Gehalt von $80 \%$, der zum vorzeitigen Abbruch der Sequenz führte, ohne ein ATG-Startcodon zu lokalisieren. Durch Sequenzvergleich der cDNA-Sequenzen wurden keine Homologien mit bekannten Nukleotidsequenzen gefunden. Die cDNA-Sequenz und die daraus abgeleiteten Aminosäuren sind im Anhang unter 8.2 beschrieben.

\title{
4.2.3 Charakterisierung des ST 249-Produktes
}

Zur Gewinnung von Antikörpern gegen die C-terminale Proteindomäne des Klons 249 wurde die cDNA von 860 bp aus dem Vektor pGAD-GH ausgeschnitten und in den Leserahmens der GST-cDNA-Sequenz des Vektors pGEX-4T-3 kloniert und sequenziert. Das in E. coli BL-21-Zellen exprimierte GST-249 Fusionsprotein wurde über eine Glutathion-Agarose Matrix gereinigt, durch SDS-PAGE getrennt und durch CoomassieFärbung analysiert (Abb. 15).

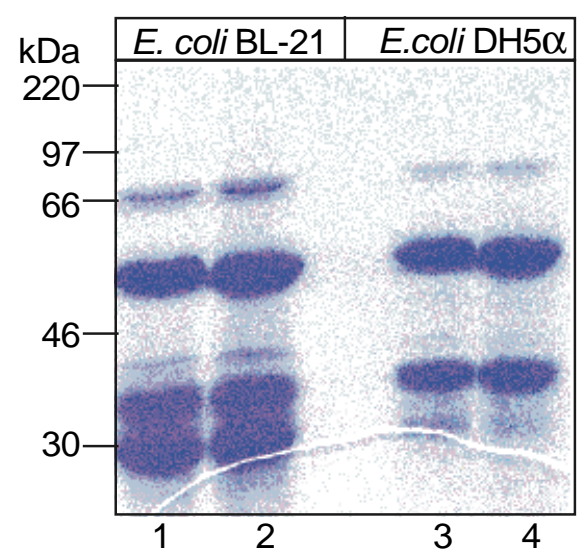

\begin{abstract}
Abb. 15: Analyse des gereinigten GSTFusionsproteins über SDS-PAGE und CoomassieFärbung. Die Expression des GST-249Fusionsprotein wurde in E. coli BL-21- und E. coli DH5 $\alpha$-Zellen bei $22{ }^{\circ} \mathrm{C}$ für 3 Stunden induziert, die Fusionsproteine an Glutathion-Agarose gebunden und die Proteine unter reduzierenden (Bahn 1 und 3) und nicht-reduzierenden (Bahn 2 und 4) Bedingungen solubilisiert. Das isolierte GST-Fusionsprotein wurde durch SDS-PAGE (10\% Acrylamid) aufgetrennt und die Proteinbanden durch Coomassie angefärbt.
\end{abstract}

Es waren eine $50 \mathrm{kDa}$ - und zwei weitere $35 \mathrm{kDa}$ - und $28 \mathrm{kDa}-$ Banden sichtbar. Bei dem 50 kDa-Protein handelt es sich um das Fusionsprotein aus GST (28 kDa) und dem 
translatierten Anteil von 614 bp der cDNA-Sequenz (22,5 kDa). Es ist zu vermuten, daß es sich bei den beiden anderen Proteinen um proteolytische Abbauprodukte handelt.

Nach Variation der Inkubationstemperatur während des Kulturwachstums, des verwendeten E. coli-Stammes und der Dauer und Art der Ultraschallbehandlung, zeigte sich ein geringerer Abbau des GST-Fusionsproteins bei Verwendung des E. coli- Stammes DH5 $\alpha$ und einer Inkubationstemperatur von $22{ }^{\circ} \mathrm{C}$ während der Induktion mit IPTG. Die Aufschlußbedingungen hatten keinen Einfluß auf die Integrität des GST-Fusionsproteins. Nach Spaltung des Fusionsproteins mit Thrombin und Entfernung des GST war keine Coomassie-anfärbbare Bande mehr im SDS-Gel nachweisbar.

Das gesamte 50 kDa-Fusionsprotein wurde deshalb zur Immunisierung von Kaninchen verwendet und das Antiserum im Western-Blot getestet. Dazu wurden Homogenate, zytosolische, die gesamte Membranfraktion, membranassoziierte (1 M NaCl-Extrakt) und integrale Membranproteine (TX100-Extrakt) von HeLa-Zellen und Hautfibroblasten präpariert und nach SDS-PAGE und Transfer auf Nitrozellulose mit dem Antikörper auf die Präsenz von reaktiven Proteinen getestet.

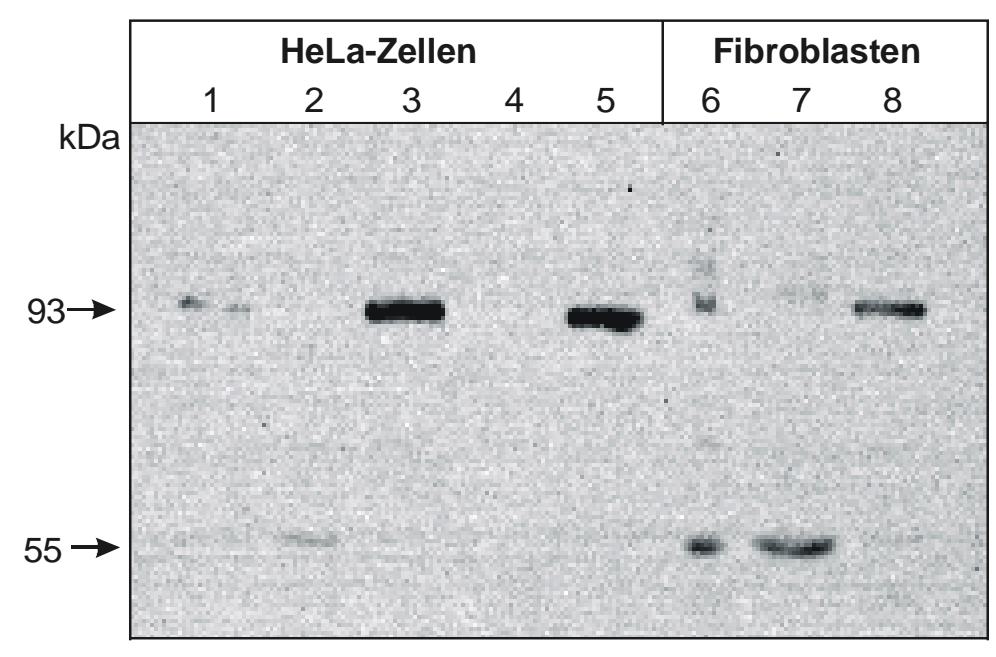

Abb. 16: Western-Blot-Analyse von p93 in HeLa- und Fibroblasten-Zellen. Ca. $35 \mu \mathrm{g}$ Proteine aus Homogenat (Bahn 1 und 6), Zytosol (Bahn 2 und 7), Gesamtmembranfraktion (Bahn 3 und 8), $1 \mathrm{M} \mathrm{NaCl-}$ Membranextrakt (Bahn 4) und TX-100 solubilisierten Membranen (Bahn 5) wurden durch SDS-PAGE getrennt und auf Nitrozellulose geblottet. Nach Inkubation des Blots mit anti-p93-Antikörpern erfolgte der immunologische Nachweis über eine Chemoluminiszenzreaktion.

In dem Homogenat von HeLa-Zellen wurde eine 93 kDa-Bande (Abb. 16, Bahn 1) und in den zytosolischen Fraktionen eine schwächere 55 kDa-Bande detektiert (Bahn 2). Nur das 93 kDa-Protein war in der Gesamt-Membranfraktion (Bahn 3) zu finden, das durch HochSalz Extraktion nicht von den Membranen abgelöst werden konnte (Bahn 4). Durch nachfolgende Solubilisierung in einem TX-100/SDS-haltigem Puffer konnte das 93 kDa- 
Protein vollständig aus der Membranfraktion extrahiert werden (Bahn 5). Die Befunde lassen vermuten, daß das Protein mit einer apparenten molaren Masse von $93 \mathrm{kDa}$ ein integrales Membranprotein ist, das möglicherweise einen $55 \mathrm{kDa}$ abspaltbaren zytoplasmatischen Anteil besitzt.

In dem Homogenat von humanen Hautfibroblasten konnte ebenfalls eine $93 \mathrm{kDa}$ - und eine 55 kDa-Bande detektiert werden (Bahn 6), wobei das Verhältnis der Proteine mehr auf die Seite des zytosolischen $55 \mathrm{kDa}$ - Proteins verschoben ist.

Um die Zuordnung des p93 zu Typ I oder Typ II integralen Membranproteinen zu ermöglichen, und andererseits eine mögliche Glykosylierung festzustellen, wurden Membranfraktionen in Abwesenheit oder Anwesenheit von Trypsin bzw. PNGase F behandelt. Nach einer 40 min Inkubation bei $37{ }^{\circ} \mathrm{C}$ in Gegenwart von $1 \mathrm{mg}$ Trypsin war keine immunreaktive Bande nachweisbar (Bahn 2). Das zeigt, daß das Trypsin-sensitive zytoplasmatische Ende des p93, gegen das die Antikörper gerichtet sind, den C-Terminus enthält und es sich deshalb wahrscheinlich um ein Typ I Protein handelt (Abb. 17, Bahn 2). PNGase F-Behandlung erzeugt keine Veränderung im elektrophoretischen Laufverhalten (Bahn 4), das auf die Abwesenheit von N-glykosylierten Kohlehydratketten hindeutet.

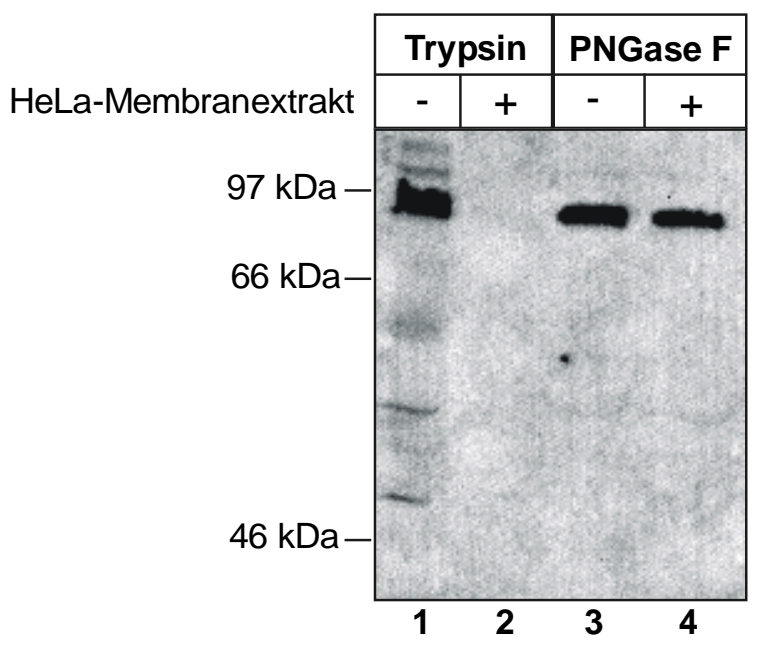

Abb. 17: Trypsin- und PNGase F-Verdau von p93. Aus HeLa-Zellen wurden durch Differentialzentrifugation Gesamt-Membranfraktionen isoliert und mit Trypsin (Bahn 2) oder PNGase F (Bahn 4) behandelt. Nach Solubilisieren der Membranen wurden die Ansätze durch SDS-PAGE aufgetrennt, auf Nitrozellulose geblottet und mit dem anti-249-Antiserum inkubiert. Der immunologische Nachweis des p93 erfolgte über Chemoluminiszenzreaktion. 


\subsubsection{Subzelluläre Lokalisation von $\mathbf{p 9 3}$}

Zur Analyse der subzellulären Verteilung des $93 \mathrm{kDa}$ Proteins wurde der postnukleäre Überstand (PNS) von HeLa-Zellen einer Percoll-Dichtegradientenzentrifugation unterzogen. Nach Zusammenfassung der Fraktionen 1-2 (höchste Dichte, höchste B-Hexosaminidaseaktivität, I), 3-4 (II), 5-6 (III), 7-8 (IV), 9-10 (2. Aktivitätsgipfel der ß-Hexosaminidaseaktivität, V) und 11-12 (VI) wurden die Membranen durch Ultrazentrifugation von Percoll getrennt. Der Solubilisierung der Membranen schloß sich eine SDS-PAGE und Western-Blot-Analyse an.

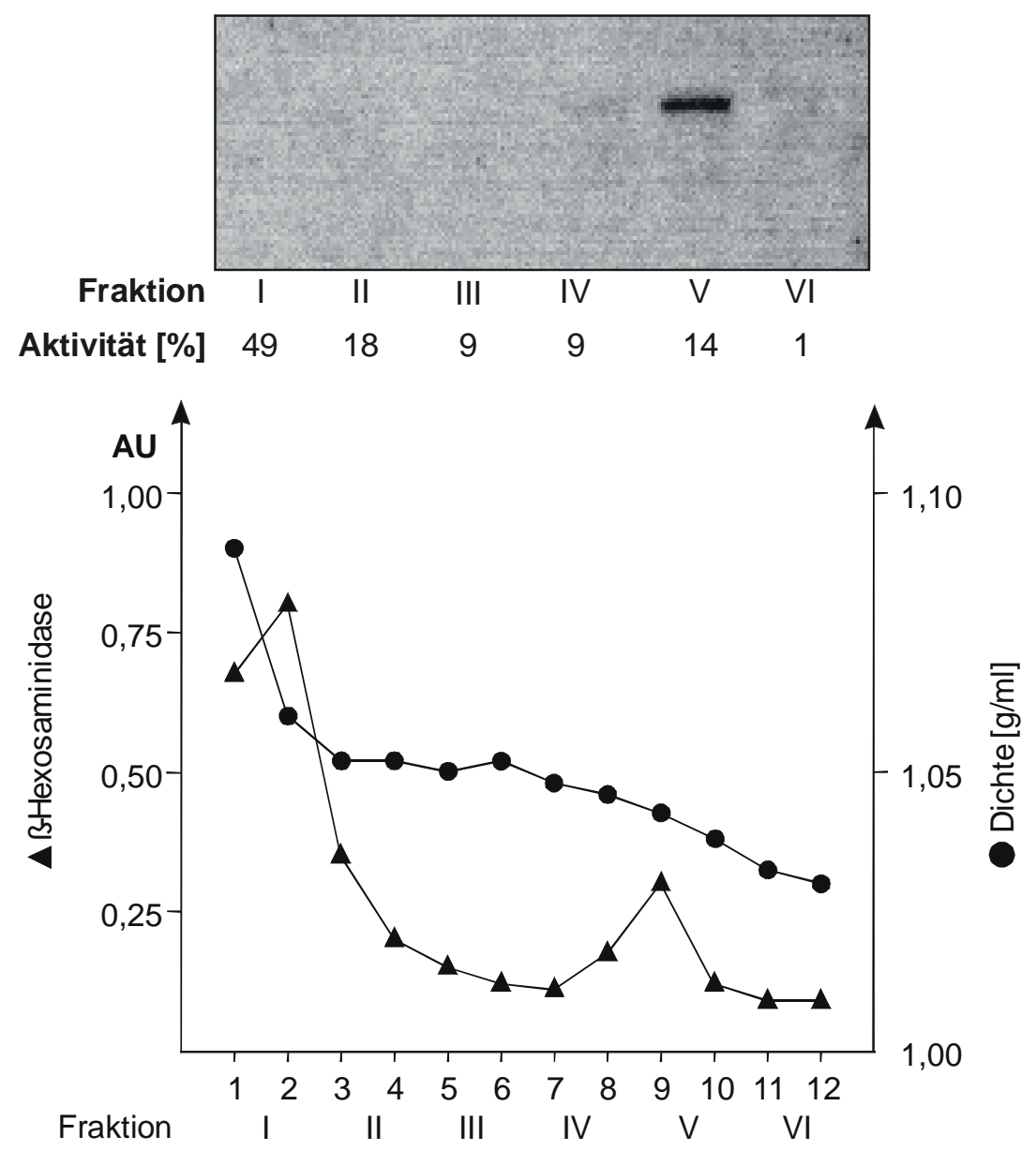

Abb. 18: Subzelluläre Lokalisation des p93 und B-Hexosaminidase-Aktivität in Percoll-Gradienten. Der PNS aus HeLa-Zellen wurde auf einen Percoll-Gradienten aufgetragen und für 30 min bei $20.000 \mathrm{rpm}$

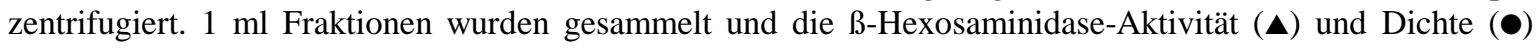
bestimmt (unterer Teil). Wie angegeben wurden jeweils 2 Fraktionen (Fraktionen I-VI) vereinigt und das Percoll durch Zentrifugation entfernt. Anschließend erfolgte die Analyse durch p93-Western-Blot (oberer Teil). Die Zahlen unterhalb der Abbildung geben die Aktivität der ß-Hexosaminidase bezogen auf die wiedergefundene Gesamtaktivität an.

Die Gesamtheit des 93 kDa-Proteins war in den leichten Membranfraktionen IV und V detektierbar, die aus Golgi-, Endosomen-, ER- und Plasmamembranen besteht (Abb.18, oben). 


\subsubsection{Subzelluläre Fraktionierung nach Behandlung von HeLa-Zellen mit Cytochalasin B/ Nocodazol}

Um festzustellen, ob es sich bei dem p93 um ein zytoskelettales Protein handelt und ob p93 in Organellen lokalisiert ist, die sich unter dem Einfluß von Aktinfilament- oder Mikrotubuli-Depolymerisation in periphere Vesikelstrukturen auflösen (z. B. Golgi-Apparat), wurden HeLa-Zellen mit Cytochalasin B/ Nocodazol inkubiert, um die Polymerisation der Mikrotubuli und Aktinfilamente zu verhindern.

HeLa-Zellen einer $6 \mathrm{~cm}$-Platte wurden für 30 min bei $37^{\circ} \mathrm{C}$ in $\mathrm{An}$ - und Abwesenheit von Cytochalasin B/ Nocodazol in serumfreiem Medium (MEM/BSA) inkubiert. Nach Abtrennung der Kernfraktion wurde der PNS in einem 20\% Percoll-Gradienten fraktioniert und anschließend jeweils 3 Fraktionen vereinigt. Nach Abtrennung des Percolls wurden die Membranen der vereinigten Fraktionen durch SDS-PAGE aufgetrennt, geblottet und immunreaktive Banden mit einem affinitätsgereinigten Antikörper gegen p93 detektiert (Abb. 19).

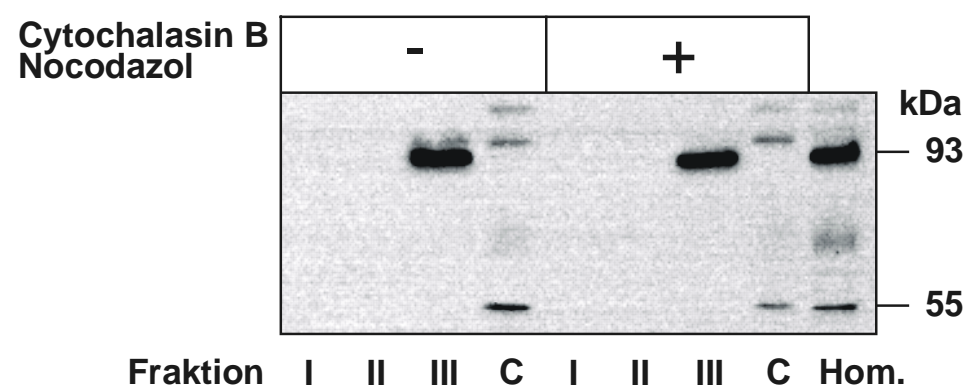

Abb.19: Subzelluläre Fraktionierung von postnukleären Überständen aus HeLa-Zellen nach Behandlung mit Cytochalasin B/Nocodazol. HeLa-Zellen wurden für 30 min in An- und Abwesenheit von Cytochalasin B/Nocodazol in serumfreiem Medium inkubiert, der PNS in einem 20\% Percoll-Gradienten fraktioniert und anschließend jeweils 3 Fraktionen vereinigt (I-III). Die zytosolischen Fraktionen 10 und 11 wurden vereinigt (C), dialysiert und lyophilisiert. Nach Auftrennung der Fraktionen durch SDS-PAGE und Blotten auf Nitrozellulose wurde der Blot mit einem affinitätsgereinigten Antikörper gegen p93 inkubiert und über ECL nachgewiesen.

Durch die induzierte Depolymerisation der Aktinfilamente und Mikrotubuli kommt es nicht zu einer Verschiebung der p93-Immunoreaktivität zur löslichen, zytosolischen Fraktion (C), was auf die Lokalisation des p93 in der Plasmamembran oder Endosomen hinweist. 


\subsection{Interaktion zwischen der zytoplasmatischen Domäne des

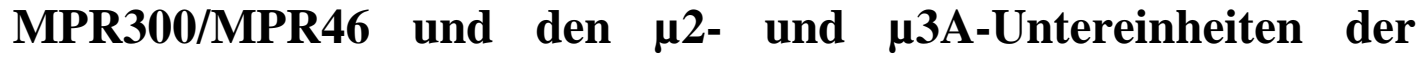 Adaptorkomplexe AP-2 und AP-3}

Das Two-Hybrid-System sollte angewandt werden, um die strukturellen Voraussetzungen für die Wechselwirkung zwischen der zytoplasmatischen Domäne des MPR46 und der $\mu 2$-Untereinheit des AP-2-Komplexes $\mathrm{zu}$ bestimmen. Es ist bekannt, daß es zu einer Wechselwirkung zwischen beiden Proteinen im Prozeß der Endozytose des MPR46 kommt (Johnson et al., 1990; Sosa et al., 1993; Denzer et al., 1997). Andererseits sollten die Vorteile des Systems genutzt werden, um mögliche Interaktionen zwischen der neu beschriebenen $\mu 3 \mathrm{~A}$-Untereinheit des AP-3-Komplexes und der gesamten und mutierten zytoplasmatischen Domänen des MPR46 zu untersuchen.

Von der zytoplasmatischen Domäne des humanen MPR46 wurden verschiedene C-terminale Verkürzungsmutanten (StopH63, StopV48, StopA44), eine N-terminale Deletionsmutante, der die Reste 1-16 fehlen, und verschiedene Alanin-Austauschmutanten hergestellt, die in Abb. 20 dargestellt sind. Die Konstrukte wurden in den DBD-Vektor pAS2 kloniert und die Mutationen durch Sequenzierung überprüft. In den AD-Vektor pGAD-424 wurden die gesamte $\mu 2$-cDNA des AP-2-Komplexes der Maus bzw. die $\mu 3 \mathrm{~A}-\mathrm{cDNA}$ des AP-3-Komplexes der Ratte kloniert.

DBD-Konstrukt

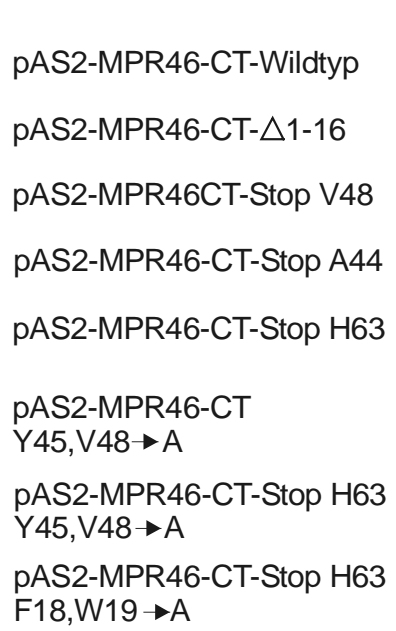

Gal4-Fusionsprotein

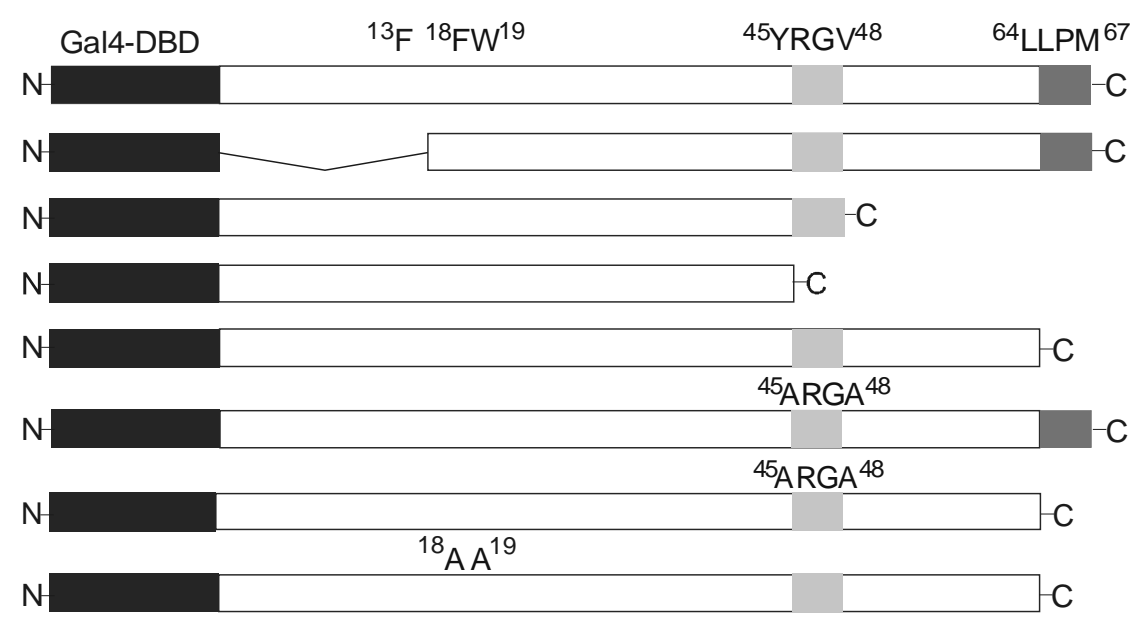

Abb. 20: Schematische Darstellung der Wildtyp- und mutanten zytoplasmatischen Domänen des MPR46. N-terminal sind die verschiedenen MPR46-CT-Konstrukte mit der Gal4-DBD (schwarze Kästchen) fusioniert. Einzelne Aminosäuren und Sequenzen, die Bestandteile wichtiger Sortierungs- und Internalisierungssignale sind, sind hervorgehoben und deren Position in der MPR46-CT-Domäne durch Zahlen markiert. 


\subsubsection{Two-Hybrid-Analyse der Interaktion zwischen Wildtyp und mutanten zytoplasmatischen Domänen des MPR300/MPR46 und der $\mu 2$-Untereinheit des AP-2-Komplexes}

Nach Kotransformation der DBD-Konstrukte und des AD-Konstruktes pGAD424- $\mu 2$ in HF7c-Hefezellen wurde das Wachstum der $\mathrm{His}^{+}-$Kolonien auf (-His)-Selektionsmedium nach einer Inkubation von 5 Tagen bei $30{ }^{\circ} \mathrm{C}$ in Gegenwart von $5 \mathrm{mM}$ 3-AT anhand der Anzahl und des Durchmessers der Kolonien kategorisiert (Abb. 21). Als Kontrollen wurden Hefezellen mit dem MPR46-CT bzw. MPR300-CT im DBD-Vektor pAS2 und der $\alpha$-Untereinheit der Kasein-Kinase 2 (CK2) im AD-Vektor pGAD424 kotransformiert, da beide Rezeptoren in vitro durch Kasein-Kinase 2 phosphoryliert werden können (Rosorius et al., 1993 b; Körner et al., 1994).

\section{DBD}

pAS2

pLamin C

pAS2-MPR300-CT-Wildtyp

pAS2-MPR300-CT-StopV29

pAS2-MPR46-CT-Wildtyp

pAS2-MPR46-CT- $\triangle 1-16$

pAS2-MPR46-CT- StopV48

pAS2-MPR46-CT-StopA44

pAS2-MPR46-CT-StopH63

pAS2-MPR46-CT-Y45, V48 $\rightarrow$ A

pAS2-MPR46-CT-StopH63-Y45, V48 $\rightarrow$ A

pAS2-MPR46-CT-StopH63-F18,W19 $\rightarrow$ A

pAS2-MPR46-CT-Wildtyp

pAS2-MPR300-CT-Wildtyp
AD

+ His $\quad-$ His

Wachstum auf -His

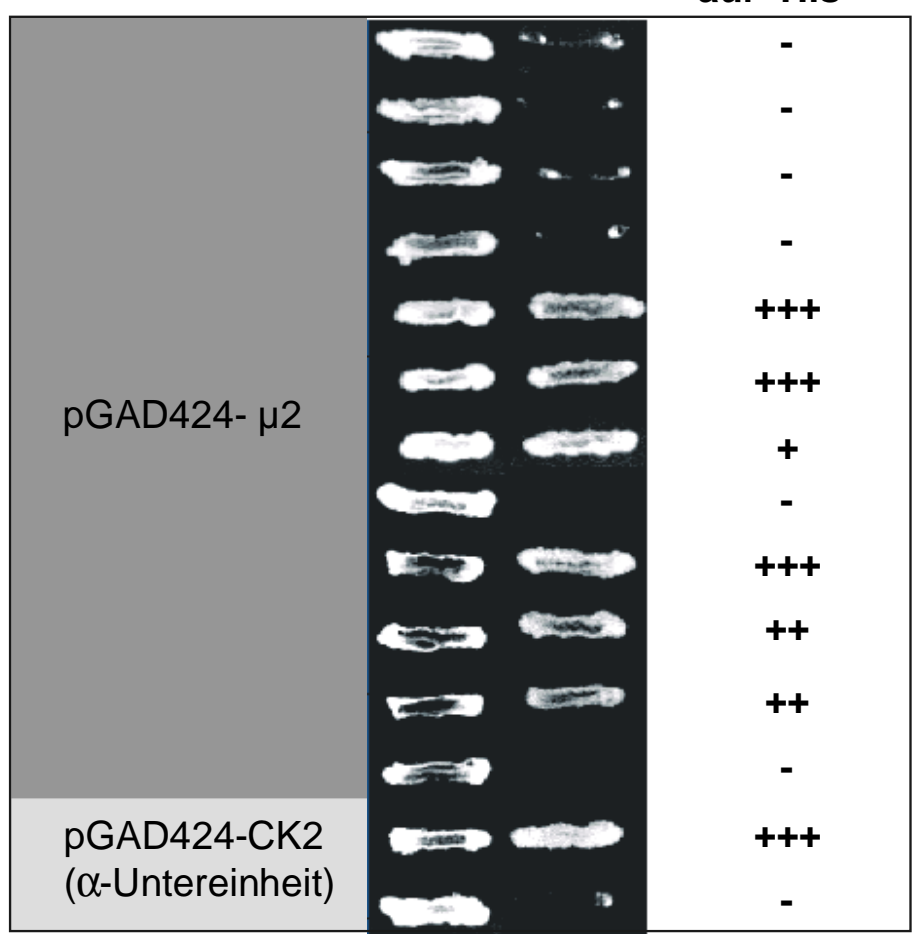

Abb. 21: Two-Hybrid-Analyse der Interaktion zwischen Wildtyp- und mutanten zytoplasmatischen Domänen des MPR46/MPR300 und der $\boldsymbol{\mu} 2$-Untereinheit des AP-2-Komplexes. HF7c-Hefezellen wurden mit den angegebenen DBD-(linke Seite) und AD-Konstrukten (grauer Kasten) kotransformiert, Aliquots der Ansätze auf (+His)- und (-His/5 mM 3-AT)-Selektionsmedium ausplattiert und das Wachstum der Kolonien nach 5 Tagen Inkubation bei $30^{\circ} \mathrm{C}$ dargestellt. Das Wachstum der transformierten Hefezellen auf (-His)Medium wurde in stark (+++), mittel (++), schwach (+) und kein Wachstum (-) eingeteilt. 
Während kotransformierte Hefezellen von MPR46-CT-Wildtyp mit der $\mu 2$-Untereinheit bzw. der $\alpha$-Untereinheit der CK2 ein starkes Wachstum auf Histidin-Mangelmedium (-His) zeigten, wiesen weder der Wildtyp MPR300-CT noch die MPR300-CT-StopV29-Mutante in Gegenwart von $\mu 2$ oder der CK2- $\alpha$-Untereinheit Histidin-unabhängiges Wachstum auf (Abb. 21). Hefezellen, die die Mutante MPR46-CT-StopH63, der das Di-Leucin-Motiv fehlt, bzw. MPR46-CT- $\Delta 1-16$ und die $\mu 2$-Untereinheit koexprimieren, wachsen auf (-His)-Selektionsmedium und zeigen in Anzahl und Durchmesser der Kolonien keinen Unterschied zum MPR46-CT-Wildtyp.

Die weitere C-terminale Verkürzung des MPR46-CT (StopV48) in Gegenwart des $\mu 2-$ Konstruktes führt zu einer starken Abnahme des Wachstums auf Histidin-freiem Medium, das schließlich nach Verkürzung des MPR46-CT unter Deletion der Tyrosin-haltigen Region (StopA44) unterbunden wird. Wenn im intakten MPR46-CT nur Tyr45 und Val48 gegen Alanin (Y45,V48 $\rightarrow \mathrm{A}$ ) ausgetauscht werden, so wuchsen $\mu 2$-kotransformierte Hefezellen auf Histidin-freiem Medium, wobei die Anzahl und der Durchmesser der Kolonien jedoch kleiner war im Vergleich zum Wildtyp MPR46-CT. Die zusätzliche Deletion des Di-Leucin-Motives in den Alanin-Austauschmutanten $($ StopH63-Y45,V48 $\rightarrow$ A) hatte keinen Einfluß auf das Histidin-unabhängige Wachstum der Hefezellen. Die gleichzeitige Entfernung des Di-Leucin-Motives und der Austausch des diaromatischen Signals Phe18, Trp19 gegen Alanin (StopH63-F18,W19 $\rightarrow$ A) verhindert das Wachstum von $\mu 2$-koexprimierenden Hefezellen auf (-His)-Selektionsmedium. Die Spezifität der Interaktion wurde durch das fehlende Wachstum von Hefezellen bestätigt, die die isolierte Gal4-DBD bzw. Lamin C und die $\mu$ 2-Untereinheit koexprimieren.

In Vorversuchen wurden die cDNAs der Wildtyp- und mutanten zytoplasmatischen Domänen des MPR46/MPR300 in die DBD-Vektoren pGBT9 und pAS2-1 kloniert. Nach Kotransformation der DBD-Konstrukte mit den AD-Konstrukten pGAD424- $\mu 2$ in HF7c wuchsen bei keinem der Transformationsansätze Hefezellen auf (-His)-Selektionsmedium. 


\subsubsection{Quantitative Bestimmung der Wechselwirkung zwischen dem MPR300-/ MPR46-CT und $\mu 2$}

Zur Quantifizierung der Wechselwirkung der Gal4-Fusionsproteine wurden SFY526-Zellen mit den bezeichneten DBD-Konstrukten und pGAD424- $\mu 2$ kotransformiert und auf (+His)-Selektionsmedium ausplattiert. Der Nachweis der lacZ-ReportergenAktivierung erfolgte durch Bestimmung der B-Galaktosidase-Aktivität im Filter-Test bzw. durch Bestimmung der $\beta$-Galaktosidase-Aktivität von 5 Einzelkolonien eines Transformationsansatzes im Flüssig-Test.

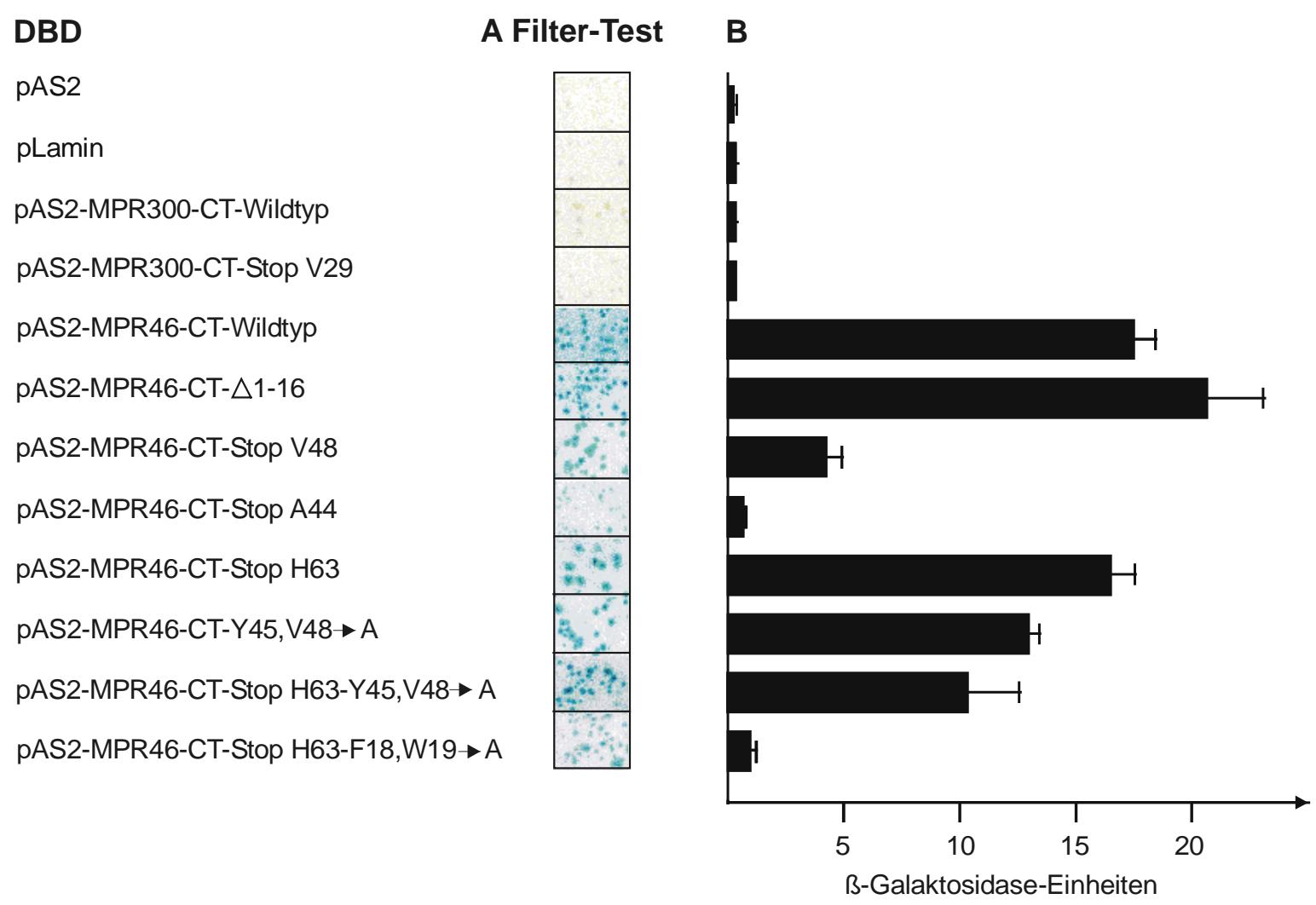

Abb. 22: Bestimmung der B-Galaktosidase-Aktivität im Filter- und Flüssig-Test. SFY526-Zellen wurden mit den angegebenen DBD-Konstrukten und dem AD-Konstrukt pGAD424- $\mu 2$ kotransformiert und auf SD/LT-Agarplatten ausplattiert. Nach einer dreitägigen Inkubation bei $30{ }^{\circ} \mathrm{C}$ wurde die $B$-Galaktosidase-Aktivität im Filter-Test bestimmt (Abb. 22 A). 5 Einzelkolonien wurden gepickt und die B-Galaktosidase-Aktivität in den Hefehomogenaten nach Miller bestimmt (Abb. 22 B).

In sämtlichen kotransformierten Zellen mit His ${ }^{+}$-Phänotyp war ß-Galaktosidase-Aktivität im Filter- (Abb. 22 A) und Flüssig-Test (Abb. 22 B) nachweisbar. Während nach Deletion des Di-Leucin-Motives (StopH63) keine signifikante Verminderung der B-GalaktosidaseAktivität im Vergleich zum MPR46-CT-Wildtyp meßbar war, wurde nach zusätzlicher Deletion der 15 Aminosäuren vor dem Di-Leucin-Motiv (StopV48) eine Reduktion auf $25 \%$ des Wildtyp-Wertes gemessen. Die weitere Deletion des Tyrosin-haltigen 
Internalisierungssignals (StopA44) vermindert die B-Galaktosidase-Expression auf 3,8\% des Wildtyp-Wertes und war im Filter-Test nicht mehr nachweisbar. Nach AlaninAustausch der Phe18- und Trp19-Reste bei gleichzeitiger Deletion des Di-Leucin-Motives $($ StopH63,F18W19 $\rightarrow$ A) war eine Reduktion der B-Galaktosidase-Aktivität auf 5,5\% des Wildtyp-Wertes meßbar.

Der Alanin-Austausch der Tyr45- und Val48-Reste im gesamten MPR46-CT $($ Y45V48 $\rightarrow$ A) bewirkt eine Abnahme der Wechselwirkung um 25\% im Vergleich zum Wildtyp-Wert, die nach zusätzlicher Deletion des Di-Leucin-Motives (StopH63, $\mathrm{Y} 45 \mathrm{~V} 48 \rightarrow \mathrm{A})$ um weitere $15 \%$ reduziert war. Nach Deletion der ersten 16 Aminosäuren $(\Delta$ 1-16) nach der Transmembrandomäne war ein Anstieg der lacZ-Reportergen-Aktivität um 18\% im Vergleich zum Wildtyp meßbar. Die Interaktion zwischen dem MPR46-CT und der $\mu 2$-Kette ist spezifisch, da Hefezellen, die mit der isolierten Gal4-DBD bzw. dem nicht-verwandten Lamin $C$ und $\mu 2$ kotransformiert wurden, keinen lac $Z^{+}$-Phänotyp zeigen. Nach Expression des MPR300-CT und der MPR300-CT-StopV29-Mutante in Gegenwart von $\mu 2$ war keine B-Galaktosidase-Aktivität im Filter- und Flüssig-Test nachweisbar, was mit dem fehlenden Wachstum auf (-His)-Medium übereinstimmt. 


\subsubsection{Two-Hybrid-Analyse der Interaktion zwischen Wildtyp und mutanten zytoplasmatischen Domänen des MPR300/MPR46 und der $\mu 3 A-$ Untereinheit des AP-3-Komplexes}

Zum Nachweis der Aktivierung des HIS3-Reportergens wurden Hefezellen vom Stamm HF7c mit den angegebenen DBD- und AD-Konstrukten kotransformiert und das Wachstum der His ${ }^{+}$-Kolonien auf (-His)-Selektionsmedium nach einer Inkubation von 5 Tagen bei $30^{\circ} \mathrm{C}$ anhand des Durchmessers und der Anzahl der Kolonien kategorisiert (Abb. 23).

\begin{tabular}{|c|c|c|c|c|}
\hline DBD & AD & + His & -His & $\begin{array}{l}\text { Wachstum } \\
\text { auf -His }\end{array}$ \\
\hline pAS2 & & $x=0$ & + & - \\
\hline pLamin C & & $\Rightarrow$ & 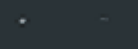 & - \\
\hline pAS2-MPR300-CT-Wildtyp & & $\Rightarrow$ & $=$ & - \\
\hline pAS2-MPR300-CT-StopV29 & & mas & & - \\
\hline pAS2-MPR46-CT-Wildtyp & & $\Leftrightarrow$ & 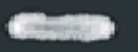 & +++ \\
\hline pAS2-MPR46-CT- $\triangle 1-16$ & & +8 & $\Rightarrow$ & +++ \\
\hline pAS2-MPR46-CT-StopV 48 & pGAD424- $\mu 3 A$ & $\Rightarrow$ & 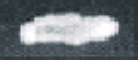 & ++ \\
\hline pAS2-MPR46-CT-StopA44 & & $\Rightarrow$ & & - \\
\hline pAS2-MPR46-CT-StopH63 & & 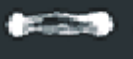 & $\Rightarrow$ & ++ \\
\hline pAS2-MPR46-CT-Y45, V48 $\rightarrow$ A & & $\Longrightarrow$ & $\cos$ & +++ \\
\hline pAS2-MPR46-CT-StopH63-Y45,V48 $\rightarrow$ A & & $=$ & $\Leftrightarrow$ & ++ \\
\hline pAS2-MPR46-CT-StopH63-F18,W19 $\rightarrow$ A & & $=0$ & & - \\
\hline pAS2-MPR46-CT-Wildtyp & $\begin{array}{l}\text { pGAD424-CK2 } \\
\text { ( } \alpha \text {-Untereinheit) }\end{array}$ & 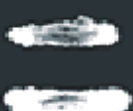 & 200 & $\begin{array}{c}+++ \\
-\end{array}$ \\
\hline
\end{tabular}

Abb. 23: Two-Hybrid-Analyse der Interaktion zwischen Wildtyp- und mutanten zytoplasmatischen Domänen des MPR46/MPR300 mit der $\mu 3$ A-Untereinheit des AP-3-Komplexes. HF7c-Zellen wurden mit den angegebenen DBD- (links) und AD-Konstrukten (grauer Kasten) kotransformiert, Aliquots der Transformationsansätze auf (+His)- und (-His/5 mM 3-AT)-Selektionsmedium ausplattiert und das Wachstum der Kolonien auf (-His)-Agarplatten nach 5 Tagen analysiert. Das Wachstum der Kolonien auf (-His)Medium ist ein Nachweis für eine Protein-Protein-Interaktion zwischen den Gal4-Fusionsproteinen. Das Wachstum der transformierten Hefezellen auf (-His)-Medium wurde in stark (+++), mittel (++), schwach (+) und kein Wachstum (-) eingeteilt.

Hefezellen, die die zytoplasmatische Domäne des Wildtyp-MPR46 und $\mu 3 \mathrm{~A}$ koexprimieren, zeigen ein starkes Wachstum auf Histidin-freiem Medium (Abb. 23). Die Deletion der 16 Aminosäuren nach der Transmembrandomäne des MPR46 bewirkt keine Wachstumsverminderung. Bei Transformation von Konstrukten, bei denen das Di-Leucin- 
Motiv (MPR46CT-StopH63) bzw. die C-terminalen 29 Aminosäuren (MPR46CTStopV48) in den Gal4-Fusionsproteinen deletiert wurden, ist das Wachstum der Hefezellen auf Histidin-freiem Medium im Vergleich zur Wildtyp-Domäne vermindert. Hefezellen, die Mutanten (MPR46-CT-StopA44), bei denen zusätzlich das Tyrosin-haltige Internalisierungssignal deletiert wurde, und $\mu 3 \mathrm{~A}$ koexprimieren, zeigen kein Histidinunabhängiges Wachstum. Nach Kotransformation von Alanin-Austauschmutanten des Tyrosin-Internalisierungssignals (MPR46-CT-Y45,V48 $\rightarrow$ A) und $\mu 3 \mathrm{~A}$ wuchsen Kolonien auf Histidin-freiem Medium, deren Anzahl und Durchmesser kleiner war im Vergleich zum Wildtyp. Die zusätzliche Deletion des Di-Leucin-Motivs (MPR46-CT-StopH63$\mathrm{Y} 45, \mathrm{~V} 48 \rightarrow \mathrm{A})$ in der Alanin-Austauschmutante hatte keinen Einfluß auf das Histidinunabhängige Wachstum. Hefezellen, die das Gal4-Fusionsprotein MPR46CT-StopH63$\mathrm{F} 18, \mathrm{~W} 19 \rightarrow \mathrm{A}$ in Gegenwart von $\mu 3 \mathrm{~A}$ koexprimieren, bilden keine Kolonien auf (-His)-Selektionsmedium. Das fehlende Wachstum von Hefezellen, die die isolierte Gal4DBD bzw. Lamin $\mathrm{C}$ und $\mu 3 \mathrm{~A}$ koexprimieren, unterstützt die Spezifität der Wechselwirkung der Wildtyp- und mutanten zytoplasmatischen Domänen des MPR46 und $\mu 3 \mathrm{~A}$.

Nach Koexpression des Wildtyp MPR300-CT bzw. der MPR-300-CT-StopV29-Mutante und $\mu 3 \mathrm{~A}$ war kein Histidin-unabhängiges Wachstum der Hefezellen nachweisbar.

\subsubsection{Quantitative Bestimmung der Wechselwirkung zwischen dem MPR300-/ MPR46-CT und $\mu 3 A$}

Zum Nachweis der lacZ-Reportergen-Aktivierung und zur Quantifizierung der Wechselwirkung zwischen den Gal4-Fusionsproteinen, wurden SFY526-Hefezellen mit den in Abb. 24 bezeichneten DBD-Konstrukten und $\mu 3 \mathrm{~A}$ kotransformiert, auf (+His)-Medium ausplattiert und die Expression der B-Galaktosidase in den gewachsenen Kolonien im Filter-Test bestimmt. Anschließend wurden 5 Einzelkolonien jedes Transformationsansatzes in SD/-LT-Selektionsmedium kultiviert und die B-GalaktosidaseAktivität der Hefehomogenate quantifiziert. 


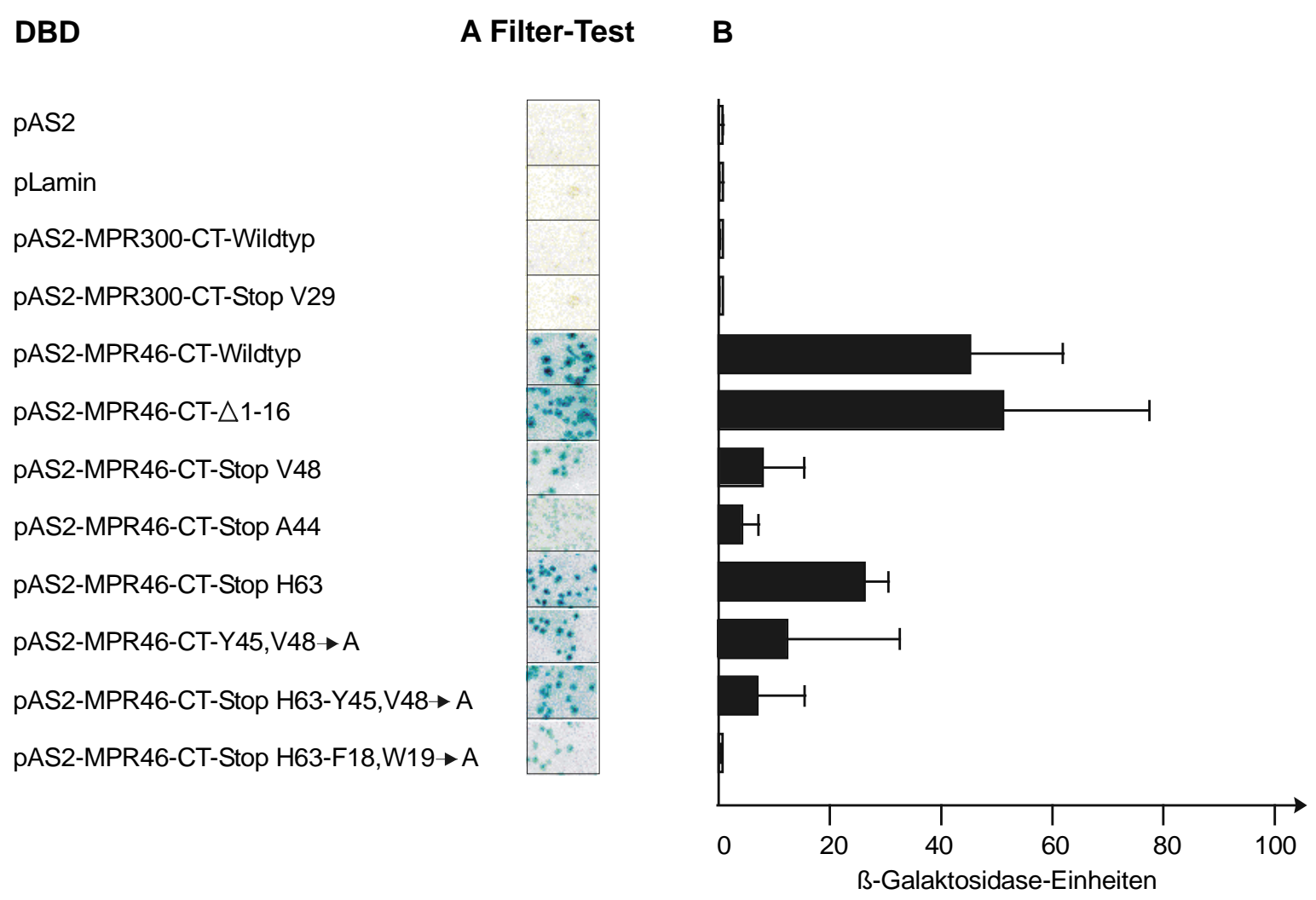

Abb. 24: Bestimmung der B-Galaktosidase-Aktivität im Filter- und Flüssig-Test. SFY526-Zellen wurden mit den bezeichneten DBD-Konstrukten (links) und dem AD-Konstrukt pGAD424- $\mu 3 \mathrm{~A}$ kotransformiert und auf SD/-LT-Agarplatten ausplattiert. Nach einer Inkubation von 3 Tagen bei $30{ }^{\circ} \mathrm{C}$ wurde die $\mathrm{B}$ Galaktosidase-Aktivität im Filter-Test analysiert (Abb. 24 A). Anschließend wurden 5 Einzelklone gepickt und die B-Galaktosidase-Aktivität in den Zellhomogenaten bestimmt (Abb. 24 B). In dem Balkendiagramm sind die nach Miller berechneten Mittelwerte der B-Galaktosidase-Einheiten von 5 Einzelkolonien und die errechneten Standardabweichungen dargestellt (Abb. 24 B).

In Übereinstimmung mit der Fähigkeit zu Histidin-unabhängigem Wachstum wurde bei allen $\mathrm{His}^{+}$-Kolonien B-Galaktosidase-Aktivität im Filter- und im Flüssig-Test gemessen (Abb. 24 A, B). In Hefezellen, die den MPR46-CT-Wildtyp bzw. die Deletionsmutante MPR46-CT- $\Delta 1-16$ in Gegenwart von $\mu 3 \mathrm{~A}$ koexprimieren, korreliert die Expression von B-Galaktosidase mit dem starken Wachstum der Kolonien auf (-His)-Mangelmedium. Während nach Deletion des Di-Leucin-Motives (MPR46-CT-StopH63) eine Erniedrigung der ß-Galaktosidase-Aktivität um 42\% gemessen wird, bewirkt die zusätzliche Deletion der 15 Aminosäuren vor dem Di-Leucin-Motiv (MPR46-CT-StopV48) eine Verminderung um $82 \%$ im Vergleich zum Wildtyp MPR46-CT. Nach Deletion des Di-Leucin-Motives und des Tyrosin-Internalisierungssignals (MPR46-CT-StopA44) sinkt die B-GalaktosidaseExpression auf 10\% des Wildtyp-Wertes und ist im Filter-Test nicht mehr nachweisbar, was mit der Unfähigkeit zu Histidin-unabhängigem Wachstum übereinstimmt. Nach Alanin-Austausch der Tyr45- und Val48-Reste geht die Wechselwirkung um 73\% zurück; die noch zusätzliche Deletion des Di-Leucin-Motives vermindert die Interaktion um 
weitere 12\% im Vergleich zu MPR46-CT-Wildtyp-haltigen Zellen. Nach AlaninAustausch der F18- und W19-Reste und Deletion des Di-Leucin-Motives kann weder im Filter- noch im Flüssig-Test ß-Galaktosidase nachgewiesen werden.

Nach Kotransformation von Hefezellen, die die isolierte DBD, Lamin C, den MPR300-CT und die MPR300-CT-StopV29-Mutante in Gegenwart von $\mu 3 \mathrm{~A}$ koexprimieren, war weder im Filter- noch im Flüssig-Test ß-Galaktosidase-Aktivität meßbar, was mit dem Unvermögen zum Wachstum auf Histidin-freiem Medium übereinstimmt.

\subsubsection{Kopräzipitationsanalysen}

Zur Verifizierung der im Two-Hybrid-System gefundenen Wechselwirkung auf Proteinebene wurde die Kopräzipitationsanalyse zwischen GST-Fusionsproteinen der MPR46-CT und den in vitro-translatierten $\mu 2 / \mu 3 \mathrm{~A}-$ Untereinheiten durchgeführt.

\subsubsection{Darstellung der GST-Fusionsproteine der zytoplasmatischen Domäne des MPR46}

Sämtliche MPR46-cDNAs wurden über die Restriktionsendonukleasen EcoRI und SalI aus den pGBT9-MPR46-CT-Konstrukten ausgeschnitten und über dieselben Schnittstellen in den Vektor pGEX-4T-1 kloniert und anschließend sequenziert. Die MPR46-CT-GSTFusionsproteine wurden in E. coli exprimiert, gereinigt und der Proteingehalt bestimmt. Die Intaktheit der Fusionsproteine wurde durch SDS-PAGE und Coomassie-Färbung im Vergleich zu reinem GST verifiziert.

\subsubsection{In vitro-Bindung zwischen Wildtyp- und mutanten MPR46-CT-Domänen und der $\mu$ 2-Untereinheit des AP-2-Komplexes}

Mit Hilfe des TNT $^{\circledR}$ gekoppelten Retikulozyten-Lysat-Systems wurden die Konstrukte pPoly-Luciferase und pSPUTK- $\mu 2$ in Gegenwart von $\left[{ }^{35} \mathrm{~S}\right]$-Methionin transkribiert und translatiert. Nach Auftrennung der Translationsprodukte über SDS-PAGE und anschließender Autoradiographie ergeben sich eine einzelne, radioaktiv markierte 61 kDa-Luciferase-(Abb. 25, Bahn 1) bzw. eine 55 kDa- $\mu$ 2-Bande (Abb. 25, Bahn 3). Um zu bestimmen, ob der Unterschied zwischen der apparenten $(55 \mathrm{kDa})$ und der vorausgesagten 
molaren Masse von $\mu 2(50 \mathrm{kDa})$ auf Phosphorylierung zurückzuführen ist, wurden $5 \mu 1$ des in vitro-translatierten $\mu 2$ mit alkalischer Phosphatase behandelt und anschließend durch SDS-PAGE aufgetrennt. Hierbei zeigte sich keine Veränderung des Laufverhaltens, so daß eine Phosphorylierung der $\mu 2$-Kette im Retikulozytenlysat ausgeschlossen werden kann (Bahn 4). Nach densitometrischer Auswertung der Autoradiographien und Subtraktion der unspezifischen Bindung an GST (Bahn 5) wurde gezeigt, daß 4,3\% der eingesetzten $\mu 2-U n t e r e i n h e i t$ durch den MPR46-CT kopräzipitiert werden (Bahn 6). Die Deletionsmutanten MPR46-CT-StopH63 und MPR46-CT- $\Delta 1-16$ binden $\mu 2$ nicht spezifisch (Bahn 7 bzw. 8).

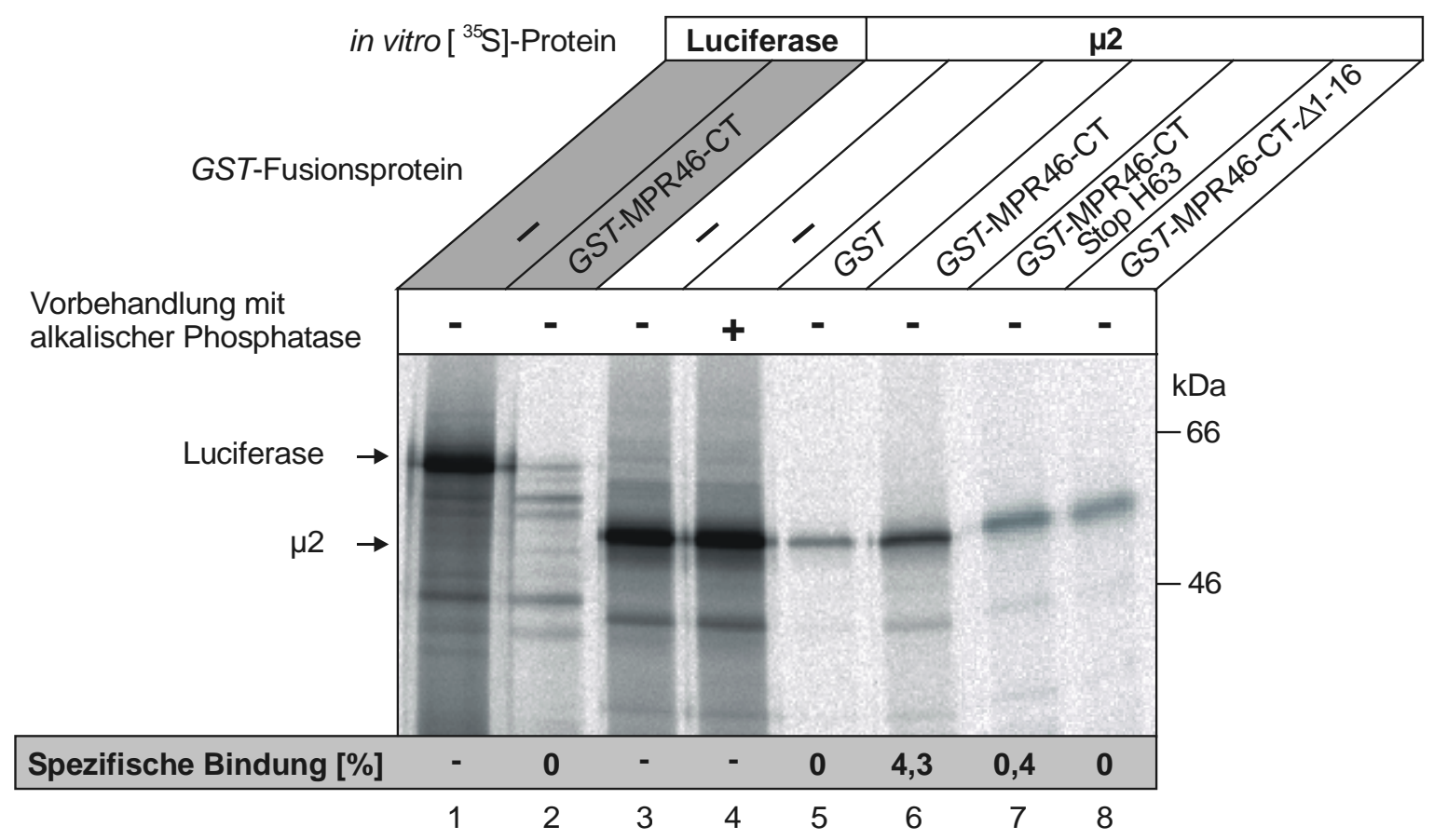

Abb. 25: In vitro-Bindung zwischen Wildtyp- und mutanten GST-MPR46-CT-Fusionsproteinen und der $\boldsymbol{\mu 2}$-Untereinheit des AP-2-Komplexes. Äquimolare Mengen (0,72 nmol) an GST bzw. Wildtyp- und mutanten GST-MPR46-CT-Fusionsproteinen wurden mit $5 \mu 1\left[{ }^{35} \mathrm{~S}\right]$-markierter, in vitro-translatiertem $\mu 2$ für 2 Stunden inkubiert, die Komplexe mit Glutathion-Agarose präzipitiert, gewaschen und nach Extraktion der gebundenen Proteine durch SDS-PAGE aufgetrennt. Zum Ausschluß einer unspezifischen Wechselwirkung wurden 0,72 nmol GST-MPR46-CT mit $5 \mu 1$ in vitro-translatierter Luciferase inkubiert und in analoger Weise weiterbehandelt (Bahn 2). Nach Autoradiographie wurden die radioaktiv markierten Banden densitometrisch ausgewertet und die spezifische Bindung in \% des gesamten eingesetzten Translationsproduktes nach Abzug der unspezifischen Bindung an GST bestimmt. Zum Vergleich wurden jeweils 20\% der eingesetzten Translationsprodukte von Luciferase (Bahn 1) und $\mu 2$ (Bahn 3) auf das Gel aufgetragen. 


\subsubsection{In vitro-Bindung zwischen Wildtyp- und mutanten MPR46-CT-Domänen und der $\mu$ 3A-Untereinheit des AP-3-Komplexes}

Die Analyse der kopräzipitierbaren $\mu 3 \mathrm{~A}$-Untereinheit erfolgte analog der Analyse der $\mu 2$-Bindung. $20 \%$ der für die in vitro-Bindungsansätze eingesetzten Translationsprodukte wurden durch SDS-PAGE aufgetrennt. Nach autoradiographischer Auswertung waren eine $61 \mathrm{kDa}$ Luciferase-(Bahn 1) bzw. eine $50 \mathrm{kDa} \mu 3 \mathrm{~A}-$ Bande (Bahn 3) detektierbar (Abb. 26).

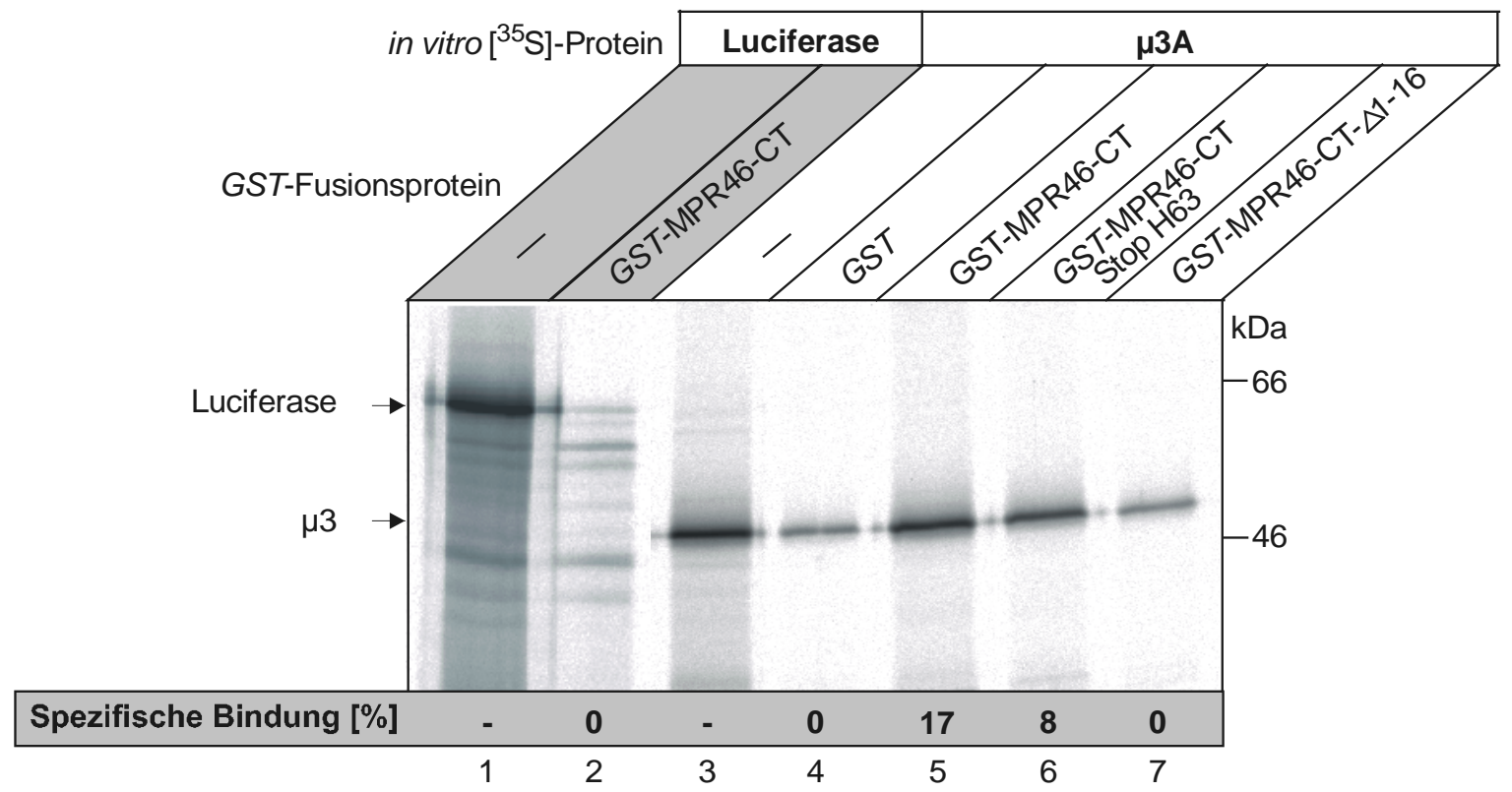

Abb. 26: In vitro-Bindung zwischen Wildtyp- und mutanten GST-MPR46-CT-Fusionsproteinen und der $\boldsymbol{\mu 3 A}$-Untereinheit des AP-3-Komplexes. Äquimolare Mengen (0,72 nmol) an GST bzw. Wildtyp- und mutanten GST-MPR46-CT-Fusionsproteinen wurden mit $5 \mu \mathrm{l}$ in vitro-translatierter, $\left[{ }^{35} \mathrm{~S}\right]-$ Methionin markierter Luciferase bzw. $\mu 3 \mathrm{~A}$ für 2 Stunden bei $4{ }^{\circ} \mathrm{C}$ inkubiert, die Komplexe mit Glutathion-Agarose präzipitiert, gewaschen und nach Extraktion der gebundenen Proteine durch SDS-PAGE aufgetrennt. Die radioaktiv markierten Banden wurden densitometrisch ausgewertet und die spezifische Bindung in $\%$ des gesamten eingesetzten Translationsproduktes nach Abzug der unspezifischen Bindung an GST bestimmt. Zum Vergleich wurden $20 \%$ der gesamten eingesetzten Translationsprodukte von Luciferase (Bahn 1) und $\mu 3 \mathrm{~A}$ (Bahn 3) auf das Gel aufgetragen. Das Experiment wurde parallel zur Kopräzipitation mit $\mu 2$ (Abb. 25) unter identischen Bedingungen durchgeführt.

Äquimolare Mengen an GST-MPR46-CT und GST wurden jeweils mit $5 \mu 1$ in vitro-translatierter, $\left[{ }^{35} \mathrm{~S}\right]$-markierter Luciferase bzw. $\mu 3 \mathrm{~A}$ inkubiert, die Protein-Komplexe mit Glutathion-Agarose präzipitiert, gewaschen und nach Extraktion mit Solubilisierungspuffer durch SDS-PAGE aufgetrennt. Während der Wildtyp MPR46-CT $17 \%$ des eingesetzten $\mu 3$ A-Proteins kopräzipitiert, bindet die MPR46-CTStopH63-Mutante (Bahn 6) 8\% des eingesetzten $\mu 3$ A. Die Mutante, bei der die 16 Aminosäuren nach der Transmembrandomäne deletiert wurden, bindet nicht spezifisch an

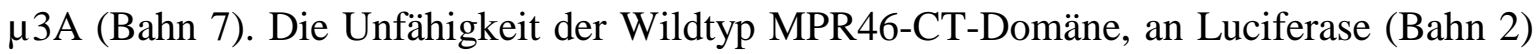


zu binden, unterstreicht die Spezifität der Wechselwirkung zwischen dem MPR46-CT und $\mu 3 \mathrm{~A}$. 


\section{Diskussion}

\subsection{Wechselwirkung des MPR300-CT mit der C-terminalen Domäne von Periplakin}

In mehreren Two-Hybrid-Screens mit dem MPR300-CT als Köderprotein und einer HeLaS3-cDNA-Bibliothek wurden multiple, überlappende cDNA-Klone mit Insertlängen von 1,3-2,3 kb isoliert, die eine starke Wechselwirkung (gemessen an der Wachstumsrate auf His-freiem Medium und der $ß$-Galaktosidase-Aktivität im Flüssig-Test) mit der zytoplasmatischen MPR300-Domäne zeigten, nicht aber mit der zytoplasmatischen Domäne des MPR46.

Der Vergleich der cDNA-Sequenzen mit bekannten Sequenzen der NCBI-Datenbank belegte die Identität mit dem kürzlich beschriebenen humanen Periplakin (Ruhrberg et al., 1997; Aho et al., 1998; GB-Accession-Nr.: AF013717).

Sequenzvergleiche und die Analyse der Domänenstruktur ergaben, daß es sich bei dem 195 kDa-Periplakin um ein neues Mitglied der Plakin-Familie handelt, zu der Desmoplakin, Envoplakin, das bullöse Pemphigoid Antigen (BPAG1) und Plectin gehören (Ruhrberg \& Watt, 1997). Während Plectin und das BPAG1 in Hemidesmosomen lokalisiert sind und unter Beteiligung der Integrine von zentraler Bedeutung für die Verbindung von Epithelzellen an die darunterliegende Basalmembran sind, sind Desmoplakin, Envoplakin und Periplakin Bestandteile der zytoplasmatischen Plaques der Desmosomen, die unter Vermittlung der Cadherine für die Zell-Adhäsion zwischen benachbarten Epithelzellen wichtig sind (Green \& Jones, 1996). Außerdem vermitteln die Plakine auch die Verknüpfung von Intermediärfilamenten (IF) mit Bestandteilen der Aktinfilamente und Mikrotubuli und regulieren die Aktinfilamentdynamik (Andrä et al., 1998; Svitkina et al., 1996). Durch elektronenmikroskopische Studien wurde gezeigt, daß die membranassoziierte Fraktion des Periplakins mit desmosomalen Plaques und Keratinfilamenten kolokalisiert (Ruhrberg et al., 1997). Neben der membranassoziierten Fraktion ist auch ein zytosolischer Anteil des Periplakins nachweisbar, der Zelltypabhängig variieren kann und, wie die eigenen Experimente zeigten, in HeLa-Zellen 25\% des Gesamt-Periplakins beträgt. Western- und Northern-Blot-Analysen ergaben, daß Periplakin hauptsächlich in Keratinozyten und Geweben mit epithelialem Anteil, in Hirn 
und verschiedenen Tumorzellinien exprimiert wird (Ruhrberg et al., 1997; Aho et al., 1998).

Die Struktur von Periplakin besteht aus 6 N-terminalen, putativen $\alpha$-helikalen Untereinheiten, einer zentralen, $\alpha$-helikalen stabförmigen Rod-Domäne und einer C-terminalen, $\alpha$-helikalen Linker-Domäne (Ruhrberg et al., 1997). Im Unterschied zu Periplakin besitzen alle anderen Plakin-Proteine im C-Terminus zusätzliche Subdomänen mit charakteristischen Aminosäure-Wiederholungseinheiten, die in unterschiedlicher Anzahl und Lokalisation vorkommen und aufgrund ihres Homologiegrades als Subdomänen A, B und C bezeichnet werden (Abb. 27, Ruhrberg \& Watt, 1997).

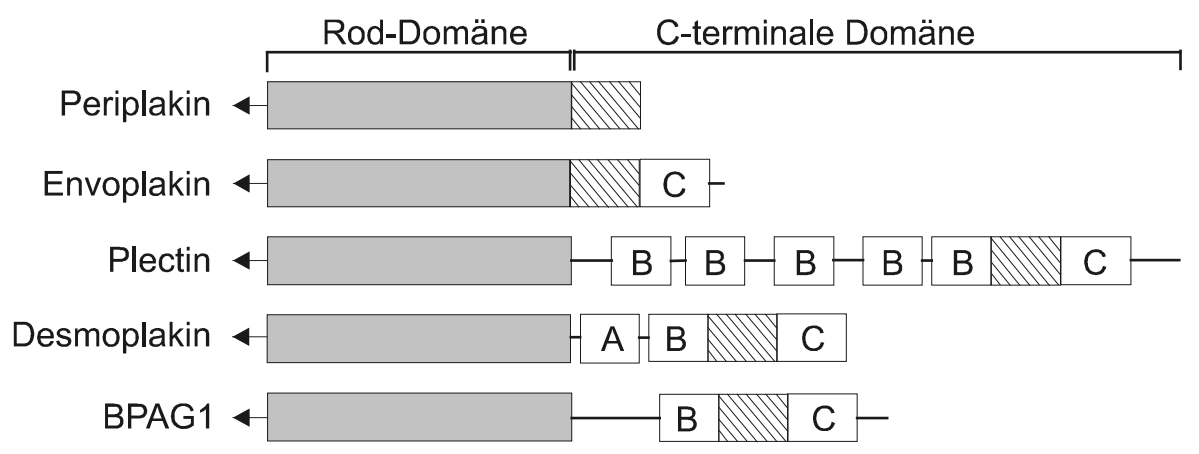

Abb. 27: Schematische Darstellung der C-terminalen Domänen der Plakin-Proteine. Die Linker-Region ist als schraffiertes Kästchen und die A-, B- und C-Subdomänen als offene Kästchen dargestellt (aus Aho et al., 1998).

Die N-terminalen Domänen sind für die Lokalisation der Plakine an der Plasmamembran und die Bindung an Komponenten der Desmosomen und Hemidesmosomen verantwortlich. Plectin und BPAG1 besitzen außerdem im N-terminalen Bereich eine Aktin-Bindungsdomäne und kolokalisieren mit Aktinfilamenten (Yang et al., 1996; Mc Lean et al., 1996). Die zentralen Rod-Domänen sind für die Ausbildung von Homodimeren (z. B. Plectin) bzw. Heterodimeren (Envoplakin mit Periplakin) von Bedeutung. Die C-terminalen Subdomänen A, B und C von Desmoplakin, BPAG 1 und Plectin werden dagegen für die Assoziation mit Intermediärfilamenten verantwortlich gemacht (Ruhrberg \& Watt, 1997). Durch Überexpression der C-terminalen Domänen von Plectin und Desmoplakin konnte gezeigt werden, daß für die Bindung an Intermediärfilamente die gesamte Linker-Region im Kontext mit einer B- und/ oder C-Subdomäne notwendig sind (Nikolic et al., 1996; Stappenbeck et al., 1993). Es kann daher vermutet werden, daß Periplakin nicht direkt an IF's bindet, da die C-terminale Domäne keine B- und C-Subdomänen enthält (Abb. 27). Es ist außerdem anzunehmen, daß die durch 
Immunogold-Elektronenmikroskopie nachgewiesene Kolokalisation von Periplakin in desmosomalen Plaques verschiedener Schichten der Epidermis mit Keratinfilamenten (Ruhrberg et al., 1997) auf die Heterodimerisierung mit Envoplakin zurückzuführen ist, das zumindest die C-Subdomäne enthält. Beim Sequenzvergleich der C-terminalen Aminosäuresequenzen der einzelnen Plakin-Proteine sind die größten Homologien in einem Bereich von 111 Aminosäuren zu finden, der in allen Plakinen vor der Subdomäne C lokalisiert ist und der gesamten Linker-Region des Periplakins entspricht.

Mit den vorliegenden Two-Hybrid-Analysen konnte als erster potenzieller Bindungspartner für die C-terminale Periplakindomäne der zytoplasmatische Anteil des MPR300 nachgewiesen werden. Die Versuche, den interagierenden Bereich im Periplakin einzugrenzen, scheiterten. Weder der Rod-Anteil noch die Linker-Region allein oder ihre $\mathrm{N}$ - und C-terminalen Hälften sind in der Lage, an den MPR300-CT zu binden. Ob die Bindungsstelle für den MPR300-CT in der Übergangsregion zwischen der Rod- und der Linker-Domäne lokalisiert ist, könnte durch Verkürzungen vom $\mathrm{N}$ - und C-Terminus geklärt werden. Da diese Anordnung zwischen Rod-Domäne und Linker-Region nur noch im Envoplakin vorhanden ist (Ruhrberg et al., 1996), sollte überprüft werden, ob dieser Bereich des Envoplakins den MPR300-CT ebenfalls bindet und ob die C-Subdomäne die Bindung hemmt.

Die Wechselwirkung der zytoplasmatischen Domäne des MPR300 mit der C-terminalen Periplakindomäne in der Hefe konnte durch ß-Galaktosidase-Aktivitätsbestimmung quantifiziert und auf Proteinebene durch Kopräzipitation des in vitro-translatierten, $\left[{ }^{35} \mathrm{~S}\right]$-markierten MPR300-CT mit dem gereinigten GST-Periplakin-Fusionsprotein bestätigt werden. Die Spezifität der Wechselwirkung wurde mit der isolierten Gal4-DBD, Lamin C, p53, Luciferase und dem MPR46-CT in verschiedenen Testverfahren geprüft. Zusammen mit der Analyse mutierter MPR300-CT-Formen ergab sich, daß die 29 Aminosäuren nach der Transmembrandomäne mit dem intakten Tyrosin-haltigen Signal für die Wechselwirkung ausreichend sind. Da der gleichzeitige Alanin-Austausch der Tyr26und Val29-Reste in der gesamten zytoplasmatischen Rezeptordomäne jedoch die Wechselwirkung mit Periplakin um ca. 60\% gegenüber dem Wildtyp unterdrückt, ist zu vermuten, daß sich a) die Region distal des Internalisierungssignals hemmend auf die Wechselwirkung mit der Periplakindomäne auswirkt, und b) die Bindungsstelle des Periplakins das Internalisierungssignal einschließt. In ihren initialen Studien zur 
Lokalisation des Internalisierungssignals in der zytoplasmatischen Domäne des MPR300 benutzten Canfield et al. (1991) u. a. genau diese Mutanten, die im Gesamtrezeptormolekül nach Expression in MPR300-defizienten Zellen entweder den Wildtyp-MPR300 ersetzen konnte (StopN30) bzw. nicht mehr in der Lage war (Tyr26,Val29 $\rightarrow$ Ala), die Rezeptorabhängige Endozytose eines lysosomalen Enzyms zu vermitteln. Es lag daher nahe, die Wirkung der Bindung der Periplakindomäne auf endozytotische Funktionen des MPR300 zu untersuchen. Durch Überexpression der C-terminalen Periplakindomäne, die nicht mit Membranen assoziieren kann und auch komplett in der zytosolischen Fraktion nachweisbar war, sollte die Wechselwirkung des MPR300 mit den AP-2-Adaptoren verhindert werden, in deren Folge die Internalisierung des MPR300 von der Plasmamembran abnimmt. Tatsächlich internalisierten BHK-Zellen, die die Periplakindomäne überexprimierten, 30-60\% weniger des M6P-haltigen Liganden als vektortransfizierte Kontrollzellen. Diese Befunde lassen jedoch noch keine Schlußfolgerungen über die physiologische Bedeutung des Periplakins bei der Regulation der MPR300-abhängigen Endozytose zu. Es ist nicht bekannt, ob BHK-Zellen ähnlich wie die epithelialen COS-Zellen Desmosomen bilden können, und damit theoretisch die Möglichkeit besteht, daß die überexprimierte Periplakindomäne über Heterodimerbildung das Intermediärfilament-Netzwerk zerstört, wie es nach Überexpression der C-terminalen Desmoplakin-Domäne beobachtet wurde (Stappenbeck \& Green, 1992). Andererseits liegen keine Befunde vor, daß die Intermediärfilamente wie Aktinfilamente oder Mikrotubuli für frühe Rezeptor-vermittelte Endozytose-Prozesse wichtig sind (Geli \& Riezman, 1998). Eher kann eine dritte Möglichkeit in Erwägung gezogen werden, daß die Interaktion zwischen dem MPR300-CT und Periplakin für den intrazellulären Transport von internalisierten Desmosomen zum Lysosom von Bedeutung ist. Die Assemblierung und Bildung von Desmosomen ist abhängig von der extrazellulären $\mathrm{Ca}^{2+}$-Konzentration. So werden desmosomale Komponenten, besonders die Glykoproteine, bei niedriger $\mathrm{Ca}^{2+}$-Konzentration $(<0.1 \mathrm{mM})$ und in Abwesenheit von Zellkontakten schnell abgebaut (Pasdar \& Nelson, 1989). Die internalisierten Desmosomen besitzen eine charakteristische Struktur, bei denen die Plaques an die Vesikel (Desmosome-associated vacuoles, DAV) geheftet sind. Die internalisierten DAV in MDCK-Zellen fusionieren erst auf der Stufe der späten, MPR300positiven Endosomen mit dem lysosomalen Pathway, während frühe Endosomen von den DAV getrennt bleiben (Burdett, 1993). Es ist deshalb vorstellbar, daß die Bindung von Periplakin der DAV an die zytoplasmatische Domäne des MPR300 in späten Endosomen 
als Erkennungs- oder Docking-Protein für die nachfolgende Fusion der internalisierten DAV dient.

Nach Transfektion von MCF7- und HeLa-Zellen konnte in den isolierten, Hygromycinresistenten Klonen keine Überexpression der Periplakindomäne durch Western-Blot nachgewiesen werden. Möglicherweise hat die stabile Überexpression der Periplakindomäne eine toxische Wirkung auf die Zellen, da in COS7-Zellen, die mit der C-terminalen Desmoplakin-Domäne transient transfiziert wurden, der Anteil der transfizierten Zellen 6 Tage nach dem Glyzerinschock stark absank. Schon 9 Stunden nach der Transfektion war die Auflösung des Intermediärfilament-Systems nachweisbar, während das Aktinfilament- und Mikrotubuli-System unbeeinflußt blieben (Stappenbeck \& Green, 1992). Die überlebenden Zellen zeigten ein intaktes Intermediärfilament-Netzwerk sowie eine sehr geringe Expression der Desmoplakin-Domäne (Stappenbeck \& Green, 1992). Diese Vermutung wird dadurch unterstützt, daß die transfizierten HeLa- und MCF7-Zellen gegenüber den BHK-Zellen ein stark vermindertes Wachstum besaßen.

Der immunozytochemische Nachweis einer Kolokalisation des MPR300 und Periplakin in Keratinozyten und HeLa-Zellen konnte nicht gezeigt werden. In eigenen Untersuchungen war nur bei konfluent gewachsenen Keratinozyten eine Periplakin-Färbung entlang der Plasmamembran von benachbarten Zellen detektierbar. Der Nachweis der Kolokalisation wird zusätzlich durch die geringe stationäre Konzentration des MPR300 an der Plasmamembran (5-10\% der Gesamtrezeptorzahl; Braulke, 1996) und unterschiedliche Zellpermeabilisierungsmethoden für den MPR300 und desmosomales Periplakin erschwert (T. Di Colandrea, London, persönliche Mitteilung).

Die funktionelle Bedeutung des Periplakins ist noch völlig unklar. Periplakin wurde kürzlich als eines der Antigene bei Patienten mit paraneoplastischem Pemphigus identifiziert (Mahoney et al., 1998; Proby et al., 1999). Diese seltene Autoimmunkrankheit ist durch eine pathologische Blasenbildung der Haut und begleitende Thymome, Sarkome und Lymphome charakterisiert (Anhalt et al., 1990). 


\subsection{Interaktion der zytoplasmatischen Domäne des MPR300/MPR46 mit den $\mu 2$ - und $\mu 3 A$-Untereinheiten der AP-2- und AP-3- Komplexe}

Die strukturellen Voraussetzungen für die Internalisierung des MPR46 von der Plasmamembran $\mathrm{zu}$ den Endosomen sind gut charakterisiert. Die Analyse der Endozytoseraten von Deletions- und Austauschmutanten des MPR46-CT und PlasmonResonanz-Bindungsstudien mit synthetischen MPR46-CT-Peptiden und AP-2 belegen die Bedeutung multipler Sortierungssignale in der zytoplasmatischen Rezeptordomäne (Höning et al., 1997; Denzer et al., 1997). Bonifacino und Mitarbeiter zeigten, daß die Tyrosin-haltigen Internalisierungssignale vom Typ YXX $\varnothing$ in den zytoplasmatischen Domänen verschiedener integraler Membranrezeptoren direkt an die $\mu 2$-Untereinheit des AP-2-Komplexes binden (Ohno et al., 1995; Marks et al., 1997; Bonifacino \& Dell' Angelica, 1999) Die $\mu 2$-Untereinheit besitzt eine bipartite Struktur, wobei die N-terminalen Aminosäuren 1-145 die Bindung an die ß2-Untereinheit von AP-2 vermitteln, während die C-terminalen Aminosäuren 164-435 mit Tyrosin-haltigen Signalen zytoplasmatischer Rezeptordomänen interagieren (Abb. 28 B, Aguilar et al., 1997). 3-D-Kristallstrukturen der Komplexe einer N-terminalen Deletionsmutante (aa 158-435) von $\mu 2$ und Peptiden der Internalisierungssequenzen des EGF-Rezeptors bzw. TGN38 belegen, daß die Bindungsstelle für den kritischen Tyr-Rest aus einer hydrophoben Tasche der Phe174-, Trp421-, Arg423-Reste und einem Netzwerk aus Wasserstoffbrücken zwischen der Tyrosin-OH-Gruppe des Internalisierungssignals und den Resten Asp176, Lys 203 und Arg 423 von $\mu 2$ aufgebaut ist (Owen \& Evans, 1998). In in vitro-Bindungsstudien interagiert die konservierte Sequenz GYPQ (aa 119-122) der $\mathrm{N}$-terminalen $\mu 2$-Domäne mit Di-Leucin-Motiven von CD3 $\gamma$ und der invarianten Kette des MHC-II-Komplexes (Bremnes et al., 1998).

In der vorliegenden Arbeit wurde durch Two-Hybrid-Analysen eine spezifische Interaktion zwischen dem gesamten MPR46-CT und der $\mu$ 2-Untereinheit des AP-2-Komplexes gezeigt. Die Daten wurden durch Kopräzipitationsanalysen bestätigt, die eine in vitroInteraktion zwischen dem MPR46-CT und $\mu 2$ belegen, bei der 4,3\% der eingesetzten in vitro-translatierten $\mu 2$-Ketten kopräzipitiert werden konnten. In ähnlichen Experimenten konnten Ohno et al. (1995) mit einer Drei-Fach-Wiederholungs-Hexapeptidsequenz des Internalisierungssignals von TGN38 nur $0,3-0,4 \%$ der eingesetzten $\mu 2$-Ketten 
kopräzipitieren. Aus anderen Studien ist bekannt, daß zytoplasmatische Domänen mit Tyrosin-haltigen Internalisierungssignalen nur eine schwache Wechselwirkung mit $\mu 2$ zeigen mit einer $\mathrm{K}_{\mathrm{d}}$ von $10 \mu \mathrm{M}$ (Boll et al., 1996).

In Plasmon-Resonanz-Bindungsstudien mit einem isolierten Peptid, das der Aminosäuresequenz 2-16 der zytoplasmatischen Domäne des MPR46 entspricht, konnte eine Interaktion mit AP-2 nachgewiesen werden (Höning et al., 1997). Die Deletion dieser Aminosäuren 2-16 in der gesamten zytoplasmatischen MPR46-Domäne im Two-HybridTest mit der $\mu 2$-Kette hatte jedoch keinen Einfluß auf das His-unabhängige Wachstum und die ß-Galaktosidase-Expression der Hefezellen. Möglicherweise bindet eine andere AP-2-Untereinheit des Gesamtkomplexes an dieses autonome Internalisierungssignal des MPR46. Die Gründe für die fehlende Kopräzipitation der in vitro-translatierten $\mu 2-K e t t e$

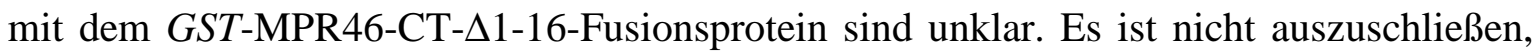
daß das relativ große, N-terminale GST-Protein die Bindung von $\mu 2$ stört.

Die Bindungspartner von Di-Leucin-haltigen Internalisierungsmotiven sind im Gegensatz zu den Tyrosin-haltigen Internalisierungssignalen wenig charakterisiert. Da nach Deletion des C-terminalen Di-Leucin-Motives (StopH63) des MPR46-CT keine Verminderung des His-unabhängigen Wachstums $\mathrm{zu}$ beobachten war, ist $\mathrm{zu}$ vermuten, daß die $\mu 2$-Untereinheit nicht an dieses Motiv bindet. Zu gleichen Schlußfolgerungen kommen andere Arbeitsgruppen in ihren Two-Hybrid-Analysen, die keine Protein-Interaktion zwischen dem isolierten Di-Leucin-Motiv (DKQTLL) ${ }_{3}$ von CD3- $\gamma$ und den isolierten $\mu 1$ -

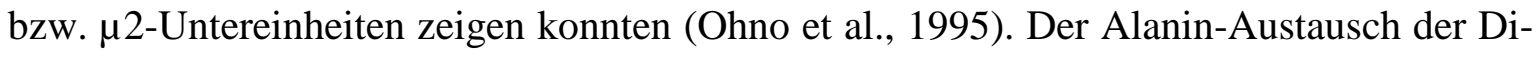
Leucin-Reste eines C-terminalen Peptids des MPR46-CT war ebenfalls nicht mit Veränderungen der Dissoziationskonstanten zu AP-2 verbunden (Höning et al., 1997). Bremnes und Mitarbeiter (1998) konnten in Peptid-Phagen-Interaktionsstudien eine Wechselwirkung zwischen synthetischen Peptiden der invarianten Kette der Klasse II

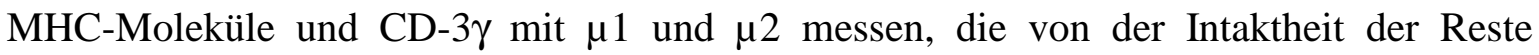
118-122 in $\mu 1$ bzw. $\mu 2$ abhängig war.

Das schwache His-unabhängige Wachstum der mit der MPR46-CT-StopV48-Mutante transformierten Hefezellen, bei der das Tyrosin-haltige Internalisierungssignal an den C-Terminus plaziert wurde, unterstreicht die Bedeutung von distalen Sequenzen für die Bindung von $\mu 2$. In Two-Hybrid-Interaktionsstudien zwischen $\mu 2$ und TGN38-CTMutanten, bei denen das Tyrosin-haltige Internalisierungssignal an den C-Terminus gesetzt wurde, wurde eine 2-3-fach stärkere Wechselwirkung gemessen (Ohno et al., 1996). Da 
nach Deletion des Di-Leucin-Motives (StopH63) keine Abnahme der Interaktion zwischen dem MPR46-CT und $\mu 2$ zu beobachten war, ist es möglich, daß das Cluster von sauren Aminosäuren $\left({ }^{50} \boldsymbol{D D Q L G E E S E E R} \boldsymbol{D} \boldsymbol{D}^{62}\right)$ zwischen dem Tyrosin-haltigen Internalisierungssignal und dem Di-Leucin-Motiv wichtig für die Wechselwirkung ist. Die erhaltenen Daten werden durch Untersuchungen unterstützt, die einen inhibierenden Einfluß synthetischer MPR46-CT-Peptide (aa 49-58; aa 54-62) auf die in vitro-Interaktion zwischen AP-2 und dem MPR46-CT belegen (Höning et al., 1997). Das positive elektrostatische Oberflächenpotenzial von benachbarten Regionen der $\mu 2$-Bindungsstelle würde eine ionische Wechselwirkung mit negativ-geladenen Carboxylatgruppen der sauren Aminosäuren im Bereich der Reste 48-61 ermöglichen (Owen \& Evans, 1998). Die eigenen Untersuchungen unterstreichen, daß für die Bindung von $\mu 2$ das intakte Tyrosin-haltige Internalisierungssignal des MPR46-CT essentiell ist und distal gelegene Sequenzen für die Interaktion notwendig sind. Für diese Vermutung spricht, daß nach Alanin-Austausch der kritischen Tyr45- und Val48-Reste die Interaktion nicht abbricht, während nach Deletion des gesamten Tyrosin-haltigen Internalisierungssignals keine Wechselwirkung mehr zu beobachten ist. Zur genaueren Definition des Einflusses der sauren Reste müßte die Interaktion von $\mu 2$ mit Alanin-Austauschmutanten der sauren Aminosäuren in der gesamten Rezeptordomäne untersucht werden.

In Analogie zu $\mu 2$ sollte das Bindungsverhalten von Wildtyp- und mutanten MPR46-CTDomänen mit der $\mu 3 \mathrm{~A}$-Untereinheit des AP-3-Komplexes untersucht werden. Beim Homologiescreen einer Rattenhirn-cDNA-Bibliothek wurden zwei 47 kDa-Proteine $(\mu 3 \mathrm{~A}$ und $\mu 3 \mathrm{~B}$ ) isoliert, die $\mathrm{zu} 80 \%$ untereinander und $\mathrm{zu} 30 \%$ identisch $\mathrm{zu} \mu 1$ und $\mu 2$ sind (Pevsner et al., 1994). Der AP-3-Komplex ist wie AP-1 und AP-2 ein heterotetramerer Komplex, der aus je einem großen $\delta-(160 \mathrm{kDa})$ und $33-(140 \mathrm{kDa})$ Adaptin, einer mittleren $\mu 3-(47 \mathrm{kDa})$ und einer kleinen $\sigma 3-(22 \mathrm{kDa})$ Untereinheit zusammengesetzt ist und ubiquitär exprimiert wird (Dell' Angelica et al., 1997; Simpson et al., 1997; Abb. 28 A). Neben der ubiquitär exprimierten $\mu 3 \mathrm{~A}$-Untereinheit existieren gehirnspezifische $\mu 3 \mathrm{~B}$ - und B3B-Isoformen (Pevsner et al., 1994; Newman et al., 1995). Der AP-3-Komplex wurde am TGN und/ oder endosomalen Strukturen lokalisiert, wobei die Anlagerung an Membranen in GTP- und Brefeldin A-abhängiger Weise durch die kleine GTPase ARF 1 reguliert wird (Ooi et al., 1998). Verschiedene Untersuchungen in Hefe- und Säugetierzellen belegen, daß AP-3 am Clathrin-unabhängigen Transport lysosomaler Membranproteine vom TGN oder 
endosomalen Strukturen zu den Lysosomen bzw. Melanosomen, Lysosomen-ähnlichen Organellen der Melanozyten, beteiligt ist (Cowles et al., 1997; Le Borgne et al., 1998; Dell' Angelica et al., 1999 b). Die Deletion des $\mu 3$ A-Homologs der Hefe blockiert den Transport der alkalischen Phosphatase (ALP) zur Vakuole, die dem Lysosom der Säugerzelle entspricht, während der Vps45p- und Clathrin-abhängige Transport der löslichen vakuolären Hydrolase Carboxypeptidase Y (CPY) unbeeinflußt bleibt (Cowles et al., 1997). Auch die verminderte Pigmentierung von Pigmentgranula in Drosophila mit Mutationen im Garnet-Gen, dessen Produkt der $\delta$-Untereinheit des AP-3 entspricht, ließen vermuten, daß AP-3 an der Proteinsortierung zu den Lysosomen beteiligt ist (Simpson et al., 1997). Die Hemmung der AP-3-Funktion durch $\mu 3$ A-Antisense-Oligonukleotide zeigte weiterhin, daß AP-3 am selektiven Transport von lysosomalen Membranproteinen, wie LAMP I und LIMP II, beteiligt ist, während die AP-1- und MPR300-abhängige Sortierung von löslichen lysosomalen Enzymen unbeeinflußt blieb (Le Borgne et al., 1998). Schließlich werden die Befunde durch Daten unterstützt, die in Fibroblasten von Patienten mit Hermansky-Pudlak-Syndrom, deren AP-3-Komplexe aufgrund einer Mutation der B3A-Untereinheit beschleunigt abgebaut werden, eine Fehlsortierung der lysosomalen Membranproteine CD63, LAMP I und LAMP II zur Plasmamembran belegen, während die Verteilung des MPR300, der nicht in Lysosomen zu finden ist, gegenüber Kontrollzellen nicht verändert war (Dell’ Angelica et al., 1999 b).

Die Selektivität des AP-3-vermittelten Transports wird ebenso wie für andere AdaptorUntereinheiten auf Wechselwirkungen mit Signalstrukturen von zytoplasmatischen Domänen der Cargo- oder Membrankomponenten zurückgeführt. Two-Hybrid-Analysen und in vivo-Daten zum Transport von lysosomalen Membranproteinen in AP-3-defizienten Zellen lassen vermuten, daß AP-3 sowohl an Tyrosin-haltige Sortierungssignale vom Typ YXXØ als auch an Di-Leucin-Motive bindet (Odorizzi et al., 1998). In der zytoplasmatischen MPR46-Domäne sind sowohl ein Tyrosin-haltiges Internalisierungssignal $\left({ }^{45} \mathbf{Y R G V}^{48}\right.$ ) vom Typ YXXØ (Marks et al., 1997), das für die AP-2-abhängige Internalisierung des Rezeptors von der Plasmamembran von Bedeutung ist (Johnson et al., 1990), als auch ein Di-Leucin-Motiv $\left({ }^{63} \mathbf{H L L P M}^{67}\right)$, das die Sortierung am TGN vermittelt (Johnson \& Kornfeld, 1992 b), lokalisiert. Ein weiteres Sortierungssignal umfaßt die Phe18- und Trp19-Reste, die für die Bindung von TIP47 und den Rücktransport von Endosomen zum TGN wichtig sind (Diaz \& Pfeffer, 1998). Die Wechselwirkung der 
bekannten Adaptorkomplexe mit Tyrosin-haltigen Signalen vom Typ YXX $\varnothing$ wird durch die $\mu$-Untereinheiten vermittelt, die direkt mit diesen Sequenzen interagieren (Ohno et al., 1995, 1996; Owen \& Evans, 1998). Es sollte daher mit Hilfe des Two-Hybrid-Systems untersucht werden, ob die $\mu 3 \mathrm{~A}-$ Untereinheit des AP-3-Komplexes an die zytoplasmatische MPR46-Domäne bindet, und welche strukturellen Voraussetzungen für die mögliche Interaktion notwendig sind. Zu diesem Zweck wurden die oben genannten MPR46-CTMutanten verwendet, bei denen die wichtigen Aminosäuren der beschriebenen Sortierungssignale gezielt mutiert und/oder deletiert wurden.

Die vorliegenden Two-Hybrid-Analysen zeigten, daß der MPR46-CT und die $\mu 3 \mathrm{~A}-$ Untereinheit des AP-3-Komplexes interagieren. Die Bindung zwischen dem MPR46-CT- und $\mu 3$ A-Fusionsproteinen ist spezifisch, da die isolierte Gal4-DBD und das nicht-verwandte Lamin $\mathrm{C}$ nicht mit $\mu 3 \mathrm{~A}$ interagieren. Die im Two-Hybrid-System erhaltenen Ergebnisse wurden durch Kopräzipitationsanalysen bestätigt, die eine in vitroBindung zwischen GST-MPR46-CT und dem in vitro-translatierten $\mu 3 \mathrm{~A}$ nachweisen. Damit stehen die Ergebnisse im Widerspruch zu in vitro-Studien, die keine Bindung der zytoplasmatischen Domäne des MPR46 an den AP-3-Komplex belegen, während AP-1 und AP-2 zur Interaktion fähig sind (Höning et al., 1998). Dabei muß allerdings berücksichtigt werden, daß die Interaktion in den Plasmon-Resonanz-Bindungsstudien mit synthetischen Peptiden des MPR46-CT und dem gesamten heterotetrameren AP-3-Komplex in vitro durchgeführt wurde, während in den eigenen Untersuchungen Interaktionen zwischen MPR46-CT-Fusionsproteinen und der isolierten $\mu 3 \mathrm{~A}-$ Untereinheit in Hefezellen gemessen wurden. Ähnliche Widersprüche bestehen $\mathrm{zu}$ Two-Hybrid-Analysen anderer Arbeitsgruppen, die eine Bindung des gesamten LAMP I-CT (Stephens \& Banting, 1998) bzw. eines DBD-Fusionsproteins der C-terminalen 27 Aminosäuren des TGN38-CT und des Tyrosin-haltigen Sortierungssignals von LAMP I an $\mu 3 \mathrm{~A}$ zeigten (Dell'Angelica et al., 1999 b), die durch Plasmon-Resonanz-Experimente mit gereinigten AP-3-Adaptorkomplexen nicht detektiert wurde (Höning et al., 1998).

Für verschiedene lysosomale und melanosomale Membranproteine wurde die Bedeutung von Di-Leucin-Motiven für die AP-3-Bindung und den AP-3-abhängigen Transport gezeigt (Odorizzi et al., 1998). Nach Deletion des Di-Leucin-Motives des MPR46-CT (StopH63) wurde in der vorliegenden Arbeit ein schwächeres His-unabhängiges Wachstum der Hefezellen sowie eine Abnahme der ß-Galaktosidase-Aktivität um 50\% im Vergleich zum 
Wildtyp-Wert gemessen. Mit dem GST-MPR46-CT-StopH63-Fusionsprotein können im Vergleich zur Wildtyp-MPR46-CT-Domäne nur $50 \%$ der in vitro-translatierten $\mu 3 \mathrm{~A}-$ Untereinheit präzipitiert werden. Verschiedene in vitro- und in vivo-Untersuchungen belegen, daß Di-Leucin-Motive in den zytoplasmatischen Domänen lysosomaler Membranproteine selektiv mit AP-3 interagieren und für die korrekte Sortierung ins Lysosom/Vakuole wichtig sind (Odorizzi et al., 1998). Für den AP-3-abhängigen direkten Transport von ALP (Vowels \& Payne, 1998) und dem t-SNARE Vam3p (Darsow et al., 1998) in die Vakuole ist ein Di-Leucin-Motiv mit einem kritischen Glutamat-Rest in (-4)-Position von Bedeutung. Die korrekte Sortierung von LAMP I/Tyrosinase-Chimären in das Melanosom (Simmen et al., 1999) und LIMP II ins Lysosom (Sandoval et al., 1994) ist von der Intaktheit des Di-Leucin-Motivs abhängig, wobei im Falle von LIMP II die sauren Reste in (-4)- und (-5)-Position relativ zum Di-Leucin-Motiv wichtig sind (Pond et al., 1995). Plasmon-Resonanz-Bindungsstudien mit synthetischen Peptiden der zytoplasmatischen Domänen von LIMP II und Tyrosinase bestätigen, daß für die Bindung von AP-3 ein Di-Leucin-Motiv vom Typ $\left(\mathrm{D} / \mathrm{E}^{(-5)} \mathrm{E}^{(-4)} \mathrm{XXXLL/I)}\right.$ mit benachbarten sauren Resten in (-4)- und (-5)- Position von Bedeutung ist, während mit einem aus der MPR46-CT-Sequenz abgeleitetem synthetischen Peptid, das ebenfalls ein Di-Leucin-Motiv $\left(\mathrm{E}^{(-6)} \mathrm{E}^{(-5)} \mathrm{RD}^{(-3)} \mathrm{D}^{(-2)} \mathrm{HLL}\right)$ mit benachbarten sauren Resten in (-2)-, (-3)-, (-5)- und (-6)-Position enthält, keine Interaktion gemessen werden konnte (Höning et al., 1998). Die Existenz dieses Motives ist jedoch für die Bindung von AP-3 nicht ausreichend, da mit der zytoplasmatischen Domäne der invarianten Kette des MHC Klasse II-Moleküls trotz Existenz einer DDXXXLI-Konsensussequenz keine Interaktion meßbar ist.

Da Two-Hybrid-Analysen und Studien in AP-3-defizienten Zellen die Bedeutung von Tyrosin-haltigen Sortierungssignalen vom Typ YXX $\varnothing$ für die AP-3-Bindung bzw. den AP-3-abhängigen Transport belegen (Ohno et al., 1998; Le Borgne et al., 1998; Dell' Angelica et al., 1999 b; Simmen et al., 1999), wurden MPR46-CT-Mutanten mit Deletion der gesamten bzw. Teilen der Internalisierungssequenz (StopA44 bzw. StopV48) oder Alanin-Austausch der kritischen Reste $(Y 45, V 48 \rightarrow \mathrm{A})$ auf ihre Fähigkeit zur Interaktion mit $\mu 3 \mathrm{~A}$ im Two-Hybrid-System untersucht.

Während Hefezellen, die mit $\mu 3 \mathrm{~A}$ und der Deletionsmutante MPR46-CT-StopV48, bei der das Tyrosin-haltige Internalisierungssignal am C-Terminus lokalisiert ist, kotransformiert wurden, ein schwaches His-unabhängiges Wachstum aufweisen, kann nach Transformation 
der Deletionsmutante MPR46-CT-StopA44, der das gesamte Internalisierungssignal fehlt, kein Wachstum mehr beobachtet werden. Die Bedeutung des Tyrosin-haltigen Signals für die Bindung von $\mu 3 \mathrm{~A}$ wird durch Two-Hybrid-Analysen unterstützt, die eine Interaktion mit den zytoplasmatischen Domänen von TGN38 und LAMP I zeigen (Ohno et al., 1996; Dell` Angelica et al., 1997; Stephens \& Banting, 1998), die nach Alanin-Austausch der kritischen Tyr- bzw. Leu-Reste des Tyrosin-haltigen Internalisierungssignals von TGN 38 abbricht (Ohno et al., 1996). Im Gegensatz zum TGN38-CT kann nach gleichzeitigem Alanin-Austausch der Tyr45- und Val48-Reste des MPR46-CT noch ein His-unabhängiges Wachstum sowie eine schwache $\beta$-Galaktosidase-Aktivität beobachtet werden. Es muß jedoch beim Vergleich der Daten kritisch bemerkt werden, daß die gemessene ß-Galaktosidase-Aktivität in Hefezellen, die die zytoplasmatische Domäne von TGN38 und $\mu 3$ A koexprimieren (ca. 0,1 B-Gal-Einheiten; Stephens \& Banting, 1998), verglichen mit dem MPR46-CT (ca. 50 ß-Gal-Einheiten), sehr niedrig ist.

Interessanterweise können Hefezellen, die mit $\mu 3 \mathrm{~A}$ und der Austauschmutante MPR46CT-StopH63,Y45V48 $\rightarrow$ A, bei der das Di-Leucin-Motiv deletiert und die kritischen Reste des Tyrosin-haltigen Internalisierungssignals gegen Alanin ausgetauscht wurden, kotransformiert wurden, auf His-Mangelmedium wachsen. Die Diskrepanz zwischen der Deletionsmutante MPR46-CT-StopA44 und der Austauschmutante kann damit erklärt werden, daß a) die Konformation der gesamten zytoplasmatischen Domäne für die Bindung an AP-3 wichtig ist, oder b) Aminosäuren, die zwischen Tyrosin-haltigem Internalisierungssignal und dem Di-Leucin-Motiv lokalisiert sind, die Interaktion mit AP-3 modulieren. Für die letzte Vermutung spricht das schwache His-unabhängige Wachstum von Hefezellen, die mit der MPR46-CT-StopV48-Mutante und $\mu 3 \mathrm{~A}$ kotransformiert wurden, da in dieser Mutante die Sequenz zwischen dem Tyrosin-haltigen Internalisierungssignal und dem Di-Leucin-Motiv fehlt. Es ist möglich, daß das Cluster von sauren Aminosäuren vor dem Di-Leucin-Motiv die Interaktion mit $\mu 3 \mathrm{~A}$ moduliert, da saure Reste in (-4)-Position relativ zum Di-Leucin-Motiv in allen Proteinen mit AP-3abhängigem Transport konserviert sind (Darsow et al., 1998). In vitro-Bindungsstudien belegen, daß nach Austausch der vor dem Di-Leucin-Motiv lokalisierten sauren Reste in -(4)- und (-5)-Position der zytoplasmatischen LIMP II-Domäne die Bindungsaffinität zu AP-3 um den Faktor 120 abnimmt (Höning et al., 1998). 
Zusammenfassend lassen die erhaltenen Ergebnisse vermuten, daß sowohl das Tyrosinhaltige Internalisierungssignal als auch das Di-Leucin-Motiv in der zytoplasmatischen Domäne des MPR46 wichtig für die Bindung der $\mu 3$ A-Kette sind, da die Interaktion erst nach Deletion beider Sortierungssignale abbricht. Die Bedeutung beider Sortierungssignale für die AP-3-Bindung wird durch Inhibitionsstudien mit Antisense-Oligonukleotiden gegen die $\mu 3 \mathrm{~A}$-Untereinheit unterstützt, die eine Fehlsortierung der integralen, lysosomalen Membranproteine LIMP II, das ein Di-Leucin-Motiv in der zytoplasmatischen Domäne enthält, und LAMP I, dessen Sortierung ein intaktes Tyrosin-haltiges Sortierungssignal benötigt, zeigen (Le Borgne et al., 1998). Für die korrekte Sortierung der Tyrosinase ins Lysosom sind ein Tyrosin-haltiges Sortierungssignal und ein Di-Leucin-Motiv in der zytoplasmatischen Domäne von Bedeutung (Simmen et al., 1999). Die Aminosäuren 49-63 des MPR46-CT scheinen neben den beschriebenen Sortierungssignalen ebenfalls von Bedeutung $\mathrm{zu}$ sein, da die Interaktion zwischen $\mu 3 \mathrm{~A}$ und der Mutante MPR46-CTStopH63,Y45,V48 $\rightarrow$ A, bei der das Di-Leucin deletiert und die kritischen Reste des Tyrosin-haltigen Internalisierungssignals gegen Alanin ausgetauscht wurden, nicht abbricht. Die Identifizierung der kritischen Reste innerhalb dieses Sequenzbereiches müßte durch kürzere, überlappende Austauschmutanten in der gesamten zytoplasmatischen MPR46-Domäne genauer eingegrenzt werden.

Die Deletion der ersten 16 Aminosäuren nach der Transmembrandomäne ergab keine Beeinträchtigung der Bindung an $\mu 3 \mathrm{~A}$. In der vorliegenden Arbeit wurde außerdem gezeigt, daß Hefezellen, die mit der Mutante MPR46-CT-StopH63,F18,W19 $\rightarrow$ A und $\mu 3$ A kotransformiert wurden, nicht auf His-Mangelmedium wuchsen und keine ß-Galaktosidase-Aktivität aufwiesen. In in vitro-Bindungstudien kann das GSTFusionsprotein dieser MPR46-CT-Mutante jedoch $\mu 3 \mathrm{~A}$ kopräzipitieren. Möglicherweise ist die fehlende Interaktion im Two-Hybrid-System auf eine geringere Expression oder Stabilität des Gal4-Fusionsproteins zurückzuführen.

Die physiologische Bedeutung der Protein-Interaktion zwischen dem MPR46-CT und AP-3 in vivo ist unklar. Da der MPR46 an TGN-Membranen in AP1-haltige, Clathrinbeschichtete Vesikel sortiert wird, ist es unwahrscheinlich, daß AP-3 bei der Sortierung des MPR46 am TGN wichtig ist. Für diese Vermutung spricht, daß der AP-3-abhängige Transport wahrscheinlich in Clathrin-unabhängiger Weise erfolgt, da AP-3 nicht mit Clathrin-beschichteten Einschnürungen am TGN kolokalisiert und nicht mit Clathrin- 
beschichteten Vesikeln assoziiert ist (Newman et al., 1995; Simpson et al., 1996, 1997). Andererseits könnte die potenzielle Bindung von AP-3 an die zytoplasmatische MPR46-Domäne am TGN aber aufgrund einer höheren Affinität von AP-1 zum MPR46-CT blockiert werden. Zu den Faktoren, die die Affinität der Adaptoren zu Sequenzmotiven beeinflussen, gehören die Aminosäuresequenz der Tyrosin-haltigen Sortierungssignale und deren benachbarter Reste (Ohno et al., 1998), die Position des Sortierungssignals in Bezug auf die Transmembrandomäne und den C-Terminus der zytoplasmatischen Domäne (Rohrer et al., 1996), der Oligomerisierungsgrad des Rezeptors (Arneson \& Miller, 1995) und posttranslationale Modifikationen (Mauxion et al., 1996). Da AP-3 hauptsächlich an endosomalen Strukturen lokalisiert wurde, könnte die Wechselwirkung zwischen dem MPR46-CT und $\mu 3 \mathrm{~A}$ möglicherweise beim Transport des Rezeptors von frühen zu späten Endosomen wichtig sein (Ooi et al., 1998). Für diese Vermutung würde auch die unterschiedliche Verteilung der beiden MPRs in den Endosomen sprechen. Während der MPR300, dessen Verteilung in AP-3-defizienten Zellen nicht verändert ist (Le Borgne et al., 1998; Dell' Angelica et al., 1999 b), vorwiegend in vesikulären endosomalen Strukturen lokalisiert ist, befindet sich der MPR46 bevorzugt in sogenannten assoziierten, tubulären Endosomenstrukturen (ATV) (Klumpermann et al., 1993).

Es ist auch möglich, daß AP-3 für den Transport des MPR46 von Endosomen zur Plasmamembran von Bedeutung ist. Für diesen Sortierungsschritt ist die Phosphorylierung des Serinrestes 57 in der zytoplasmatischen MPR46-Domäne wichtig (Breuer et al., 1997), der innerhalb einer Sequenz von sauren Aminosäuren $\left({ }^{56} \mathrm{ESEER}^{60}\right)$ lokalisiert ist. Dieser phosphorylierten Sequenz wird gleichzeitig die Funktion einer hochaffinen Bindungsstelle für AP-1 zugeschrieben (Mauxion et al., 1996).

Das Two-Hybrid-System bietet für weitere Untersuchungen ein wertvolles Werkzeug, die essentiellen Aminosäuren bzw. von Regionen $\mu 3 \mathrm{~A}$ für die Wechselwirkung mit dem MPR46-CT einzugrenzen. 3 D-Kristallstrukturanalysen und die Überexpression von dominant-negativen $\mu 2$-Adaptoruntereinheiten in Zellkultursystemen belegen, daß die Asp176- und Trp421-Reste ein wichtiger Bestandteil der Bindungsstelle für Tyrosinhaltige Internalisierungssignale sind und die Mutation dieser Reste die Endozytose des Transferrinrezeptors stark erniedrigt (Owen \& Evans, 1998; Nesterov et al., 1999). In sämtlichen $\mu$-Untereinheiten verschiedener Spezies ist der Asp176-Rest konserviert, 
während der in den $\mu 1$-, $\mu 2$ - und $\mu 4$-Untereinheiten konservierte Trp421-Rest in den $\mu 3$-Untereinheiten gegen einen Glycin-Rest ausgetauscht ist (Abb. 28 C). Die Analyse von 33A-Austauschmutanten im Two-Hybrid-System könnte die Funktion dieser kritischen Reste für die Bindung an Tyrosin-haltige Signale klären. Weiterhin wäre es interessant, die Wechselwirkung des MPR46-CT mit der $\mu 4$-Untereinheit des kürzlich beschriebenen AP-4-Komplexes zu untersuchen (Dell' Angelica et. al., 1999 a).

A
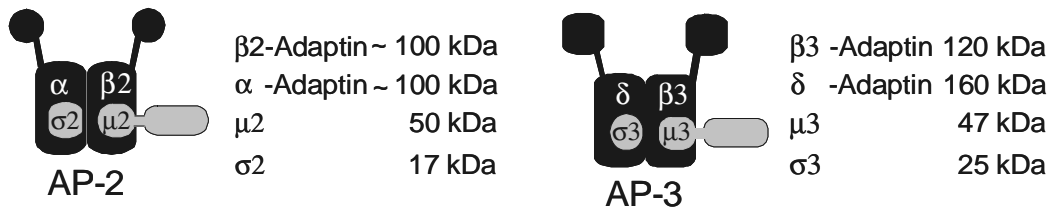

B

C

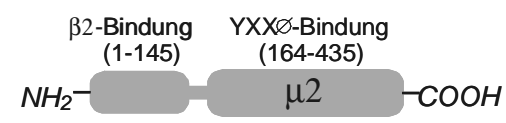

$\begin{array}{lccccc}\text { Aminosäurerest } & \mathbf{1 7 3 - 1 7 6} & \mathbf{2 0 3} & \mathbf{4 0 1} & \mathbf{4 0 4} & \mathbf{4 2 0 - 4 2 3} \\ \text { Maus } \mu 2 & \text { LFLD } & \text { K } & \text { V } & \text { L } & \text { KWVR } \\ \text { Humanes } \mu 2 & \text { LFLD } & \text { K } & \text { V } & \text { L } & \text { KWVR } \\ \text { Ratten } \mu 2 & \text { LFLD } & \text { K } & \text { V } & \text { L } & \text { KWVR } \\ \text { Drosophila } \mu 2 & \text { LFLD } & \text { K } & \text { V } & \text { L } & \text { KWVR } \\ \text { C. elegans } \mu 2 & \text { LFLD } & \text { K } & \text { V } & \text { L } & \text { KWVR } \\ \text { Maus } \mu 1 \mathrm{~A} & \text { VFLD } & \mathbf{R} & \text { V } & \text { L } & \text { PWVR } \\ \text { Maus } \mu 1 \mathrm{~B} & \text { VFLD } & \text { K } & \text { V } & \text { M } & \text { PWVR } \\ \text { Drosophila } \mu 1 & \text { VFLD } & \mathbf{R} & \text { V } & \text { L } & \text { PWVR } \\ \text { C. elegans } \mu 1 & \text { VFLD } & \mathbf{R} & \text { V } & \text { L } & \text { PWVR } \\ \text { Ratten } \mu 3 A & \text { AYFD } & \text { C } & \text { V } & \text { L } & \text { KGVK } \\ \text { Ratten } \mu 3 B & \text { AYFD } & \text { C } & \text { V } & \text { L } & \text { KG I K } \\ \text { Drosophila } \mu 3 & \text { AYFD } & \text { C } & \text { V } & \text { L } & \text { KGVK } \\ \text { C. elegans } \mu 3 & \text { AYFD } & \text { C } & \text { V } & \text { L } & \text { KGVK } \\ \text { Humanes } \mu 4 & \text { VFLD } & \text { K } & \text { L } & \text { L } & \text { KWVR } \\ \text { Huhn } \mu 4 & \text { VFVD } & \text { K } & \text { L } & \text { L } & \text { RWVR }\end{array}$

Abb. 28 A: Schematische Darstellung der heterotetrameren AP-2- und AP-3-Komplexe. B: Bipartite Struktur der $\mu 2$-Untereinheit des AP-2-Komplexes. Während die N-terminalen Reste 1-145 mit der ß2-Untereinheit von AP-2 interagieren, binden die C-terminalen Aminosäuren 164-435 an Tyrosin-haltige Signale vom Typ YXX $\varnothing$ (Aguilar et al., 1997). C: Darstellung der für die Bindung an YXX $\varnothing$-Signale wichtigen Aminosäurereste der $\mu 2$-Untereinheit der Maus und Vergleich mit anderen $\mu$-Untereinheiten verschiedener Spezies. Mit Tyrosin (Y)- und hydrophoben Resten ( $\varnothing$ ) interagierende Aminosäuren sind fett bzw. normal gedruckt (aus Bonifacino \& Dell’ Angelica; 1999).

Überraschender Weise konnte nach Kotransformation des MPR300-CT mit den $\mu 2$ - und $\mu 3 \mathrm{~A}$-Untereinheiten weder ein His-unabhängiges Wachstum noch eine $B$-GalaktosidaseAktivität nachgewiesen werden. Da Deletionsmutanten des TGN38-CT, deren Tyrosinhaltiges Internalisierungssignal am C-Terminus des Köderproteins plaziert wurde, eine um den Faktor 5- und 2-3 -fach stärkere Interaktion mit $\mu 1$ bzw. $\mu 2$ im Vergleich zum Wildtyp 
zeigen (Ohno et al., 1996), wurde der MPR300-CT in analoger Weise verkürzt. Nach Expression der MPR300-CT-StopV29-Mutante in Gegenwart von $\mu 2$ bzw. $\mu 3 \mathrm{~A}$ konnte in den Hefezellen jedoch ebenfalls kein His-unabhängiges Wachstum beobachtet werden. Da der MPR300-CT direkt an AP-2 bindet und für die Internalisierung von der Plasmamembran ein Tyrosin-haltiges Sortierungssignal (aa 24-29) essentiell ist (Glickman et al., 1989; Canfield et al., 1991), ist aus den eigenen Daten abzuleiten, daß der MPR300-CT als Köderprotein für Interaktionsstudien mit Adaptoruntereinheiten im Two-Hybrid-System nicht geeignet ist (siehe auch 5.3). Es ist jedoch anzumerken, daß die meisten untersuchten Protein-Interaktionen mit den $\mu$-Adaptoruntereinheiten nicht mit zytoplasmatischen Wildtyp-Domänen, sondern nur unter Verwendung von Chimären aus den 27 N-terminalen Aminosäuren des TGN38-CT und C-terminal plazierten, isolierten Tyrosin-haltigen Hexapeptidsequenzen der zytoplasmatischen Rezeptordomänen bzw. von Drei-Fach-Wiederholungseinheiten der Hexapeptidsequenzen nachgewiesen werden konnten (Ohno et al. 1995; 1996). Two-Hybrid-Studien zur Wechselwirkung der zytoplasmatischen WT-Domänen von TGN38 und LAMP I mit den bekannten $\mu$-Untereinheiten zeigen, daß die Protein-Interaktionen sehr schwach sind (Stephens \& Banting, 1998). In den oben genannten Studien sind aber weder die Wildtypdomänen der beiden Mannose-6-Phosphat-Rezeptoren bzw. daraus abgeleitete Hexapeptidsequenzen ihrer Internalisierungssignale mit den $\mu$-Adaptoruntereinheiten auf Interaktion im TwoHybrid-System untersucht worden. 


\subsection{Das Hefe-Two-Hybrid-System}

In der vorliegenden Arbeit wurde das Hefe-Two-Hybrid-System a) zur Identifizierung von neuen Proteinen, die mit der zytoplasmatischen Domäne des MPR300 interagieren, und b) zur Bestimmung der strukturellen Voraussetzungen der Wechselwirkung zwischen zwei bekannten interagierenden Proteinen (zytoplasmatische Domäne des MPR46 und den $\mu$-Ketten der Adaptorproteine), angewendet. Hierzu wurde die gesamte zytoplasmatische Domäne des MPR300 bzw. MPR46 als Fusionsprotein mit der Gal4-DNABindungsdomäne (DBD) in einem Hefewirtsstamm exprimiert und auf Interaktionen mit Fusionsproteinen verschiedener cDNA-Bibliotheken untersucht, die aus einer N-terminalen Transaktivierungs-Domäne (AD) und der Gesamtheit der exprimierten Proteine einer Zellinie oder eines Organs bzw. den $\mu$-Ketten von AP-2 und AP-3 zusammengesetzt sind.

Die Vorteile des Two-Hybrid-Systems gegenüber üblichen Methoden zur Detektion von Protein-Interaktionen in vitro, wie Koimmunpräzipitation, chemische Quervernetzung und Affinitätschromatographie mit dem Köderprotein, bestehen in der Sensitivität des Systems sowie der sofortigen Verfügbarkeit der cDNA des interagierenden Proteins (Yang et al., 1995). Der entscheidenste Schritt nach Isolierung der cDNA eines interagierenden Proteins ist jedoch der Nachweis, daß die gefundene Wechselwirkung in einem unabhängigen System in vivo reproduzierbar ist und eine funktionelle Bedeutung besitzt. Diese Bestätigung ist essentiell, da in einem Two-Hybrid-Screen Fusionsproteine aus verschiedenen zellulären Kompartimenten oder aus unterschiedlichen Entwicklungs- und Differenzierungsstufen zur Interaktion mit dem Köderprotein fähig sind, deren Assoziation in der Zelle aufgrund subzellulärer Kompartimentierung oder differentieller Genexpression nicht möglich wäre (Allen et al., 1995). Neben der Bestätigung der gefundenen Interaktion ist ein Nachweis in vitro notwendig, da die Wechselwirkung im Hefe-Modell-System aufgrund mißgefalteter Fusionsproteine oder unter Beteiligung eines Hefeproteins zustande kommen kann (Fields \& Sternglanz, 1994).

Da die Protein-Protein-Interaktion im Kern der Hefezelle erfolgt, sind die zu erwartenden Kandidaten für die Wechselwirkung mit der zytoplasmatischen Domäne des MPR300 begrenzt. Sämtliche DBD- und AD-Fusionsproteine werden im Zytoplasma an freien Ribosomen translatiert und durch Kernlokalisierungssignale in den Kern der Hefezelle dirigiert, so daß Interaktionen, die auf im ER/Golgi-stattfindenden, posttranslationalen Modifikationen, wie Glykosylierung, Phosphorylierung, Acylierung und 
Disulfidbrückenbildung beruhen, nicht detektiert werden können. Die zytoplasmatische Domäne des MPR300 ist weder glykosyliert noch existieren Disulfidbrücken zwischen 2 Cysteinresten und für beschriebene Serinphosphorylierungen und Acetylierungen liegen keine Angaben über deren physiologische Bedeutung vor. Es bestehen daher zunächst keine strukturellen Vorbehalte, die zytoplasmatische Domäne des MPR300 als Köderprotein zu nutzen. In publizierten cDNA-Bibliotheken-Screens konnten mit den zytoplasmatischen Domänen verschiedener integraler Membranrezeptoren, wie z. B. dem Insulin-Rezeptor (O’Neill et al., 1997; Liu \& Roth, 1995), dem IGF I-Rezeptor (Furlanetto et al., 1997), dem Tumor-Nekrose-Faktor-Rezeptor (Rothe et al., 1994; Hsu et al., 1995), dem CD40-Rezeptor (Hu et al., 1994) und dem TGF-ß-Rezeptor (Kawabata et al., 1995) als Köderproteinen, neue, zytosolische, bindende Proteine gefunden werden. Es ist jedoch zu bedenken, daß die meisten der verwendeten zytoplasmatischen Domänen bzw. Fragmente daraus eine Länge von 20-100 Aminosäuren besaßen. In den eigenen vorliegenden Untersuchungen wurden nach dreimaligem Screenen einer HeLa-cDNABibliothek mit dem 167 Aminosäure-umfassenden MPR300-CT nur 5 unabhängige, spezifisch interagierende, neue Proteine detektiert, von denen zwei weiter charakterisiert wurden. In einer anderen Untersuchung mit dem gesamten MPR300-CT als Köderprotein wurde lediglich ein spezifisch interagierendes Protein, TIP 47, isoliert, während andere bekannte interagierende Proteine, wie CK2, $\mu 1$ und $\mu 2$, nicht isoliert wurden (Diaz \& Pfeffer, 1998). Eine andere Arbeitsgruppe fand mit der zytoplasmatischen MPR300-Domäne als Köderprotein im Two-Hybrid-Screen keine interagierenden Proteine (B. Hoflack, persönliche Mitteilung). Zusammenfassend ist zu sagen, daß die gesamte zytoplasmatische Domäne des MPR300 aufgrund ihrer Länge für einen cDNA-BibliothekScreen im Two-Hybrid-System nicht besonders geeignet erscheint.

Ein weiterer kritischer Punkt bei der Analyse von Protein-Interaktionen mit dem TwoHybrid-System ist die Auswahl geeigneter DBD-Vektoren. Die Interaktion zwischen dem MPR46-CT und den $\mu 2$ - und $\mu 3$ A-Untereinheiten konnte nur unter Verwendung des DBDVektors pAS2 nachgewiesen werden, während mit den DBD-Vektoren pGBT9 und pAS2-1 kein His-unabhängiges Wachstum der kotransformierten Hefezellen beobachtet wurde. Da die Expression des Köderproteins in den Vektoren pAS2 und pAS2-1 durch den gleichen Promotor $(A D H 1)$ induziert wird, kann ausgeschlossen werden, daß die nichtdetektierte Protein-Interaktion bei Verwendung von pAS2-1 aufgrund einer geringeren Konzentration des Köderproteins im Kern resultiert (Clontech, Yeast Protocols Handbook). 
Im Gegensatz zu den Vektoren pAS2-1 und pGBT9 induziert der Vektor pAS2 die Expression von Fusionsproteinen, die zwischen der Gal4-DBD und dem Köderprotein eine eingefügte Sequenz von 26 Aminosäuren enthalten. Ohno und Mitarbeiter (1996) konnten zeigen, daß der Abstand des Tyrosin-haltigen Internalisierungssignals des TGN38-CT von der Gal4-DBD die Stärke der Wechselwirkung mit den $\mu 1$ - und $\mu 2$-Untereinheiten beeinflußt. Möglicherweise blockiert die Gal4-DBD bei Verwendung der Vektoren pGBT9 und pAS2-1 die Wechselwirkung von N-terminalen Sequenzen des MPR46-CT mit den $\mu 2$ - und $\mu 3 \mathrm{~A}$-Untereinheiten.

Die Auswahl einer geeigneten cDNA-Bibliothek ist neben der Konstruktion eines geeigneten Köderproteins ein entscheidender Gesichtspunkt für einen erfolgreichen TwoHybrid-Screen. Da die mRNA zur Herstellung der HeLa-cDNA-Bibliothek mit Oligo-dTPrimern transkribiert wurde, besitzen alle cDNA-Sequenzen den kompletten 3'-nichttranslatierten Bereich, so daß bei einer durchschnittlichen cDNA-Länge von 1,5 kb N-terminale Domänen möglicher, größerer (>400-500 aa) interagierender Fusionsproteine nicht repräsentiert sind. Ferner ist zu bedenken, daß die Gesamtheit der amplifizierten cDNA-Sequenzen an EcoRI-Adaptoren ligiert wird, so daß nur 1/6 aller cDNAs eine korrekte Orientierung und den richtigen Leserahmen bezüglich der Gal4-AD besitzen (Fields \& Sternglanz, 1994).

Weitere kritische Punkte, die vor der Anwendung im cDNA-Bibliothek-Screen geklärt werden müssen, sind die Expression und Stabilität des DBD-MPR300-CT-Fusionsproteins, die Nicht-Toxizität der Überexpression des Köderproteins und die Unfähigkeit des Köderproteins zur autonomen Transaktivierung der Reportgene HIS3 und lacZ. Schließlich sollten Positiv- und Negativkontrollen für Interaktionspartner für die Testung der cDNABibliotheken einbezogen werden. Dazu wurde die Wechselwirkung mit der CK2 ausgewählt, für die in vitro-Daten bereits vorliegen, die zeigen, daß die Ser82- und Ser156-Reste durch CK2 phosphoryliert werden können (Rosorius et al., 1993 b). Als Negativkontrolle können dann u. a. mutante MPR300-CT-Formen exprimiert werden, die nicht mehr an CK2 binden sollten, wie die C-terminale Verkürzungsmutante StopL75.

Nach Screenen einer humanen HeLa-S3-cDNA-Bibliothek mit dem MPR300-CT als Köderprotein konnten 288 His $^{+}$-Klone isoliert werden, von denen $10 \%$ einen lacZ-positiven Phänotyp zeigten. Durch weitere Analysen zur Spezifität der gefundenen Wechselwirkung wurden $80 \%$ der isolierten cDNA-Klone aussortiert, die eine falsch positive Wechselwirkung mit dem MPR300-CT zeigten. Das Auftreten von falsch 
positiven Wechselwirkungen stellt einen großen Nachteil des Two-Hybrid-Systems dar, da trotz Verwendung von Wirtsstämmen mit unterschiedlichen Reportergen-Promotoren (HF7c: GAL1-HIS3; (GAL4-17-mer) $)_{3}$ CYC1-LacZ) und Kontrolltransformationen mit Köderprotein-fremden Proteinen, wie z.B. Lamin C, p53 und dem MPR46-CT, die Spezifität und funktionelle Bedeutung der gefundenen Interaktion erst durch nachfolgende Untersuchungen an eukaryontischen Zellkultursystemen endgültig bewiesen werden kann (Bartel et al., 1993). Dazu gehören die Kopräzipitation mit dem MPR300, Studien zum Transport neusynthetisierter lysosomaler Enzyme, zur Kinetik des intrazellulären Transportes zum Lysosom, zur Endozytosefähigkeit von Mannnose-6-Phosphat-haltigen Liganden, zur Endozytose und dem Abbau von IGF II nach Translationshemmung (Antisense-Oligonukleotide) bzw. Überexpression des isolierten, interagierenden Proteins in einem geeigneten Zellkultur-System. Untersuchungen zum Transport des MPR300 von der Plasmamembran zum Golgi-Apparat, von den Endosomen zur Plasmamembran, zum Rücktransport zum Golgi oder Kinetikstudien zum Transport des MPR300 zwischen den Kompartimenten können aufgrund fehlender etablierter Techniken nicht durchgeführt werden.

Im Falle von bekannten cDNA-Sequenzen mit definierten, biochemischen Eigenschaften des Genproduktes kann anhand der Lokalisation und Funktion des isolierten Proteins abgeschätzt werden, ob die gefundene Wechselwirkung mit dem Köderprotein sinnvoll erscheint. D. h., wenn Interaktionspartner für den MPR300-CT als Membranproteine innerer Mitochondrien-Membranen oder ribosomale Proteine identifiziert worden sind, dann ist eine wirkliche Interaktion unwahrscheinlich. Bei unbekannten cDNA-Sequenzen ist diese Beurteilung jedoch nicht möglich, so daß nur durch Verwendung von gezielten Mutanten des Köderproteins eine Aussage getroffen werden kann, ob eine weitere Charakterisierung des gefundenen Proteins vernünftig ist. Die Herstellung von Mutanten, bei denen wie bei den rab-Proteinen der Austausch einer einzigen Aminosäure die Wechselwirkung mit interagierenden Proteinen unterbindet (Stenmark et al., 1995), ist jedoch für die zytoplasmatische MPR300-Domäne schwierig, da multiple Signalstrukturen (Di-Leucin-Motiv, Tyrosin-haltiges Internalisierungssignal, Phosphorylierungsstellen) existieren (Rosorius et al., 1993 b; Denzer et al., 1997), die im Kontext mit benachbarten Sequenzen an andere Proteine, wie z.B. $\mu 1$ und $\mu 2$, binden. 
Das His-unabhängige Wachstum und die ß-Galaktosidase-Expression der isolierten Klone erlaubt zwar Aussagen über die Affinität der interagierenden Proteine, doch sind diese Parameter kein Indiz für die physiologische Bedeutung der gefundenen Interaktion in vivo. Während bei der Interaktion zwischen dem MPR46-CT und $\mu 2$, die für die Internalisierung des MPR46 von der Plasmamembran und die Ausbildung von Clathrin-beschichteten Vesikeln wichtig ist, nach Koexpression in Hefezellen eine B-Galaktosidase-Aktivität von ca. 20 B-Galaktosidase-Einheiten gemessen wird, ergibt die Wechselwirkung des MPR300-CT mit der C-terminalen Periplakindomäne, deren physiologische Bedeutung noch unbekannt ist, einen Wert von ca. 230 ß-Galaktosidase-Einheiten.

Die falsch positiven Klone konnten durch Kotransformationen mit verschiedenen KontrollKonstrukten in zwei Gruppen unterteilt werden. Die erste Gruppe enthielt cDNA-Klone, deren Gal4-AD eine DNA-Bindungsdomäne enthielt, so daß Hefezellen, die das isolierte AD-Fusionsprotein in Abwesenheit des MPR300-CT exprimierten, nach Selektion auf (-Leu)-Medium einen lac $Z^{+}$-Phänotyp aufwiesen. Die zweite Gruppe umfaßte cDNA-Klone, deren Fusionsproteine entweder mit der isolierten Gal4-DBD-Domäne oder mit Lamin C interagierten, so daß der $\mathrm{His}^{+}$-Phänotyp auf einer fehlenden oder unspezifischen Wechselwirkung mit dem MPR300-CT beruht. In der vorliegenden Arbeit wurden, nach Sequenzierung und Vergleich der cDNA-Sequenzen unter Verwendung der NCBI-BLASTN-Programmes, die auch von anderen Autoren als falsch positive Klone identifizierten Proteine, wie die mutierte Form des Tumor-Suppressor-Proteins p53 (Farrell et al., 1991), das p53-Bindungsprotein (Iwabuchi et al., 1998), das humane E2-Ubiquitinkonjugierende Enzym (hE2-25K; Kalchmann et al., 1996) und das hMCM2 (Hu et al., 1993), charakterisiert.

Neben der HeLa-cDNA-Bibliothek wurden eine humane Nieren-cDNA- und eine Rattenhirn-cDNA-Bibliothek mehrere Male mit dem MPR300-CT als Köderprotein gescreent. Bei der Transformation der humanen Nieren-cDNA-Bibliothek wuchsen keine $\mathrm{His}^{+}$-Klone. Nach dem Screening der Ratten-Hirn-cDNA-Bibliothek wurden 17 Klone mit $\mathrm{His}^{+}$- und lacZ ${ }^{+}$-Phänotyp der Hefezellen isoliert. Nach Sequenzierung wurden 14 identische Klone mit einer cDNA-Länge von 2,4 kb identifiziert, deren cDNA-Sequenzen jedoch keinen offenen Leserahmen mit der Gal4-DBD-Domäne besaßen. Ausgehend von der Gal4-AD-Fusionsstelle wurde der Leserahmen nach 22 Aminosäuren durch ein TGA-Stopcodon unterbrochen. Ein Vergleich der abgeleiteten Aminosäuresequenzen ergab 
keine signifikanten Homologien mit bekannten Proteinen. Ein weiterer cDNA-Klon besaß nach 4 Aminosäuren ein TGA-Stopcodon. 


\section{Zusammenfassung}

Für den gerichteten intrazellulären Transport des 300 kDa Mannose-6-Phosphat-Rezeptors (MPR300) entlang des Biosynthese- und Endozytoseweges sind Signalstrukturen wichtig, die hauptsächlich in der zytoplasmatischen Rezeptordomäne lokalisiert sind und bei Sortierungsprozessen in bestimmten zellulären Kompartimenten selektiv mit zytosolischen und membranständigen Proteinen, wie z. B. AP-1, AP-2, TIP47, CK2, TIP35 und PACS-1, interagieren.

Im ersten Teil der Arbeit wurden mit Hilfe des Hefe-Two-Hybrid-Systems zwei Proteine aus einer HeLa cDNA-Bibliothek identifiziert, die spezifisch mit der zytoplasmatischen Domäne des MPR300 (MPR300-CT) interagieren. Die Stärke der Interaktion wurde durch Messung der lacZ-Reportergen-Aktivität quantifiziert und durch Kopräzipitationsanalysen mit rekombinanten Proteinen verifiziert. Für die Wechselwirkung zwischen Periplakin, einem Mitglied der Plakin-Familie, und dem MPR300-CT sind die N-terminalen 29 Aminosäuren der Rezeptordomäne, die das Tyrosin-haltige Internalisierungssignal umfassen, ausreichend und notwendig. Andererseits sind für die Bindung an die zytoplasmatische MPR300-Domäne die gesamte Linker- und Anteile der stabförmigen Rod-Domäne des Periplakins notwendig. Die Überexpression der C-terminalen Periplakindomäne vermindert in BHK-Zellen die Endozytose von M6P-haltigen Liganden auf 32-49\%. Bei dem noch unbekannten Protein handelt es sich um ein integrales, möglicherweise endosomales $93 \mathrm{kDa}$ Protein, das auch mit der zytoplasmatischen Domäne des MPR46 interagiert.

Im zweiten Teil der Arbeit wurden die strukturellen Voraussetzungen für die Wechselwirkung zwischen der zytoplasmatischen Domäne des MPR46 (MPR46-CT) und den $\mu 2$ - und $\mu 3$ A-Untereinheiten der Adaptorkomplexe AP-2 und AP-3 im Two-HybridSystem untersucht und durch Kopräzipitationsanalysen verifiziert.

Die Wechselwirkung zwischen dem MPR46-CT und $\mu 2$ wird durch den C-terminalen Sequenzbereich der zytoplasmatischen Rezeptordomäne vermittelt, der die Aminosäurereste 45-64 umfaßt. Für die Interaktion sind das Tyrosin-haltige 
Internalisierungsignal und weitere strukturelle Determinanten, wahrscheinlich ein Cluster von sauren Aminosäuren innerhalb der Reste 49-63, wichtig.

Durch die Two-Hybrid-Analysen und Kopräzipitationsexperimente konnte auch erstmals die Interaktion zwischen dem MPR46-CT und $\mu 3$ A nachgewiesen werden. Für die Bindung von $\mu 3 \mathrm{~A}$ sind das Di-Leucin-Motiv, das Tyrosin-haltige Internalisierungssignal sowie weitere, dazwischenliegende Sequenzen der zytoplasmatischen MPR46-Domäne notwendig. 


\section{Literaturverzeichnis}

Aguilar, R. C., OHNO, H., Roche, K. W., Bonifacino, J. S. (1997): Functional domain mapping of the clathrin-associated adaptor medium chains $\mu 1$ and $\mu$ 2. J. Biol. Chem., 43: 27160-27166.

AHO, S., MC LEAN, W. H. I., LI, K., UITTO, J. (1998): cDNA cloning, mRNA expression, and chromosomal mapping of human and mouse periplakin genes. Genomics, 48: 242-247.

Allen, J. B., Walberg, M. W., Edwards, M. C., Elledge, S. J. (1995): Finding prospective partners in the library: the two-hybrid system and phage display find a match. Trends Biochem. Sci., 20: 511-516.

Altschul, S. F., Gish, W., Miller, W., MYers, E. W., Lipman, D. J. (1990): Basic local alignment search tool. J. Mol. Biol., 215: 403-410.

AndrÄ, K., Nikolic, B., Stöcher, M., Drenckhahn, D., Wiche, G. (1998): Not just scaffolding: plectin regulates actin dynamics in cultured cells. Genes \& Development, 12 : 3442-3451.

Anhalt, G. J., Kim, S. C., Stanley, J. R., Korman, N. J., Jabs, D. A., Kory, M., IZUMi, H., RATRIE, H., MutASIM, D., ARISS-ABDO, L. (1990): Paraneoplastic pemphigus. An autoimmune mucocutaneous disease associated with neoplasia. N. Engl. J. Med., 323: 1729-1735.

ARNESON, L. S. \& MILlER, J. (1995): Efficient endosomal localization of major histocompatibility complex class II-invariant chain complexes requires multimerization of the invariant chain targeting sequence. J. Cell Biol., 129: 1217-1228.

Bartel, P. L., Chien, C. T., Sternglanz, R., Fields, S. (1993): Elimination of false positives that arise in using the two-hybrid system. BioTechniques, 14: 920-924.

BARTEL, P. L. \& FIELDS, S. (1995): Analyzing protein-protein interactions using twohybrid system. Methods in Enzymology, 254: 241-260.

BIRNBOIM, H. C. \& DOLY, J. (1979): A rapid alkaline extraction procedure for screening recombinant plasmid DNA. Nucl. Acids Res., 7: 1513-1523.

Bleekemolen, J. E., Stein, M., von Figura, K., Slot, J. W., GeuZe, H. J. (1988): The two mannose-6-phosphate receptors have almost identical subcellular distributions in U937 monocytes. Eur. J. Cell Biol., 47: 366-372.

Boll, W., OhnO, H., Songyang, Z., RAPOPORT, I., CANTley, L. C., Bonifacino, J. S., KIRCHHAUSEN, T. (1996): Sequence requirements for the recognition of tyrosine-based endocytic signals by clathrin AP-2 complexes. EMBO J., 15: 5789-5795.

Bonifacino, J. S. \& Dell' ANGEliCA, E. C. (1999): Molecular bases for the recognition of tyrosine-based sorting signals. J. Cell Biol., 145: 923-926. 
BRAULKE, T. (1996): Origin of lysosomal proteins. In: Lloyd J. B., Mason R. W. (eds.) Subcellular Biochemistry: Biology of the lysosome, Vol. 27: 15-49, Plenum Press, New York.

BREeden, L. \& NASMYTH, K. (1985): Regulation of the yeast HO gene. Cold Spring Harbor Symp. Quant. Biol., 50, 643-650.

Bremnes, T., LAUVRaK, V., Lindqvist, B., BAKKe, O. (1998): A region from the medium chain adaptor subunit $(\mu)$ recognizes leucine- and tyrosine-based sorting signals. $J$. Biol. Chem., 273: 8638-8645.

Breuer, P., Körner, C., BöKer, C., Herzog, A., Pohlmann, R., Braulke, T. (1997): Serine phosphorylation site of the $46 \mathrm{kDa}$ mannose 6-phosphate receptor is required for transport to the plasma membrane in Madin-Darby canine kidney and mouse fibroblast cells. Mol. Biol. Cell, 8: 567-576.

BREUER, P. \& BRAUlKe T. (1998): Stabilization of mutant 46-kDa mannose 6-phosphate receptors by proteasomal inhibitor lactacystin. J. Biol. Chem., 273: 33254-33258.

BURDETT, I. D. (1993): Internalisation of desmosomes and their entry into the endocytic pathway via late endosomes in MDCK cells. Possible mechanisms for the modulation of cell adhesion by desmosomes during development. J. Cell Sci., 106: 1115-1130.

CANFIELD, W. M. \& KoRNFELD, S. (1989): The chicken liver cation-independent mannose 6-phosphate receptor lacks the high affinity binding site for insulin-like growth factor II. $J$. Biol. Chem., 264: 7100-7103.

Canfield, W. M., Johnson, K. F., Ye, R. D., Gregory, W., Kornfeld, S. (1991): Localization of the signal for rapid internalization of the bovine cation-independent mannose-6-phosphate/ insulin-like growth factor-II receptor to amino acids 24 - 29 of the cytoplasmic tail. J. Biol. Chem., 266: 5682-5688.

Causin, C., Waheed, A., Braulke, T., Junghans, U., Maly, P., Humbel, R. E., von FIGURA, K. (1988): Mannose 6-phosphate/insulin-like growth factor II-binding proteins in human serum and urine. Their relation to the mannose 6-phosphate/insulin-like growth factor II receptor. Biochem. J., 252: 795-799.

Chao, H., Waheed, A., Pohlmann, R., Hille, A., von Figura, K. (1990): Mannose 6phosphate receptor dependent secretion of lysosomal enzymes. EMBO J., 9: 3507-3513.

CHEN, C. \& OKAYAMA, H. (1987): High-efficiency transformation of mammalian cells by plasmid DNA. Mol. Cell Biol., 7: 2745-2752.

Chen, H. J., Remmler, J., Delaney, J. C., Messner, D. J., Lobel, P. (1993): Mutational analysis of the cation-independent mannose 6-phosphate/ insulin-like growth factor II receptor. A consensus casein kinase II site followed by 2 leucines near the carboxyl terminus is important for intracellular targeting of lysosomal enzymes. J. Biol. Chem., 268: 22338-22346. 
Chen H. J., YuAn, J., LOBel, P. (1997): Mutational analysis of the cation-independent mannose 6- phosphate/ insulin-like growth factor II receptor. J. Biol. Chem., 272: 70037012.

Chien, C. T., Bartel, P. L., Sternglanz, R., Fields, S. (1991): The two-hybrid system: A method to identify and clone genes for proteins that interact with a protein of interest. Proc. Natl. Acad. Sci. USA, 88: 9578-9582.

Chirgwin, J. M., Przybyla, A. E., Mac Donald, R. J., RutTer, W. J. (1979): Isolation of biologically active ribonucleic acid from sources enriched in ribonuclease. Biochemistry, 18: 5294-5299.

Clairmont, K. B. \& Czech, M. P. (1989): Chicken and Xenopus mannose 6-phosphate receptors fail to bind insulin-like growth factor II. J. Biol. Chem., 264: 16390-16392.

Cowles, C. R., OdorizzI, G., PAYNe, G.S., EMr, S.D. (1997): The AP-3 adaptor complex is essential for cargo-selective transport to the yeast vacuole. Cell, 91: 109-118.

Dahms, N. M., Rose, P. A., Molkentin, J. D., Zhang, Y., BrZYCKi, M.A. (1993): The bovine mannose 6-phosphate/insulin-like growth factor II receptor. The role of arginine residues in mannose 6-phosphate binding. J. Biol. Chem., 268: 5457-5463.

DARsOw, T., BURD, C. G., EMR, S. D. (1998): Acidic di-leucine motif essential for AP-3dependent sorting and restriction of the functional specificity of the Vam3p vacuolar $t-$ SNARE. J. Cell Biol., 142: 913-922.

Dell' Angelica, E. C., Ohno, H., Ooi, C. E., Rabinovich, E., Roche, K. W., BONIFACINO, J. S. (1997): AP-3: an adaptor-like protein complex with ubiquitous expression. EMBO J., 16: 917-928.

Dell' AngelicA, E. C., Mullins, C., BonifaCinO, J. S. (1999 a): AP-4, a novel protein complex related to clathrin adaptors. J. Biol. Chem., 74: 7278-85.

Dell' Angelica, E. C., Shotelersuk, V., Aguilar, R. C., Gahl, W. A., Bonifacino, J. S. (1999 b): Altered trafficking of lysosomal proteins in Hermansky-Pudlak syndrome due to mutations in the beta 3A subunit of the AP-3 adaptor. Mol. Cell, 3: 11-21.

DENNIS, P. A. \& RIFKIN, D. B. (1991): Cellular activation of latent transforming growth factor $B$ requires binding to the cation-independent mannose 6-phosphate/insulin-like growth factor type II receptor. Proc. Natl. Acad. Sci., USA, 88: 580-584.

Denzer, K., Weber, B., Hille-Rehfeld, A., von Figura, K., Pohlmann, R. (1997): Identification of three internalization sequences in the cytoplasmic tail of the $46 \mathrm{kDa}$ mannose 6-phosphate receptor. Biochem J., 326: 497-505.

Diaz, E., Schimmöller, F., PfefFer, S. R. (1997): A novel Rab9 effector required for endosome-to-TGN transport. J. Cell Biol., 138: 283-290.

DIAZ, E. \& PFEFFER, S. R. (1998): TIP47: a cargo selection device for mannose 6phosphate receptor trafficking. Cell, 93: 433-443. 
Dittmer, F., Ulbrich, E. J., Hafner, A., Schmahl, W., Meister, T., Pohlmann, R., VON FIGURA, K. (1999): Alternative mechanisms for trafficking of lysosomal enzymes in mannose 6-phosphate receptor-deficient mice are cell type-specific. J. Cell Sci., 112 :15911597.

Draper, R. K., GODA, Y., BROdSKy, F. M., PFEFFER, S. R. (1990): Antibodies to clathrin inhibit endocytosis but not the recycling to the trans Golgi network in vitro. Science, 248: 1539-1541.

Farrell, P. J., Allan, G. J., Shanahan, F., Vousden, K. H., CrooK, T. (1991): p53 is frequently mutated in Burkitt's lymphoma cell lines. EMBO J., 10: 2879-2887.

Feilotter, H. E., HANNON, G. J., RudDEl, C. J., BEACH, D. (1994): Construction of an improved host strain for two hybrid screening. Nucleic Acids Res., 22: 1502-1503.

FeInBerG, A. P. \& Vogelstein, B. (1983): A technique for radiolabeling DNA restriction endonuclease fragments to high specific activity. Anal. Biochem., 132: 6-13.

FIELDS, S. \& SONG, O. (1989): A novel genetic system to detect protein-protein interactions. Nature, 340: 245-246.

FIELDS, S. \& STERNGLANZ, R. (1994): The two-hybrid system: an assay for protein-protein interactions. Trends Genet., 10: 286-292.

Furlanetto, R. W., Dey, B. R., LOPACZYnski, W., NiSSley, S. P. (1997): 14-3-3 proteins interact with the insulin-like growth factor receptor but not the insulin receptor. Biochem. J., 327: 756-771.

Gallusser, A. \& KirchHausen, T. (1993): The $\beta 1$ and $B 2$ subunits of the AP complexes are the clathrin coat assembly proteins. EMBO J., 12: 5237-5244.

GELI, M. I. \& RIEZMAN, H. (1998): Endocytic internalization in yeast and animal cells: similar and different. J. Cell Sci., 111: 1031-1037.

Gietz, D., St. Jean, A., Woods, R. A., Schiestl, R. A. (1992): Improved method for high efficiency transformation of intact yeast cells. Nucleic Acids Res., 20: 1425-1432.

Glickman, J. N., Conibear, E., Pearse, B. M. (1989): Specificity of binding of clathrin adaptors to signals on the mannose 6-phosphate/insulin-like growth factor II receptor. EMBO J., 8: 1041-1047.

GLICKMAN, J. N. \& KORNFELD, S. (1993): Mannose 6-phosphate-independent targeting of lysosomal enzymes in I-cell disease B lymphoblasts. J. Cell Biol., 123: 99-108.

GREEN, K. J. \& JONES, J. C. R. (1996): Desmosomes and hemidesmosomes: structure and function of molecular components. FASEB J., 10: 871-881.

GRIFFiths, G., MATteOni, R., BACK, R., Hoflack, B. (1990): Characterization of the cation-independent mannose 6-phosphate receptor-enriched prelysosomal compartment in NRK cells. J. Cell Sci., 95: 441-461. 
GuARANTE, L. (1993): Strategies for the identification of interacting proteins. Proc. Natl. Acad. Sci. USA, 90: 1639-1641.

GUBLER, U. \& HOFFMAN, B. J. (1983): A simple and very efficient method for generating cDNA libraries. Gene, 25: 263-269.

HANAHAN, D. (1985): Techniques for transformation of E. coli. Glover, D. M., eds., in: DNA cloning, IRL press, Oxford.

Hemer, F., KÖRner, C., Braulke, T. (1993): Phosphorylation of the human 46-kDa mannose 6-phosphate receptor in the cytoplasmic domain at serine 56. J. Biol. Chem., 268: 17108-17113.

HILLE-REHFELD, A. (1995): Mannose-6-phosphate receptors in sorting and transport of lysosomal enzymes. Biochim. Biophys. Acta, 1241: 177-194.

HIRST, J. \& RoBinson, M. S. (1998): Clathrin and adaptors. Biochim. Biophys. Acta, 1404: 173-193.

Höning, S., SosA, M., Hille-Rehfeld, A., von FIgURA, K. (1997): The 46-kDa mannose 6-phosphate receptor contains multiple binding sites for clathrin adaptors. J. Biol. Chem., 272: 19884-19890.

HÖNING, S., SANDOVAL, I. V., vON FIGURA, K. (1998): A di-leucine-based motif in the cytoplasmic tail of LIMP-II and tyrosinase mediates selective binding of AP-3. EMBO J., 17: $1304-1314$.

HofFman, C. S. \& Winston, F. (1987): A ten-minute DNA preparation from yeast efficiently releases autonomous plasmids for transformation of Escherichia coli. Gene, 57: 267-272.

Hoflack, B., Fujimoto, K., KoRnFELD, S. (1987): The interaction of phosphorylated oligosaccharides and lysosomal enzymes with bovine liver cation-dependent mannose 6phosphate receptor. J. Biol. Chem., 262: 123-129.

Hsu, H., Xiong, J., Goeddel, D. V. (1995): The TNF receptor 1-associated protein TRADD signals cell death and NF-kappa B activation. Cell, 81: 495-504.

Hu, B., Burkhart, R., Schulte, D., Musahl, C., KnipPers, R. (1993): The P1-family: a new class of nuclear mammalian proteins related to the yeast $\mathrm{Mcm}$ replication proteins. Nucleic Acids Res., 21: 5289-5293.

Hu, H. M., O' Rourke, K., Boguski, M. S., DixiT, V. M. (1994): A novel RING finger protein interacts with the cytoplasmic domain of CD40. J. Biol. Chem., 269: 30069-30072.

Itin, C., RANCAO, C., NAKAJIMA, Y., PFefFER, S. R. (1997): A novel assay reveals a role for soluble N-ethylmaleinimide-sensitive fusion attachment protein in mannose 6phosphate receptor transport from endosomes to the trans Golgi network. J. Biol. Chem., 272: $27737-27744$. 
Iwabuchi, K., Li, B., Massa, H. F., Trask, B. J., Date, T., FieldS, S. (1998): Stimulation of p53-mediated transcriptional activation by the p53-binding proteins, 53BP1 and 53BP2. J. Biol. Chem., 273:26061-26068.

JADOT, M., CANFIELD, W. M., GREGORY, W., KoRNFELD, S. (1992): Characterization of the signal for rapid internalization of the bovine mannose 6-phosphate/insulin like growth factor-II receptor. J. Biol. Chem., 267: 11069-11077.

Johnson, K. F., Chan, W., Kornfeld, S. (1990): Cation-dependent mannose 6phosphate receptor contains two internalization signals in its cytoplasmic domain. Proc. Natl. Acad. Sci. USA, 87: 10010-10014.

JOHnsOn, K. F. \& KoRnFELD, S. (1992 a): The cytoplasmic tail of the mannose-6phosphate/insulin-like growth factor-II receptor has two signals for lysosomal enzyme sorting in the Golgi. J. Cell Biol., 119: 249-257.

Johnson, K. F. \& KoRnFELD, S. (1992 b): A His-Leu-Leu sequence near the carboxyterminal terminus of the cytoplasmic domain of the cation-dependent mannose 6phosphate receptor is necessary for the lysosomal enzyme sorting function. J. Biol. Chem., 267: 17110-17115.

Kalchmann, M. A., Graham, R. K., Xia, G., Koide, H. B., Hodgson, J., Graham, K., GoldberG, Y. P., Gietz, R. D., PiCKART, C. M., HAYden, M. R. (1996): Huntingtin is ubiquitinated and interacts with a specific ubiquitin-conjugating enzyme. J. Biol. Chem., 271: $19385-19394$.

KANG, J. X., LI, Y., LEAF, A. (1998 a): Mannose-6-phosphate/insulin-like growth factor-II is a receptor for retinoic acid. Proc. Natl. Acad. Sci. USA, 95: 13671-13676.

KAnG, J. X., Bell, J., LeAF, A., BeARD, R. L., Chandraratna, R. L. (1998 b): Retinoic acid alters the intracellular trafficking of the mannose 6-phosphate/insulin-like growth factor II receptor and lysosomal enzymes. Proc. Natl. Acad. Sci. USA, 95: 13687-13691.

Kasper, D., DitTmer, F., Von Figura, K., Pohlmann, R. (1996): Neither type of mannose 6-phosphate receptor is sufficient for targeting of lysosomal enzymes along intracellular routes. J. Cell Biol., 134: 615-634.

Kawabata, M., Chytil, A., Moses, H. L. (1995): Cloning of a novel type II serine/ threonine kinase receptor through interaction with the type I transforming growth factor $-\beta$ receptor. J. Biol. Chem., 270: 5625-5630.

Keegan, L., Gill, G., Ptashne, M. (1986): Separation of DNA binding from the transcription-activating function of a eukaryotic regulatory protein. Science, 231: 699-704.

Kirchiausen, T., Bonifacino, J. S., Riezman, H. (1997): Linking cargo to vesicle formation: receptor tail interactions with coat proteins. Curr. Opin. Cell Biol., 9: 488-495.

Klumpermann, J., Hille, A., VeenendaAl, T., OORschot, V., Stoorvogel, W., von FigurA, K., GEUZE, H. J. (1993): Differences in the endosomal distributions of the two mannose-6-phosphate receptors. J. Cell Biol., 121: 997-1010. 
Körner, C., Herzog, A., Weber, B., Rosorius, O., Hemer, F., Schmidt, B., BRAULKE, T. (1994): In vitro phosphorylation of the 46-kDa mannose 6-phosphate receptor by casein kinase II. Structural requirements for efficient phosphorylation. J. Biol. Chem., 269: 16529-16532.

KÖRnER, C., NÜRnberg, B., UhDE, M., BraulKe, T. (1995): Mannose 6phosphate/insulin-like growth factor II receptor fails to interact with G-proteins. Analysis of mutant cytoplasmic receptor domains. J. Biol. Chem., 270: 287-295.

Köster, A., Saftig, P., Matzner, U., von Figura, K., Peters, C., Pohlmann, R. (1993): Targeted disruption of the $\mathrm{M}_{\mathrm{r}} 46.000$ mannose 6-phosphate receptor gene in mice results in misrouting of lysosomal proteins. EMBO J., 12: 5219-5223.

Kornfeld, S. \& Mellman, I. (1989): The biogenesis of lysosomes. Annu. Rev. Cell Biol., 5: 483-525.

Lau, M. M. H., Stewart, C. E. H., LiU, Z., Bhatt, H., Rotwein, P., Stewart, C. L. (1994): Loss of the imprinted IGF2/cation-independent mannose 6-phosphate receptor results in fetal overgrowth and perinatal lethality. Genes Dev., 8: 2953-2963.

LAEMMLI, U. K. (1970): Cleavage of structural proteins during assembly of the head of bacteriophage T4. Nature, 227: 680-685.

LE Borgne, R. \& Hoflack, B. (1998): Protein transport from the secretory to the endocytic pathway in mammalian cells. Biochim. Biophys. Acta., 1404: 195-209.

Le Borgne, R., AlconadA, A., BAuer, U., Hoflack, B. (1998): The mammalian AP-3 adaptor- like complex mediates the intracellular transport of lysosomal membrane glycoproteins. J. Biol. Chem., 45: 29451-29461.

LI, B. \& FIELDS, S. (1993): Identification of mutations in p53 that affect its binding to SV40 large T antigen by using the yeast two-hybrid system. FASEB J., 7: 957-963.

Lemansky, P., Gieselmann, V., Hasilik, A., VOn Figura, K. (1985): Synthesis and transport of lysosomal acid phosphatase in normal and I-cell fibroblasts. J. Biol. Chem., 260: 9023-9030.

LIU, F. \& ROTH, R. A. (1995): Grb-IR: A SH2-domain-containing protein that binds to the insulin receptor and inhibits its function. Proc. Natl. Acad. Sci. USA, 92: 10287-10291.

Lobel, P., Fujimoto, K., Ye, R. D., GRIFFithS, G., KoRnFeld, S. (1989): Mutations in the cytoplasmic domain of the $275 \mathrm{kd}$ mannose 6-phosphate receptor differentially alter lysosomal enzyme sorting and endocytosis. Cell, 57: 787-796.

Lombardi, D., Soldati, T., Riederer, M. A., GodA, Y., Zerial, M., PFefFer, S. R. (1993): Rab9 functions in transport between late endosomes and the trans Golgi network in vitro. EMBO J., 12: 677-682.

Lowry, O. H., Rosebrough, N. J., Farr, A. L., RAndall, R. J. (1951): Protein measurement with the Folin phenol reagent. J. Biol. Chem., 193: 265-275. 
Ludwig, T., LE BoRgne, R., Hoflack, B. (1995): Roles for mannose-6-phosphate receptors in lysosomal enzyme sorting, IGF-II binding and clathrin-coat assembly. Trends Cell Biol., 5: 202-206.

MAC Pherson, I. A. \& STOKeR, M. G. P. (1962): J. Virology, 16: 147-152.

MAHONEy, M. G., AHo, S., UitTo, J., StAnLEY, J. R. (1998): The members of the plakin family of proteins recognized by paraneoplastic pemphigus antibodies include periplakin. J. Invest. Dermatol., 111: 308-313.

MARKS, M. S., OHNO, H., KirchHAuSEN; T., Bonifacino, J. S. (1997): Protein sorting by tyrosine-based signals: adapting the Ys and wherefores. Trends Cell Biol., 7: 124-128.

MARTINEZ, O. \& Goud, B. (1998): Rab proteins. Biochim. Biophys. Acta, 1404: 101-112.

Mauxion, F., Le Borgne, R., Munier-LehmanN, H., Hoflack, B. (1996): A casein kinase II phosphorylation site in the cytoplasmic domain of the cation-dependent mannose 6-phosphate receptor determines the high affinity interaction of the AP-1 golgi asssembly proteins with membranes. J. Biol. Chem., 271: 2171-2178.

Mc Lean, W. H., Pulkkinnen, L., SMith, F. J., RugG, E. L., LANe, E. B, Bullrich, F., Burgeson, R. E., Amano, S., Hudson, D. L., Owaribe, K. (1996): Loss of plectin causes epidermolysis bullosa with muscular dystrophy: cDNA cloning and genomic organization. Genes Dev., 10: 1724-1735.

Meresse, S., Ludwig, T., Frank, R., Hoflack, B. (1990): Phosphorylation of the cytoplasmic domain of the bovine cation- independent mannose 6- phosphate receptor. $J$. Biol. Chem., 265: 18833-18842.

MiLLER, J. H. (1972): Experiments in molecular genetics. Cold Spring Harbor Lab., Cold Spring Harbor, NY.

Newman, L. S., MC KeEVER, M. O., OKANO, H. J., DARnell, R. B. (1995): Beta-NAP, a cerebellar degeneration antigen, is a neuron-specific vesicle coat protein. Cell, 82: 773-783.

Nesterov, A., Carter, R. Y., Sorkina, T., Gill, G. N., Sorkin, A. (1999): Inhibition of the receptor-binding function of clathrin adaptor protein AP-2 by dominant-negative mutant $\mu 2$ subunit and its effects on endocytosis. EMBO J., 18: 2489-2499.

Nikolic, B., Mac Nulty, E., Mir, B., Wiche, G. (1996): Basic amino acid residue cluster within nuclear targeting sequence motif is essential for cytoplasmic plectinvimentin network junctions. J. Cell Biol., 134: 1455-1467.

Nykjaer, A., Christensen, E. I., Vorum, H., Hager, H., Petersen, C. M., RoigaARd, H., Min, H. Y., Vilhardt, F., Moller, L. B., Kornfeld, S., Gliemann, J. (1998): Mannose 6-phosphate/insulin-like growth factor-II receptor targets the urokinase receptor to lysosomes via a novel binding interaction. J. Cell Biol., 141: 815-828.

OdORIZZI, G., COWles, C. R., EMr, S. D. (1998): The AP-3 complex: a coat of many colours. Trends Cell Biol., 8: 282-288. 
Ohno, H., Stewart, J., Fournier, M. C., Bosshart, H., Rhee, I., Miyatake, S., SAito, T., Gallusser, A., KirchHAusen, T., BonifacinO, J. S. (1995): Interaction of tyrosine-based sorting signals with clathrin-associated proteins. Science, 269: 1872-1875.

OHNO, H., Fournier, M. C., POY, G., BONIFACINO, J. S. (1996): Structural determinants of interaction of tyrosine-based sorting signals with the adaptor medium chains. J. Biol. Chem., 271: 29009-29015.

Ohno, H., Aguilar, R. C., Yeh, D., Taura, D., Saito, T., Bonifacino, J. S. (1998): The medium subunits of adaptor complexes recognize distinct but overlapping sets of tyrosine-based sorting signals. J. Biol. Chem., 40: 25915-25921.

OoI, C. E., Dell' AngeliCA, E. C., Bonifacino, J. S. (1998): ADP-Ribosylation factor 1 (ARF1) regulates recruitment of the AP-3 adaptor complex to membranes. J. Cell Biol., 142: 391-402.

O’Neill, T. J., ZHU, Y., Gustafson, T. A. (1997): Interaction of MAD2 with the carboxyl terminus of the insulin receptor but not with the IGFIR. J. Biol. Chem., 272: 10035-10040.

OWEN, D. J. \& Evans, P. R. (1998): A structural explanation for the recognition of tyrosine-based endocytic signals. Science, 282: 1327-1332.

PASDAR, M. \& NELSON, W. J. (1989): Regulation of desmosome assembly in epithelial cells: kinetics of synthesis, transport, and stabilization of desmoglein I, a major protein of the membrane core domain. J. Cell Biol., 109: 163-177.

Pevsner, J., Volknandt, W., Wong, P. R., Scheller, R. H. (1994): Two rat homologs of clathrin-associated adaptor proteins. Gene, 146: 279-283.

Pond, L., Kuhn, L. A., Teyton, L., Schutze, M. P., TAiner, J. A., Jackson, M. R., PETERSON, P. A. (1995): A role for acidic residues in di-leucine motif-based targeting to the endocytic pathway. J. Biol. Chem., 270: 19989-19997.

Press, B., Feng, Y., Hoflack, B., Wandinger-Ness, A. (1998): Mutant rab 7 causes the accumulation of cathepsin D and cation-independent mannose 6-phosphate receptor in an early endocytic compartment. J. Cell Biol., 5: 1075-1089.

Proby, C., Fujil, Y., Owaribe, K., Nishikawa, T., Amagai, M. (1999): Human autoantibodies against HD1/plectin in paraneoplastic pemphigus. J. Invest. Dermatol., 112: 153-156.

Rapoport, I., Miyazali, M., Boll, W., Duckworth, B., Cantley, L. C., Shoelson, S., KIRCHHAUSEN, T. (1997): Regulatory interactions in the recognition of endocytic sorting signals by AP-2 complexes. EMBO J., 9: 2240-2250.

Rapoport, I., Yu, C. C., Cupers, P., Shoelson, S. E., KirchHausen, T. (1998): Dileucine-based sorting signals bind to the B-chain at a site distinct and regulated differently from the tyrosine-based motif-binding site. EMBO J., 17: 2148-2155. 
Riederer, M. A., Soldati, T., Shapiro, A. D., Lin, J., PfeFfer, S. R. (1994): Lysosome biogenesis requires rab9 function and receptor recycling from endosomes to the trans-golgi network. J. Cell Biol., 125: 573-582.

Roberts, D. L., WeIX, D. J., DAhMS, N. M., KIM, J. J. P. (1998): Molecular basis of lysosomal enzyme recognition: three-dimensional structure of the cation-dependent mannose 6-phosphate receptor. Cell, 93: 639-648.

RoHrer, J., SCHWEIZER, A., Johnson, K. F., KornFeld, S. (1995): A determinant in the cytoplasmic tail of the cation-dependent mannose-6-phosphate receptor prevents trafficking to lysosomes. J. Cell Biol., 130: 1297-1306.

RoHrer, J., SCHWEIZER, A., Russell, D., KorNFELD, S. (1996): The targeting of Lamp1 to lysosomes is dependent on the spacing of its cytoplasmic tail tyrosine sorting motif relative to the membrane. J. Cell Biol., 132: 565-576.

Rosorius, O., Issinger, O. G., BraulKe, T. (1993 a): Phosphorylation of the cytoplasmic tail of the $300 \mathrm{kDa}$ mannose 6-phosphate-receptor is required for the interaction with a cytosolic protein. J. Biol. Chem., 268: 21470-21473.

Rosorius, O., Mieskes, G., Issinger, O. G., KÖRner, C., Schmidt, B., VON Figura, K., BRAUlKe, T. (1993 b): Characterization of phosphorylation sites in the cytoplasmic domain of the $300 \mathrm{kDa}$ mannose-6-phosphate receptor. Biochem. J., 292: 833-838.

Rosorius, O., ISSINGER, O. G., BRAULKE, T. (1996): Brain-specific interaction of a 91$\mathrm{kDa}$ membrane-bound protein with the cytoplasmic tail of the $300-\mathrm{kDa}$ mannose 6phosphate receptor. Biochem. Biophys. Res. Commun., 221: 525-530.

Rothe, M., Wong, S. C., Henzel, W. J., Goeddel, D. V. (1994): A novel family of putative signal transducers associated with the cytoplasmic domain of the $75 \mathrm{kDa}$ tumor necrosis factor receptor. Cell, 78: 681-692.

Ruhrberg, C., Hajibagheri, M. A. N., Simon, M., Dooley, T. P., WatT, F. M. (1996): Envoplakin, a novel precursor of the cornified envelope that has homology to desmoplakin. J. Cell Biol., 134: 715-729.

RuHrberG, C. \& WATT, F. M. (1997): The plakin family: versatile organizers of cytoskeletal architecture. Curr. Opin. Genet. Dev., 7: 392-397.

Ruhrberg, C., Hajibagheri, M. A., PArry, D. A. D., WATT, F. M. (1997): Periplakin, a novel component of cornified envelopes and desmosomes that belongs to the plakin family and forms complexes with envoplakin. J. Cell Biol., 139: 1835-1849.

SAiki, R. K., Gelfant, D. H., Stoffel, S., Scharf, S. J., Higushi, R. M., HoRn, G. T., Mullis, K. B., EHRLICH, H. A. (1988): Primer-directed enzymatic amplification of DNA with a thermostable DNA polymerase. Science, 239: 487-491.

SAMBROOK, J., FRITSCH, E. F., MANIATIS, T. (1989): Molecular cloning: a laboratory manual (second edition). Cold Spring Harbour Laboratory, Cold Spring Harbour, New York. 
SANDOVAl, I. V., ARREDONDO, J. J., AlcAldE, J., GonZAleZ NoriegA, A., VANDEKERCKHOVE, J., JimENEZ, M. A., RICO, M. (1994): The residues Leu(Ile)475Ile(Leu, Val, Ala)476, contained in the extended carboxyl cytoplasmic tail, are critical for targeting of the resident lysosomal membrane protein LIMP II to lysosomes. J. Biol. Chem., 269: 6622-6631.

SANDOVAL, I. V. \& BAKKE, O. (1994): Targeting of membrane proteins to endosomes and lysosomes. Trends Cell Biol., 4: 292-297.

SANGER, S., Nicklen, S., COUlSEN, A. R. (1977): DNA sequencing with chain termination inhibitors. Proc. Natl. Acad. Sci. USA, 74: 5463-5467.

Schmidt, B., Kiecke-Siemsen, C., Waheed, A., BraulKe, T., VON FigurA, K. (1995): Localization of the insulin-like growth factor II binding site to amino acids 1508-1566 in repeat 11 of the mannose-6-phosphate/ insulin like growth factor type II receptor. J. Biol. Chem., 270: 14975-14982.

SCHWEIZER, A., KoRnfeld, S., ROHRER, J. (1996): Cysteine 34 of the cytoplasmic tail of the cation-dependent mannose 6-phosphate receptor is reversibly palmitoylated and required for normal trafficking and lysosomal enzyme sorting. J. Cell Biol., 132: 577-584.

SCHWEIZER, A., KORNFELD, S., ROHRER, J. (1997): Proper sorting of the cation-dependent mannose 6-phosphate receptor in endosomes depends on a pair of aromatic amino acids in its cytoplasmic tail. Proc. Natl. Acad. Sci. USA, 94: 14471-14476.

Simmen, T., Schmidt, A., Hunziker, W., BeERmann, F. (1999): The tyrosinase tail mediates sorting to the lysosomal compartment in MDCK cells via a di-leucine and a tyrosine-based signal. J. Cell Sci., 112: 45-53.

Simpson, F., Bright, N. A., West, M. A., Newman, L. S., DARnell, R. B., Robinson, M. S. (1996): A novel adaptor-related protein complex. J. Cell Biol., 133: 749-760.

Simpson, F., Peden, A. A., Christopoulou, L., Robinson, M. S. (1997): Characterization of the adaptor-related protein complex, AP-3. J. Cell Biol., 137: 835-845.

SCHIESTL, R. H. \& GIETZ, R. D. (1989): High efficiency transformation of intact cells using single stranded nucleic acids as a carrier. Curr. Genet., 16: 339-346.

SÖllner, T., WhiteheART, S. W., BrunNer, M., ERdJUMENT-BromaGe, H., Geromanos, S., Tempst, P., Rothman, J. E. (1993): SNAP receptors implicated in vesicle targeting and fusion. Nature, 362: 318-324.

SosA, M. A., SchmidT, B., VON FigurA, K., Hille-ReHFELD, A. (1993): In vitro binding of plasma membrane coated vesicle adaptors to the cytoplasmic domain of lysosomal acid phosphatase. J. Biol. Chem., 268: 12537-12543.

STAPPENBECK, T. S. \& GREEN, K. J. (1992): The desmoplakin carboxyl terminus coaligns with and specifically disrupts intermediate filament networks when expressed in cultured cells. J. Cell Biol., 116: 1197-1209. 
Stappenbeck, T. S., Bornslaeger, E. A., Corcoran, C. M., LuU, H. H., Virata, M. L., GREEN, K. J. (1993): Functional analysis of desmoplakin domains: Specification of the interaction with with keratin versus vimentin intermediate filament networks. J. Cell Biol., 123: 691-705.

Stein, M., Zijderhand-Bleekemolen, J. E., Geuze, H., HasiliK, A., von Figura, K. (1987): $M_{\mathrm{r}} 46.000$ mannose 6-phosphate specific receptor: Its role in targeting of lysosomal enzymes. EMBO J., 6: 2677-2681.

Stenmark, H., Vitale, G., Ullrich, O., Zerial, M. (1995): Rabaptin-5 is a direct effector of the small GTPase rab5 in endocytic membrane fusion. Cell, 83: 423-432.

STEPHENS, D. J. \& BANTING, G. (1998): Specificity of interaction between adaptorcomplex medium chains and the tyrosine-based sorting motifs of TGN38 and lgp120. Biochem. J., 335: 567-572.

SVITKINA, T. M., Verkhovsky, A. B., BorISy, G. G. (1996): Plectin sidearms mediate interactions of intermediate filaments with microtubules and other components of the cytoskeleton. J. Cell Biol., 135: 991-1007.

TONG, P. Y. \& KORNFELD, S. (1989): Ligand interactions of the cation-dependent mannose 6-phosphate receptor. Comparison with the cation-independent mannose 6phosphate receptor. J. Biol. Chem., 264: 7970-7975.

TONG, P. Y., GREgORY, W., Kornfeld, S. (1989): Ligand interactions of the cationindependent mannose 6-phosphate receptor. The stoichiometry of mannose 6-phosphate binding. J. Biol. Chem., 264: 7962-7969.

Valdez, A. C., Cabaniols, J. P., Brown, M. J., Roche, P. A. (1999): Syntaxin 11 is associated with SNAP-23 on late endosomes and the trans-Golgi network. J. Cell Sc., 112: 845-854.

VON FIGURA, K. \& HASILIK, A. (1986): Lysosomal enzymes and their receptors. Annu. Rev. Biochem., 55: 167-193.

Vowels, J. J. \& PAYNE, G. S. (1998): A dileucine-like sorting signal directs transport into an AP-3-dependent, clathrin-independent pathway to the yeast vacuole. EMBO J., 17: 2482-2493.

Wan, L., Molloy, S. S., Thomas, L., LiU, G., XianG, Y., RybaK, S. L., Thomas, G. (1998): PACS-1 defines a novel gene family of cytosolic sorting proteins required for trans-Golgi network localization. Cell, 94 : 205-216.

Wendland, M., Waheed, A., Von Figura, K., Pohlmann, R. (1991): Mr 46.000 mannose 6-phosphate receptor: The role of histidine and arginine residues for binding of ligands. J. Biol. Chem., 266: 2917-2923. 
Westlund, B., DAHMS, N. M., Kornfeld, S. (1991): The bovine mannose 6phosphate/insulin-like growth factor II receptor. Localization of mannose 6-phosphate binding sites to domains 1-3 and 7-11 of the extracytoplasmic region. J. Biol. Chem., 266: 23233-23239.

Westscott, K. R. \& Rome, L. H. (1988): Cation-independent mannose 6-phosphate receptor contains covalently bound fatty acid. J. Cell. Biochem., 38: 23-33.

YANG, M., WU, Z., FIELDS, S. (1995): Protein-peptide interactions analyzed with the yeast two-hybrid system. Nucleic Acids Res., 23: 1152-1156.

Yang, Y., Dowling, J., Yu, Q. C., Kouklis, P., Cleveland, D. W., FuChS, E. (1996): An essential cytoskeletal linker protein connecting actin microfilaments to intermediate filaments. Cell, 86: 655-665.

Yeast protocols handbook; Clontech; 1998.

ZHU, Y., TRAUB, L. M., KORNFELD, S. (1999): High-affinity binding of the AP-1 adaptor complex to trans-golgi network membranes devoid of mannose 6-phosphate receptors. Mol. Biol. Cell, 10: 537-549. 


\section{Anhang}

\subsection{Oligonukleotidsequenzen}

Tab. 5: Oligonukleotide zur Darstellung der MPR300/MPR46-CT- und Periplakin-Mutanten

\begin{tabular}{|l|l|}
\hline Bezeichnung & Oligonukleotidsequenz (5' $\rightarrow$ 3'-Richtung) \\
\hline$S T 18-F$ & GTC CTA CAA AGC ATC AAA GGC AAA TAA GGA AG \\
\hline$S T 18-R$ & CTT CCT TAT TTG CCT TTG ATG CTT TGT AGG AC \\
\hline$S T 20-F$ & GGA ATT CCG CAA GAA GAA GAG GAG GGA AAC AGT G \\
\hline$S T 21-R$ & CGG GAT CCC GTC ACA CCT TTG AGT ATT TGT AG \\
\hline$S T 22-F$ & GGA ATT CCG CCG ACT GGT AGT GGG AG \\
\hline$S T 23-R$ & CGG GAT CCC GTC ATG CTG CAG GCA CAT TTC G \\
\hline$S T 24-R$ & CGG GAT CCC GTC ACA CAC CAC GAT ATG CTG C \\
\hline$S T 25-F$ & GGA ATTC CG CGC CTT CTG GCA GGA TCT T \\
\hline$S T 26-R$ & CGG GAT CCC GCT ACA TTG GTA ATA AAT G \\
\hline$S T 28-R$ & CGG GAT CCC GTC AAT GGT CAT CCC TTT CTT C \\
\hline$S T 29-F$ & CGG GAT CCC GCA GCG ACT GGT AGT GGG A \\
\hline$F 18-F$ & CCC CAC TTA GCC GCG GCG CAG GAT CTT GGC \\
\hline$F 18-R$ & GGG GTG AAT CGG CGC CGC GTC CTA GAA CCG \\
\hline$Y 45-F$ & GTG CCT GCA GCA GCT CGT GGT GCG GGG GAT GAC CAG \\
\hline$Y 45-R$ & CAC GGA CGT CGT CGA GCA CCA CGC CCC CTA CTG GTC \\
\hline$P P-1-F$ & GGA ATT CCA AGC GGG AGC AGC GGG AG \\
\hline$P P-2-R$ & CCG CTC GAG CGG CTA CAC TGA GAT CTC CTC CCA \\
\hline$P P-3-F$ & GGA ATT CCA AGG GTC CCA ATG GG AG \\
\hline$P P-4-R$ & CCG CTC GAG CGG CTA CTT CTG CCC AGA TAC \\
\hline$P P 5-F$ & CGG GAT CCC GAC CAT GCT GAT CGA AAG GTG TGA T \\
\hline$P P 6-R$ & CGG GAT CCC GCT ACT TCT GCC CAG ATA C \\
\hline
\end{tabular}

Tab. 6: Oligonukleotide zur Subklonierung der $\mu 2$ - und $\mu 3$ A-Untereinheiten

\begin{tabular}{|l|l|}
\hline Bezeichnung & Oligonukleotidsequenz $\left(\mathbf{5}^{\prime} \rightarrow \mathbf{3}\right.$ '-Richtung $)$ \\
\hline$\mu 2-F$ & GAA GAT CTT CAT GAT CGG AGG CTT ATT CAT \\
\hline$\mu 2-R$ & GAA GAT CTT CCT AGC AGC GGG TTT CAT AAA \\
\hline$\mu 2-B-F$ & GAA GAT CTT CAC CAT GAT CGG AGG CTT ATT C \\
\hline$\mu 3-F$ & GGA ATT CAT GAT CCA CAG TCT ATT T \\
\hline$\mu 3-R$ & CGG GAT CCC GTC ATG TCC TCA CTT GGA A \\
\hline$\mu 3-B-F$ & GAA GAT CTT CAC CAT GAT CCA CAG TCT ATT T \\
\hline
\end{tabular}

Schnittstellen der Oligonukleotide, die für die Subklonierung der PCR-Produkte verwendet wurden, sind einfach unterstrichen dargestellt. Eingefügte TGA-Stopcodons und Mutationen der Oligonukleotidsequenz sind fett gedruckt dargestellt. 


\subsection{Oligonukleotidsequenz des cDNA-Klons ST249 und abgeleitete Aminosäuresequenz}

Der sequenzierte Anteil der kodierenden Sequenz des cDNA-Klons ST249 beginnt im 5'-translatierten Bereich und endet am 3'-Ende mit einem Stopcodon (fettgedruckt). Die Aminosäuresequenz wurde nach Festlegung des durch die Gal4-AD-Domäne vorgegebenen Leserahmens ermittelt und ist im Einbuchstaben-Kode unterhalb der kodierenden Nukleotidsequenz dargestellt. Die Zahlen links und rechts von der Sequenz geben die Position der Nukleotide an.

TTAGCCGCGGTGTCCGGAACAGCGGCAGCCAGCTTGGGATCCGCGCAGCCCACCGATCTG

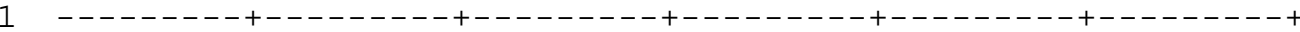
AATCGGCGCCACAGGCCTTGTCGCCGTCGGTCGAACCCTAGGCGCGTCGGGTGGCTAGAC

$\begin{array}{lllllllllllllllllllll}\mathrm{L} & \mathrm{A} & \mathrm{A} & \mathrm{V} & \mathrm{S} & \mathrm{G} & \mathrm{T} & \mathrm{A} & \mathrm{A} & \mathrm{A} & \mathrm{S} & \mathrm{L} & \mathrm{G} & \mathrm{S} & \mathrm{A} & \mathrm{Q} & \mathrm{P} & \mathrm{T} & \mathrm{D} & \mathrm{L}\end{array}$

GGCGCCCACAAGCGGCCGGCATCCGTGTCGAGCAGCGCTGCCGTGGAGCACGAGCAGCGT

$61---------+---------+---------+---------+---------+---------+$ CCGCGGGTGTTCGCCGGCCGTAGGCACAGCTCGTCGCGACGGCACCTCGTGCTCGTCGCA

$\begin{array}{llllllllllllllllllll}G & A & H & K & R & P & A & S & V & S & S & S & A & A & V & E & H & E & Q & R\end{array}$

GAGGCGGCAGCCAAGGAGAAACAACCGCCGCCGCCTGCGCACCGGGGCCCGGCCGACAGC

$121---------+---------+---------+---------+---------+---------+$ CTCCGCCGTCGGTTCCTCTTTGTTGGCGGCGGCGGACGCGTGGCCCCGGGCCGGCTGTCG

$\begin{array}{lllllllllllllllllllll}\mathrm{E} & \mathrm{A} & \mathrm{A} & \mathrm{A} & \mathrm{K} & \mathrm{E} & \mathrm{K} & \mathrm{Q} & \mathrm{P} & \mathrm{P} & \mathrm{P} & \mathrm{P} & \mathrm{A} & \mathrm{H} & \mathrm{R} & \mathrm{G} & \mathrm{P} & \mathrm{A} & \mathrm{D} & \mathrm{S}\end{array}$

CTGTCCACCGCGGCCGGGGCCGCCGAGCTGAGCGCGGAAGGTGCGGGCAAGAGCCGCGGG

$181---------+---------+---------+---------+---------+---------+$ GACAGGTGGCGCCGGCCCCGGCGGCTCGACTCGCGCCTTCCACGCCCGTTCTCGGCGCCC

$\begin{array}{lllllllllllllllllllllllllllll}L & S & T & A & A & G & A & A & E & L & S & A & E & G & A & G & K & S & R & G\end{array}$

TTTGGAGAGGACTGGGTCAACAGGCCCAAGACCGTGCGCGACACGCTGCTGGCGCTGCAC

$241---------+---------+---------+---------+---------+---------+$ AAACCTCTCCTGACCCAGTTGTCCGGGTTCTGGCACGCGCTGTGCGACGACCGCGACGTG $\begin{array}{lllllllllllllllllllll} & \mathrm{F} & \mathrm{G} & \mathrm{E} & \mathrm{D} & \mathrm{W} & \mathrm{V} & \mathrm{N} & \mathrm{R} & \mathrm{P} & \mathrm{K} & \mathrm{T} & \mathrm{V} & \mathrm{R} & \mathrm{D} & \mathrm{T} & \mathrm{L} & \mathrm{L} & \mathrm{A} & \mathrm{L} & \mathrm{H}\end{array}$ CAGCACGGCCACTCGGGGCCCTTCGAGAGCAAGTTTAAGAAGGAGCCGGCCCTGACTGCA $301---------+---------+---------+---------+---------+---------+$ GTCGTGCCGGTGAGCCCCGGGAAGCTCTCGTTCAAATTCTTCCTCGGCCGGGACTGACGT $\begin{array}{llllllllllllllllllll}Q & H & G & H & S & G & P & F & E & S & K & F & K & K & E & P & A & L & T & A\end{array}$ GGCAGGTTGTTGGGTTTCGAGGCCAACGGGGCCAACGGGTTTAAAGCAGTTGCAAGAACA

$361---------+---------+---------+---------+---------+---------+$ CCGTCCAACAACCCAAAGCTCCGGTTGCCCCGGTTGCCCAAATTTCGTCAACGTTCTTGT

$\begin{array}{llllllllllllllllllllllll}G & R & L & L & G & F & E & A & N & G & A & N & G & F & K & A & V & A & R & T\end{array}$ GCAAGGAAAAGGAAGCCCTCTCCAGAACCAGAAGGTGAAGTCGGGCCCCCTAAGATCAAC

GCAAGGAAAAGGAAGCCCICICCAGAACCAGAAGGIGAAGICGGGCCCCCIAAGATCAAC CGTTCCTTTTCCTTCGGGAGAGGTCTTGGTCTTCCACTTCAGCCCGGGGGATTCTAGTTG $\begin{array}{lllllllllllllllllllll}A & R & K & R & K & P & S & P & E & P & E & G & E & V & G & P & P & K & I & N\end{array}$ GGAGAGGCCCAGCCGTGGCTGTCCACATCCACAGAGGGGCTCAAGATCCCCATGACTCCT $481---------+---------+---------+---------+---------+---------+$ CCTCTCCGGGTCGGCACCGACAGGTGTAGGTGTCTCCCCGAGTTCTAGGGGTACTGAGGA 
ACATCCTCTTTTGTGTCTCCGCCACCACCCACTGCCTCACCTCATTCCAACCGGACCACA

$541---------+---------+---------+---------+---------+---------+$ TGTAGGAGAAAACACAGAGGCGGTGGTGGGTGACGGAGTGGAGTAAGGTTGGCCTGGTGT

$\begin{array}{llllllllllllllllllllll}\mathrm{T} & \mathrm{S} & \mathrm{S} & \mathrm{F} & \mathrm{V} & \mathrm{S} & \mathrm{P} & \mathrm{P} & \mathrm{P} & \mathrm{P} & \mathrm{T} & \mathrm{A} & \mathrm{S} & \mathrm{P} & \mathrm{H} & \mathrm{S} & \mathrm{N} & \mathrm{R} & \mathrm{T} & \mathrm{T}\end{array}$

CCGCCTGAAGCGGCCCAGAATGGCCAGTCCCCCATGGCAGCCCTGATCTTAGTAGCAGAC

$601--------+---------+--------+--------+---------+---------+$ GGCGGACTTCGCCGGGTCTTACCGGTCAGGGGGTACCGTCGGGACTAGAATCATCGTCTG

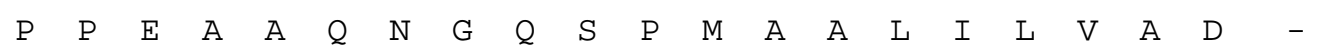

AATGCAGGGGGCAGTCATGCCTCAAAAGATGCCAACCAGGTTCACTCCACTACCAGGAGG

$661--------+--------+--------+--------+--------+--------+$ TTACGTCCCCCGTCAGTACGGAGTTTTCTACGGTTGGTCCAAGTGAGGTGATGGTCCTCC

$\begin{array}{llllllllllllllllllllll}\mathrm{N} & \mathrm{A} & \mathrm{G} & \mathrm{G} & \mathrm{S} & \mathrm{H} & \mathrm{A} & \mathrm{S} & \mathrm{K} & \mathrm{D} & \mathrm{A} & \mathrm{N} & \mathrm{Q} & \mathrm{V} & \mathrm{H} & \mathrm{S} & \mathrm{T} & \mathrm{T} & \mathrm{R} & \mathrm{R}\end{array}$ AATAGCAACAGTCCGCCCTCTCCGTCCTCTATGAACCAAAGAAGGCTGGGCCCCATAGAG

$721--------+--------+--------+---------+---------+--------+$ TTATCGTTGTCAGGCGGGAGAGGCAGGAGATACTTGGTTTCTTCCGACCCGGGGTATCTC $\begin{array}{lllllllllllllllllllllll}\mathrm{N} & \mathrm{S} & \mathrm{N} & \mathrm{S} & \mathrm{P} & \mathrm{P} & \mathrm{S} & \mathrm{P} & \mathrm{S} & \mathrm{S} & \mathrm{M} & \mathrm{N} & \mathrm{Q} & \mathrm{R} & \mathrm{R} & \mathrm{L} & \mathrm{G} & \mathrm{P} & \mathrm{I} & \mathrm{E}\end{array}$ GTGGGGGGCCAGGGAGCAGGCAACACAGGAGGACTGGAGCCAGTGCACCCTGCCAGCCTC

$781---------+---------+---------+---------+---------+--------+$ CACCCCCCGGTCCCTCGTCCGTTGTGTCCTCCTGACCTCGGTCACGTGGGACGGTCGGAG $\begin{array}{llllllllllllllllllllll}V & G & G & Q & G & A & G & N & T & G & G & L & E & P & V & H & P & A & S & L\end{array}$ CCGGACTCCTCTCTGGCAACCAGTGCCCCGCTGTGCTGCACCCTCTGCCACGAGCGGCTG $841---------+---------+---------+---------+---------+---------+$ GGCCTGAGGAGAGACCGTTGGTCACGGGGCGACACGACGTGGGAGACGGTGCTCGCCGAC $\begin{array}{llllllllllllllllllllll}P & D & S & S & L & A & T & S & A & P & L & C & C & T & L & C & H & E & R & L\end{array}$ GAGGACACCCATTTTGTGCAGTGCCCGTCCGTCCCTTCGCACAAGTTCTGCTTCCCTTGC

$901---------+---------+---------+---------+---------+---------+$ CTCCTGTGGGTAAAACACGTCACGGGCAGGCAGGGAAGCGTGTTCAAGACGAAGGGAACG $\begin{array}{lllllllllllllllllllllllllll}E & D & T & H & F & V & Q & C & P & S & V & P & S & H & K & F & C & F & P & C\end{array}$ TCCAGACAAAGCATCAAACAGCAGGGAGCTAGTGGAGAAGTCTATTGTCCCAGTGGGGAA 961 AGGTCTGTTTCGTAGTTTGTCGTCCCTCGATCACCTCTTCAGATAACAGGGTCACCCCTT AGGTCTGTTTCGTAGTTTGTCGTCCCTCGATCACCTCTTCAGATAACAGGGTCACCCCTI
$\begin{array}{lllllllllllllllllllllll}\text { S } & R & O & \text { S } & \text { I } & \text { K } & 0 & O & \text { G } & \text { A } & \text { S } & \text { G } & \text { E } & \text { V } & \text { Y } & \text { C } & \text { P } & \text { S } & \text { G } & \text { E }\end{array}$ AAATGCCCTCTTGTGGGCTCCAATGTCCCCTGGGCCTTTATGCAAGGGGAAATTGCAACC $1021---------+---------+---------+---------+---------+---------+1080$ TTTACGGGAGAACACCCGAGGTTACAGGGGACCCGGAAATACGTTCCCCTTTAACGTTGG
$\begin{array}{lllllllllllllllllllllllllll}K & C & P & L & V & G & S & N & V & P & W & A & F & M & Q & G & E & I & A & T & -\end{array}$ ATCCTTGCTGGAGATGTGAAAGTGAAAAAAGAGAGAGACTCGTGA $1081--------+--------+--------+---------+-----1125$ TAGGAACGACCTCTACACTTTCACTTTTTTCTCTCTCTGAGCACT

$\begin{array}{lllllllllllllllllllll}I & \mathrm{~L} & \mathrm{~A} & \mathrm{G} & \mathrm{D} & \mathrm{V} & \mathrm{K} & \mathrm{V} & \mathrm{K} & \mathrm{K} & \mathrm{E} & \mathrm{R} & \mathrm{D} & \mathrm{S} & * & -\end{array}$

Abb. 27: cDNA-Sequenz und abgeleitete Aminosäuresequenz des cDNA-Klons ST249 


\section{Danksagung}

Herrn Prof. Dr. K. von Figura möchte ich an dieser Stelle für die Vergabe des Themas und die Unterstützung dieser Arbeit danken.

Herrn Prof. Dr. T. Braulke gilt mein besonderer Dank für seine intensive Betreuung und stetige Diskussionsbereitschaft.

Herrn Prof. Dr. D. G. Robinson danke ich für die Übernahme des Korreferats.

Herzlichen Dank gilt meinen lieben Kollegen für die freundliche Atmosphäre, für ihre Hilfsbereitschaft und Unterstützung. Dies gilt besonders für Uwe Andag, Peter Breuer, Stefanie Heidrich, Susanne Hupe, Nicole Jacksch, Christian Körner, Bernd Kübler, Philip Putzer, Liliana Shalamanova, Olaf Zwad und viele andere.

Ein ganz besonders herzlicher Dank geht an Peter Breuer für seine geduldige Hilfestellung bei der Einarbeitung in das Two-Hybrid-System und bei molekularbiologischen Tricks.

Ich bedanke mich bei allen Mitarbeitern für geleistete Hilfsbereitschaft, technische Unterstützung und kollegiale Zusammenarbeit.

Mein Dank gilt besonders meiner Mutter. 


\section{Lebenslauf}

Am 9. März 1965 wurde ich als erstes Kind meiner Eltern, Brigitte Storch, geb. Kleisinger und Ekkehard Storch, in Wiesbaden geboren. Ich habe die deutsche Staatsbürgerschaft. Von 1971-1975 besuchte ich die Justus von Liebig-Grundschule in Wiesbaden-Erbenheim. Von 1975-1984 besuchte ich das Gutenberg-Gymnasium in Wiesbaden und legte dort im Juni 1984 mein Abitur ab. Im Wintersemester 84/85 begann ich das Studium der Humanmedizin an der Johannes-Gutenberg-Universität in Mainz und legte im August 1986 mein Physikum ab. Im Wintersemester 1987/88 begann ich das Studium der Chemie an der Johannes-Gutenberg-Universität in Mainz. Im April 1988 legte ich das 1. Staatsexamen in Humanmedizin ab. Meine Vordiplomsprüfung in Chemie erfolgte im März 1990. Im Rahmen eines integrierten Auslandsstudiums des DAAD absolvierte ich von September 1990 bis März 1991 einen Teil meines Hauptstudiums an der University of California in Irvine. Die mündliche Diplom-Hauptprüfung legte ich im Mai 1994 mit der Fächerkombination Organische Chemie, Anorganische Chemie, Physikalische Chemie und Biochemie ab. Meine Diplomarbeit fertigte ich unter Anleitung von Prof. Dr. C. KochBrandt am Institut für Biochemie an. Die Abgabe der Diplomarbeit mit dem Titel „Untersuchungen zur Regulation der Clusterin-Gens durch Onkogene“ erfolgte im Juli 1995. Im Januar 1996 begann ich am Institut für Biochemie II unter der Anleitung von Prof. Dr. K. von Figura den experimentellen Teil der hier vorliegenden Dissertation mit dem Titel „Wechselwirkungen von Proteinen mit den zytoplasmatischen Domänen der Mannose-6-Phosphat-Rezeptoren". 